\title{
Basic Ground-Water Hydrology
}

\author{
Vater-Supply Paper 2220
}

repared in cooperation with the orth Carolina Department of Natural Resources nd Community Development

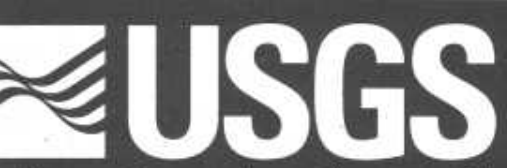




\section{Basic Ground-Water Hydrology}

By RALPH C. HEATH

Prepared in cooperation with the

North Carolina Department of

Natural Resources and Community

Development 


\title{
U.S. Department of the Interior \\ Gale A. Norton, Secretary
}

\section{U.S. Geological Survey \\ Charles G. Groat, Director}

\author{
U.S. Geological Survey, Reston, Virginia: 1983 \\ First printing 1983 \\ Second printing 1984 \\ Third printing 1984 \\ Fourth printing 1987 \\ Fifth printing 1989 \\ Sixth printing 1991 \\ Seventh printing 1993 \\ Eighth printing 1995 \\ Ninth printing 1998 \\ Tenth printing 2004, revised
}

For sale by U.S. Geological Survey, Information Services

Box 25286, Denver Federal Center

Denver, CO 80225

For more information about the USGS and its products:

Telephone: 1-888-ASK-USGS

World Wide Web: http://www.usgs.gov/

Any use of trade, product, or firm names in this publication is for descriptive purposes only and does not imply endorsement by the U.S. Government.

Although this report is in the public domain, it contains copyrighted materials that are noted in the text. Permission to reproduce those items must be secured from the individual copyright owners.

Suggested citation:

Heath, Ralph C., 1983, Basic ground-water hydrology: U.S. Geological Survey Water-Supply Paper 2220, 86 p.

\section{Library of Congress Cataloging-in-Publications Data}

Heath, Ralph C.

Basic ground-water hydrology

(Geological Survey water-supply paper ; 2220

Bibliography: p. 81

1. Hydrology. I. North Carolina Dept. of Natural Resources and Community Development. II.Title. III. Series.
GB1003.2.H4
1982
551.49
$82-6000384$

ISBN 0-607-68973-0 


\section{CONTENTS}

Page
Pa.

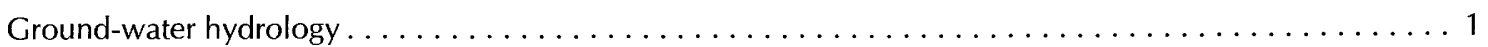

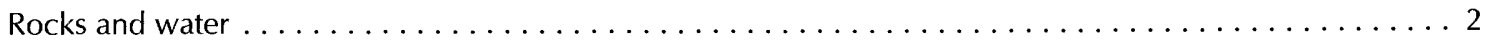

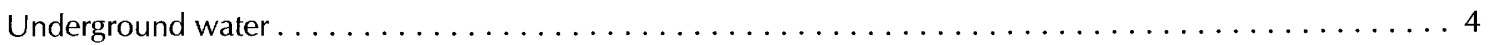

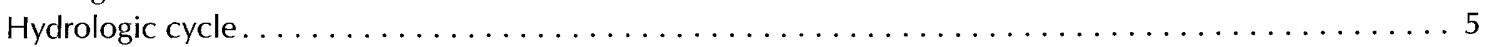

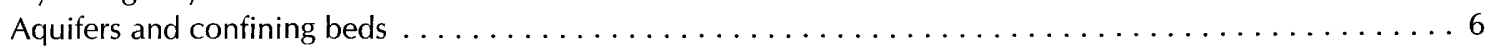

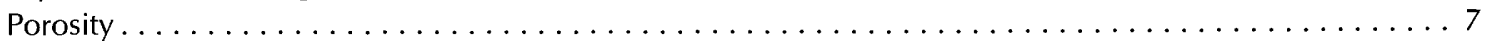

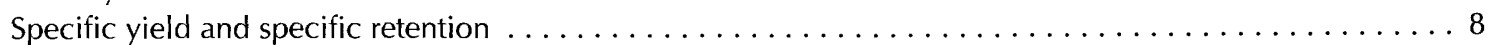

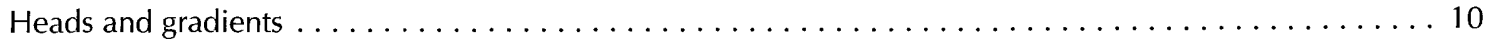

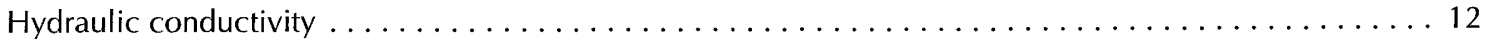

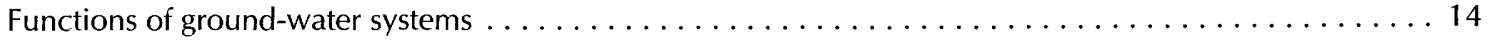

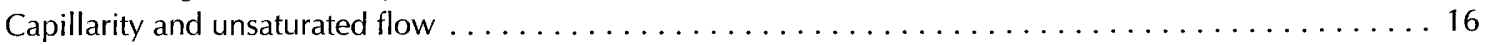

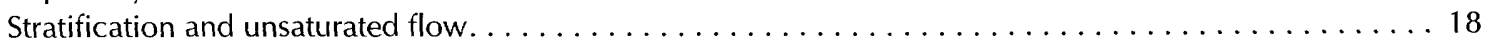

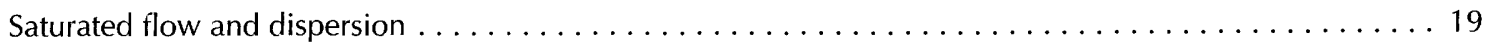

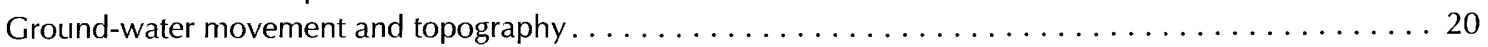

Ground-water flow nets. . . . . . . . . . . . . . . . . . . . . . . . . . . 21

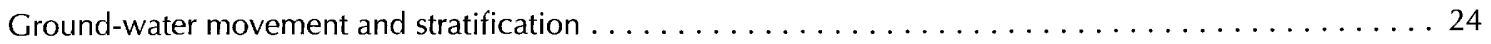

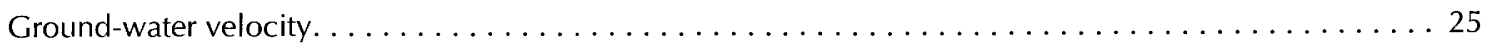

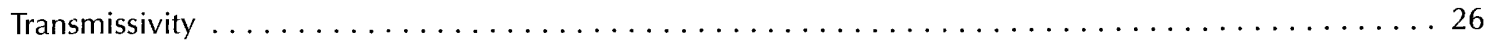

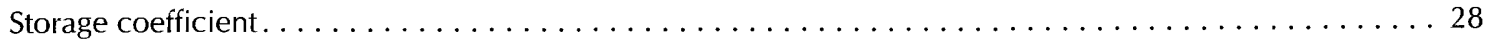

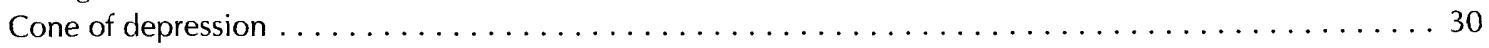

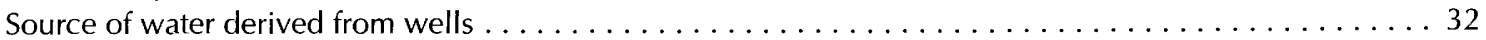

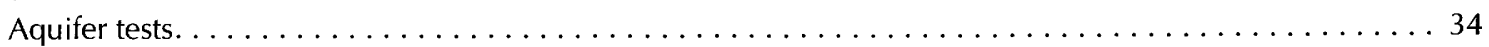

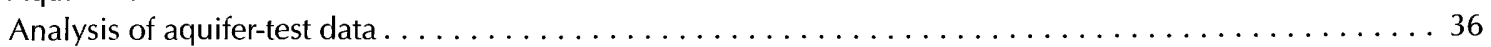

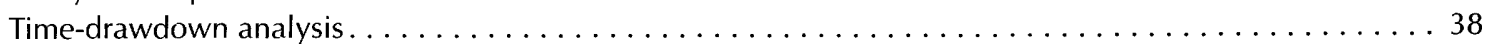

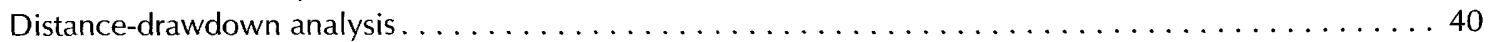

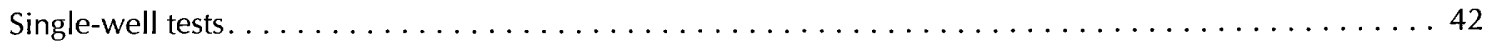

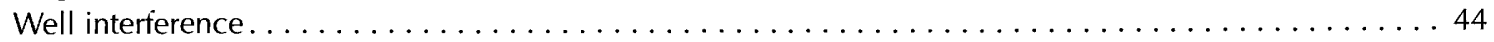

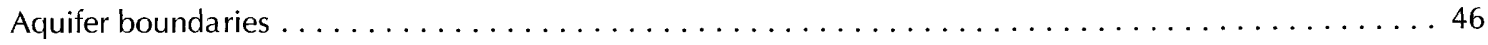

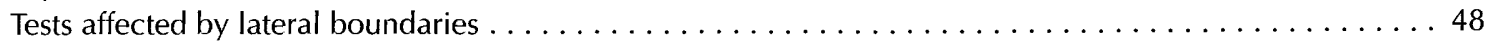

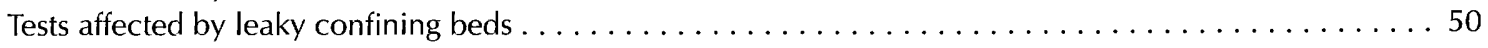

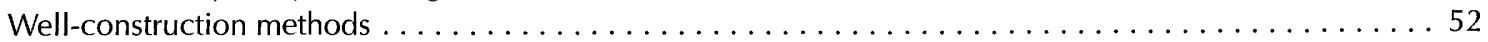

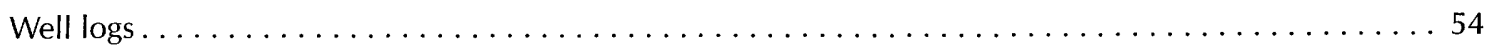

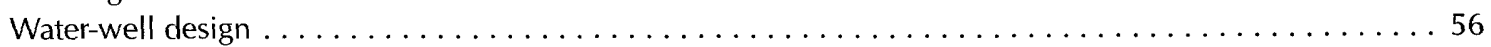

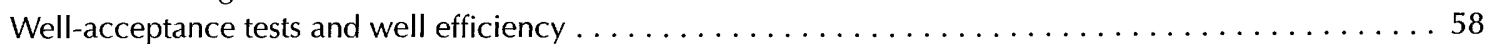

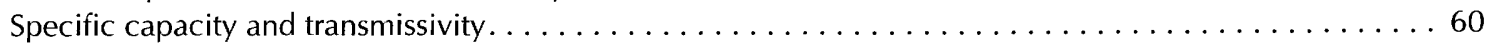

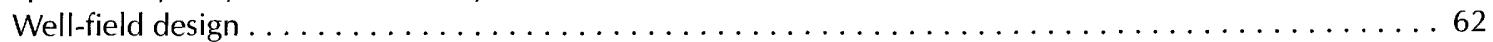

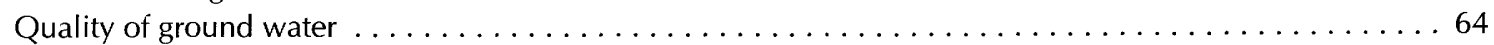

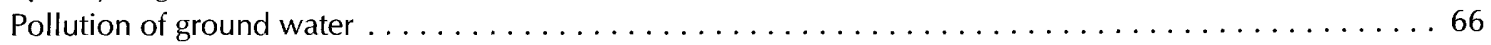

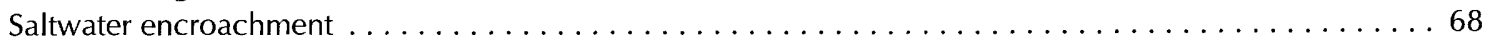

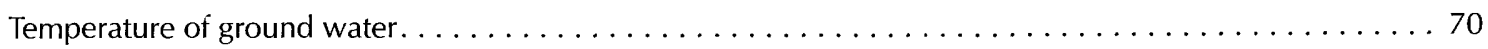

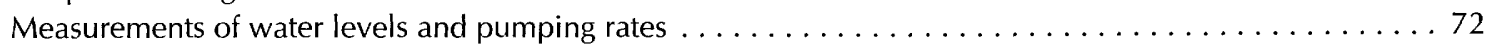

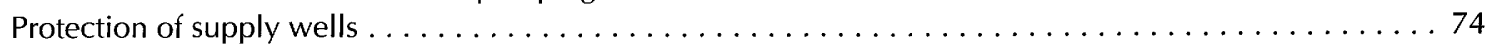

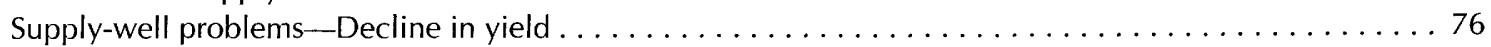

Supply-well problems-Changes in water quality $\ldots \ldots \ldots \ldots \ldots \ldots \ldots \ldots \ldots$

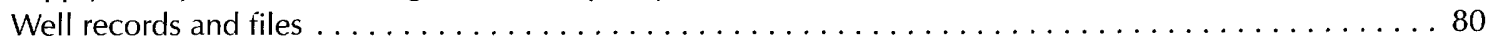

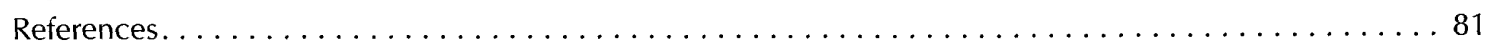

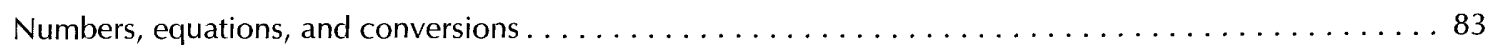

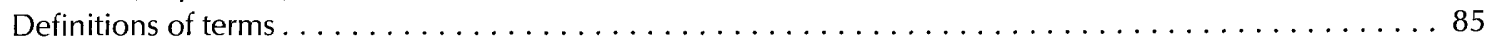

Relation of units of hydraulic conductivity, transmissivity, recharge rates, and flow rates . . . . . . . 86 


\section{PREFACE}

Ground water is one of the Nation's most valuable natural resources. It is the source of about 40 percent of the water used for all purposes exclusive of hydropower generation and electric powerplant cooling.

Surprisingly, for a resource that is so widely used and so important to the health and to the economy of the country, the occurrence of ground water is not only poorly undenstood but is also, in fact, the subject of many widespread misconceptions. Common misconceptions include the belief that ground water occurs in underground rivers resembling surface streams whose presence can be detected by certain individuals. These misconceptions and others have hampered the development and conservation of ground water and have adversely affected the protection of its quality.

In order for the Nation to receive maximum benefit from its ground-water resource, it is essential that everyone, from the rural homeowner to managers of industrial and municipal water supplies to heads of Federal and State water-regulatory agencies, become more knowledgeable about the occurrence, development, and protection of ground water. This report has been prepared to help meet the needs of these groups, as well as the needs of hydrologists, well drillers, and others engaged in the study and developrnent of ground-water supplies. It consists of 45 sections on the basic elements of ground-water hydrology, arranged in order from the most basic aspects of the subject through a discussion of the methods used to determine the yield of aquifers to a discussion of common problems encountered in the operation of ground-water supplies.

Each section consists of a brief text and one or more drawings or maps that illustrate the main points covered in the text. Because the text is, in effect, an expanded discussion of the itlustrations, most of the illustrations are not captioned. However, where more than one drawing is included in a section, each drawing is assigned a number, given in parentheses, and these numbers are inserted at places in the text where the reader should refer to the drawing.

In accordance with U.S. Geological Survey policy to encourage the use of metric units, these units are used in most sections. In the sections dealing with the analysis of aquifer (pumping) test data, equations are given in both consistent units and in the inconsistent inchpound units still in relatively common use among ground-water hydrologists and well drillers. As an aid to those who are not familiar with metric units and with the conversion of groundwater hydraulic units from inch-pound units to metric units, conversion tables are given on the inside back cover.

Definitions of ground-water terms are given where the terms are first introduced. Because some of these terms will be new to many readers, abbreviated definitions are also given on the inside front cover for convenient reference by those who wish to review the definitions from time to time as they read the text. Finally, for those who need to review some of the sim. ple mathematical operations that are used in ground-water hydrology, a section on numbers, equations, and conversions is included at the end of the text.

Ralph C. Heath 
The science of hydrology would be relatively simple if water were unable to penetrate below the earth's surface.

Harold E. Thomas

Ground-water hydrology is the subdivision of the science of hydrology that deals with the occurrence, movement, and quality of water beneath the Earth's surface. It is interdisciplinary in scope in that it involves the application of the physical, biological, and mathematical sciences. It is also a science whose successful application is of critical importance to the welfare of mankind. Because ground-water hydrology deals with the occurrence and movement of water in an almost infinitely complex subsurface environment, it is, in its most advanced state, one of the most complex of the sciences. On the other hand, many of its basic principles and methods can be understood readily by nonhydrologists and used by them in the solution of ground-water problems. The purpose of this report is to present these basic aspects of ground-water hydrology in a form that will encourage more widespread understanding and use.

The ground-water environment is hidden from view except in caves and mines, and the impression that we gain even from these are, to a large extent, misleading. From our observations on the land surface, we form an impression of a "solid" Earth. This impression is not altered very much when we enter a limestone cave and see water flowing in a channel that nature has cut into what appears to be solid rock. In fact, from our observations, both on the land surface and in caves, we are likely to conclude that ground water occurs only in underground rivers and "veins." We do not see the myriad openings that exist between the grains of sand and silt, between particles of clay, or even along the fractures in granite. Consequently, we do not sense the presence of the openings that, in total volume, far exceed the volume of all caves.

R. L. Nace of the U.S. Geological Survey has estimated that the total volume of subsurface openings (which are occupied mainly by water, gas, and petroleum) is on the order of $521,000 \mathrm{~km}^{3}\left(125,000 \mathrm{mi}^{3}\right)$ beneath the United States alone. If we visualize these openings as forming a continuous cave beneath the entire surface of the United States, its height would be about $57 \mathrm{~m}$ (186 ft). The openings, of course, are not equally distributed, the result being that our imaginary cave would range in height from about $3 \mathrm{~m}$ (10 ft) beneath the Piedmont Plateau along the eastern seaboard to about $2,500 \mathrm{~m}$ $(8,200 \mathrm{ft})$ beneath the Mississippi Delta. The important point to be gained from this discussion is that the total volume of openings beneath the surface of the United States, and other land areas of the world, is very large.

Most subsurface openings contain water, and the importance of this water to mankind can be readily demonstrated by comparing its volume with the volumes of water in other parts of the hydrosphere. ${ }^{1}$ Estimates of the volumes of water in the hydrosphere have been made by the Russian hydrologist $M$. I. L'vovich and are given in a book recently translated into English. Most water, including that in the oceans and in

\footnotetext{
${ }^{1}$ The hydrosphere is the term used to refer to the waters of the Earth and, in its broadest usage, includes all water, water vapor, and ice regardless of whether they occur beneath, on, or above the Earth's surface.
}

the deeper subsurface openings, contains relatively large concentrations of dissolved minerals and is not readily usable for essential human needs. We will, therefore, concentrate in this discussion only on freshwater. The accompanying table contains L'vovich's estimates of the freshwater in the hydrosphere. Not surprisingly, the largest volume of freshwater occurs as ice in glaciers. On the other hand, many people impressed by the "solid" Earth are surprised to learn that about 14 percent of all freshwater is ground water and that, if only water is considered, 94 percent is ground water.

Ground-water hydrology, as noted earlier, deals not only with the occurrence of underground water but also with its movement. Contrary to our impressions of rapid movement as we observe the flow of streams in caves, the movement of most ground water is exceedingly slow. The truth of this observation becomes readily apparent from the table, which shows, in the last column, the rate of water exchange or the time required to replace the water now contained in the listed parts of the hydrosphere. It is especially important to note that the rate of exchange of 280 years for fresh ground water is about $1 / 9,000$ the rate of exchange of water in rivers.

Subsurface openings large enough to yield water in a usable quantity to wells and springs underlie nearly every place on the land surface and thus make ground water one of the most widely available natural resources. When this fact and the fact that ground water also represents the largest reservoir of freshwater readily available to man are considered together, it is obvious that the value of ground water, in terms of both economics and human welfare, is incalculable. Consequently, its sound development, diligent conservation, and consistent protection from pollution are important concerns of everyone. These concerns can be translated into effective action only by increasing our knowledge of the basic aspects of ground-water hydrology.

FRESHWATER OF THE HYDROSPHERE AND ITS RATE OF EXCHANGE

[Modified from L'vovich (1979), tables 2 and 10]

\begin{tabular}{|c|c|c|c|c|}
\hline \multirow{2}{*}{$\begin{array}{l}\text { Parts of the } \\
\text { hydrosphere }\end{array}$} & \multicolumn{2}{|c|}{ Volume of freshwater } & \multirow{2}{*}{$\begin{array}{l}\text { Share in total } \\
\text { volume of } \\
\text { freshwater } \\
\text { (percent) }\end{array}$} & \multirow{2}{*}{$\begin{array}{c}\text { Rate of water } \\
\text { exchange } \\
\text { (yr) }\end{array}$} \\
\hline & $\mathrm{km}^{3}$ & $\mathrm{mi}^{3}$ & & \\
\hline \multicolumn{5}{|c|}{ Ice sheets and } \\
\hline glaciers -..... & $24,000,000$ & $5,800,000$ & 84.945 & 8,000 \\
\hline Ground water -- & $4,000,000$ & 960,000 & 14.158 & 280 \\
\hline \multicolumn{5}{|l|}{ Lakes and } \\
\hline reservoirs -... & 155,000 & 37,000 & .549 & 7 \\
\hline Soil moisture -.. & 83,000 & 20,000 & .294 & 1 \\
\hline $\begin{array}{l}\text { Vapors in the } \\
\text { atmosphere - }\end{array}$ & 14,000 & 3,400 & .049 & .027 \\
\hline River water -... & 1,200 & 300 & .004 & .031 \\
\hline Total …. & $28,253,200$ & $6,820,700$ & 100.000 & \\
\hline
\end{tabular}




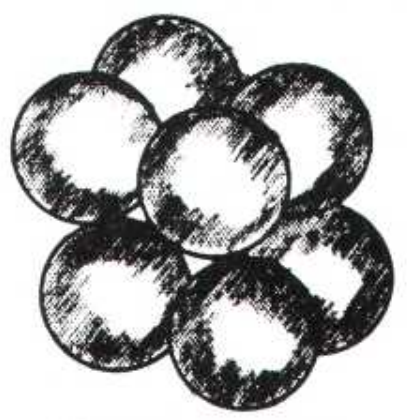

POROUS MATERIAL

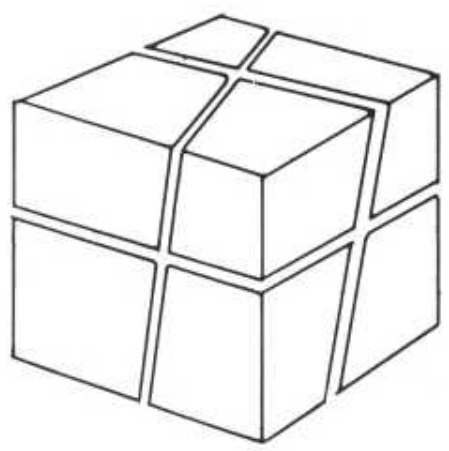

FRACTURED ROCK

(1)
PRIMARY OPENINGS

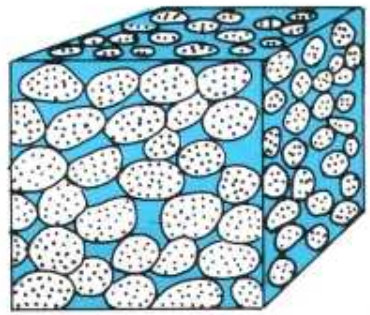

WELL-SORTED SAND

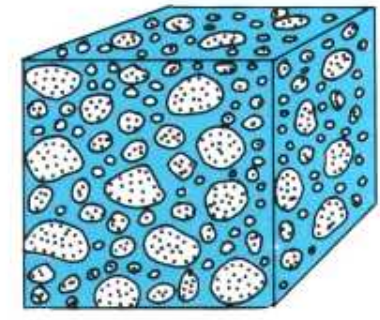

POORLY-SORTED SAND

\section{SECONDARY OPENINGS}

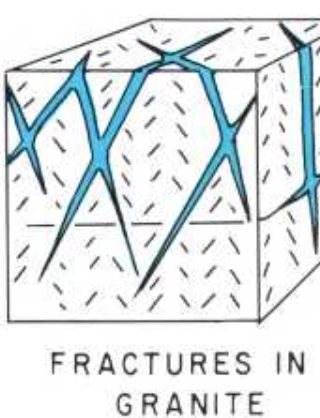

GRANITE

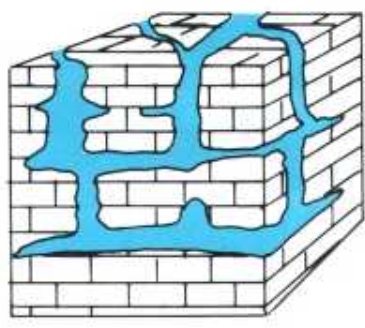

CAVERNS IN LIMESTONE
Most of the rocks near the Earth's surface are composed of both solids and voids, as sketch 1 shows. The solid part is, of course, much more obvious than the voids, but, without the voids, there would be no water to supply wells and springs.

Water-bearing rocks consist either of unconsolidated (soillike) deposits or consolidated rocks. The Earth's surface in most places is formed by soil and by unconsolidated deposits that range in thickness from a few centimeters near outcrops of consolidated rocks to more than $12,000 \mathrm{~m}$ beneath the delta of the Mississippi River. The unconsolidated deposits are underlain everywhere by consolidated rocks.

Most unconsolidated deposits consist of material derived from the disintegration of consolidated rocks. The material consists, in different types of unconsolidated deposits, of particles of rocks or minerals ranging in size from fractions of a millimeter (clay size) to several meters (boulders). Unconsolidated deposits important in ground-water hydrology include, in order of increasing grain size, clay, silt, sand, and gravel. An important group of unconsolidated deposits also includes fragments of shells of marine organisms.

Consolidated rocks consist of mineral particles of different sizes and shapes that have been welded by heat and pressure or by chemical reactions into a solid mass. Such rocks are commonly referred to in ground-water reports as bedrock. They include sedimentary rocks that were originally unconsolidated and igneous rocks formed from a molten state. Consolidated sedimentary rocks important in ground-water hydrology include limestone, dolomite, shale, siltstone, sandstone, and conglomerate. Igneous rocks include granite and basalt.

There are different kinds of voids in rocks, and it is sometimes useful to be aware of them. If the voids were formed at the same time as the rock, they are referred to as primary openings (2). The pores in sand and gravel and in other unconsolidated deposits are primary openings. The lava tubes and other openings in basalt are also primary openings. 
If the voids were formed after the rock was formed, they are referred to as secondary openings (2). The fractures in granite and in consolidated sedimentary rocks are secondary openings. Voids in limestone, which are formed as ground water slowly dissolves the rock, are an especially important type of secondary opening.

It is useful to introduce the topic of rocks and water by dealing with unconsolidated deposits on one hand and with consolidated rocks on the other. It is important to note, however, that many sedimentary rocks that serve as sources of ground water fall between these extremes in a group of semiconsolidated rocks. These are rocks in which openings include both pores and fractures-in other words, both primary and secondary openings. Many limestones and sandstones that are important sources of ground water are semiconsolidated. 
All water beneath the land surface is referred to as underground water (or subsurface water). The equivalent term for water on the land surface is surface water. Underground water occurs in two different zones. One zone, which occurs immediately below the land surface in most areas, contains both water and air and is referred to as the unsaturated zone. The unsaturated zone is almost invariably underlain by a zone in which all interconnected openings are full of water. This zone is referred to as the saturated zone.

Water in the saturated zone is the only underground water that is available to supply wells and springs and is the only water to which the name ground water is correctly applied. Recharge of the saturated zone occurs by percolation of water from the land surface through the unsaturated zone. The unsaturated zone is, therefore, of great importance to ground-water hydrology. This zone may be divided usefully into three parts: the soil zone, the intermediate zone, and the upper part of the capillary fringe.

The soil zone extends from the land surface to a maximum depth of a meter or two and is the zone that supports plant growth. It is crisscrossed by living roots, by voids left by decayed roots of earlier vegetation, and by animal and worm burrows. The porosity and permeability of this zone tend to be higher than those of the underlying material. The soil zone is underlain by the intermediate zone, which differs in thickness from place to place depending on the thickness of the soil zone and the depth to the capillary fringe.

The lowest part of the unsaturated zone is occupied by the capillary fringe, the subzone between the unsaturated and saturated zones. The capillary fringe results from the attraction between water and rocks. As a result of this attraction, water clings as a film on the surface of rock particles and rises in small-diameter pores against the pull of gravity. Water in the capillary fringe and in the overlying part of the unsaturated zone is under a negative hydraulic pressure-that is, it is under a pressure less than the atmospheric (barometric) pressure. The water table is the level in the saturated zone at which the hydraulic pressure is equal to atmospheric pressure and is represented by the water level in unused wells. Below the water table, the hydraulic pressure increases with increasing depth.

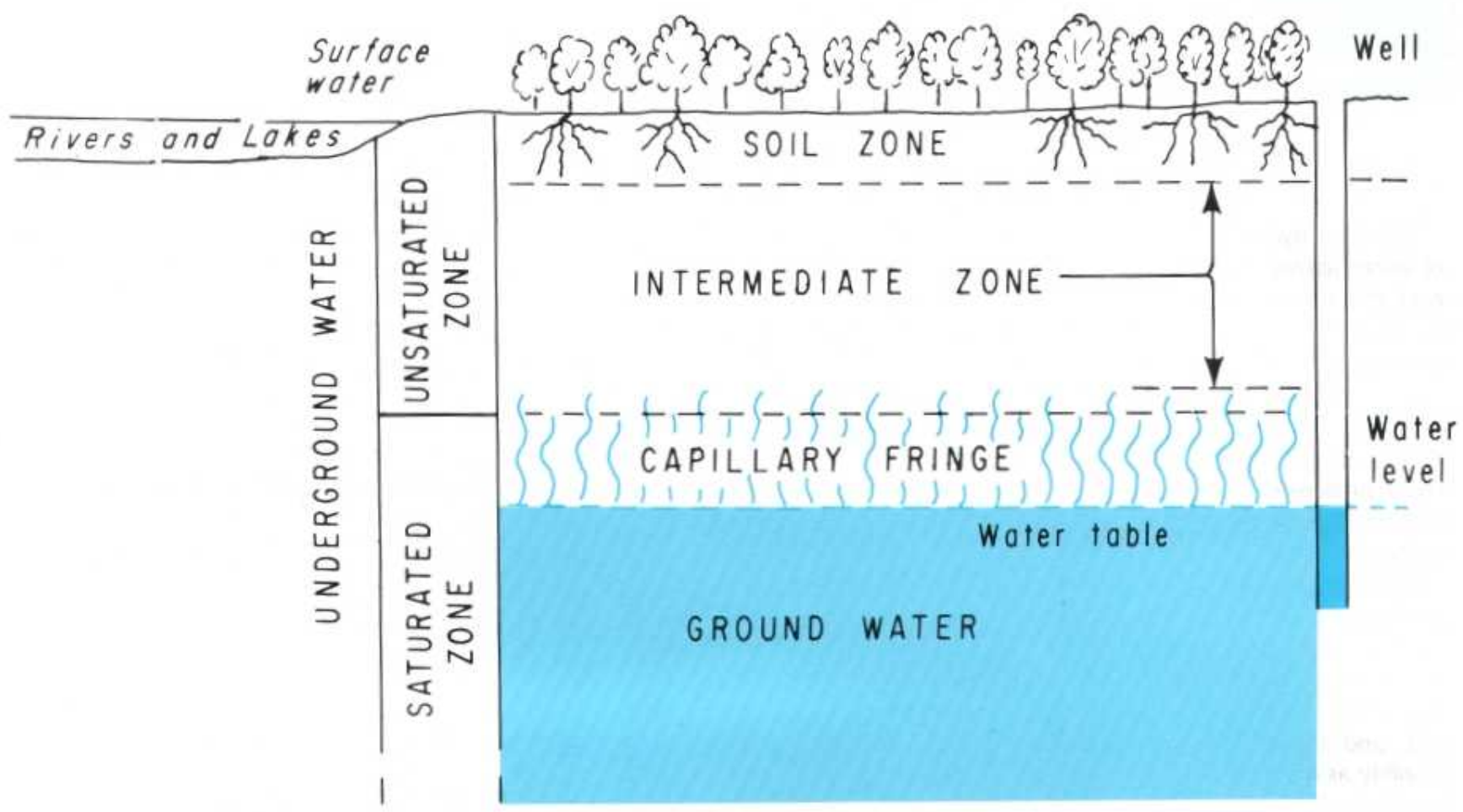




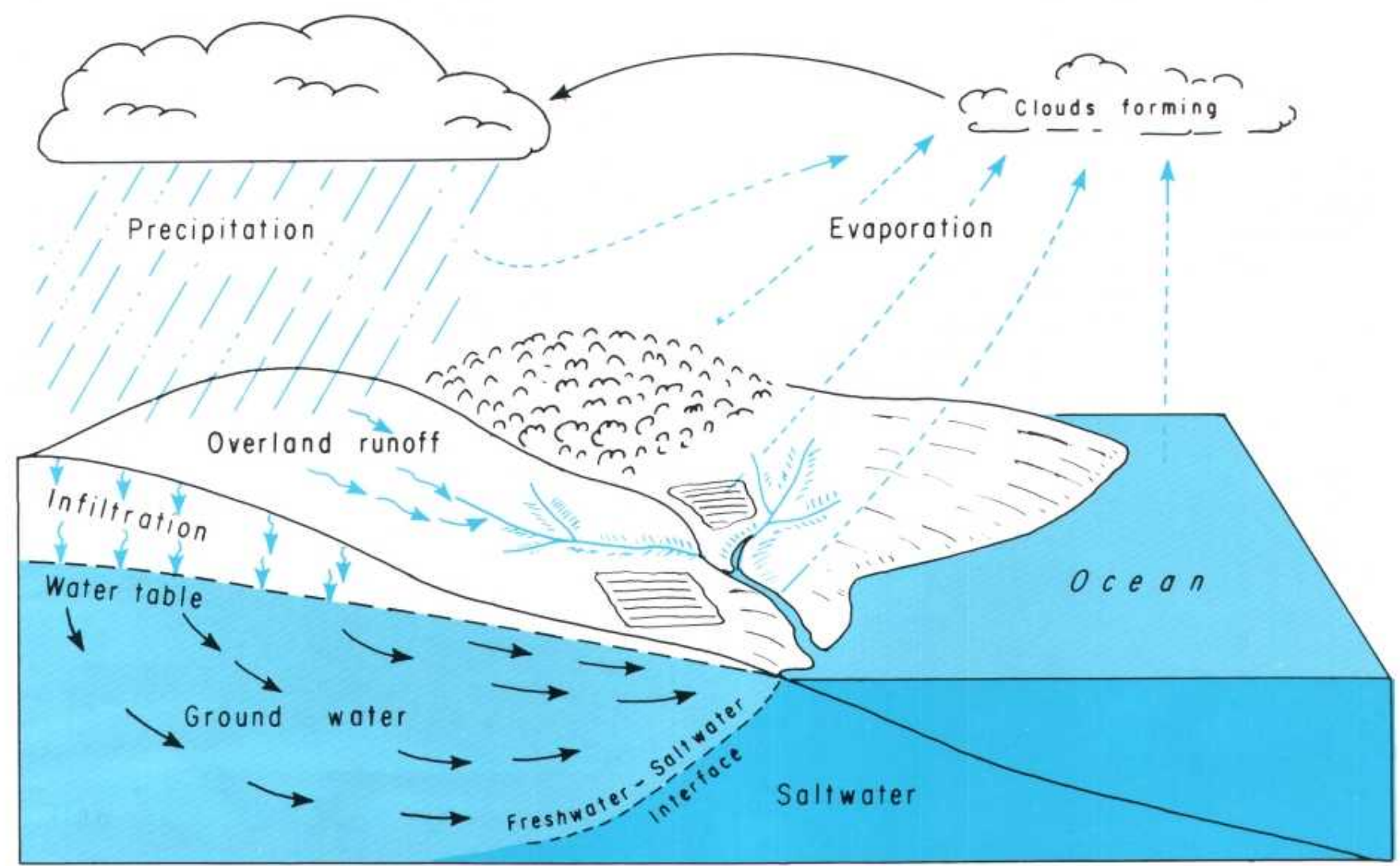

The term hydrologic cycle refers to the constant movement of water above, on, and below the Earth's surface. The concept of the hydrologic cycle is central to an understanding of the occurrence of water and the development and management of water supplies.

Although the hydrologic cycle has neither a beginning nor an end, it is convenient to discuss its principal features by starting with evaporation from vegetation, from exposed moist surfaces including the land surface, and from the ocean. This moisture forms clouds, which return the water to the land surface or oceans in the form of precipitation.

Precipitation occurs in several forms, including rain, snow, and hail, but only rain is considered in this discussion. The first rain wets vegetation and other surfaces and then begins to infiltrate into the ground. Infiltration rates vary widely, depending on land use, the character and moisture content of the soil, and the intensity and duration of precipitation, from possibly as much as $25 \mathrm{~mm} / \mathrm{hr}$ in mature forests on sandy soils to a few millimeters per hour in clayey and silty soils to zero in paved areas. When and if the rate of precipitation exceeds the rate of infiltration, overland flow occurs.

The first infiltration replaces soil moisture, and, thereafter, the excess percolates slowly across the intermediate zone to the zone of saturation. Water in the zone of saturation moves downward and laterally to sites of ground-water discharge such as springs on hillsides or seeps in the bottoms of streams and lakes or beneath the ocean.

Water reaching streams, both by overland flow and from ground-water discharge, moves to the sea, where it is again evaporated to perpetuate the cycle.

Movement is, of course, the key element in the concept of the hydrologic cycle. Some "typical" rates of movement are shown in the following table, along with the distribution of the Earth's water supply.

\section{RATE OF MOVEMENT AND DISTRIBUTION OF WATER}

[Adapted from L'vovich (1979), table 1]

\begin{tabular}{ccc}
\hline \multicolumn{1}{c}{ Location } & \multicolumn{1}{c}{$\begin{array}{c}\text { Rate of } \\
\text { movement }\end{array}$} & $\begin{array}{c}\text { Distribution of } \\
\text { Earth's water } \\
\text { supply (percent) }\end{array}$ \\
\hline $\begin{array}{c}\text { Atmosphere - } \\
\begin{array}{c}\text { Water on land } \\
\text { surface - }\end{array}\end{array}$ & $100^{\prime}$ s of kilometers per day & 0.001 \\
$\begin{array}{c}\text { Water below the } \\
\text { land surface -- }\end{array}$ & 10's of kilometers per day & .019 \\
$\begin{array}{c}\text { Ice caps and } \\
\text { glaciers - }\end{array}$ & Meters per year & 4.12 \\
$\begin{array}{c}\text { Oceans - } \\
\text { Meters per day }\end{array}$ & 1.65 \\
\hline
\end{tabular}




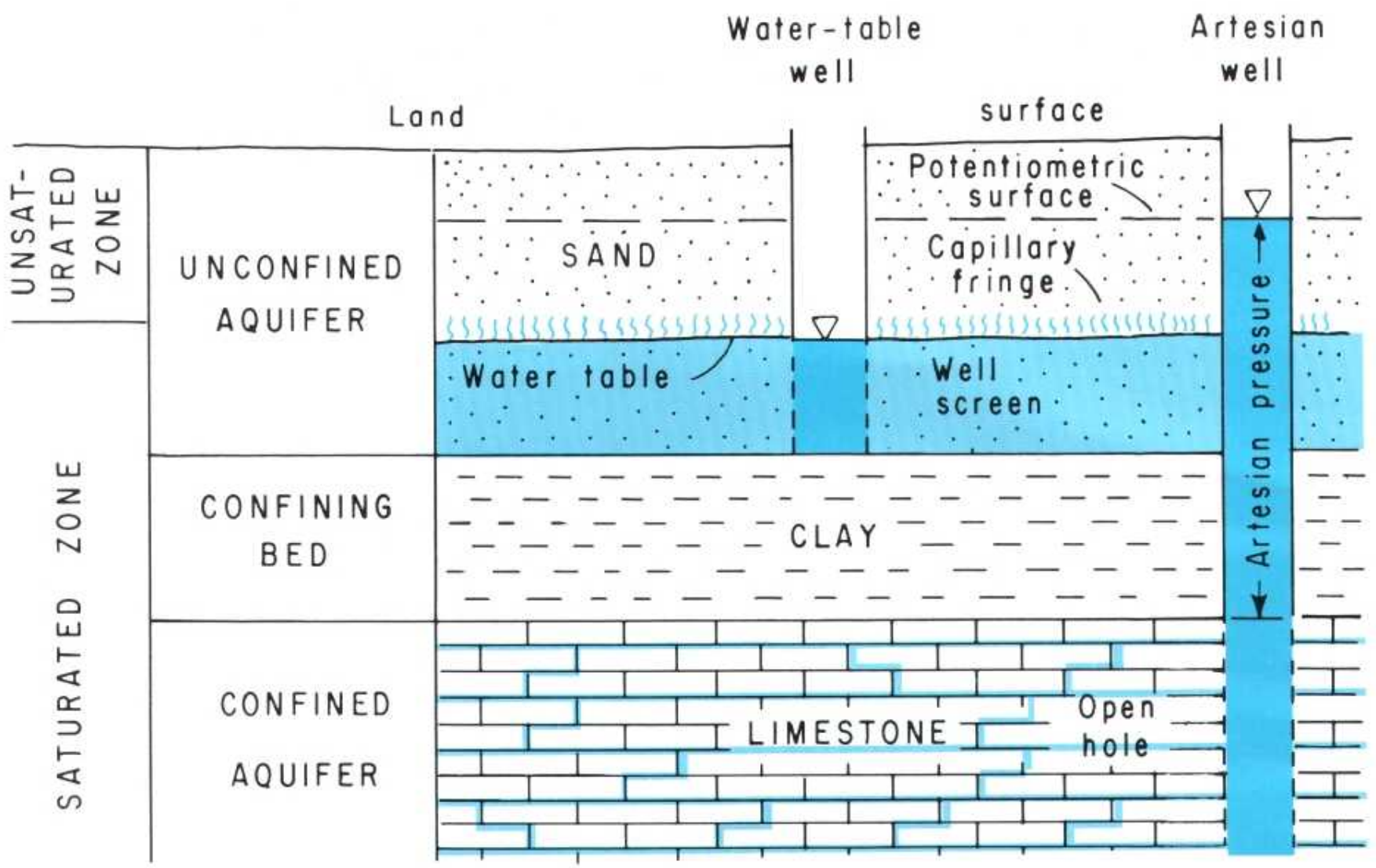

From the standpoint of ground-water occurrence, all rocks that underlie the Earth's surface can be classified either as aquifers or as confining beds. An aquifer is a rock unit that will yield water in a usable quantity to a well or spring. (In geologic usage, "rock" includes unconsolidated sediments.) A confining bed is a rock unit having very low hydraulic conductivity that restricts the movement of ground water either into or out of adjacent aquifers.

Ground water occurs in aquifers under two different conditions. Where water only partly fills an aquifer, the upper surface of the saturated zone is free to rise and decline. The water in such aquifers is said to be unconfined, and the aquifers are referred to as unconfined aquifers. Unconfined aquifers are also widely referred to as water-table aquifers.
Where water completely fills an aquifer that is overlain by a confining bed, the water in the aquifer is said to be confined. Such aquifers are referred to as confined aquifers or as artesian aquifers.

Wells open to unconfined aquifers are referred to as watertable wells. The water level in these wells indicates the position of the water table in the surrounding aquifer.

Wells drilled into confined aquifers are referred to as artesian wells. The water level in artesian wells stands at some height above the top of the aquifer but not necessarily above the land surface. If the water level in an artesian well stands above the land surface, the well is a flowing artesian well. The water level in tightly cased wells open to a confined aquifer stands at the level of the potentiometric surface of the aquifer. 
The ratio of openings (voids) to the total volume of a soil or rock is referred to as its porosity. Porosity is expressed either as a decimal fraction or as a percentage. Thus,

$$
n=\frac{V_{t}-V_{s}}{V_{t}}=\frac{V_{v}}{V_{t}}
$$

where $n$ is porosity as a decimal fraction, $V_{t}$ is the total volume of a soil or rock sample, $V_{s}$ is the volume of solids in the sample, and $V_{v}$ is the volume of openings (voids).

If we multiply the porosity determined with the equation by 100 , the result is porosity expressed as a percentage.

Soils are among the most porous of natural materials because soil particles tend to form loose clumps and because of the presence of root holes and animal burrows. Porosity of unconsolidated deposits depends on the range in grain size (sorting) and on the shape of the rock particles but not on their size. Fine-grained materials tend to be better sorted and, thus, tend to have the largest porosities.

\section{SELECTED VALUES OF POROSITY}

[Values in percent by volume]

\begin{tabular}{lcc}
\hline \multicolumn{1}{c}{ Material } & Primary openings & Secondary openings \\
\hline Equal-size spheres (marbles): & 48 & - \\
Loosest packing - & 26 & - \\
Tightest packing - & 55 & - \\
Soil - & 50 & - \\
Clay & 25 & - \\
Sand - & 20 & 10 \\
Gravel & 10 & 1 \\
Limestone - & 10 & 1 \\
Sandstone (semiconsolidated) - & -1 \\
Granite - & 10 & 1 \\
Basalt (young) & & \\
\hline
\end{tabular}

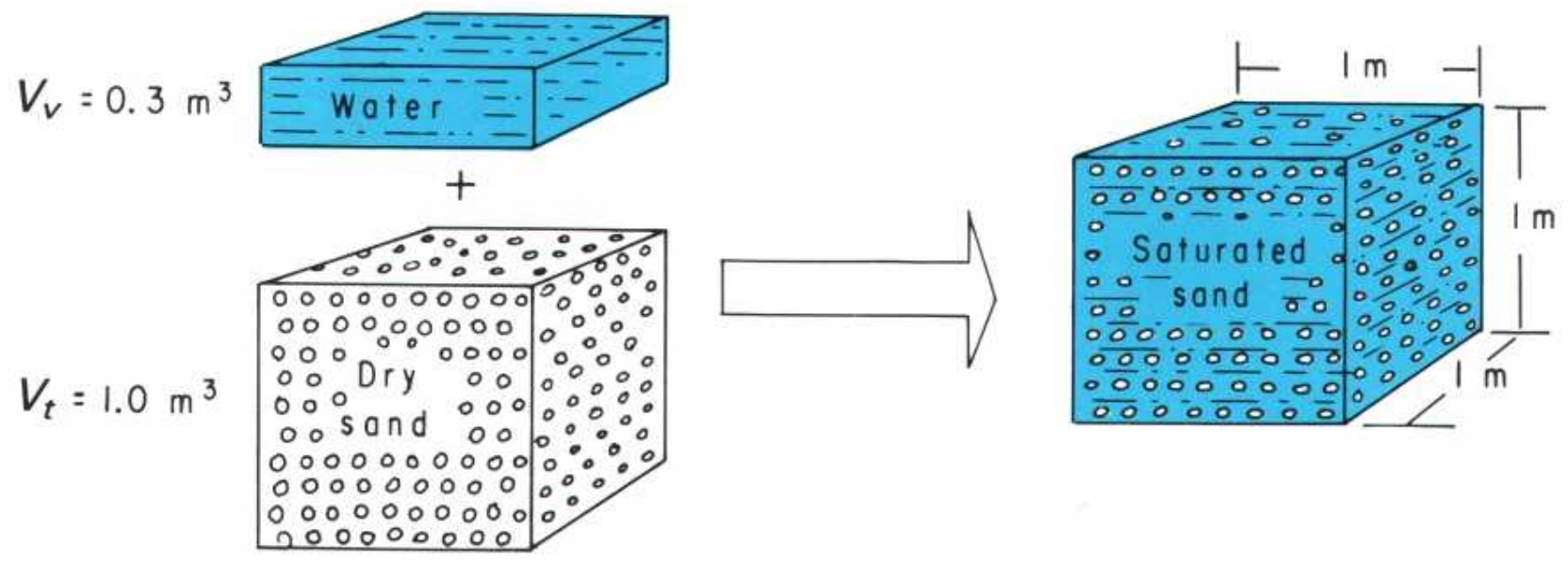

$$
\text { Porosity }(n)=\frac{\text { Volume of voids }\left(V_{v}\right)}{\text { Total volume }\left(V_{t}\right)}=\frac{0.3 \mathrm{~m}^{3}}{1.0 \mathrm{~m}^{3}}=0.30
$$


Porosity is important in ground-water hydrology because it tells us the maximum amount of water that a rock can contain when it is saturated. However, it is equally important to know that only a part of this water is available to supply a well or a spring.

Hydrologists divide water in storage in the ground into the part that will drain under the influence of gravity (called specific yield) (1) and the part that is retained as a film on rock surfaces and in very small openings (called specific retention) (2). The physical forces that control specific retention are the same forces involved in the thickness and moisture content of the capillary fringe.
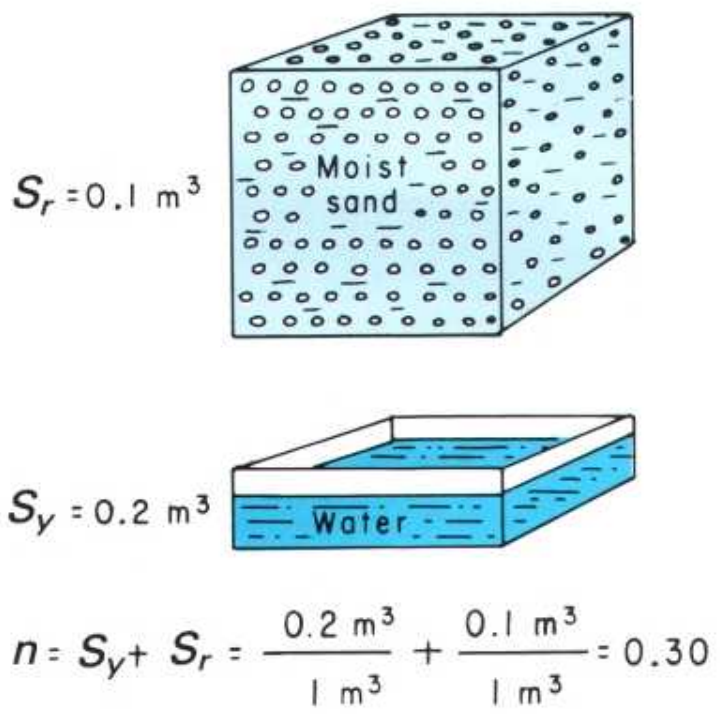

(1)

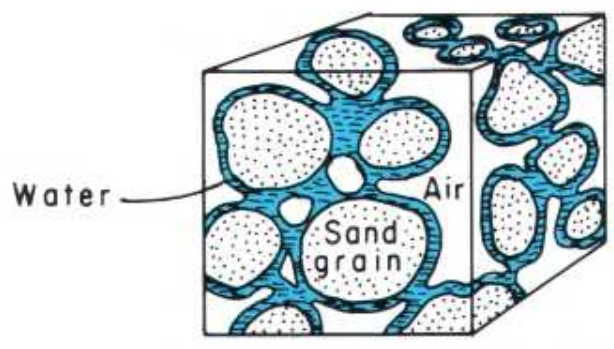

Water retained as

a film on rock surfaces and in

capillary-size

openings after gravity drainoge.

GRANULAR MATERIAL

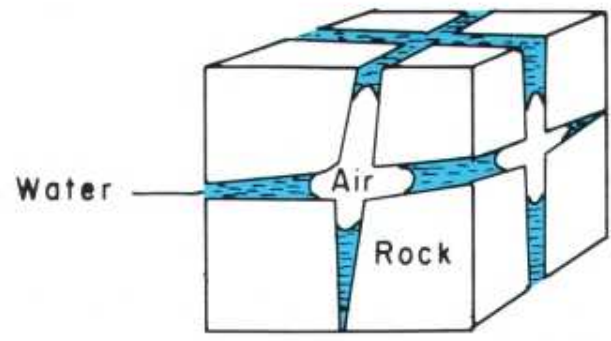

FRACTURED ROCK 
Specific yield tells how much water is available for man's use, and specific retention tells how much water remains in the rock after it is drained by gravity. Thus,

$$
\begin{gathered}
n=S_{y}+S_{r} \\
S_{y}=\frac{V_{d}}{V_{l}} \quad S_{r}=\frac{V_{r}}{V_{t}}
\end{gathered}
$$

where $n$ is porosity, $S_{y}$ is specific yield, $S_{r}$ is specific retention, $V_{d}$ is the volume of water than drains from a total volume of $V_{t}, V_{r}$ is the volume of water retained in a total volume of $V_{t}$ and $V_{t}$ is total volume of a soil or rock sample.
SELECTED VALUES OF POROSITY, SPECIFIC YIELD, AND SPECIFIC RETENTION

[Values in percent by volume]

\begin{tabular}{lccc}
\hline \multicolumn{1}{c}{ Material } & Porosity & Specific vield & Specific retention \\
\hline Soil & 55 & 40 & 15 \\
Clay - & 50 & 2 & 48 \\
Sand - & 25 & 22 & 3 \\
Gravel - & 20 & 19 & 1 \\
Limestone - & 20 & 18 & 2 \\
Sandstone (semiconsolidated) & 11 & 6 & 5 \\
Granite - & \multicolumn{1}{c}{.1} & .09 & \multicolumn{2}{c}{.01} \\
Basalt (young) & 11 & \multicolumn{2}{c}{3} \\
\hline
\end{tabular}




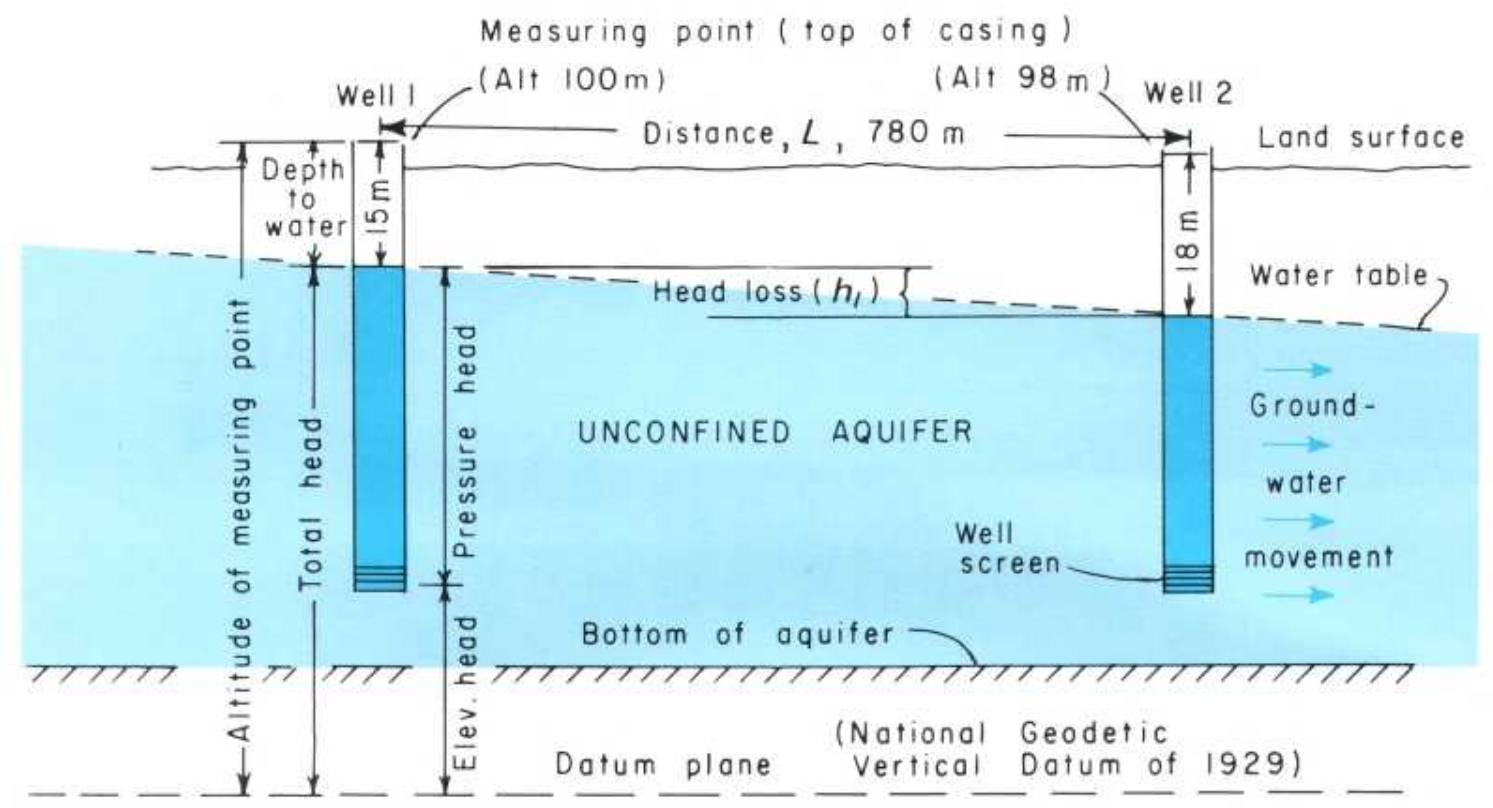

(1)

The depth to the water table has an important effect on use of the land surface and on the development of water supplies from unconfined aquifers (1). Where the water table is at a shallow depth, the land may become "waterlogged" during wet weather and unsuitable for residential and many other uses. Where the water table is at great depth, the cost of constructing wells and pumping water for domestic needs may be prohibitively expensive.

The direction of the slope of the water table is also important because it indicates the direction of ground-water movement (1). The position and the slope of the water table (or of the potentiometric surface of a confined aquifer) is determined by measuring the position of the water level in wells from a fixed point (a measuring point) (1). (See "Measurements of Water levels and Pumping Rates.") To utilize these measurements to determine the slope of the water table, the position of the water table at each well must be determined relative to a datum plane that is common to all the wells. The datum plane most widely used is the National Geodetic Vertical Datum of 1929 (also commonly referred to as "sea level') (1).

If the depth to water in a nonflowing well is subtracted from the altitude of the measuring point, the result is the total head at the well. Total head, as defined in fluid mechanics, is composed of elevation head, pressure head, and velocity head. Because ground water moves relatively slowly, velocity head can be ignored. Therefore, the total head at an observation well involves only two components: elevation head and pressure head (1). Ground water moves in the direction of decreasing total head, which may or may not be in the direction of decreasing pressure head.
The equation for total head $\left(h_{t}\right)$ is

$$
h_{t}=z+h_{p}
$$

where $z$ is elevation head and is the distance from the datum plane to the point where the pressure head $h_{p}$ is determined.

All other factors being constant, the rate of ground-water movement depends on the hydraulic gradient. The hydraulic gradient is the change in head per unit of distance in a given direction. If the direction is not specified, it is understood to be in the direction in which the maximum rate of decrease in head occurs.

If the movement of ground water is assumed to be in the plane of sketch 1-in other words, if it moves from well 1 to well 2-the hydraulic gradient can be calculated from the information given on the drawing. The hydraulic gradient is $h_{L} / L$, where $h_{L}$ is the head loss between wells 1 and 2 and $L$ is the horizontal distance between them, or

$$
\frac{h_{L}}{L}=\frac{(100 m-15 m)-(98 m-18 m)}{780 m}=\frac{85 m-80 m}{780 m}=\frac{5 m}{780 m}
$$

When the hydraulic gradient is expressed in consistent units, as it is in the above example in which both the numerator and the denominator are in meters, any other consistent units of length can be substituted without changing the value of the gradient. Thus, a gradient of $5 \mathrm{ft} / 780 \mathrm{ft}$ is the same as a gradient of $5 \mathrm{~m} / 780 \mathrm{~m}$. It is also relatively common to express hydraulic gradients in inconsistent units such as meters per 


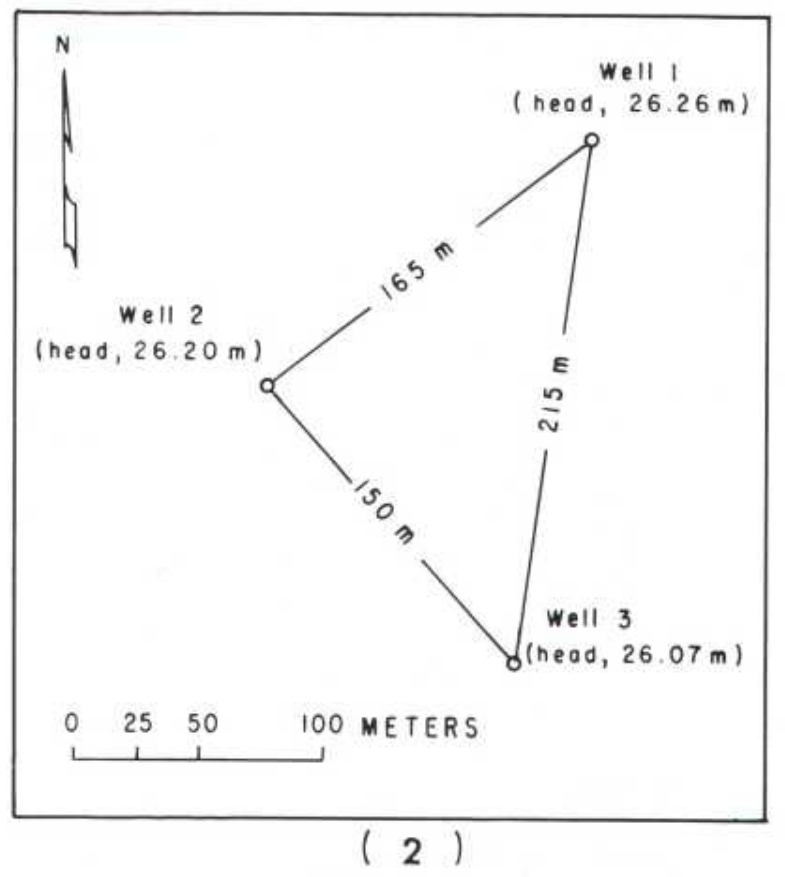

kilometer or feet per mile. A gradient of $5 \mathrm{~m} / 780 \mathrm{~m}$ can be converted to meters per kilometer as follows:

$$
\left(\frac{5 \mathrm{~m}}{780 \mathrm{~m}}\right) \times\left(\frac{1,000 \mathrm{~m}}{\mathrm{~km}}\right)=6.4 \mathrm{~m} \mathrm{~km}^{-1}
$$

Both the direction of ground-water movement and the hydraulic gradient can be determined if the following data are available for three wells located in any triangular arrangement such as that shown on sketch 2 :

1. The relative geographic position of the wells.

2. The distance between the wells.

3. The total head at each well.

Steps in the solution are outlined below and illustrated in sketch 3:

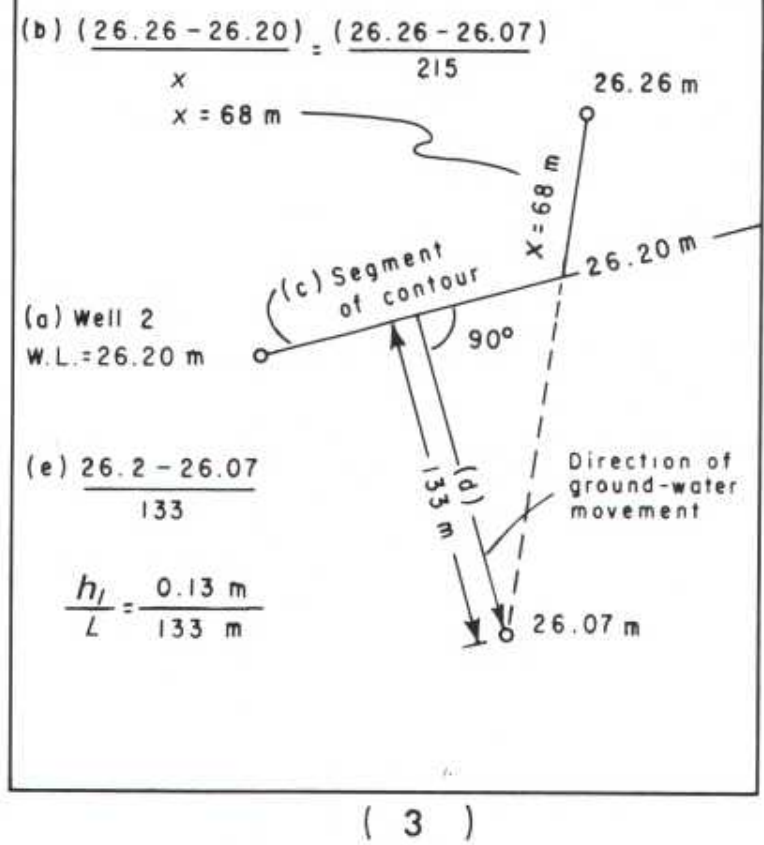

a. Identify the well that has the intermediate water level (that is, neither the highest head nor the lowest head).

b. Calculate the position between the well having the highest head and the well having the lowest head at which the head is the same as that in the intermediate well.

c. Draw a straight line between the intermediate well and the point identified in step $b$ as being between the well having the highest head and that having the lowest head. This line represents a segment of the water-level contour along which the total head is the same as that in the intermediate well.

d. Draw a line perpendicular to the water-level contour and through either the well with the highest head or the well with the lowest head. This line parallels the direction of ground-water movement.

e. Divide the difference between the head of the well and that of the contour by the distance between the well and the contour. The answer is the hydraulic gradient. 


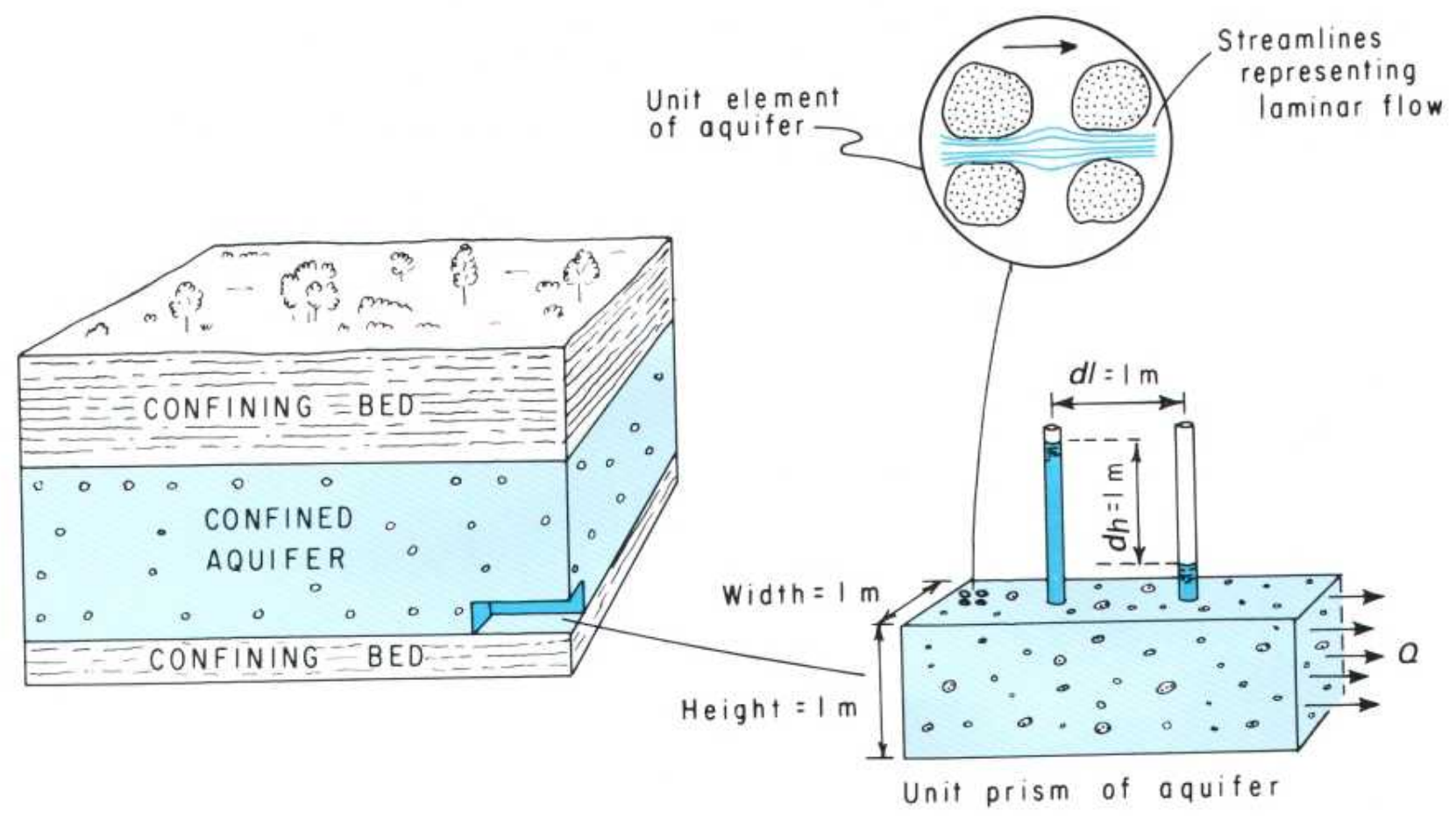

(1)

Aquifers transmit water from recharge areas to discharge areas and thus function as porous conduits (or pipelines filled with sand or other water-bearing material). The factors controlling ground-water movement were first expressed in the form of an equation by Henry Darcy, a French engineer, in 1856. Darcy's law is

$$
Q=K A\left(\frac{d h}{d l}\right)
$$

where $Q$ is the quantity of water per unit of time; $K$ is the hydraulic conductivity and depends on the size and arrangement of the water-transmitting openings (pores and fractures) and on the dynamic characteristics of the fluid (water) such as kinematic viscosity, density, and the strength of the gravitational field; $A$ is the cross-sectional area, at a right angle to the flow direction, through which the flow occurs; and $d h / d l$ is the hydraulic gradient. ${ }^{1}$

Because the quantity of water $(Q)$ is directly proportional to the hydraulic gradient $(d h / d l)$, we say that ground-water flow is laminar-that is, water particles tend to follow discrete streamlines and not to mix with particles in adjacent streamlines (1). (See "Ground-Water Flow Nets.")

\footnotetext{
${ }^{1}$ Where hydraulic gradient is discussed as an independent entity, as it is in "Heads and Gradients," it is shown symbolically as $h_{L} / L$ and is referred to as head loss per unit of distance. Where hydraulic gradient appears as one of the factors in an equation, as it does in equation 1, it is shown symbolically as dh/d to be consistent with other ground-water literature. The gradient dh/dl indicates that the unit distance is reduced to as small a value as one can imagine, in accordance with the concepts of differential calculus.
}

If we rearrange equation 1 to solve for $K$, we obtain

$$
K=\frac{Q d l}{A d h}=\frac{\left(m^{3} d^{-1}\right)(m)}{\left(m^{2}\right)(m)}=\frac{m}{d}
$$

Thus, the units of hydraulic conductivity are those of velocity (or distance divided by time). It is important to note from equation 2, however, that the factors involved in the definition of hydraulic conductivity include the volume of water $(Q)$ that will move in a unit of time (commonly, a day) under a unit hydraulic gradient (such as a meter per meter) through a unit area (such as a square meter). These factors are illustrated in sketch 1. Expressing hydraulic conductivity in terms of a unit gradient, rather than of an actual gradient at some place in an aquifer, permits ready comparison of values of hydraulic conductivity for different rocks.

Hydraulic conductivity replaces the term "field coefficient of permeability" and should be used in referring to the watertransmitting characteristic of material in quantitative terms. It is still common practice to refer in qualitative terms to "permeable" and "impermeable" material.

The hydraulic conductivity of rocks ranges through 12 orders of magnitude (2). There are few physical parameters whose values range so widely. Hydraulic conductivity is not only different in different types of rocks but may also be different from place to place in the same rock. If the hydraulic conductivity is essentially the same in any area, the aquifer in 


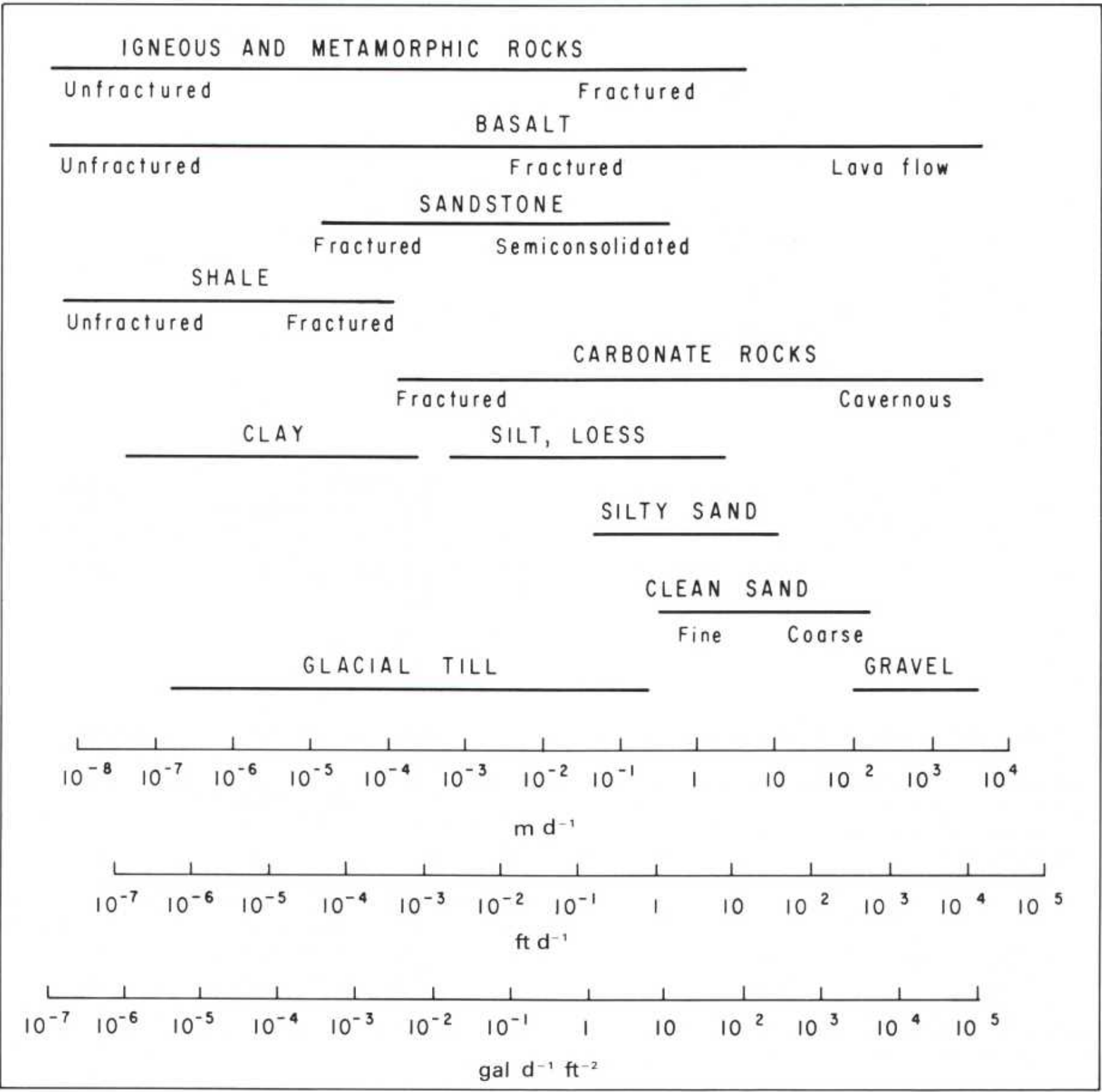

(2)

that area is said to be homogeneous. If, on the other hand, the hydraulic conductivity differs from one part of the area to another, the aquifer is said to be heterogeneous.

Hydraulic conductivity may also be different in different directions at any place in an aquifer. If the hydraulic conductivity is essentially the same in all directions, the aquifer is said to be isotropic. If it is different in different directions, the aquifer is said to be anisotropic.
Although it is convenient in many mathematical analyses of ground-water flow to assume that aquifers are both homogeneous and isotropic, such aquifers are rare, if they exist at all. The condition most commonly encountered is for hydraulic conductivity in most rocks and especially in unconsolidated deposits and in flat-lying consolidated sedimentary rocks to be larger in the horizontal direction than it is in the vertical direction. 


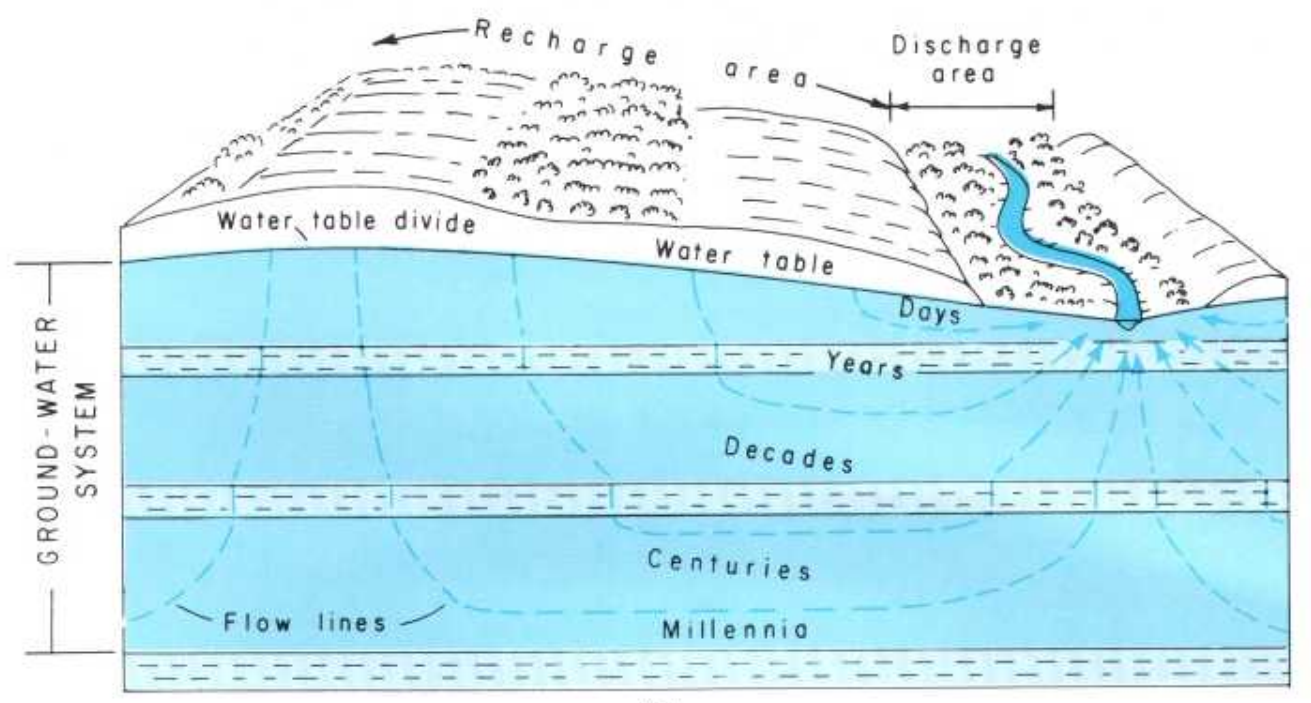

(1)

The aquifers and confining beds that underlie any area comprise the ground-water system of the area (1). Hydraulically, this system serves two functions: it stores water to the extent of its porosity, and it transmits water from recharge areas to discharge areas. Thus, a ground-water system serves as both a reservoir and a conduit. With the exception of cavernous limestones, lava flows, and coarse gravels, ground-water systems are more effective as reservoirs than as conduits.

Water enters ground-water systems in recharge areas and moves through them, as dictated by hydraulic gradients and hydraulic conductivities, to discharge areas (1).

The identification of recharge areas is becoming increasingly important because of the expanding use of the land surface for waste disposal. In the humid part of the country, recharge occurs in all interstream areas-that is, in all areas except along streams and their adjoining flood plains (1). The streams and flood plains are, under most conditions, discharge areas.

In the drier part (western half) of the conterminous United States, recharge conditions are more complex. Most recharge occurs in the mountain ranges, on alluvial fans that border the mountain ranges, and along the channels of major streams where they are underlain by thick and permeable alluvial deposits.

Recharge rates are generally expressed in terms of volume (such as cubic meters or gallons) per unit of time (such as a day or a year) per unit of area (such as a square kilometer, a square mile, or an acre). When these units are reduced to their simplest forms, the result is recharge expressed as a depth of water on the land surface per unit of time. Recharge varies from year to year, depending on the amount of precipitation, its seasonal distribution, air temperature, land use, and other factors. Relative to land use, recharge rates in forests are much higher than those in cities.

Annual recharge rates range, in different parts of the coun- try, from essentially zero in desert areas to about $600 \mathrm{~mm} \mathrm{yr}^{-1}$ $\left(1,600 \mathrm{~m}^{3} \mathrm{~km}^{-2} \mathrm{~d}^{-1}\right.$ or $\left.1.1 \times 10^{6} \mathrm{gal} \mathrm{mi}^{-2} \mathrm{~d}^{-1}\right)$ in the rural areas on Long Island and in other rural areas in the East that are underlain by very permeable soils.

The rate of movement of ground water from recharge areas to discharge areas depends on the hydraulic conductivities of the aquifers and confining beds, if water moves downward into other aquifers, and on the hydraulic gradients. (See "Ground-Water Velocity.") A convenient way of showing the rate is in terms of the time required for ground water to move from different parts of a recharge area to the nearest discharge area. The time ranges from a few days in the zone adjacent to the discharge area to thousands of years (millennia) for water that moves from the central part of some recharge areas through the deeper parts of the ground-water system (1).

Natural discharge from ground-water systems includes not only the flow of springs and the seepage of water into stream channels or wetlands but also evaporation from the upper part of the capillary fringe, where it occurs within a meter or so of the land surface. Large amounts of water are also withdrawn from the capillary fringe and the zone of saturation by plants during the growing season. Thus, discharge areas include not only the channels of perennial streams but also the adjoining flood plains and other low-lying areas.

One of the most significant differences between recharge areas and discharge areas is that the areal extent of discharge areas is invariably much smaller than that of recharge areas. This size difference shows, as we would expect, that discharge areas are more "efficient" than recharge areas, Recharge involves unsaturated movement of water in the vertical direction; in other words, movement is in the direction in which the hydraulic conductivity is generally the lowest. Discharge, on the other hand, involves saturated movement, much of it in the horizontal direction-that is, in the direction of the largest hydraulic conductivity. 

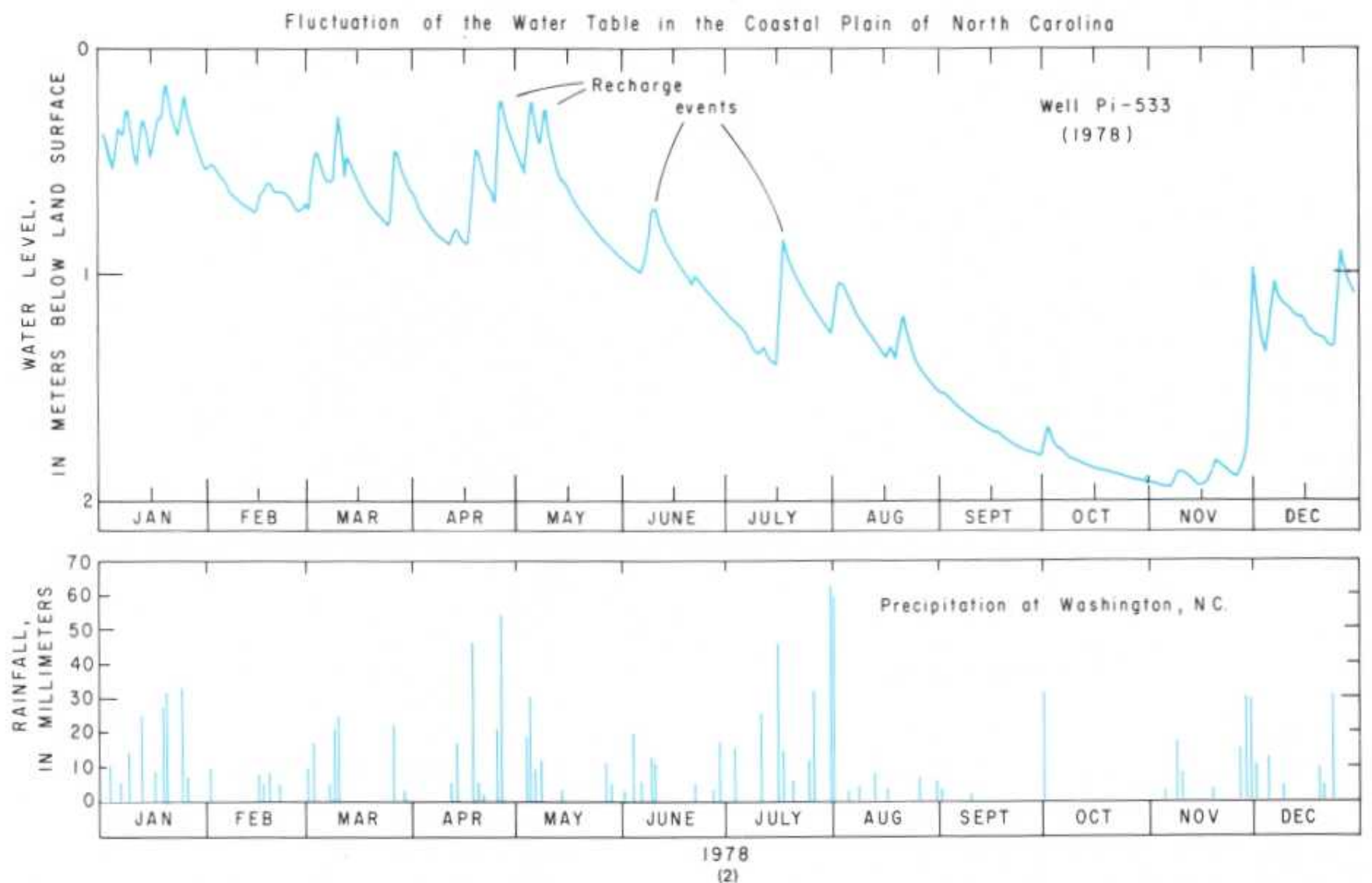

Another important aspect of recharge and discharge involves timing. Recharge occurs during and immediately following periods of precipitation and thus is intermittent (2). Discharge, on the other hand, is a continuous process as long as ground-water heads are above the level at which discharge occurs. However, between periods of recharge, ground-water heads decline, and the rate of discharge also declines. Most recharge of ground-water systems occurs during late fall, winter, and early spring, when plants are dormant and evaporation rates are small. These aspects of recharge and discharge are apparent from graphs showing the fluctuation of the water level in observation wells, such as the one shown in sketch 2. The occasional lack of correlation, especially in the summer, between the precipitation and the rise in water level is due partly to the distance of $20 \mathrm{~km}$ between the weather station and the well. 


\section{CAPILLARITY AND UNSATURATED FLOW}

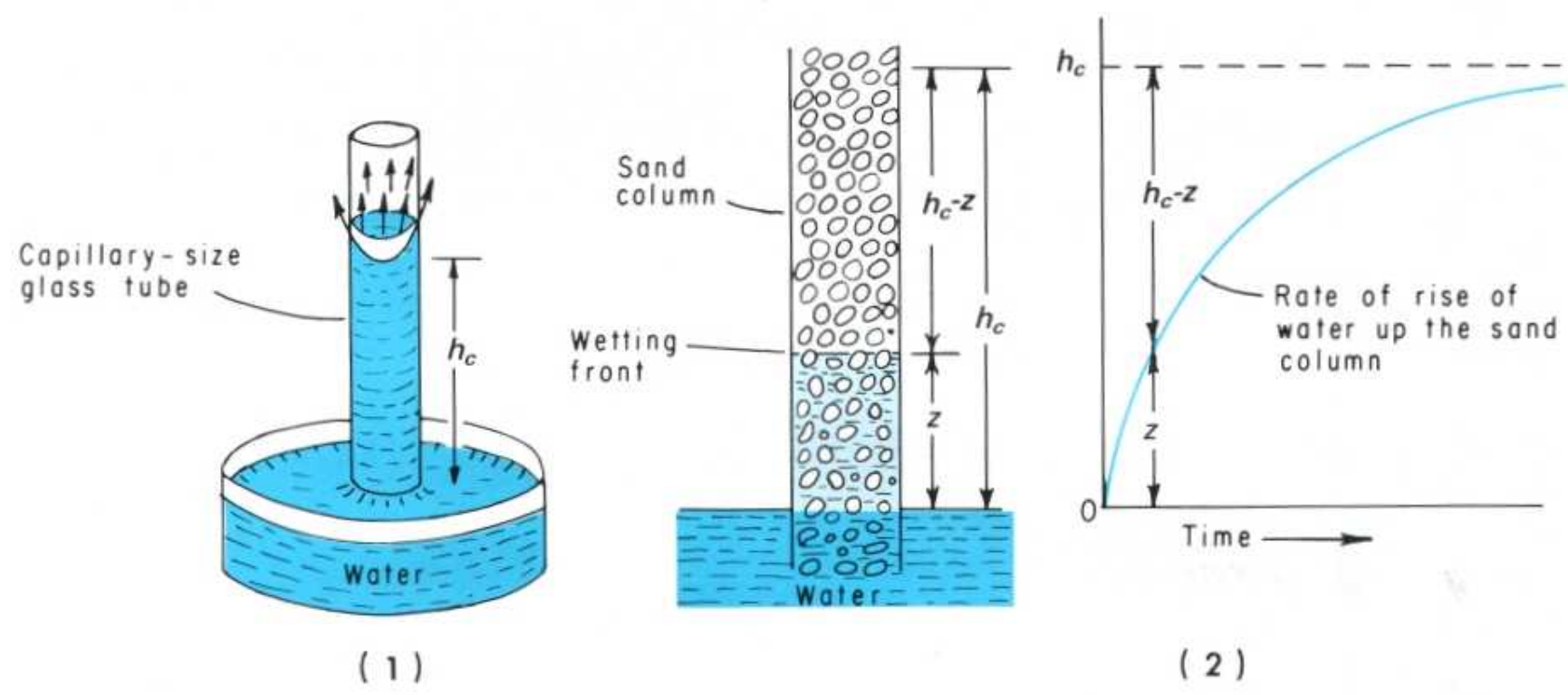

Most recharge of ground-water systems occurs during the percolation of water across the unsaturated zone. The movement of water in the unsaturated zone is controlled by both gravitational and capillary forces.

Capillarity results from two forces: the mutual attraction (cohesion) between water molecules and the molecular attraction (adhesion) between water and different solid materials. As a consequence of these forces, water will rise in smalldiameter glass tubes to a height $h_{c}$ above the water level in a large container (1).

Most pores in granular materials are of capillary size, and, as a result, water is pulled upward into a capillary fringe above the water table in the same manner that water would be pulled up into a column of sand whose lower end is immersed in water (2).

\section{APPROXIMATE HEIGHT OF CAPILLARY RISE $\left(h_{c}\right)$ IN GRANULAR MATERIALS}

\begin{tabular}{lr}
\hline Material & Rise $(\mathrm{mm})$ \\
\hline Sand: & \\
Coarse & 125 \\
Medium & 250 \\
Fine & 400 \\
Silt & 1,000 \\
\hline
\end{tabular}

Steady-state flow of water in the unsaturated zone can be determined from a modified form of Darcy's law. Steady state in this context refers to a condition in which the moisture content remains constant, as it would, for example, beneath a waste-disposal pond whose bottom is separated from the water table by an unsaturated zone.
Steady-state unsaturated flow $(Q)$ is proportional to the effective hydraulic conductivity $\left(K_{\mathrm{e}}\right)$, the cross-sectional area $(A)$ through which the flow occurs, and gradients due to both capillary forces and gravitational forces. Thus,

$$
Q=K_{e} A\left(\frac{h_{c}-z}{z}\right) \pm\left(\frac{d h}{d l}\right)
$$

where $Q$ is the quantity of water, $K_{e}$ is the hydraulic conductivity under the degree of saturation existing in the unsaturated zone, $\left(h_{c}-z\right) / z$ is the gradient due to capillary (surface tension) forces, and $d h / d l$ is the gradient due to gravity.

The plus or minus sign is related to the direction of movement-plus for downward and minus for upward. For movement in a vertical direction, either up or down, the gradient due to gravity is $1 / 1$, or 1 . For lateral (horizontal) movement in the unsaturated zone, the term for the gravitational gradient can be eliminated.

The capillary gradient at any time depends on the length of the water column ( $z$ ) supported by capillarity in relation to the maximum possible height of capillary rise $\left(h_{c}\right)(2)$. For example, if the lower end of a sand column is suddenly submerged in water, the capillary gradient is at a maximum, and the rate of rise of water is fastest. As the wetting front advances up the column, the capillary gradient declines, and the rate of rise decreases (2).

The capillary gradient can be determined from tensiometer measurements of hydraulic pressures. To determine the gradient, it is necessary to measure the negative pressures $\left(h_{p}\right)$ at two levels in the unsaturated zone, as sketch 3 shows. The equation for total head $\left(h_{t}\right)$ is

$$
h_{t}=z+h_{p}
$$




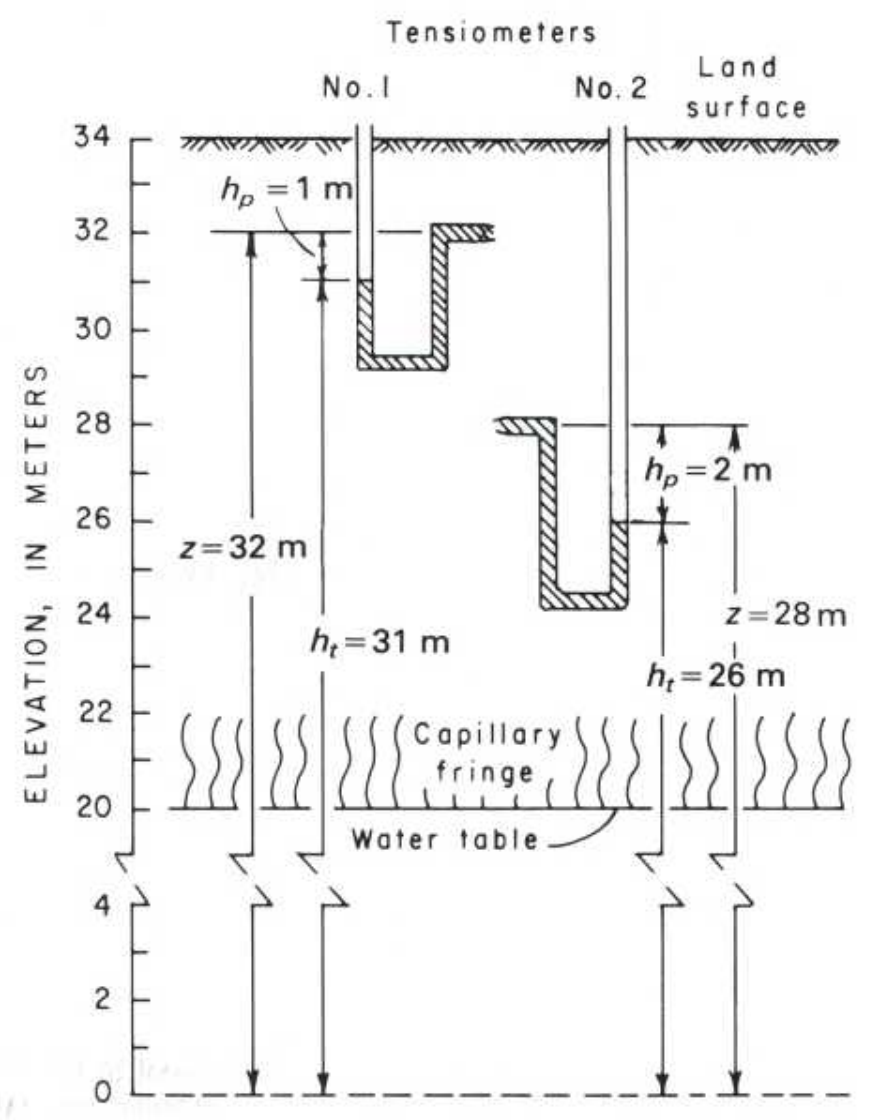

DATUM PLANE (NATIONAL GEODETIC VERTICAL DATUM 1929)

(3)

where $z$ is the elevation of a tensiometer. Substituting values in this equation for tensiometer no. 1 , we obtain

$$
h_{\mathrm{t}}=32+(-1)=32-1=31 \mathrm{~m}
$$

The total head at tensiometer no. 2 is $26 \mathrm{~m}$. The vertical distance between the tensiometers is $32 \mathrm{~m}$ minus $28 \mathrm{~m}$, or $4 \mathrm{~m}$. Because the combined gravitational and capillary hydraulic gradient equals the head loss divided by the distance between tensiometers, the gradient is

$$
\frac{h_{L}}{L}=\frac{h_{t(1)}-h_{t(2)}}{z_{(1)}-z_{(2)}}=\frac{31-26}{32-28}=\frac{5 m}{4 m}=1.25
$$

This gradient includes both the gravitational gradient $(\mathrm{dh} / \mathrm{d} /$ ) and the capillary gradient $\left.\left(\left[h_{c}-z\right] / z\right)\right)$. Because the head in tensiometer no. 1 exceeds that in tensiometer no. 2, we know that flow is vertically downward and that the gravitational gradient is $1 / 1$, or 1 . Therefore, the capillary gradient is $0.25 \mathrm{~m} \mathrm{~m}^{-1}$ $(1.25-1.00)$.

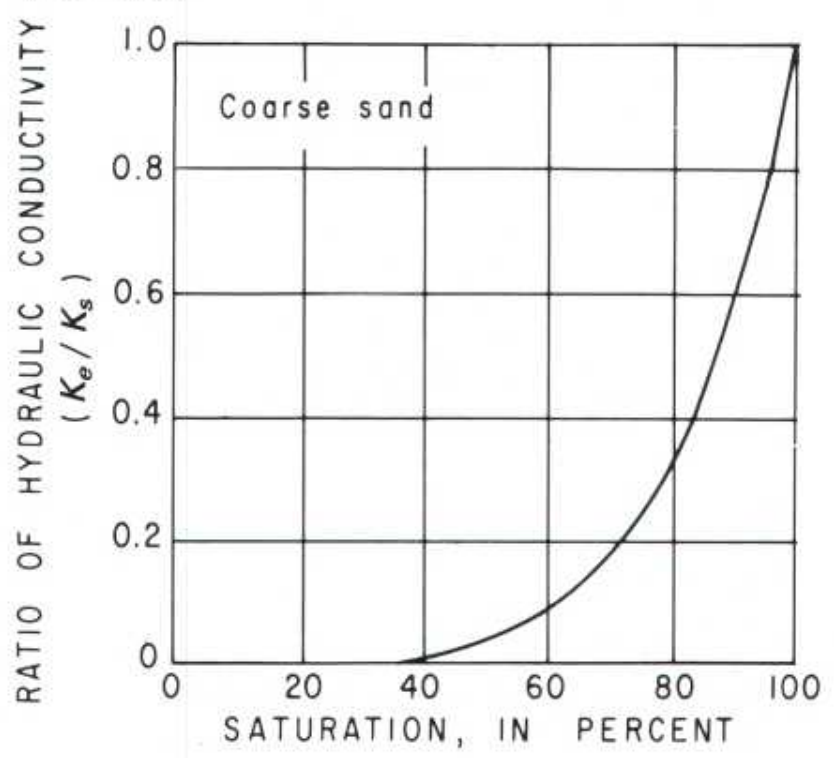

(4)

The effective hydraulic conductivity $\left(K_{e}\right)$ is the hydraulic conductivity of material that is not completely saturated. It is thus less than the (saturated) hydraulic conductivity $\left(K_{s}\right)$ for the material. Sketch 4 shows the relation between degree of saturation and the ratio of saturated and unsaturated hydraulic conductivity for coarse sand. The hydraulic conductivity $\left(K_{S}\right)$ of coarse sand is about $60 \mathrm{~m} \mathrm{~d}^{-1}$. 


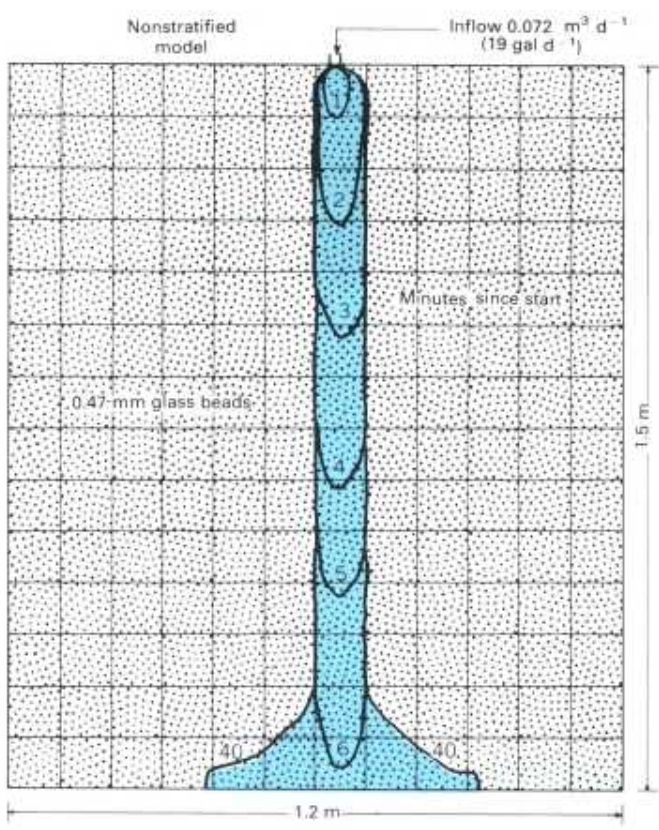

(1)

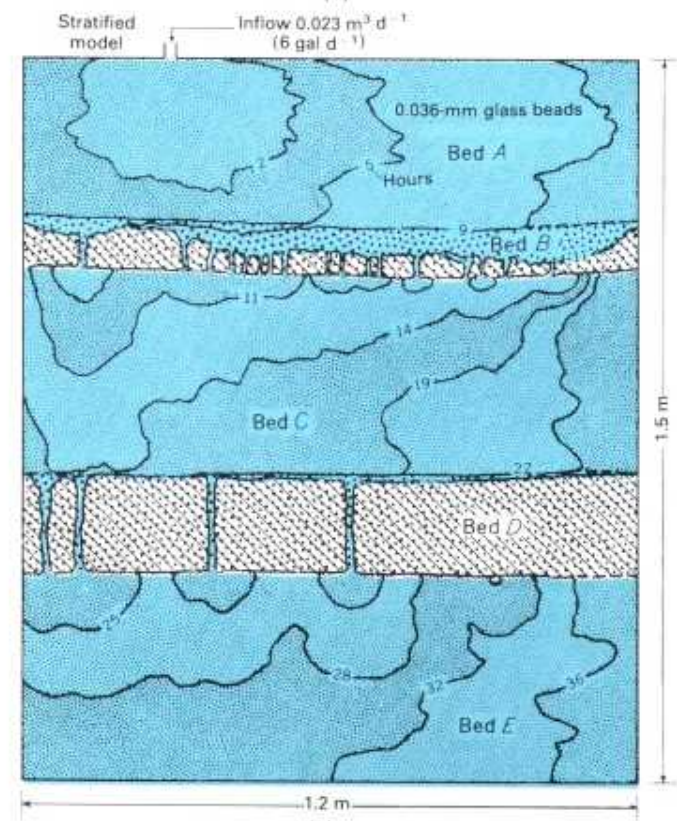

(2)

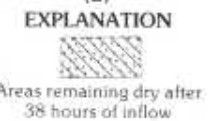

Most sediments are deposited in layers (beds) that have a distinct grain size, sorting, or mineral composition. Where adjacent layers differ in one of these characteristics or more, the deposit is said to be stratified, and its layered structure is referred to as stratification.

The layers comprising a stratified deposit commonly differ from one another in both grain size and sorting and, consequently, differ from one another in hydraulic conductivity. These differences in hydraulic conductivity significantly affect both the percolation of water across the unsaturated zone and the movement of ground water.

In most areas, the unsaturated zone is composed of horizontal or nearly horizontal layers. The movement of water, on the other hand, is predominantly in a vertical direction. In many ground-water problems, and especially in those related to the release of pollutants at the land surface, the effect of stratification on movement of fluids across the unsaturated zone is of great importance.

The manner in which water moves across the unsaturated zone has been studied by using models containing glass beads. One model (1) contained beads of a single size representing a nonstratified deposit, and another (2) consisted of five layers, three of which were finer grained and more impermeable than the other two. The dimensions of the models were about $1.5 \mathrm{~m} \times 1.2 \mathrm{~m} \times 76 \mathrm{~mm}$.

In the nonstratified model, water introduced at the top moved vertically downward through a zone of constant width to the bottom of the model (1). In the stratified model, beds $A$, $C$, and $E$ consisted of silt-sized beads (diameters of $0.036 \mathrm{~mm}$ ) having a capillary height $\left(h_{c}\right)$ of about $1,000 \mathrm{~mm}$ and a hydraulic conductivity $(K)$ of $0.8 \mathrm{~m} \mathrm{~d}^{-1}$. Beds $B$ and $D$ consisted of medium-sand-sized beads (diameters of $0.47 \mathrm{~mm}$ ) having a capillary height of about $250 \mathrm{~mm}$ and a hydraulic conductivity of $82 \mathrm{~m} \mathrm{~d}^{-1}$.

Because of the strong capillary force and the low hydraulic conductivity in bed $A$, the water spread laterally at almost the same rate as it did vertically, and it did not begin to enter bed $B$ until 9 hours after the start of the experiment. At that time, the capillary saturation in bed $A$ had reached a level where the unsatisfied (remaining) capillary pull in bed $A$ was the same as that in bed $B$. In other words, $z$ in bed $A$ at that time equaled $1,000 \mathrm{~mm}-250 \mathrm{~mm}$, or $750 \mathrm{~mm}$. (For a definition of $z$, see "Capillarity and Unsaturated Flow."')

Because the hydraulic conductivity of bed $B$ was 100 times that of bed $A$, water moved across bed $B$ through narrow vertical zones. We can guess that the glass beads in these zones were packed somewhat more tightly than those in other parts of the beds. 
Dispersion in a granular deposit

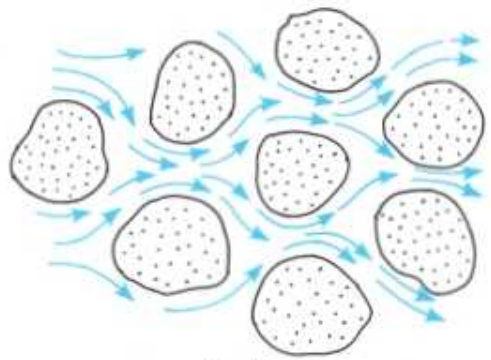

(1)

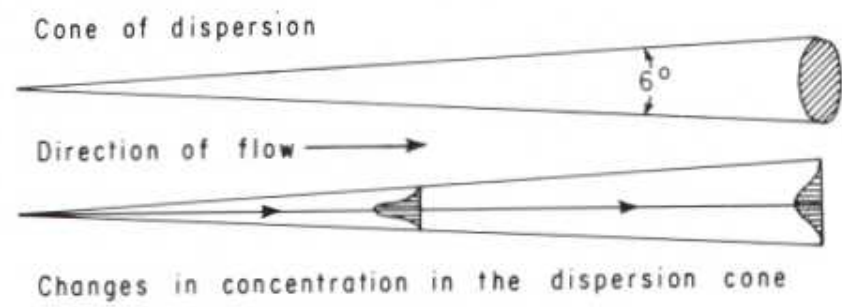

(2)

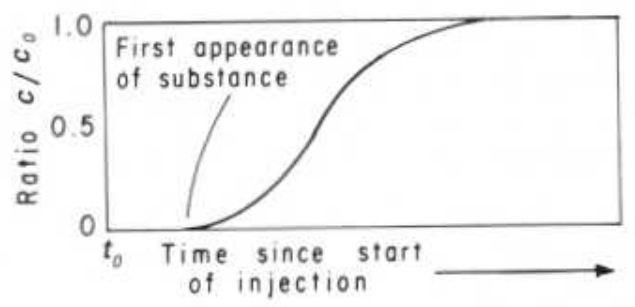

(3)
In the saturated zone, all interconnected openings are full of water, and the water moves through these openings in the direction controlled by the hydraulic gradient. Movement in the saturated zone may be either laminar or turbulent. In laminar flow, water particles move in an orderly manner along streamlines. In turbulent flow, water particles move in a disordered, highly irregular manner, which results in a complex mixing of the particles. Under natural hydraulic gradients, turbulent flow occurs only in large openings such as those in gravel, lava flows, and limestone caverns. Flows are laminar in most granular deposits and fractured rocks.

In laminar flow in a granular medium, the different streamlines converge in the narrow necks between particles and diverge in the larger interstices (1). Thus, there is some intermingling of streamlines, which results in transverse dispersion-that is, dispersion at right angles to the direction of ground-water flow. Also, differences in velocity result from friction between the water and the rock particles. The slowest rate of movement occurs adjacent to the particles, and the fastest rate occurs in the center of pores. The resulting dispersion is longitudinal-that is, in the direction of flow.

Danel (1953) found that dye injected at a point in a homogeneous and isotropic granular medium dispersed laterally in the shape of a cone about $6^{\circ}$ wide (2). He also found that the concentration of dye over a plane at any given distance from the inlet point is a bell-shaped curve similar to the normal probability curve. Because of transverse and longitudinal dispersion, the peak concentration decreased in the direction of flow.

The effect of longitudinal dispersion can also be observed from the change in concentration of a substance $(C)$ downstream from a point at which the substance is being injected constantly at a concentration of $C_{0}$. The concentration rises slowly at first as the "fastest" streamlines arrive and then rises rapidly until the concentration reaches about $0.7 C_{o}$, at which point the rate of increase in concentration begins to decrease (3).

Dispersion is important in the study of ground-water pollution. However, it is difficult to measure in the field because the rate and direction of movement of wastes are also affected by stratification, ion exchange, filtration, and other conditions and processes. Stratification and areal differences in lithology and other characteristics of aquifers and confining beds actually result in much greater lateral and longitudinal dispersion than that measured by Danel for a homogeneous and isotropic medium. 


\section{GROUND-WATER MOVEMENT AND TOPOGRAPHY}

It is desirable, wherever possible, to determine the position of the water table and the direction of ground-water movement. To do so, it is necessary to determine the altitude, or the height above a datum plane, of the water level in wells. However, in most areas, general but very valuable conclusions about the direction of ground-water movement can be derived from observations of land-surface topography.

Gravity is the dominant driving force in ground-water movement. Under natural conditions, ground water moves "downhill" until, in the course of its movement, it reaches the land surface at a spring or through a seep along the side or bottom of a stream channel or an estuary.

Thus, ground water in the shallowest part of the saturated zone moves from interstream areas toward streams or the coast. If we ignore minor surface irregularities, we find that the slope of the land surface is also toward streams or the coast. The depth to the water table is greater along the divide between streams than it is beneath the flood plain. In effect, the water table usually is a subdued replica of the land surface.

In areas where ground water is used for domestic and other needs requiring good-quality water, septic tanks, sanitary landfills, waste ponds, and other waste-disposal sites should not be located uphill from supply wells.

The potentiometric surface of confined aquifers, like the water table, also slopes from recharge areas to discharge areas. Shallow confined aquifers, which are relatively common along the Atlantic Coastal Plain, share both recharge and discharge areas with the surficial unconfined aquifers. This sharing may not be the case with the deeper confined aquifers. The principal recharge areas for these are probably in their outcrop areas near the western border of the Coastal Plain, and their discharge areas are probably near the heads of the estuaries along the major streams. Thus, movement of water through these aquifers is in a general west to east direction, where it has not been modified by withdrawals.

In the western part of the conterminous United States, and especially in the alluvial basins region, conditions are more variable than those described above. In this area, streams flowing from mountain ranges onto alluvial plains lose water to the alluvial deposits; thus, ground water in the upper part of the saturated zone flows down the valleys and at an angle away from the streams.

Ground water is normally hidden from view; as a consequence, many people have difficulty visualizing its occurrence and movement. This difficulty adversely affects their ability to understand and to deal effectively with groundwater-related problems. This problem can be partly solved
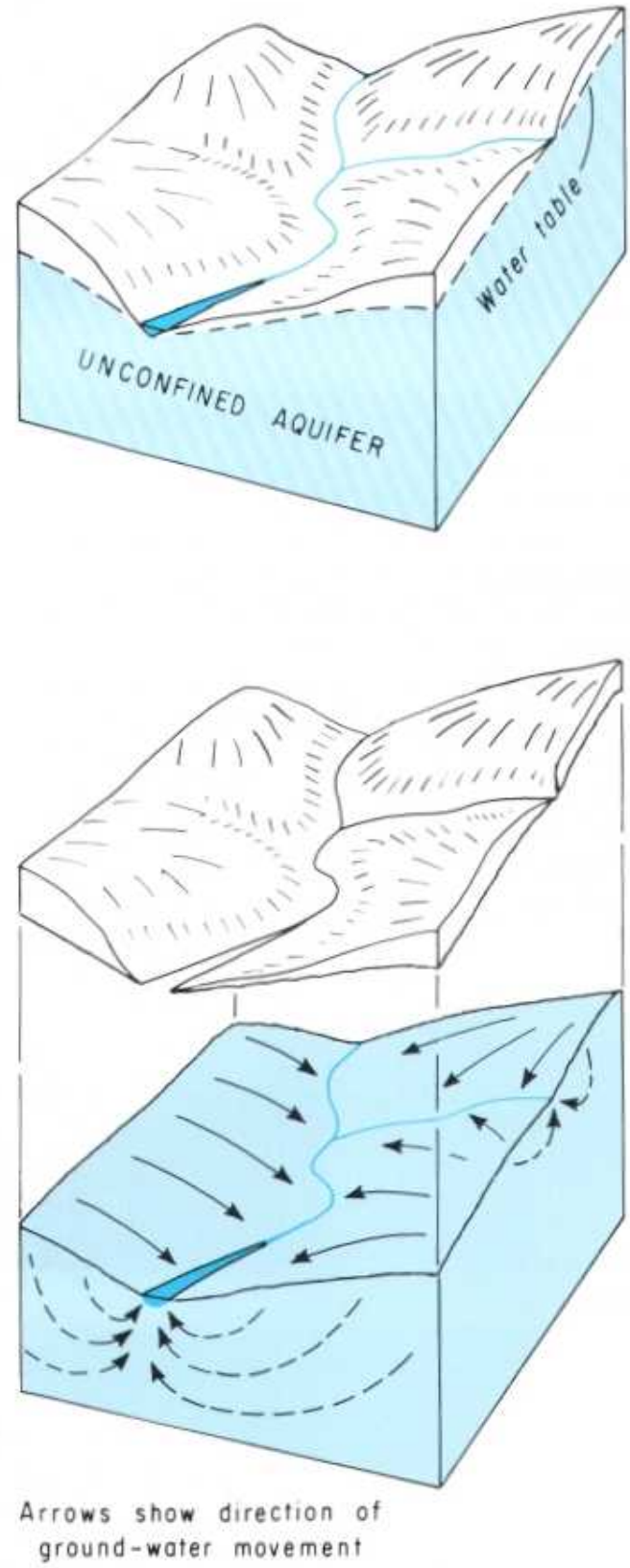

through the use of flow nets, which are one of the most effective means yet devised for illustrating conditions in groundwater systems. 
Flow nets consist of two sets of lines. One set, referred to as equipotential lines, connects points of equal head and thus represents the height of the water table, or the potentiometric surface of a confined aquifer, above a datum plane. The second set, referred to as flow lines, depicts the idealized paths followed by particles of water as they move through the aquifer. Because ground water moves in the direction of the steepest hydraulic gradient, flow lines in isotropic aquifers are perpendicular to equipotential lines-that is, flow lines cross equipotential lines at right angles.

There are an infinite number of equipotential lines and flow lines in an aquifer. However, for purposes of flow-net analysis, only a few of each set need be drawn. Equipotential lines are drawn so that the drop in head is the same between adjacent pairs of lines. Flow lines are drawn so that the flow is equally divided between adjacent pairs of lines and so that, together with the equipotential lines, they form a series of "squares."

Flow nets not only show the direction of ground-water movement but can also, if they are drawn with care, be used to estimate the quantity of water in transit through an aquifer. According to Darcy's law, the flow through any "square" is

$$
q=K b w\left(\frac{d h}{d l}\right)
$$

and the total flow through any set or group of "squares" is

$$
Q=n q
$$

where $K$ is hydraulic conductivity, $b$ is aquifer thickness at the midpoint between equipotential lines, $w$ is the distance be- tween flow lines, $d h$ is the difference in head between equipotential lines, $d l$ is the distance between equipotential lines, and $n$ is the number of squares through which the flow occurs.

Drawings 1 and 2 show a flow net in both plan view and cross section for an area underlain by an unconfined aquifer composed of sand. The sand overlies a horizontal confining bed, the top of which occurs at an elevation $3 \mathrm{~m}$ above the datum plane. The fact that some flow lines originate in the area in which heads exceed $13 \mathrm{~m}$ indicates the presence of recharge to the aquifer in this area. The relative positions of the land surface and the water table in sketch 2 suggest that recharge occurs throughout the area, except along the stream valleys. This suggestion is confirmed by the fact that flow lines also originate in areas where heads are less than $13 \mathrm{~m}$.

As sketches 1 and 2 show, flow lines originate in recharge areas and terminate in discharge areas. Closed contours (equipotential lines) indicate the central parts of recharge areas but do not normally indicate the limits of the areas.

In the cross-sectional view in sketch 2, heads decrease downward in the recharge area and decrease upward in the discharge area. Consequently, the deeper a well is drilled in a recharge area, the lower the water level in the well stands below land surface. The reverse is true in discharge areas. Thus, in a discharge area, if a well is drilled deeply enough in an unconfined aquifer, the well may flow above land surface. Consequently, a flowing well does not necessarily indicate artesian conditions.

Drawings 3 and 4 show equipotential lines and flow lines in the vicinity of a stream that gains water in its headwaters and loses water as it flows downstream. In the gaining reaches, the equipotential lines form a $\mathrm{V}$ pointing upstream; in the losing reach, they form a $V$ pointing downstream. 


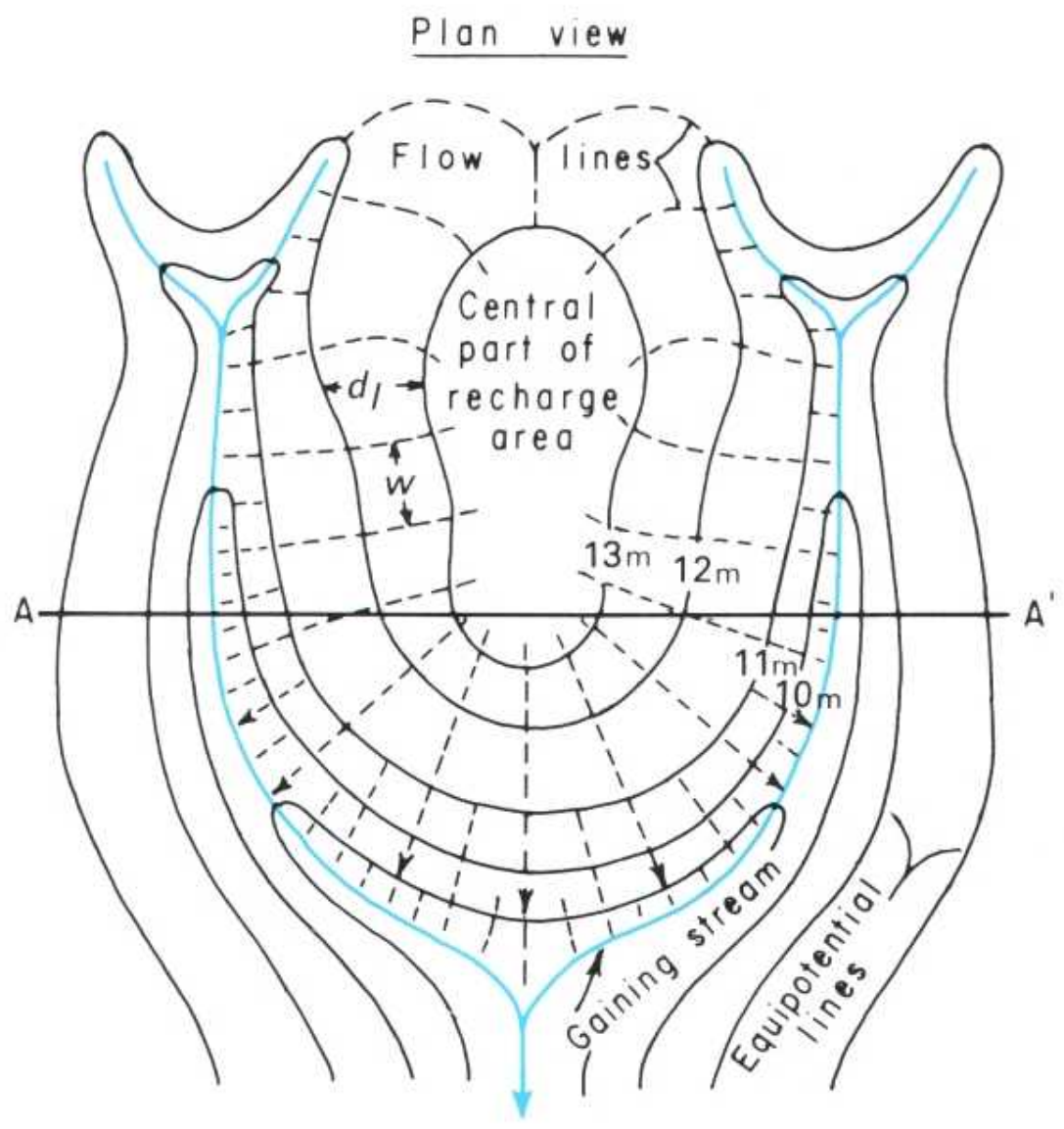

(1)

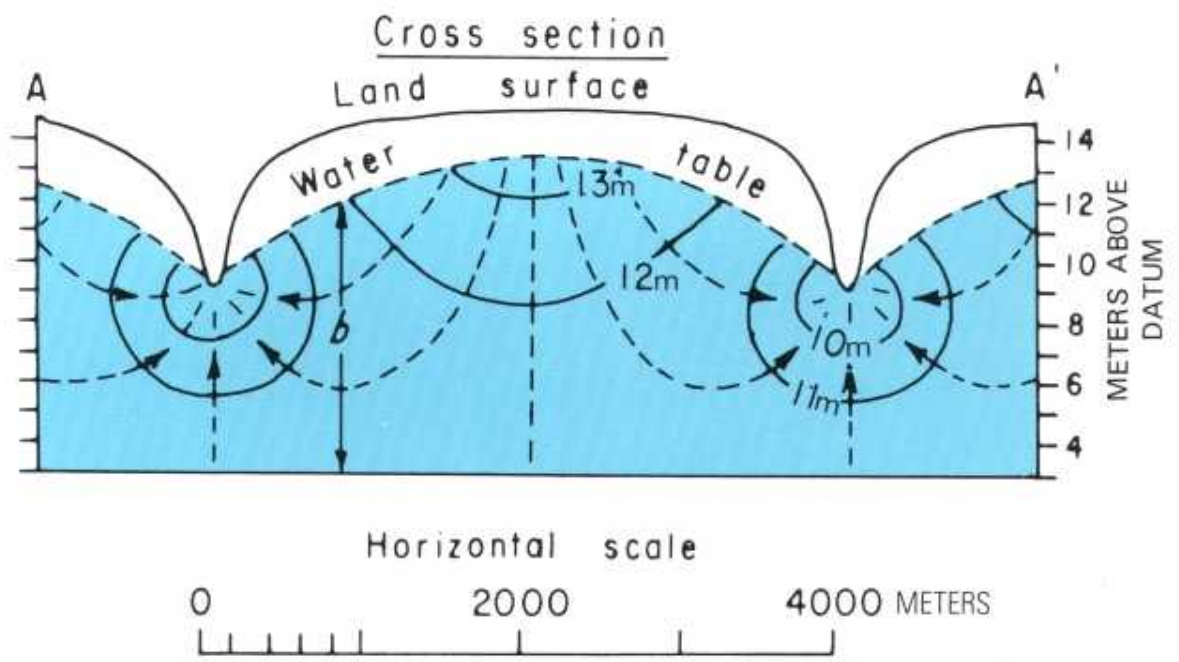

(2) 


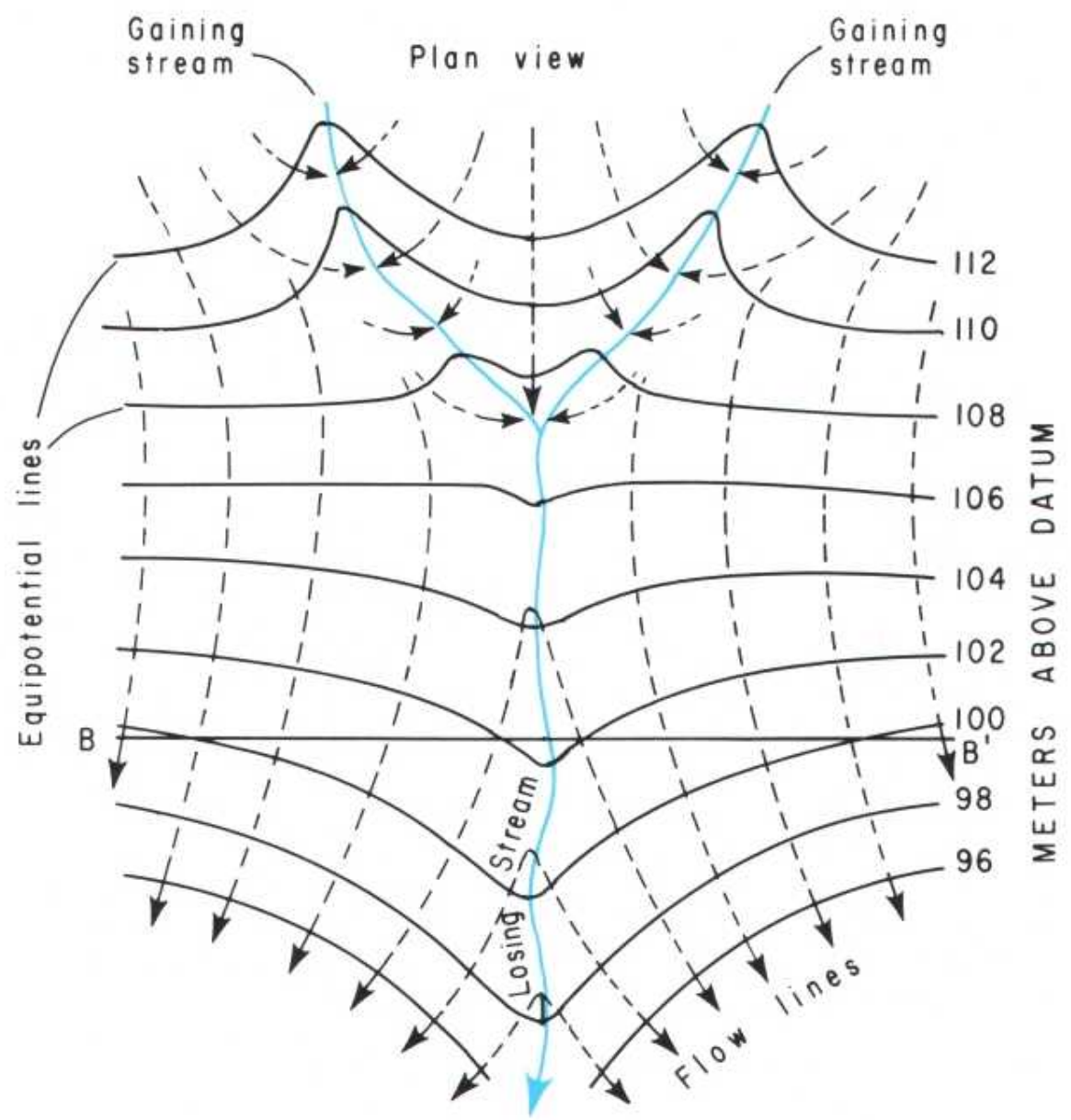

(3)

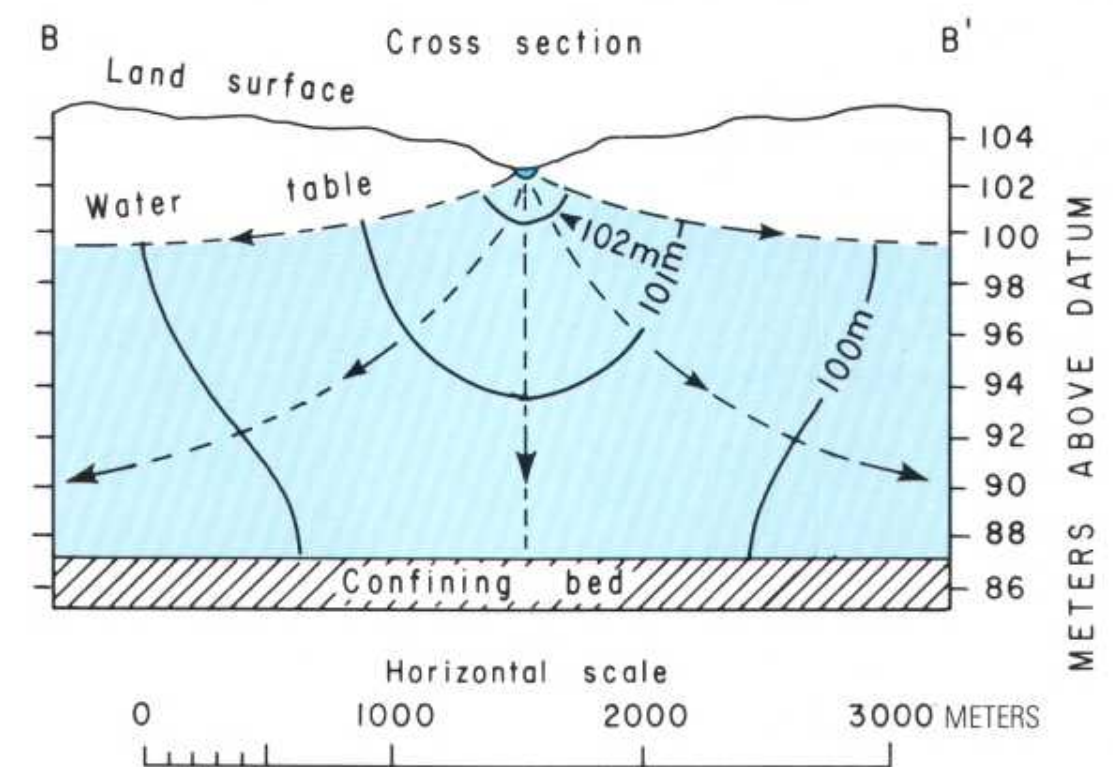

(4) 


\section{GROUND-WATER MOVEMENT AND STRATIFICATION}

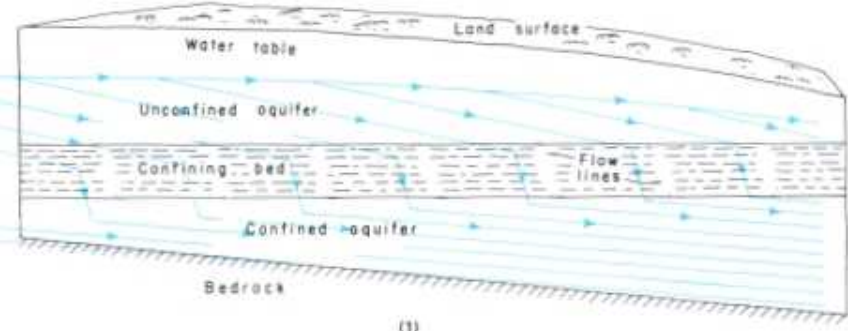

(1)

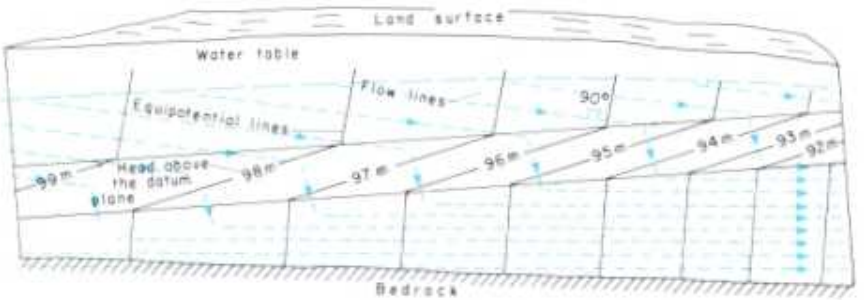

Nearly all ground-water systems include both aquifers and confining beds. Thus, ground-water movement through these systems involves flow not only through the aquifers but also across the confining beds (1).

The hydraulic conductivities of aquifers are tens to thousands of times those of confining beds. Thus, aquifers offer the least resistance to flow, the result being that, for a given rate of flow, the head loss per unit of distance along a flow line is tens to thousands of times less in aquifers than it is in confining beds. Consequently, lateral flow in confining beds usually is negligible, and flow lines tend to "concentrate" in aquifers and be parallel to aquifer boundaries (2).

Differences in the hydraulic conductivities of aquifers and confining beds cause a refraction or bending of flow lines at their boundaries. As flow lines move from aquifers into confining beds, they are refracted toward the direction perpendicular to the boundary. In other words, they are refracted in the direction that produces the shortest flow path in the confining bed. As the flow lines emerge from the confining bed, they are refracted back toward the direction parallel to the boundary (1).
The angles of refraction (and the spacing of flow lines in adjacent aquifers and confining beds) are proportional to the differences in hydraulic conductivities $(K)(3)$ such that

$$
\frac{\tan \theta_{1}}{\tan \theta_{2}}=\frac{K_{1}}{K_{2}}
$$

In cross section, the water table is a flow line. It represents a bounding surface for the ground-water system; thus, in the development of many ground-water flow equations, it is assumed to be coincident with a flow line. However, during periods when recharge is arriving at the top of the capillary fringe, the water table is also the point of origin of flow lines (1).

The movement of water through ground-water systems is controlled by the vertical and horizontal hydraulic conductivities and thicknesses of the aquifers and confining beds and the hydraulic gradients. The maximum difference in head exists between the central parts of recharge areas and discharge areas. Because of the relatively large head loss that occurs as water moves across confining beds, the most vigorous circulation of ground water normally occurs through the shallowest aquifers. Movement becomes more and more lethargic as depth increases.

The most important exceptions to the general situation described in the preceding paragraph are those systems in which one or more of the deeper aquifers have transmissivities significantly larger than those of the surficial and other shallower aquifers. Thus, in eastern North Carolina, the Castle Hayne Limestone, which occurs at depths ranging from about 10 to about $75 \mathrm{~m}$ below land surface, is the dominant aquifer because of its very large transmissivity, although it is overlain in most of the area by one or more less permeable aquifers.

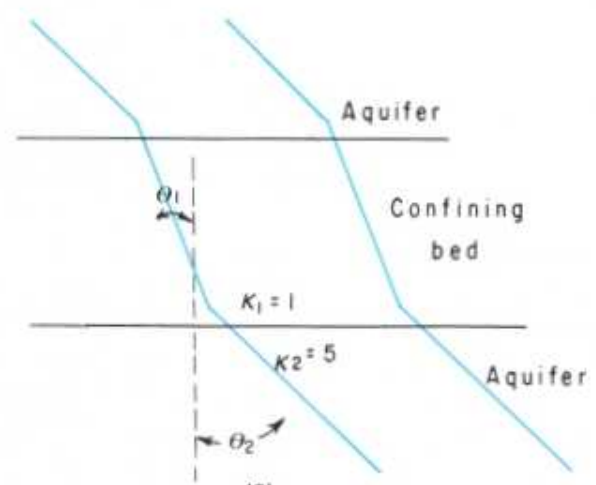

(3) 

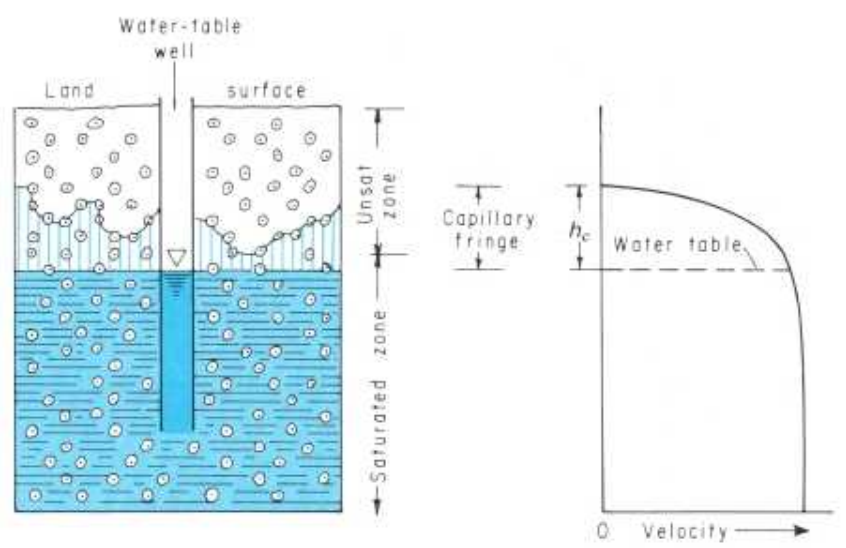

The rate of movement of ground water is important in many problems, particularly those related to pollution. For example, if a harmful substance is introduced into an aquifer upgradient from a supply well, it becomes a matter of great urgency to estimate when the substance will reach the well.

The rate of movement of ground water is greatly overestimated by many people, including those who think in terms of ground water moving through "veins" and underground rivers at the rates commonly observed in surface streams. It would be more appropriate to compare the rate of movement of ground water to the movement of water in the middle of a very large lake being drained by a very small stream.

The ground-water velocity equation can be derived from a combination of Darcy's law and the velocity equation of hydraulics.

$$
\begin{array}{cr}
Q=K A\left(\frac{d h}{d l}\right) \quad \text { (Darcy's law) } \\
Q=A v & \text { (velocity equation) }
\end{array}
$$

where $Q$ is the rate of flow or volume per unit of time, $K$ is the hydraulic conductivity, $A$ is the cross-sectional area, at a right angle to the flow direction, through which the flow $Q$ occurs, $d h / d l$ is the hydraulic gradient, and $v$ is the Darcian velocity, which is the average velocity of the entire cross-sectional area. Combining these equations, we obtain

$$
A v=K A\left(\frac{d h}{d l}\right)
$$

Canceling the area terms, we find that

$$
v=K\left(\frac{d h}{d l}\right)
$$

Because this equation contains terms for hydraulic conductivity and gradient only, it is not yet a complete expression of ground-water velocity. The missing term is porosity (n) because, as we know, water moves only through the openings in a rock. Adding the porosity term, we obtain

$$
v=\frac{K d h}{n d l}
$$

In order to demonstrate the relatively slow rate of groundwater movement, equation 1 is used to determine the rate of movement through an aquifer and a confining bed.

1. Aquifer composed of coarse sand

$$
\begin{aligned}
& K=60 \mathrm{~m} / \mathrm{d} \\
& d h / d l=1 \mathrm{~m} / 1,000 \mathrm{~m} \\
& n=0.20 \\
& V=\frac{K}{n} \times \frac{d h}{d l}=\frac{60 \mathrm{~m}}{\mathrm{~d}} \times \frac{1}{0.20} \times \frac{1 \mathrm{~m}}{1,000 \mathrm{~m}} \\
& =\frac{60 \mathrm{~m}^{2}}{200 \mathrm{~m} \mathrm{~d}^{2}}=0.3 \mathrm{~m} \mathrm{~d}^{-1}
\end{aligned}
$$

\section{Confining bed composed of clay}

$$
\begin{aligned}
& K=0.0001 \mathrm{~m} / \mathrm{d} \\
& d h / d l=1 \mathrm{~m} / 10 \mathrm{~m} \\
& n=0.50 \\
& V=\frac{0.0001 \mathrm{~m}}{\mathrm{~d}} \times \frac{1}{0.50} \times \frac{1 \mathrm{~m}}{10 \mathrm{~m}} \\
& =\frac{0.0001 \mathrm{~m}^{2}}{5 \mathrm{~m} \mathrm{~d}^{2}}=0.00002 \mathrm{~m} \mathrm{~d}^{-1}
\end{aligned}
$$

Velocities calculated with equation 1 are, at best, average values. Where ground-water pollution is involved, the fastest rates of movement may be several times the average rate. Also, the rates of movement in limestone caverns, lava tubes, and large rock fractures may approach those observed in surface streams.

Further, movement in unconfined aquifers is not limited to the zone below the water table or to the saturated zone. Water in the capillary fringe is subjected to the same hydraulic gradient that exists at the water table; water in the capillary fringe moves, therefore, in the same direction as the ground water.

As the accompanying sketch shows, the rate of lateral movement in the capillary fringe decreases in an upward direction and becomes zero at the top of the fringe. This consideration is important where unconfined aquifers are polluted with gasoline and other substances less dense than water. 
The capacity of an aquifer to transmit water of the prevailing kinematic viscosity is referred to as its transmissivity. The transmissivity $(T)$ of an aquifer is equal to the hydraulic conductivity of the aquifer multiplied by the saturated thickness of the aquifer. Thus,

$$
T=K b
$$

where $T$ is transmissivity, $K$ is hydraulic conductivity, and $b$ is aquifer thickness.

As is the case with hydraulic conductivity, transmissivity is also defined in terms of a unit hydraulic gradient.

If equation 1 is combined with Darcy's law (see "Hydraulic Conductivity"), the result is an equation that can be used to calculate the quantity of water $(q)$ moving through a unit width $(w)$ of an aquifer. Darcy's law is

$$
q=K A\left(\frac{d h}{d l}\right)
$$

Expressing area $(A)$ as bw, we obtain

$$
q=K b w\left(\frac{d h}{d l}\right)
$$

Next, expressing transmissivity $(T)$ as $K b$, we obtain

$$
q=T w\left(\frac{d h}{d l}\right)
$$

Equation 2 modified to determine the quantity of water (Q) moving through a large width $(W)$ of an aquifer is

$$
Q=T w W\left(\frac{d h}{d l}\right)
$$

or, if it is recognized that $T$ applies to a unit width $(w)$ of an aquifer, this equation can be stated more simply as

$$
Q=T W\left(\frac{d h}{d l}\right)
$$

If equation 3 is applied to sketch 1, the quantity of water flowing out of the right-hand side of the sketch can be calculated by using the values shown on the sketch, as follows:

$$
\begin{gathered}
T=K b=\frac{50 \mathrm{~m}}{\mathrm{~d}} \times \frac{100 \mathrm{~m}}{1}=5,000 \mathrm{~m}^{2} \mathrm{~d}^{-1} \\
Q=T W\left(\frac{\mathrm{dh}}{\mathrm{dl}}\right)=\frac{5,000 \mathrm{~m}^{2}}{\mathrm{~d}} \times \frac{1,000 \mathrm{~m}}{1} \times \frac{1 \mathrm{~m}}{1,000 \mathrm{~m}}=5,000 \mathrm{~m}^{3} \mathrm{~d}^{-1}
\end{gathered}
$$

Equation 3 is also used to calculate transmissivity, where the quantity of water $(Q)$ discharging from a known width of aquifer can be determined as, for example, with streamflow measurements. Rearranging terms, we obtain

$$
T=\frac{Q}{W}\left(\frac{d l}{d h}\right)
$$

The units of transmissivity, as the preceding equation demonstrates, are

$$
T=\frac{\left(\mathrm{m}^{3} \mathrm{~d}^{-1}\right)(\mathrm{m})}{(\mathrm{m})(\mathrm{m})}=\frac{\mathrm{m}^{2}}{\mathrm{~d}}
$$

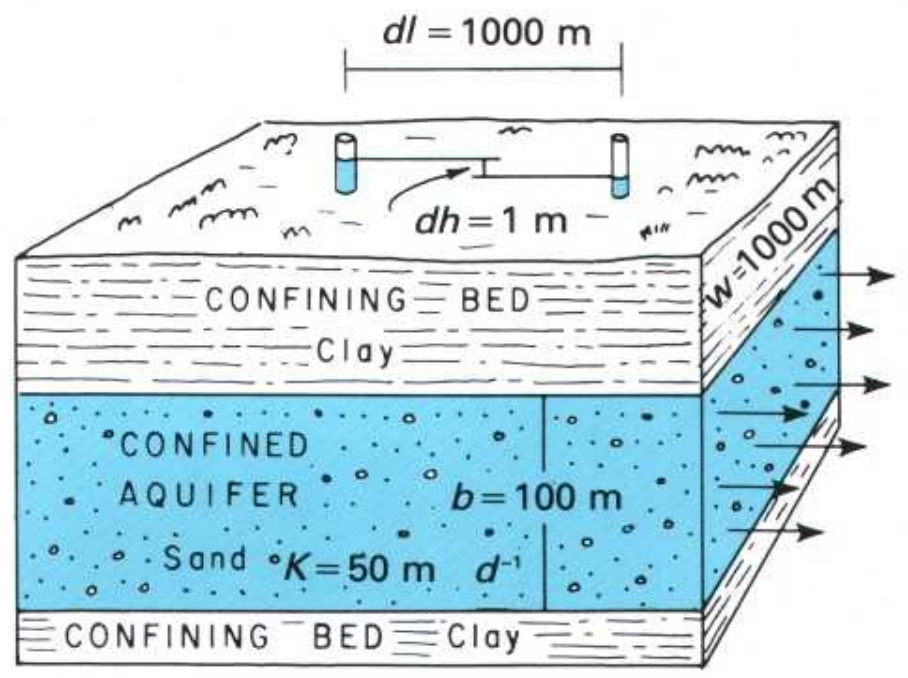

(1) 


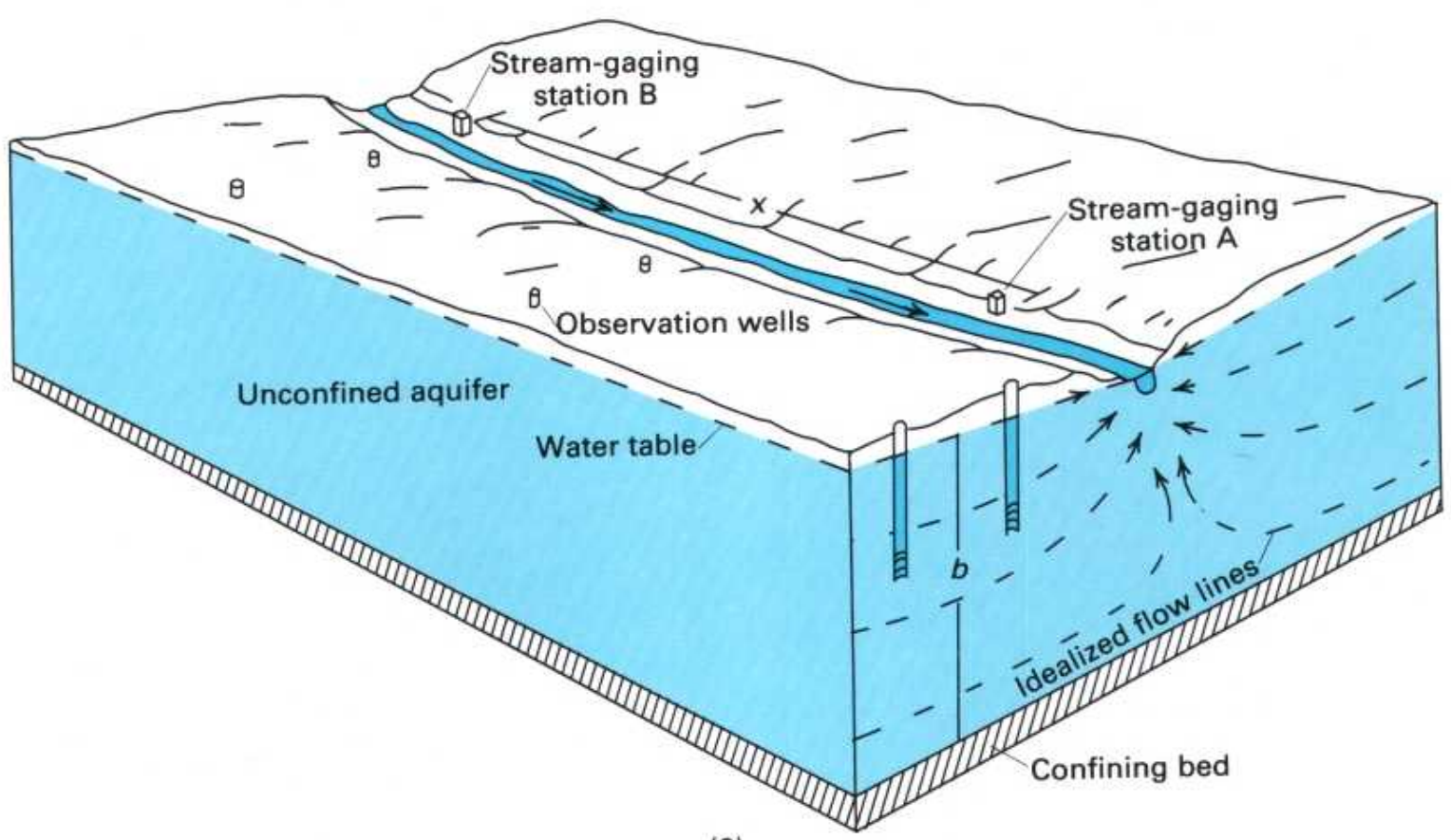

(2)

Sketch 2 illustrates the hydrologic situation that permits calculation of transmissivity through the use of stream discharge. The calculation can be made only during dry-weather (baseflow) periods, when all water in the stream is derived from ground-water discharge. For the purpose of this example, the following values are assumed: Average daily flow at stream-gaging
station A:

Average daily flow at stream-gaging station B:

$$
2.485 \mathrm{~m}^{3} \mathrm{~s}^{-1}
$$

Increase in flow due to ground-water discharge:

Total daily ground-water discharge to stream:

Discharge from half of aquifer (one sid of the stream):

$$
2.355 \mathrm{~m}^{3} \mathrm{~s}^{-1}
$$

$$
0.130 \mathrm{~m}^{3} \mathrm{~s}^{-1}
$$

$$
11,232 \mathrm{~m}^{3} \mathrm{~d}^{-1}
$$

Avtance $(x)$ between stations A and B: $\quad 5,000 \mathrm{~m}$

Average thickness of aquifer (b):

$50 \mathrm{~m}$

Average slope of the water table $(d h / d)$ determined from measurements in the observation wells:

$1 \mathrm{~m} / 2,000 \mathrm{~m}$
By equation 4,

$$
T=\frac{Q}{W} \times \frac{d l}{d h}=\frac{5,616 \mathrm{~m}^{3}}{\mathrm{~d} \times 5,000 \mathrm{~m}} \times \frac{2,000 \mathrm{~m}}{1 \mathrm{~m}}=2,246 \mathrm{~m}^{2} \mathrm{~d}^{-1}
$$

The hydraulic conductivity is determined from equation 1 as follows:

$$
K=\frac{T}{b}=\frac{2,246 \mathrm{~m}^{2}}{\mathrm{~d} \times 50 \mathrm{~m}}=45 \mathrm{~m} \mathrm{~d}^{-1}
$$

Because transmissivity depends on both $K$ and $b$, its value differs in different aquifers and from place to place in the same aquifer. Estimated values of transmissivity for the principal aquifers in different parts of the country range from less than $1 \mathrm{~m}^{2} \mathrm{~d}^{-1}$ for some fractured sedimentary and igneous rocks to $100,000 \mathrm{~m}^{2} \mathrm{~d}^{-1}$ for cavernous limestones and lava flows.

Finally, transmissivity replaces the term "coefficient of transmissibility" because, by convention, an aquifer is transmissive, and the water in it is transmissible. 

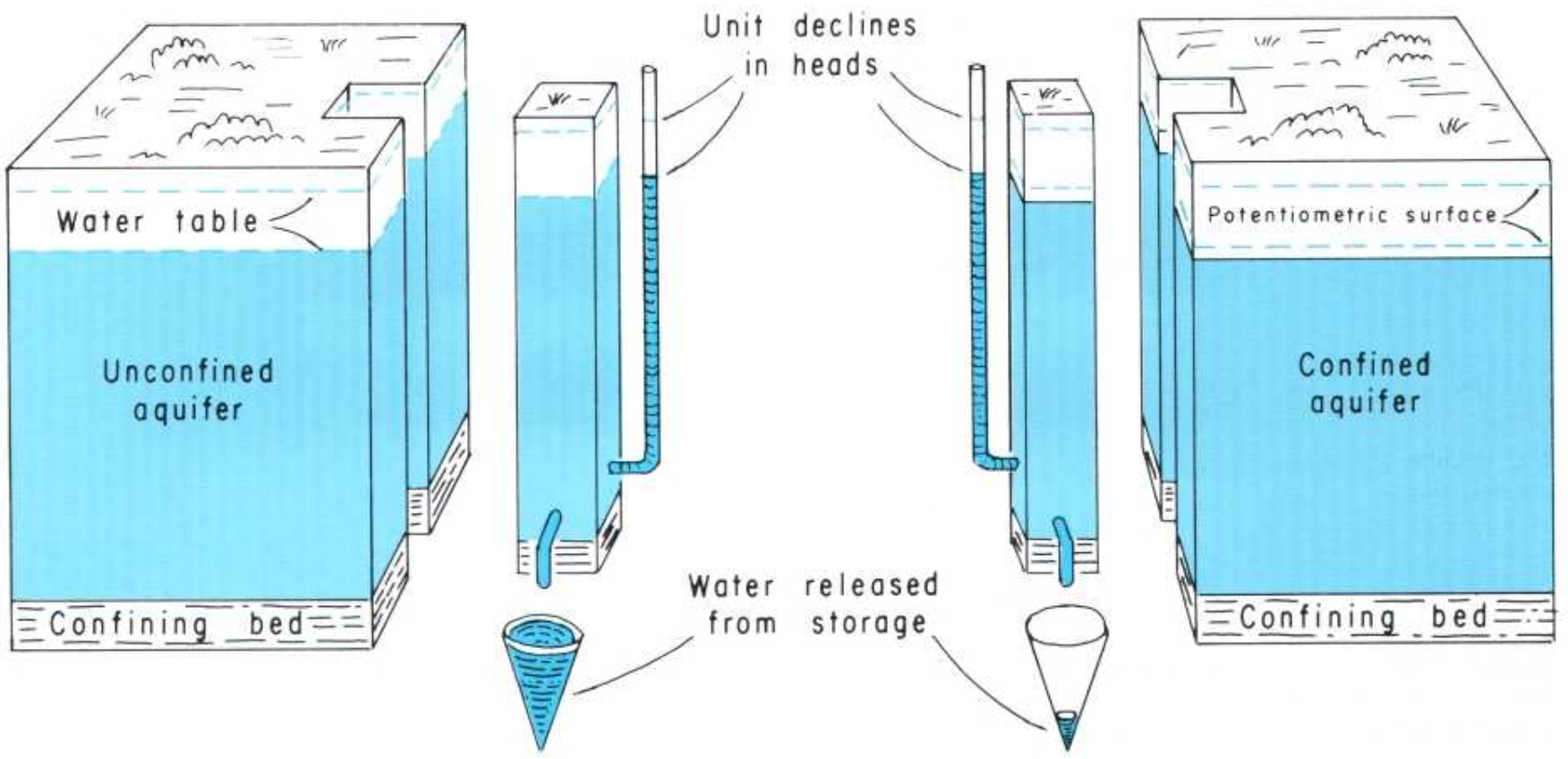

(1)
The abilities (capacities) of water-bearing materials to store and to transmit water are their most important hydraulic properties. Depending on the intended use of the information, these properties are given either in terms of a unit cube of the material or in terms of a unit prism of an aquifer.

\begin{tabular}{lll}
\multicolumn{1}{c}{ Property } & \multicolumn{1}{c}{ Unit cube of material } & Unit prism of aquifer \\
Transmissive capacity & Hydraulic conductivity $(K)$ & Transmissivity $(T)$ \\
Available storage & Specific yield $\left(S_{y}\right)$ & Storage coefficient $(S)$
\end{tabular}

The storage coefficient $(S)$ is defined as the volume of water that an aquifer releases from or takes into storage per unit surface area of the aquifer per unit change in head. The storage coefficient is a dimensionless unit, as the following equation shows, in which the units in the numerator and the denominator cancel:

$$
S=\frac{\text { volume of water }}{\text { (unit area)(unit head change) }}=\frac{\left(\mathrm{m}^{3}\right)}{\left(\mathrm{m}^{2}\right)(\mathrm{m})}=\frac{\mathrm{m}^{3}}{\mathrm{~m}^{3}}
$$

The size of the storage coefficient depends on whether the aquifer is confined or unconfined (1). If the aquifer is confined, the water released from storage when the head declines comes from expansion of the water and from compression of the aquifer. Relative to a confined aquifer, the expansion of a given volume of water in response to a decline in pressure is very small. In a confined aquifer having a porosity of 0.2 and containing water at a temperature of about $15^{\circ} \mathrm{C}$, expansion of the water alone releases about $9 \times 10^{-7} \mathrm{~m}^{3}$ of water per cubic meter of aquifer per meter of decline in head. To determine the storage coefficient of an aquifer due to expansion of the water, it is necessary to multiply the aquifer thickness by $9 \times 10^{-7}$. Thus, if only the expansion of water is considered, the storage coefficient of an aquifer $100 \mathrm{~m}$ thick would be $9 \times 10^{-5}$. The storage coefficient of most confined aquifers ranges from about $10^{-5}$ to $10^{-3}(0.00001$ to 0.001$)$. The difference between these values and the value due to expansion of the water is attributed to compression of the aquifer.

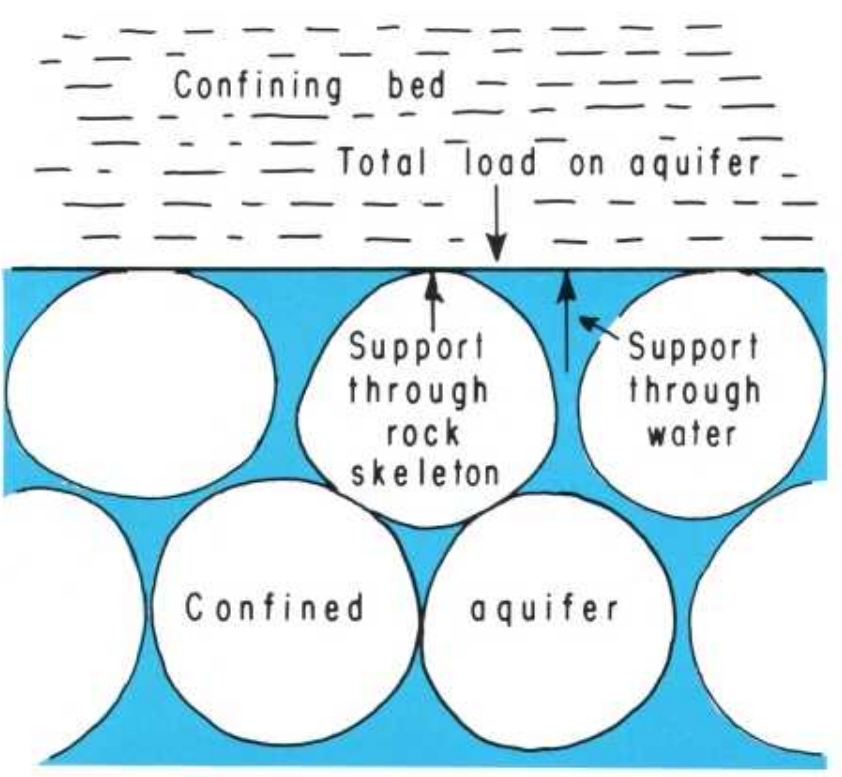

(2) 
Sketch 2 will aid in understanding this phenomenon. It shows a microscopic view of the contact between an aquifer and the overlying confining bed. The total load on the top of the aquifer is supported partly by the solid skeleton of the aquifer and partly by the hydraulic pressure exerted by the water in the aquifer. When the water pressure declines, more of the load must be supported by the solid skeleton. As a result, the rock particles are distorted, and the pore space is reduced. The water forced from the pores when their volume is reduced represents the part of the storage coefficient due to compression of the aquifer.

If the aquifer is unconfined, the predominant source of water is from gravity drainage of the sediments through which the decline in the water table occurs. In an unconfined aquifer, the volume of water derived from expansion of the water and compression of the aquifer is negligible. Thus, in such an aquifer, the storage coefficient is virtually equal to the specific yield and ranges from about 0.1 to about 0.3 .

Because of the difference in the sources of storage, the storage coefficient of unconfined aquifers is 100 to 10,000 times the storage coefficient of confined aquifers (1). However, if water levels in an area are reduced to the point where an aquifer changes from a confined condition to an unconfined condition, the storage coefficient of the aquifer immediately increases from that of a confined aquifer to that of an unconfined aquifer.

Long-term withdrawals of water from many confined aquifers result in drainage of water both from clay layers within the aquifer and from adjacent confining beds. This drainage increases the load on the solid skeleton and results in compression of the aquifer and subsidence of the land surface. Subsidence of the land surface caused by drainage of clay layers has occurred in Arizona, California, Texas, and other areas.

The potential sources of water in a two-unit ground-water system consisting of a confining bed and a confined aquifer are shown in sketch 3 . The sketch is based on the assumption that water is removed in two separate stages-the first while the potentiometric surface is lowered to the top of the aquifer and the second by dewatering the aquifer.

The differences in the storage coefficients of confined and unconfined aquifers are of great importance in determining the response of the aquifers to stresses such as withdrawals through wells, (See "Well-Field Design.")

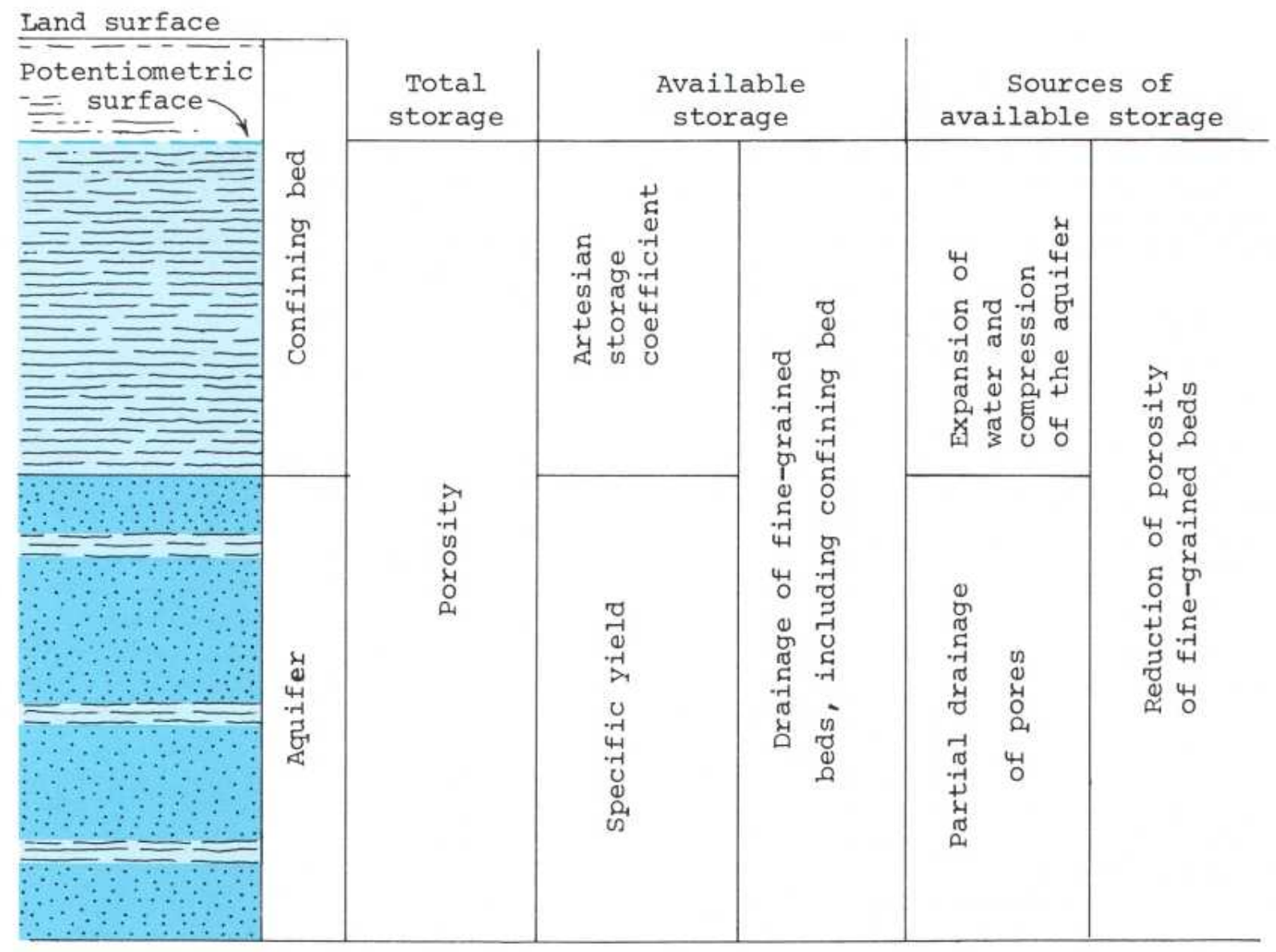

Bedrock 


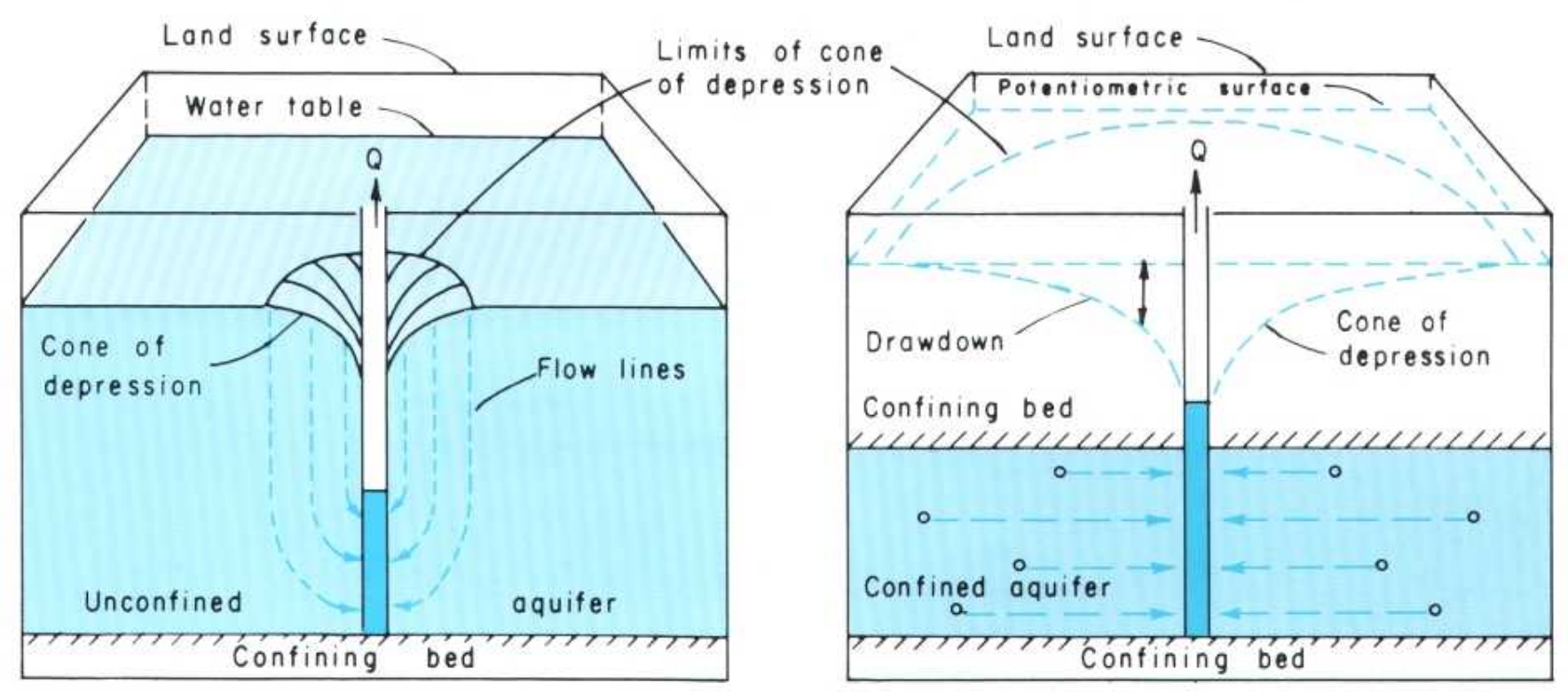

(1)

(2)

Both wells and springs serve as sources of ground-water supply. However, most springs having yields large enough to meet municipal, industrial, and large commercial and agricultural needs occur only in areas underlain by cavernous limestones and lava flows. Therefore, most ground-water needs are met by withdrawals from wells.

The response of aquifers to withdrawals from wells is an important topic in ground-water hydrology. When withdrawals start, the water level in the well begins to decline as water is removed from storage in the well. The head in the well falls below the level in the surrounding aquifer. As a result, water begins to move from the aquifer into the well. As pumping continues, the water level in the well continues to decline, and the rate of flow into the well from the aquifer continues to increase until the rate of inflow equals the rate of withdrawal.

The movement of water from an aquifer into a well results in the formation of a cone of depression (1) (2). Because water must converge on the well from all directions and because the area through which the flow occurs decreases toward the well, the hydraulic gradient must get steeper toward the well.

Several important differences exist between the cones of depression in confined and unconfined aquifers. Withdrawals from an unconfined aquifer result in drainage of water from the rocks through which the water table declines as the cone of depression forms (1). Because the storage coefficient of an unconfined aquifer equals the specific yield of the aquifer material, the cone of depression expands very slowly. On the other hand, dewatering of the aquifer results in a decrease in transmissivity, which causes, in turn, an increase in drawdown both in the well and in the aquifer.

Withdrawals from a confined aquifer cause a drawdown in artesian pressure but do not (normally) cause a dewatering of the aquifer (2). The water withdrawn from a confined aquifer is derived from expansion of the water and compression of the rock skeleton of the aquifer. (See "Storage Coefficient.") The very small storage coefficient of confined aquifers results in a very rapid expansion of the cone of depression. Consequently, the mutual interference of expanding cones around adjacent wells occurs more rapidly in confined aquifers than it does in unconfined aquifers.

Cones of depression caused by large withdrawals from extensive confined aquifers can affect very large areas. Sketch 3 shows the overlapping cones of depression that existed in 1981 in an extensive confined aquifer composed of unconsolidated sands and interbedded silt and clay of Cretaceous age in the central part of the Atlantic Coastal Plain. The cones of depression are caused by withdrawals of about $277,000 \mathrm{~m}^{3}$ $\mathrm{d}^{-1}\left(73,000,000 \mathrm{gal}^{-1}\right)$ from well fields in Virginia and North Carolina. (See "Source of Water Derived From Wells.") 


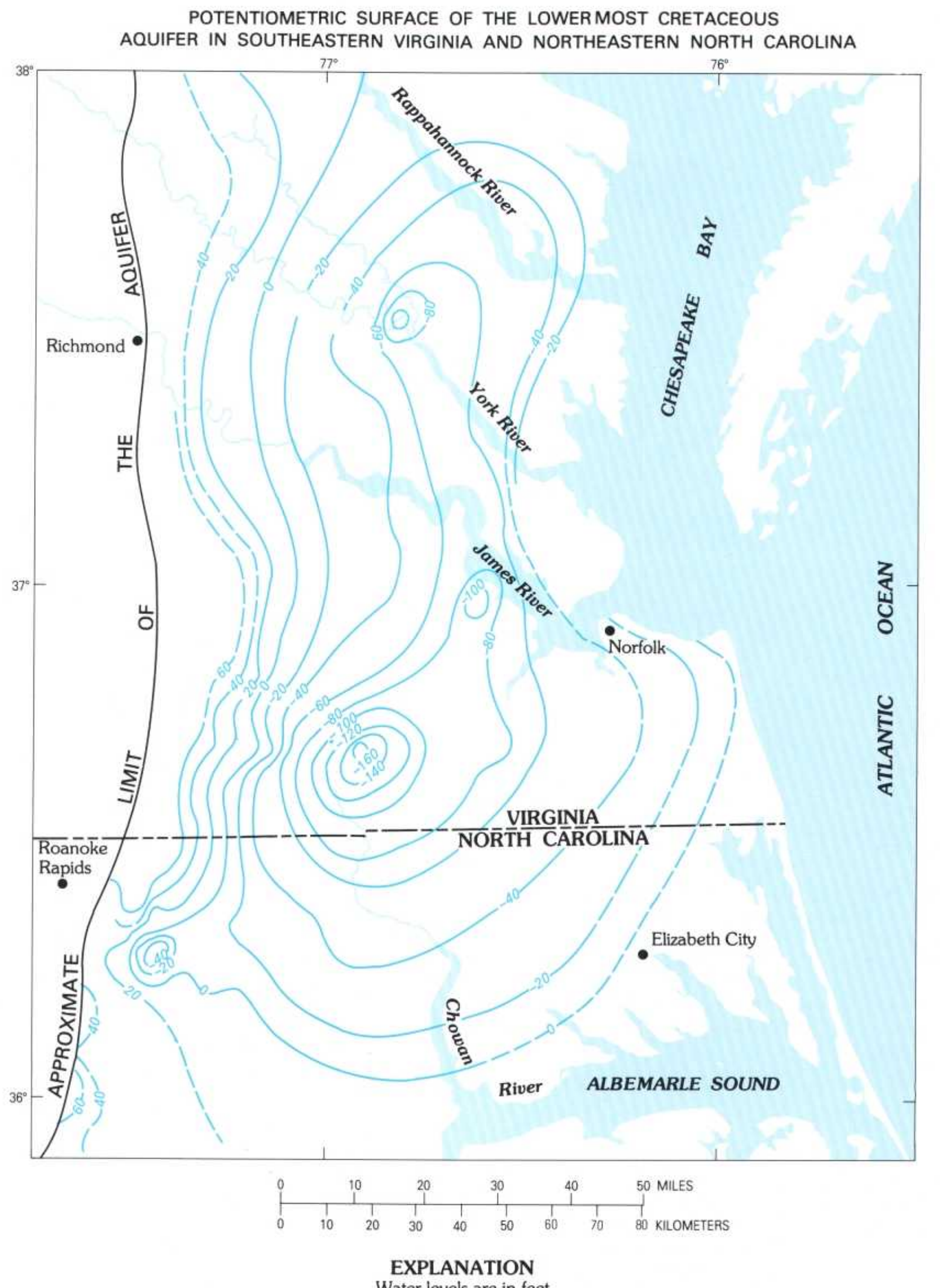

Water levels are in feet

NATIONAL GEODETIC VERTICAL DATUM 1929

(3) 
Both the economical development and the effective management of any ground-water system require an understanding of the response of the system to withdrawals from wells. The first concise description of the hydrologic principles involved in this response was presented by $C$. V. Theis in a paper published in 1940.

Theis pointed out that the response of an aquifer to withdrawals from wells depends on:

1. The rate of expansion of the cone of depression caused by the withdrawals, which depends on the transmissivity and the storage coefficient of the aquifer.

2. The distance to areas in which the rate of water discharging from the aquifer can be reduced.

3. The distance to recharge areas in which the rate of recharge can be increased.

Over a sufficiently long period of time under natural conditions-that is, before the start of withdrawals-the discharge from every ground-water system equals the recharge to it (1). In other words,

natural discharge $(D)=$ natural recharge $(R)$

In the eastern part of the United States and in the more humid areas in the West, the amount and distribution of precipitation are such that the period of time over which discharge and recharge balance may be less than a year or, at most, a few years. In the drier parts of the country-that is, in the areas that generally receive less than about $500 \mathrm{~mm}$ of precipitation annually-the period over which discharge and recharge balance may be several years or even centuries. Over shorter periods of time, differences between discharge and recharge involve changes in ground-water storage. In other words, when discharge exceeds recharge, ground-water storage $(S)$ is reduced by an amount $\Delta S$ equal to the difference between discharge and recharge. Thus,

$$
D=R+\Delta S
$$

Conversely, when recharge exceeds discharge, ground-water storage is increased. Thus,

$$
D=R-\Delta S
$$

When withdrawal through a well begins, water is removed from storage in its vicinity as the cone of depression develops (2). Thus, the withdrawal $(Q)$ is balanced by a reduction in ground-water storage. In other words,

$$
Q=\Delta S
$$

As the cone of depression expands outward from the pumping well, it may reach an area where water is discharging from the aquifer. The hydraulic gradient will be reduced toward the discharge area, and the rate of natural discharge will decrease (3). To the extent that the decrease in natural discharge compensates for the pumpage, the rate at which water is being removed from storage will also decrease, and the rate of expansion of the cone of depression will decline. If and when the reduction in natural discharge $(\Delta D)$ equals the rate of withdrawal $(Q)$, a new balance will be established in the aquifer. This balance in symbolic form is

$$
(D-\Delta D)+Q-R
$$

Conversely, if the cone of depression expands into a recharge area rather than into a natural discharge area, the hydraulic gradient between the recharge area and the pumping well will be increased. If, under natural conditions, more water was available in the recharge area than the aquifer could accept (the condition that Theis referred to as one of rejected recharge), the increase in the gradient away from the recharge area will permit more recharge to occur, and the rate of growth of the cone of depression will decrease. If and when the increase in recharge $(\Delta R)$ equals the rate of withdrawal (Q), a new balance will be established in the aquifer, and expansion of the cone of depression will cease. The new balance in symbolic form is

$$
D+Q=R+\Delta R
$$

In the eastern part of the United States, gaining streams are relatively closely spaced, and areas in which rejected recharge occurs are relatively unimportant. In this region, the growth of cones of depression first commonly causes a reduction in natural discharge. If the pumping wells are near a stream or if the withdrawals are continued long enough, ground-water discharge to a stream may be stopped entirely in the vicinity of the wells, and water may be induced to move from the stream into the aquifer (4). In other words, the tendency in this region is for withdrawals to change discharge areas into recharge areas. This consideration is important where the streams contain brackish or polluted water or where the streamflow is committed or required for other purposes.

To summarize, the withdrawal of ground water through a well reduces the water in storage in the source aquifer during the growth of the cone of depression. When and if the cone of depression ceases to expand, the rate of withdrawal is being balanced by a reduction in the rate of natural discharge and (or) by an increase in the rate of recharge. Under this condition,

$$
Q=\Delta D+\Delta R
$$




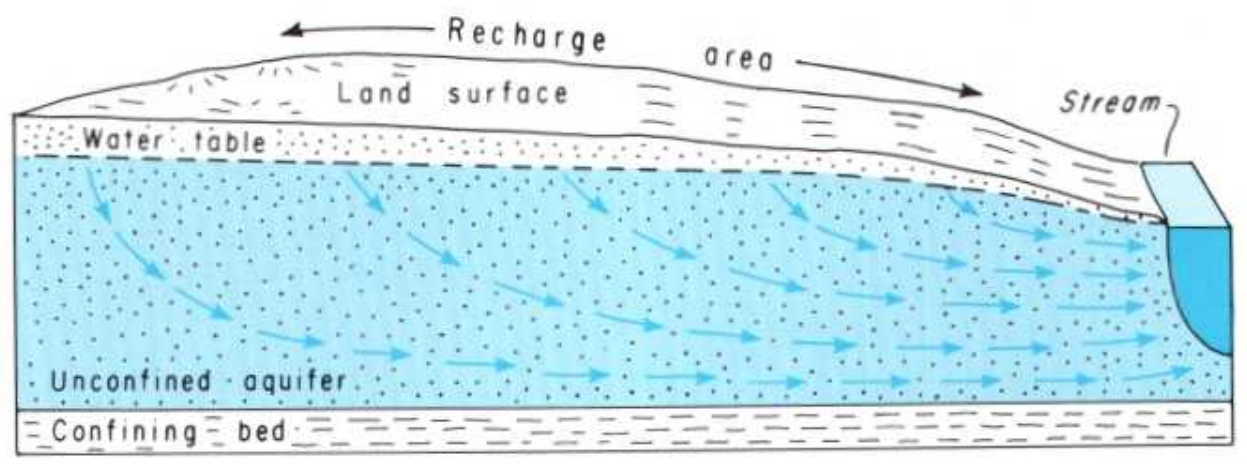

Discharge $(D)=$ Recharge $(R)$

(1)

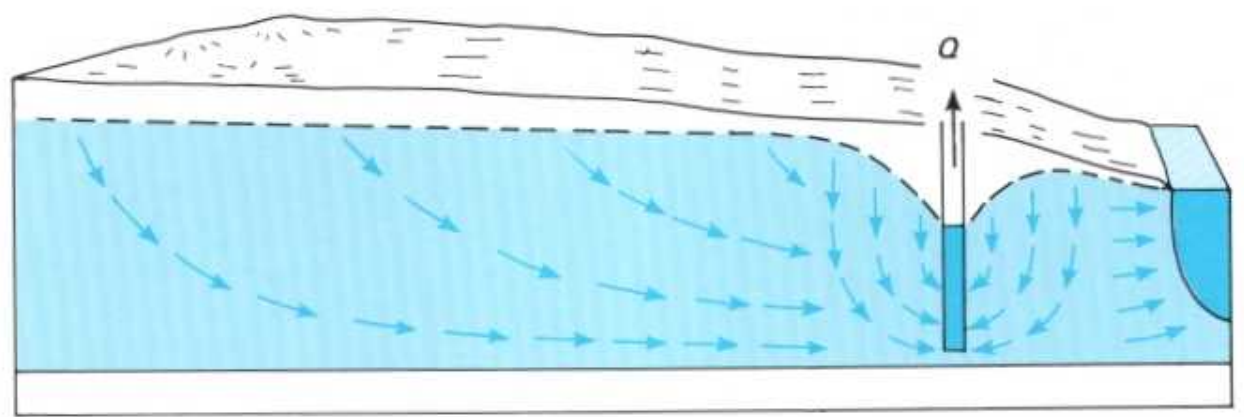

Withdrowal $(Q)$ = Reduction in storage $(\Delta S)$

(2)

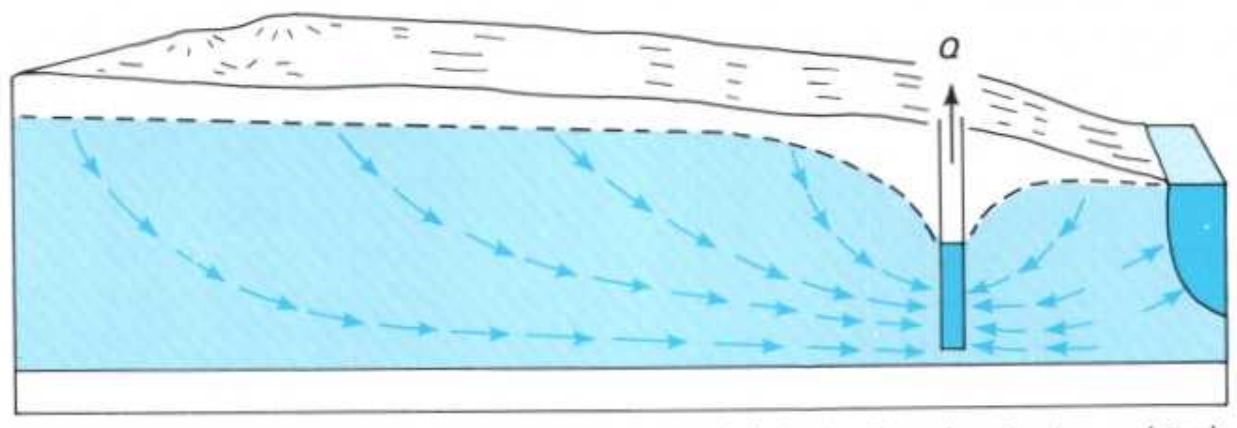

Withdrawal $(Q)=$ Reduction in storage $(\Delta S)+$ Reduction in discharge $(\triangle D)$

(3)

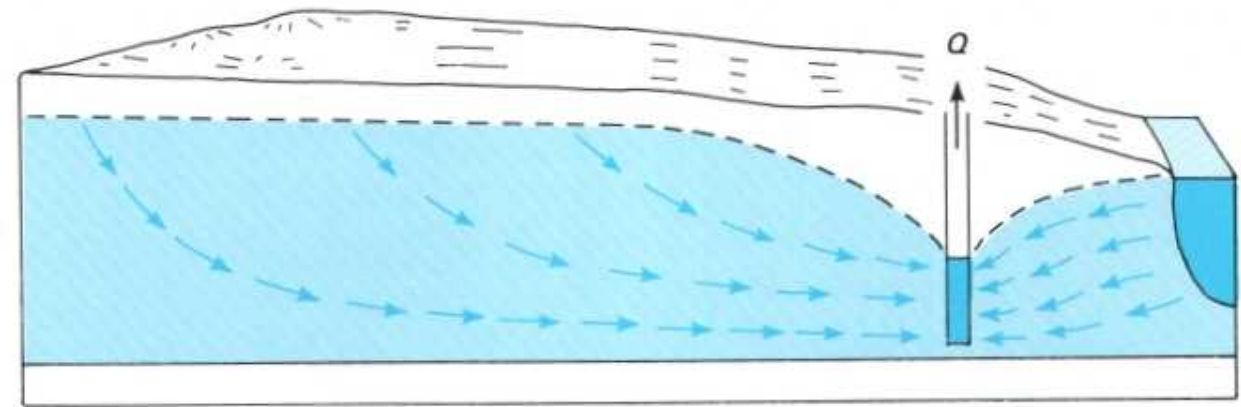

Withdrowal $(Q)$ Reduction in discharge $(\Delta D)+$ Increase in recharge $(\Delta R)$ 
MAP OF AQUIFER TEST SITE

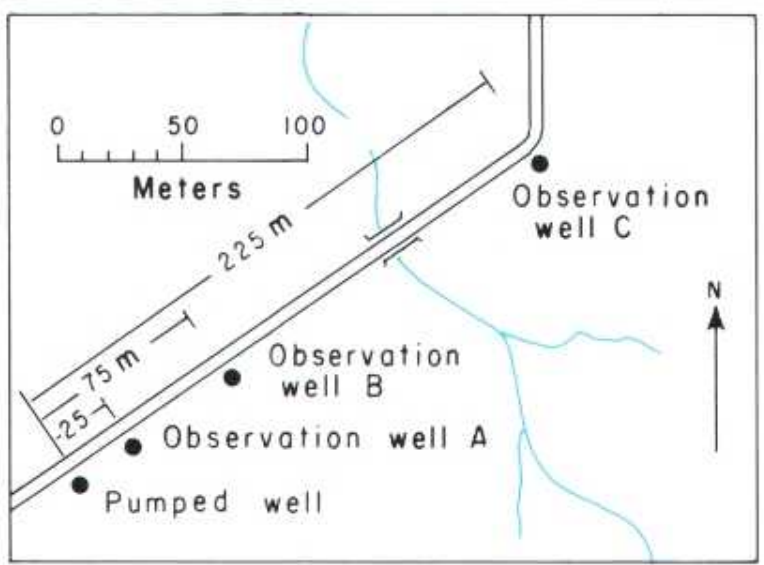

(1)

Determining the yield of ground-water systems and evaluating the movement and fate of ground-water pollutants require, among other information, knowledge of:

1. The position and thickness of aquifers and confining beds.

2. The transmissivity and storage coefficient of the aquifers.

3. The hydraulic characteristics of the confining beds.

4. The position and nature of the aquifer boundaries.

5. The location and amounts of ground-water withdrawals.

6. The locations, kinds, and amounts of pollutants and pollutant practices.

Acquiring knowledge on these factors requires both geologic and hydrologic investigations. One of the most important hydrologic studies involves analyzing the change, with time, in water levels (or total heads) in an aquifer caused by withdrawals through wells. This type of study is referred to as an aquifer test and, in most cases, includes pumping a well at a constant rate for a period ranging from several hours to several days and measuring the change in water level in observation wells located at different distances from the pumped well (1).

Successful aquifer tests require, among other things:

1. Determination of the prepumping water-level trend (that is, the regional trend).

2. A carefully controlled constant pumping rate.

3. Accurate water-level measurements made at precisely known times during both the drawdown and the recovery periods.
CHANGE OF WATER LEVEL IN WELL B

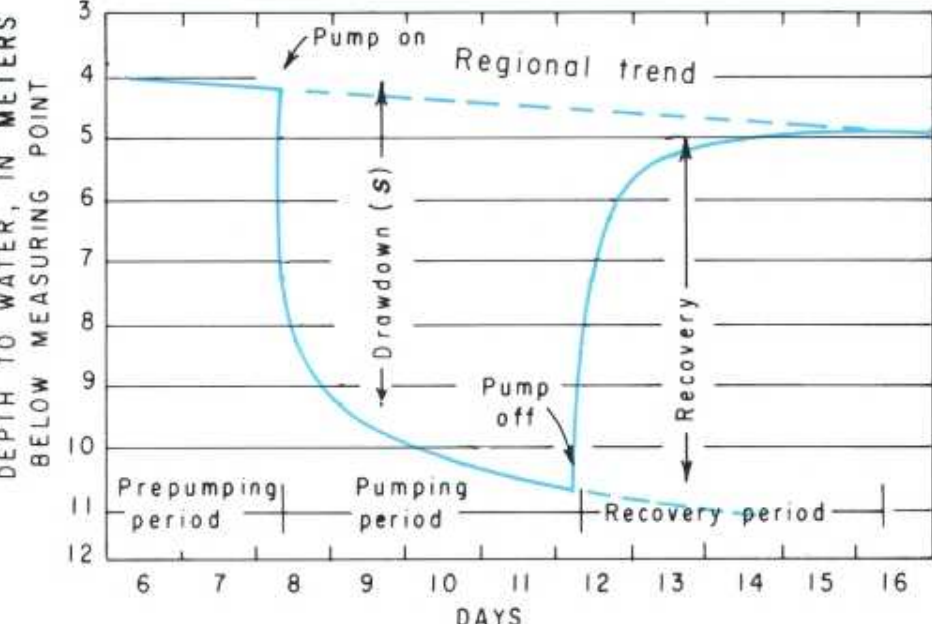

(2)
Drawdown is the difference between the water level at any time during the test and the position at which the water level would have been if withdrawals had not started. Drawdown is very rapid at first. As pumping continues and the cone of depression expands, the rate of drawdown decreases (2).

The recovery of the water level under ideal conditions is a mirror image of the drawdown. The change in water level during the recovery period is the same as if withdrawals had continued at the same rate from the pumped well but, at the moment of pump cutoff, a recharge well had begun recharging water at the same point and at the same rate. Therefore, the recovery of the water level is the difference between the actual measured level and the projected pumping level (2).

In addition to the constant-rate aquifer test mentioned above, analytical methods have also been developed for several other types of aquifer tests. These methods include tests in which the rate of withdrawal is variable and tests that involve leakage of water across confining beds into confined aquifers. The analytical methods available also permit analysis of tests conducted on both vertical wells and horizontal wells or drains.

The most commonly used method of analysis of aquifertest data-that for a vertical well pumped at a constant rate from an aquifer not affected by vertical leakage and lateral boundaries-will be covered in the discussion of "Analysis of Aquifer-Test Data." The method of aņalysis requires the use of a type curve based on the values of $W(u)$ and $1 / u$ listed in the following table. Preparation and use of the type curve are covered in the following discussion. 
SELECTED VALUES OF $W(u)$ FOR VALUES OF $1 / u$

\begin{tabular}{|c|c|c|c|c|c|c|c|c|c|c|c|c|c|c|}
\hline $1 / u$ & 10 & 7.69 & 5.88 & 5.00 & 4.00 & 3.33 & 2.86 & 2.5 & 2.22 & 2.00 & 1.67 & 1.43 & 1.25 & 1.11 \\
\hline $10^{-1}$ & 0.219 & 0.135 & 0.075 & 0.049 & 0.025 & 0.013 & 0.007 & 0.004 & 0.002 & 0.001 & 0.000 & 0.000 & 0.000 & 0.000 \\
\hline 1 & 1.82 & 1.59 & 1.36 & 1.22 & 1.04 & .91 & .79 & .70 & .63 & .56 & .45 & .37 & .31 & .26 \\
\hline 10 & 4.04 & 3.78 & 3.51 & 3.35 & 3.14 & 2.96 & 2.81 & 2.68 & 2.57 & 2.47 & 2.30 & 2.15 & 2.03 & 1.92 \\
\hline $10^{2}$ & 6.33 & 6.07 & 5.80 & 5.64 & 5.42 & 5.23 & 5.08 & 4.95 & 4.83 & 4.73 & 4.54 & 4.39 & 4.26 & 4.14 \\
\hline $10^{3}$ & 8.63 & 8.37 & 8.10 & 7.94 & 7.72 & 7.53 & 7.38 & 7.25 & 7.13 & 7.02 & 6.84 & 6.69 & 6.55 & 6.44 \\
\hline $10^{4}$ & 10.94 & 10.67 & 10.41 & 10.24 & 10.02 & 9.84 & 9.68 & ;9.55 & 9.43 & 9.33 & 9.14 & 8.99 & 8.86 & 8.74 \\
\hline $10^{5}$ & 13.24 & 12.98 & 12.71 & 12.55 & 12.32 & 12.14 & 11.99 & 11.85 & 11.73 & 11.63 & 11.45 & 11.29 & 11.16 & 11.04 \\
\hline $10^{6}$ & 15.54 & 15.28 & 15.01 & 14.85 & 14.62 & 14.44 & 14.29 & 14.15 & 14.04 & 13.93 & 13.75 & 13.60 & 13.46 & 13.34 \\
\hline $10^{7}$ & 17.84 & 17.58 & 17.31 & 17.15 & 16.93 & 16.74 & 16.59 & 16.46 & 16.34 & 16.23 & 16.05 & 15.90 & 15.76 & 15.65 \\
\hline $10^{8}$ & 20.15 & 19.88 & 19.62 & 19.45 & 19.23 & 19.05 & 18.89 & 18.76 & 18.64 & 18.54 & 18.35 & 18.20 & 18.07 & 17.95 \\
\hline $10^{9}$ & 22.45 & 22.19 & 21.92 & 21.76 & 21.53 & 21.35 & 21.20 & 21.06 & 20.94 & 20.84 & 20.66 & 20.50 & 20.37 & 20.25 \\
\hline $10^{10}$ & 24.75 & 24.49 & 24.22 & 24.06 & 23.83 & 23.65 & 23.50 & 23.36 & 23.25 & 23.14 & 22.96 & 22.81 & 22.67 & 22.55 \\
\hline $10^{11}$ & 27.05 & 26.79 & 26.52 & 26.36 & 26.14 & 25.96 & 25.80 & 25.67 & 25.55 & 25.44 & 25.26 & 25.11 & 24.97 & 24.86 \\
\hline $10^{12}$ & 29.36 & 20,09 & 28.83 & 28.66 & 28.44 & 28.26 & 28.10 & 27.97 & 27.85 & 27.75 & 27.56 & 27.41 & 27.28 & 27.16 \\
\hline $10^{13}$ & 31.66 & 31.40 & 31.13 & 30.97 & 30.74 & 30.56 & 30.41 & 30.27 & 30.15 & 30.05 & 29.87 & 29.71 & 29.58 & 29.46 \\
\hline $10^{14}$ & 33.96 & 33.70 & 33.43 & 33.27 & 33.05 & 32.86 & 32.71 & 32.58 & 32.46 & 32.35 & 32.17 & 32.02 & 31.88 & 31.76 \\
\hline
\end{tabular}

Examples: When $1 / u-10 \times 10^{-1}, W(u)=0.219$; when $1 / u=3.33 \times 10^{2}, W(u)=5.23$. 


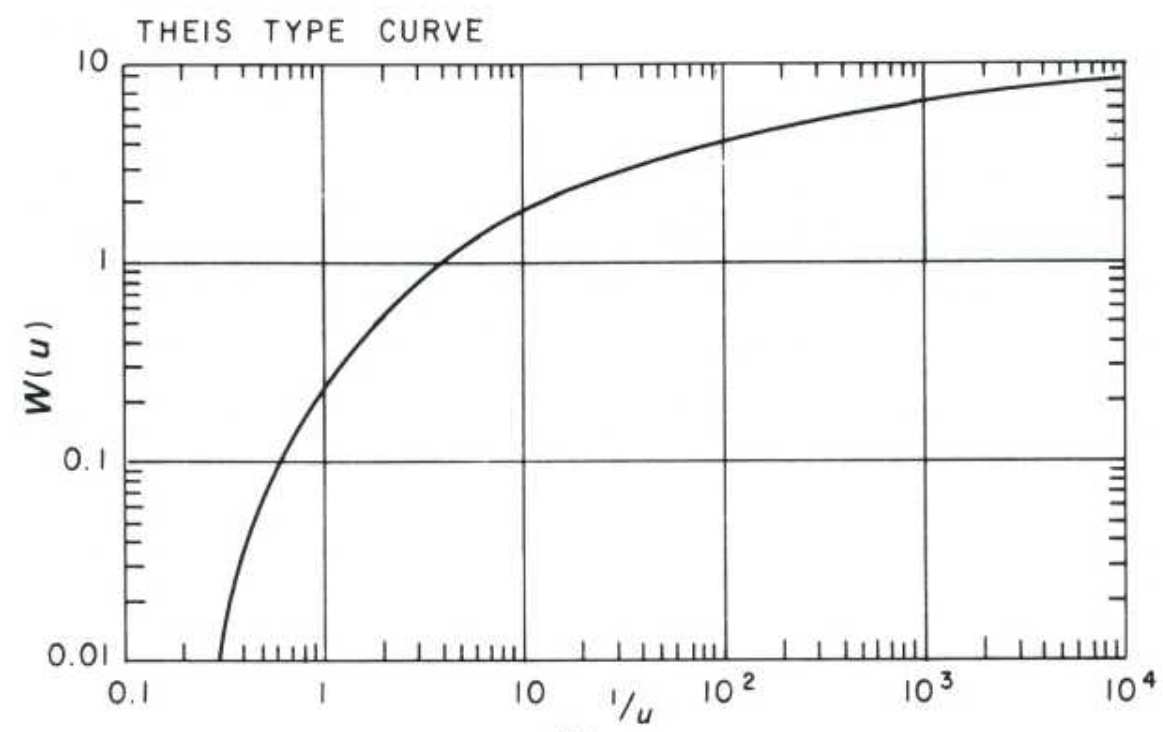

(1)

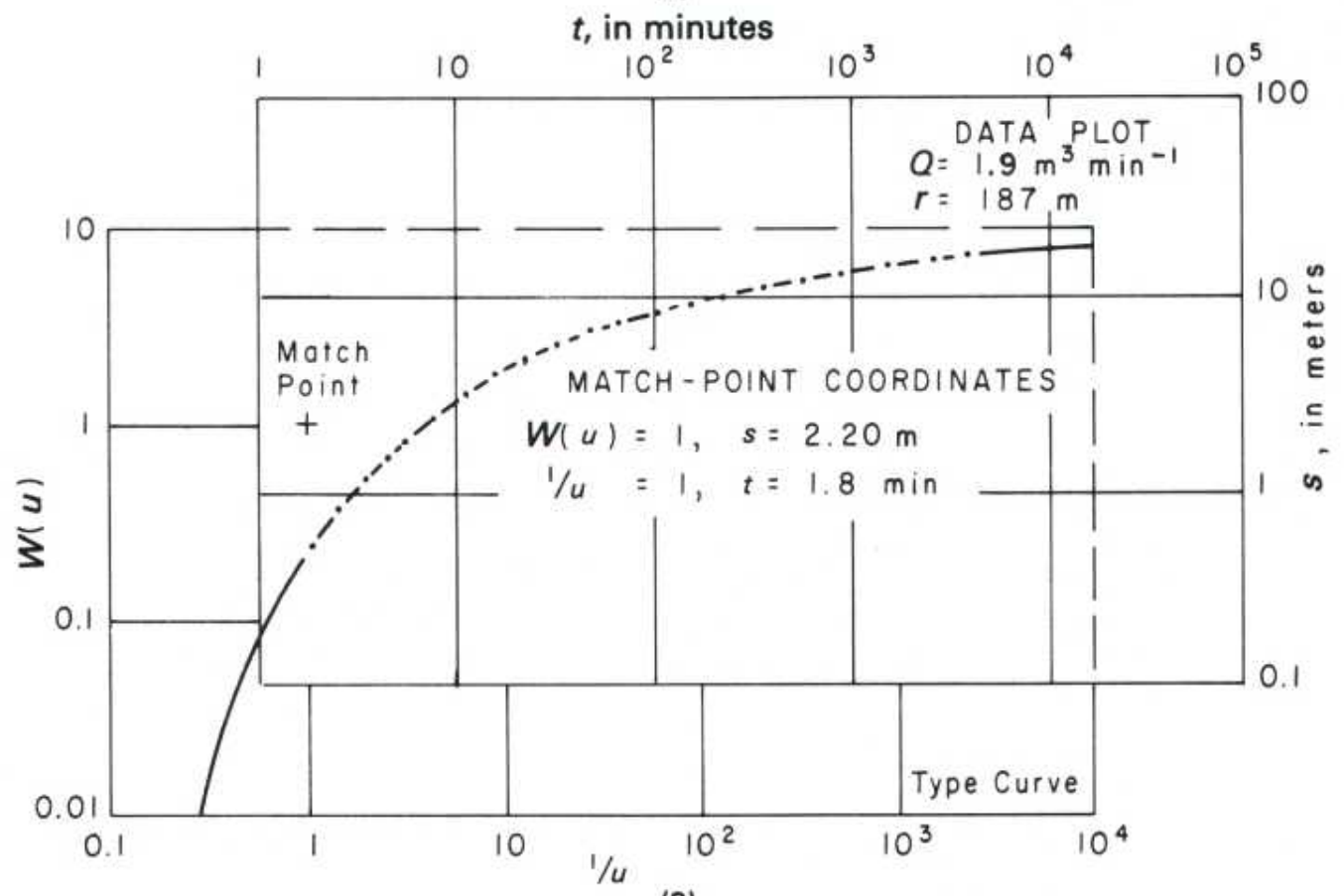

(2)

In 1935, C. V. Theis of the New Mexico Water Resources District of the U.S. Geological Survey developed the first equation to include time of pumping as a factor that could be used to analyze the effect of withdrawals from a well. Thus, the Theis equation permitted, for the first time, determination of the hydraulic characteristics of an aquifer before the development of new steady-state conditions resulting from pumping. The importance of this capability may be realized from the fact that, under most conditions, a new steady state cannot be developed or that, if it can, many months or years may be required.
Theis assumed in the development of the equation that:

1. The transmissivity of the aquifer tapped by the pumping well is constant during the test to the limits of the cone of depression.

2. The water withdrawn from the aquifer is derived entirely from storage and is discharged instantaneously with the decline in head.

3. The discharging well penetrates the entire thickness of the aquifer, and its diameter is small in comparison with the pumping rate, so that storage in the well is negligible. 
These assumptions are most nearly met by confined aquifers at sites remote from their boundaries. However, if certain precautions are observed, the equation can also be used to analyze tests of unconfined aquifers.

The forms of the Theis equation used to determine the transmissivity and storage coefficient are

$$
\begin{gathered}
T=\frac{Q W(u)}{4 \pi s} \\
S=\frac{4 T t u}{r^{2}}
\end{gathered}
$$

where $T$ is transmissivity, $S$ is the storage coefficient, $Q$ is the pumping rate, $s$ is drawdown, $t$ is time, $r$ is the distance from the pumping well to the observation well, $W(u)$ is the well function of $u$, which equals

$$
-0.577216-\log _{e} u+u-\frac{u^{2}}{2 \times 2 !}+\frac{u^{3}}{3 \times 3 !}-\frac{u^{4}}{4 \times 4 !}+\ldots
$$

and $u=\left(r^{2} S\right) /(4 T t)$.

The form of the Theis equation is such that it cannot be solved directly. To overcome this problem, Theis devised a convenient graphic method of solution that involves the use of a type curve (1). To apply this method, a data plot of drawdown versus time (or drawdown versus $t / r^{2}$ ) is matched to the type curve of $W(u)$ versus 1/u (2). At some convenient point on the overlapping part of the sheets containing the data plot and type curve, values of $s, t\left(o r t / r^{2}\right), W(u)$, and $1 / u$ are noted (2). These values are then substituted in equations 1 and 2, which are solved for $T$ and $S$, respectively.

A Theis type curve of $W(u)$ versus $1 / u$ can be prepared from the values given in the table contained in the preceding section, "Aquifer Tests." The data points are plotted on logarithmic graph paper-that is, graph paper having logarithmic divisions in both the $x$ and $y$ directions.

The dimensional units of transmissivity $(T)$ are $L^{2} t^{-1}$, where $L$ is length and $t$ is time in days. Thus, if $Q$ in equation 1 is in cubic meters per day and $s$ is in meters, $T$ will be in square meters per day. Similarly, if, in equation $2, T$ is in square meters per day, $t$ is in days, and $r$ is in meters, $S$ will be dimensionless.

Traditionally, in the United States, $T$ has been expressed in units of gallons per day per foot. The common practice now is to report transmissivity in units of square meters per day or square feet per day. If $Q$ is measured in gallons per minute, as is still normally the case, and drawdown is measured in feet, as is also normally the case, equation 1 is modified to obtain $T$ in square feet per day as follows:

$$
T=\frac{Q W(u)}{4 \pi s}=\frac{\mathrm{gal}}{\min } \times \frac{1,440 \mathrm{~min}}{\mathrm{~d}} \times \frac{\mathrm{ft}^{3}}{7.48 \mathrm{gal}} \times \frac{1}{\mathrm{ft}} \times \frac{W(u)}{4 \pi}
$$

or

$$
T\left(\text { in } \mathrm{ft}^{2} \mathrm{~d}^{-1}\right)=\frac{15.3 Q W(\mathrm{u})}{s}
$$

(when $Q$ is in gallons per minute and $s$ is in feet). To convert square feet per day to square meters per day, divide by 10.76 .
The storage coefficient is dimensionless. Therefore, if $T$ is in square feet per day, $t$ is in minutes, and $r$ is in feet, then, by equation 2,

$$
S=\frac{4 T t u}{r^{2}}=\frac{4}{1} \times \frac{\mathrm{ft}^{2}}{\mathrm{~d}} \times \frac{\min }{\mathrm{ft}^{2}} \times \frac{\mathrm{d}}{1,440 \min }
$$

or

$$
S=\frac{T t u}{360 r^{2}}
$$

(when $T$ is in square feet per day, $t$ is in minutes, and $r$ is in feet).

Analysis of aquifer-test data using the Theis equation involves plotting both the type curve and the test data on logarithmic graph paper. If the aquifer and the conditions of the test satisfy Theis's assumptions, the type curve has the same shape as the cone of depression along any line radiating away from the pumping well and the drawdown graph at any point in the cone of depression.

Use of the Theis equation for unconfined aquifers involves two considerations. First, if the aquifer is relatively fine grained, water is released slowly over a period of hours or days, not instantaneously with the decline in head. Therefore, the value of $S$ determined from a short-period test may be too small.

Second, if the pumping rate is large and the observation well is near the pumping well, dewatering of the aquifer may be significant, and the assumption that the transmissivity of the aquifer is constant is not satisfied. The effect of dewatering of the aquifer can be eliminated with the following equation:

$$
s^{\prime}=s-\left(\frac{s^{2}}{2 b}\right)
$$

where $s$ is the observed drawdown in the unconfined aquifer, $b$ is the aquifer thickness, and 's' is the drawdown that would have occurred if the aquifer had been confined (that is, if no dewatering had occurred).

To determine the transmissivity and storage coefficient of an unconfined aquifer, a data plot consisting of $s^{\prime}$ versus $t$ (or $\left.U r^{2}\right)$ is matched with the Theis type curve of $W(u)$ versus $1 / u$. Both $s$ and $b$ in equation 3 must be in the same units, either feet or meters.

As noted above, Theis assumed in the development of his equation that the discharging well penetrates the entire thickness of the aquifer. However, because it is not always possible, or necessarily desirable, to design a well that fully penetrates the aquifer under development, most discharging wells are open to only a part of the aquifer that they draw from. Such partial penetration creates vertical flow in the vicinity of the discharging well that may affect drawdowns in observation wells located relatively close to the discharging well. Drawdowns in observation wells that are open to the same zone as the discharging well will be larger than the drawdowns in wells at the same distance from the discharging well but open to other zones. The possible effect of partial penetration on drawdowns must be considered in the analysis of aquifer-test data. If aquifer-boundary and other conditions permit, the problem can be avoided by locating observation wells beyond the zone in which vertical flow exists. 
The Theis equation is only one of several methods that have been developed for the analysis of aquifer-test data. (See "Analysis of Aquifer-Test Data.") Another method, and one that is somewhat more convenient to use, was developed by C. E. Jacob from the Theis equation. The greater convenience of the Jacob method derives partly from its use of semilogarithmic graph paper instead of the logarithmic paper used in the Theis method and from the fact that, under ideal conditions, the data plot along a straight line rather than along a curve.

However, it is essential to note that, whereas the Theis equation applies at all times and places (if the assumptions are met), Jacob's method applies only under certain additional conditions. These conditions must also be satisfied in order to obtain reliable answers.

To understand the limitations of Jacob's method, we must consider the changes that occur in the cone of depression during an aquifer test. The changes that are of concern involve both the shape of the cone and the rate of drawdown. As the cone of depression migrates outward from a pumping well, its shape (and, therefore, the hydraulic gradient at different points in the cone) changes. We can refer to this condition as unsteady shape. At the start of withdrawals, the entire cone of depression has an unsteady shape (1). After a test has been underway for some time, the cone of depression begins to assume a relatively steady shape, first at the pumping well and then gradually to greater and greater distances (2). If withdrawals continue long enough for increases in recharge and (or) reductions in discharge to balance the rate of withdrawal, drawdowns cease, and the cone of depression is said to be in a steady state (3).

The Jacob method is applicable only to the zone in which steady-shape conditions prevail or to the entire cone only after steady-state conditions have developed. For practical purposes, this condition is met when $u=\left(r^{2} S\right) /(4 T t)$ is equal to or less than about 0.05 . Substituting this value in the equation for $u$ and solving for $t$, we can determine the time at which steady-shape conditions develop at the outermost observation well. Thus,

$$
t_{c}=\frac{7,200 r^{2} S}{T}
$$

where $t_{c}$ is the time, in minutes, at which steady-shape conditions develop, $r$ is the distance from the pumping well, in feet (or meters), $S$ is the estimated storage coefficient (dimensionless), and $T$ is the estimated transmissivity, in square feet per day (or square meters per day).

After steady-shape conditions have developed, the drawdowns at an observation well begin to fall along a straight line on semilogarithmic graph paper, as sketch 4 shows. Before that time, the drawdowns plot below the extension of the straight line. When a time-drawdown graph is prepared, drawdowns are plotted on the vertical (arithmetic) axis versus time on the horizontal (logarithmic) axis.

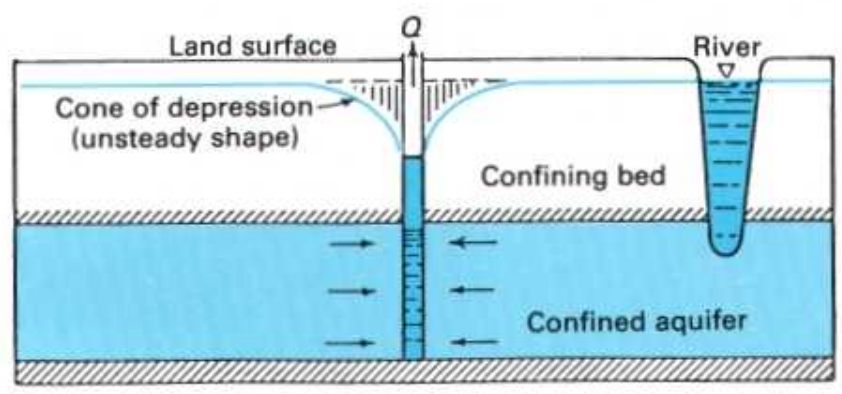

(1)

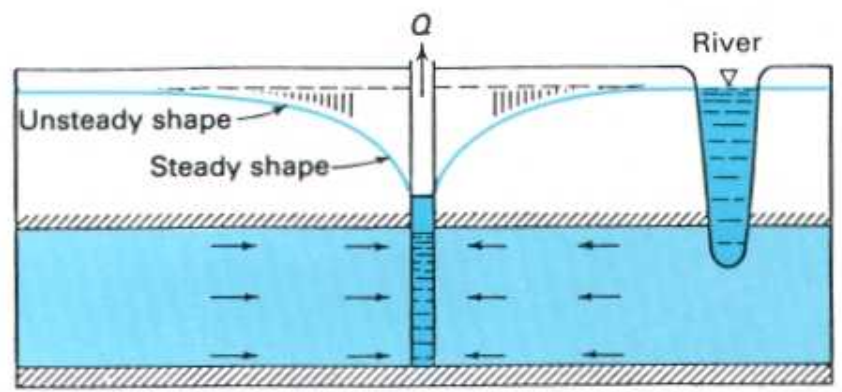

(2)

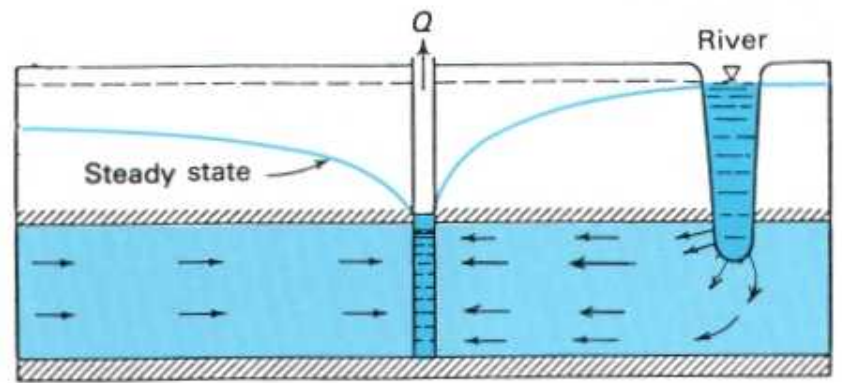

(3)

The slope of the straight line is proportional to the pumping rate and to the transmissivity. Jacob derived the following equations for determination of transmissivity and storage coefficient from the time-drawdown graphs:

$$
\begin{gathered}
T=\frac{2.3 Q}{4 \pi \Delta s} \\
S=\frac{2.25 T t_{0}}{r^{2}}
\end{gathered}
$$

where $Q$ is the pumping rate, $\Delta s$ is the drawdown across one $\log$ cycle, $t_{0}$ is the time at the point where the straight line intersects the zero-drawdown line, and $r$ is the distance from the pumping well to the observation well. 
TIME-DRAWDOWN GRAPH

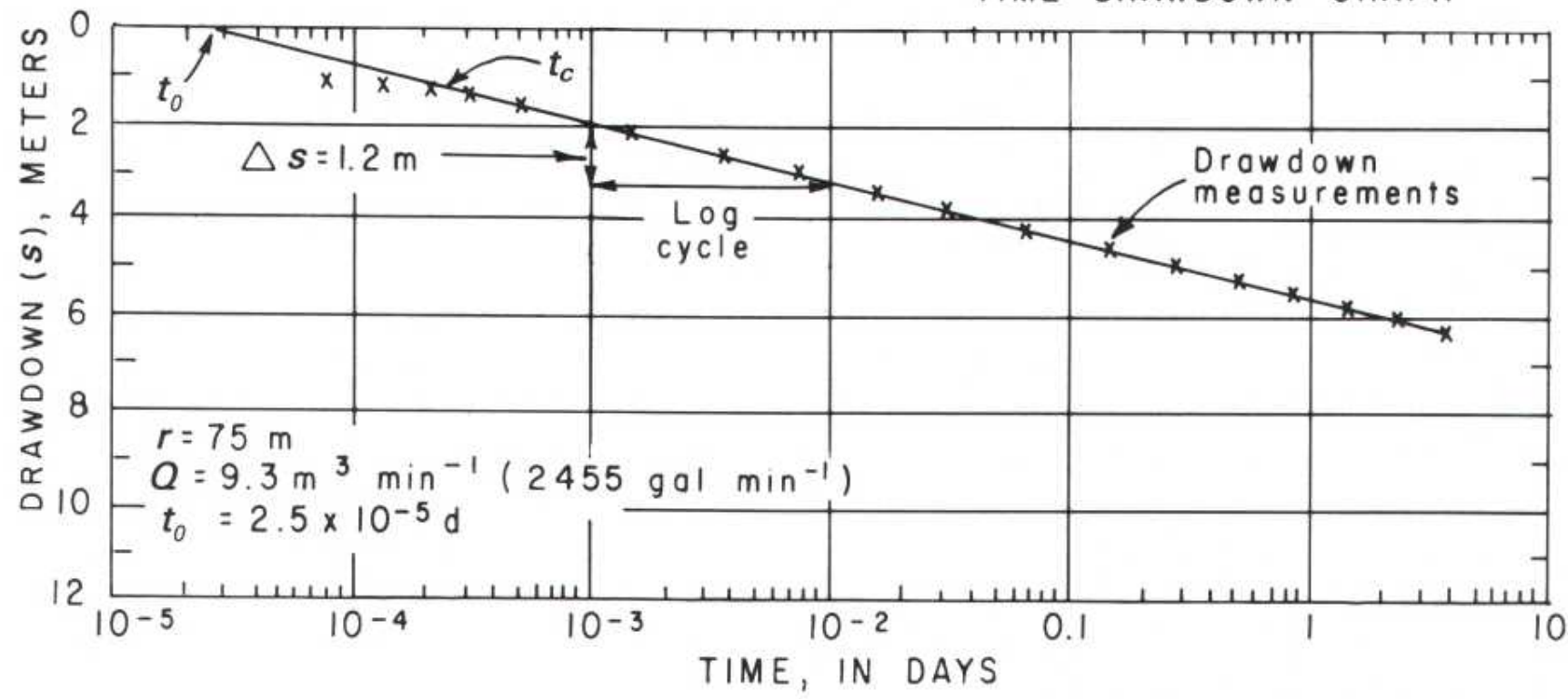

(4)

Equations 2 and 3 are in consistent units. Thus, if $Q$ is in cubic meters per day and $s$ is in meters, $T$ is in square meters per day. $S$ is dimensionless, so that, in equation 3 , if $T$ is in square meters per day, then $r$ must be in meters and $t_{0}$ must be in days.

It is still common practice in the United States to express $Q$ in gallons per minute, $s$ in feet, $t$ in minutes, $r$ in feet, and $T$ in square feet per day. We can modify equations 2 and 3 for direct substitution of these units as follows:

$$
T=\frac{2.3 \mathrm{Q}}{4 \pi \Delta s}=\frac{2.3}{4 \pi} \times \frac{\mathrm{gal}}{\mathrm{min}} \times \frac{1,440 \mathrm{~min}}{\mathrm{~d}} \times \frac{\mathrm{ft}^{3}}{7.48 \mathrm{gal}} \times \frac{1}{\mathrm{ft}}
$$

$$
T=\frac{35 Q}{\Delta S}
$$

(where $T$ is in square feet per day, $Q$ is in gallons per minute, and $\Delta s$ is in feet) and

$$
\begin{gathered}
S=\frac{2.25 T t_{0}}{r^{2}}=\frac{2.25}{1} \times \frac{\mathrm{ft}^{2}}{\mathrm{~d}} \times \frac{\mathrm{min}}{\mathrm{ft}^{2}} \times \frac{\mathrm{d}}{1,440 \mathrm{~min}} \\
S=\frac{T t_{0}}{640 r^{2}}
\end{gathered}
$$

(where $T$ is in square feet per day, $t_{0}$ is in minutes, and $r$ is in feet). 
It is desirable in aquifer tests to have at least three observation wells located at different distances from the pumping well (1). Drawdowns measured at the same time in these wells can be analyzed with the Theis equation and type curve to determine the aquifer transmissivity and storage coefficient.

After the test has been underway long enough, drawdowns in the wells can also be analyzed by the Jacob method, either through the use of a time-drawdown graph using data from individual wells or through the use of a distance-drawdown graph using "simultaneous" measurements in all of the wells. To determine when sufficient time has elapsed, see "TimeDrawdown Analysis."

In the Jacob distance-drawdown method, drawdowns are plotted on the vertical (arithmetic) axis versus distance on the horizontal (logarithmic) axis (2). If the aquifer and test conditions satisfy the Theis assumptions and the limitation of the Jacob method, the drawdowns measured at the same time in different wells should plot along a straight line (2).

The slope of the straight line is proportional to the pumping rate and to the transmissivity. Jacob derived the following equations for determination of the transmissivity and storage coefficient from distance-drawdown graphs:

$$
\begin{aligned}
& T=\frac{2.3 Q}{2 \pi \Delta s} \\
& S=\frac{2.25 T t}{r_{0}^{2}}
\end{aligned}
$$

where $Q$ is the pumping rate, $\Delta s$ is the drawdown across one $\log$ cycle, $t$ is the time at which the drawdowns were measured, and $r_{0}$ is the distance from the pumping well to the point where the straight line intersects the zero-drawdown line.

Equations 1 and 2 are in consistent units. For the inconsistent units still in relatively common use in the United States, equations 1 and 2 should be used in the following forms:

$$
T=\frac{70 Q}{\Delta s}
$$

(where $T$ is in square feet per day, $Q$ is in gallons per minute, and $\Delta s$ is in feet) and

$$
S=\frac{T t}{640 r_{0}^{2}}
$$

(where $T$ is in square feet per day, $t$ is in minutes, and $r_{0}$ is in feet).

The distance $r_{0}$ does not indicate the outer limit of the cone of depression. Because nonsteady-shape conditions exist in the outer part of the cone, before the development of steadystate conditions, the Jacob method does not apply to that part. If the Theis equation were used to calculate drawdowns in the outer part of the cone, it would be found that they would plot below the straight line. In other words, the measurable limit of the cone of depression is beyond the distance $r_{0}$.

If the straight line of the distance-drawdown graph is extended inward to the radius of the pumping well, the drawdown indicated at that point is the drawdown in the aquifer outside of the well. If the drawdown inside the well is found to be greater than the drawdown outside, the difference is attributable to well loss. (See "Single-Well Tests.")

As noted in the section on "Hydraulic Conductivity," the hydraulic conductivities and, therefore, the transmissivities of aquifers may be different in different directions. These differences may cause drawdowns measured at the same time in observation wells located at the same distances but in different directions from the discharging well to be different. Where this condition exists, the distance-drawdown method may yield satisfactory results only where three or more observation wells are located in the same direction but at different distances from the discharging well. 


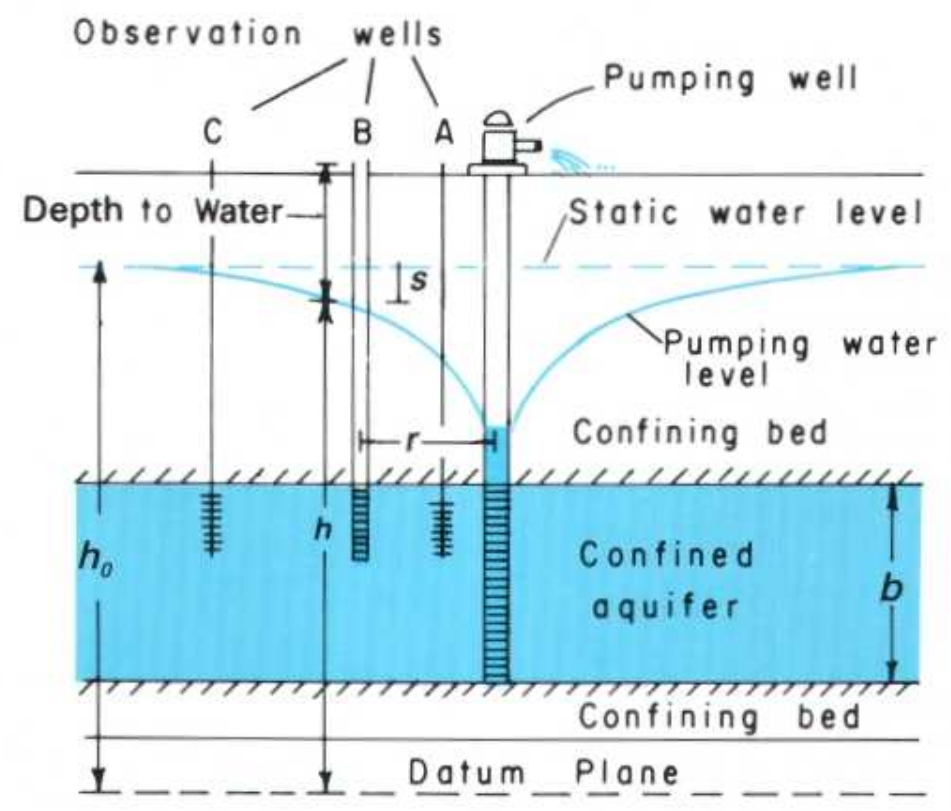

(1)

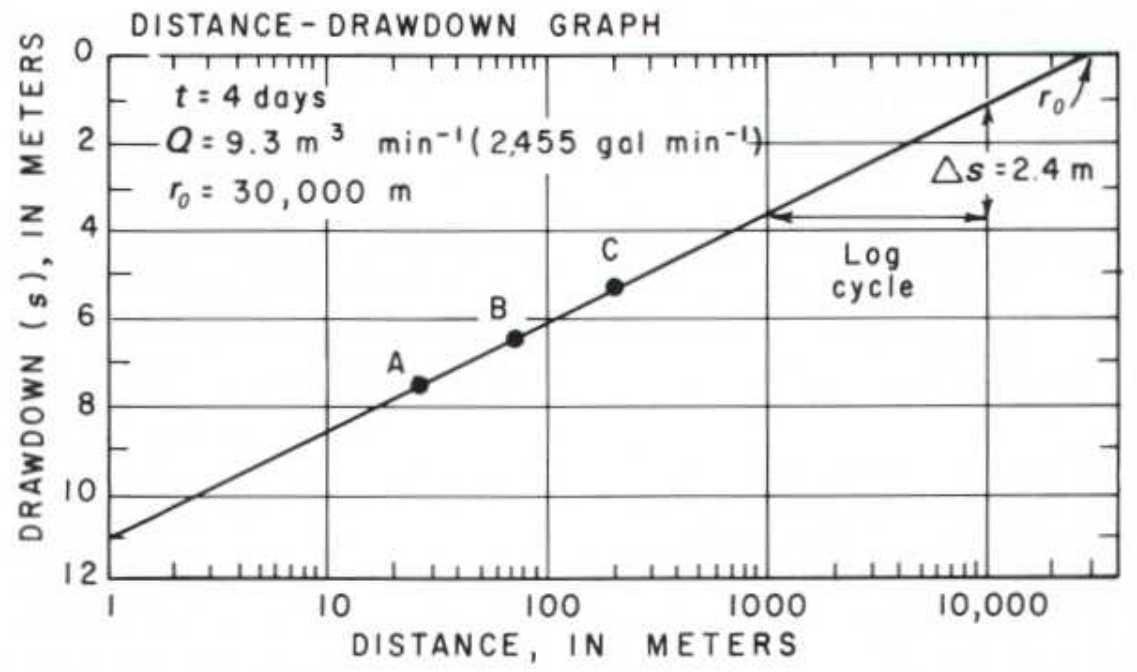

(2) 


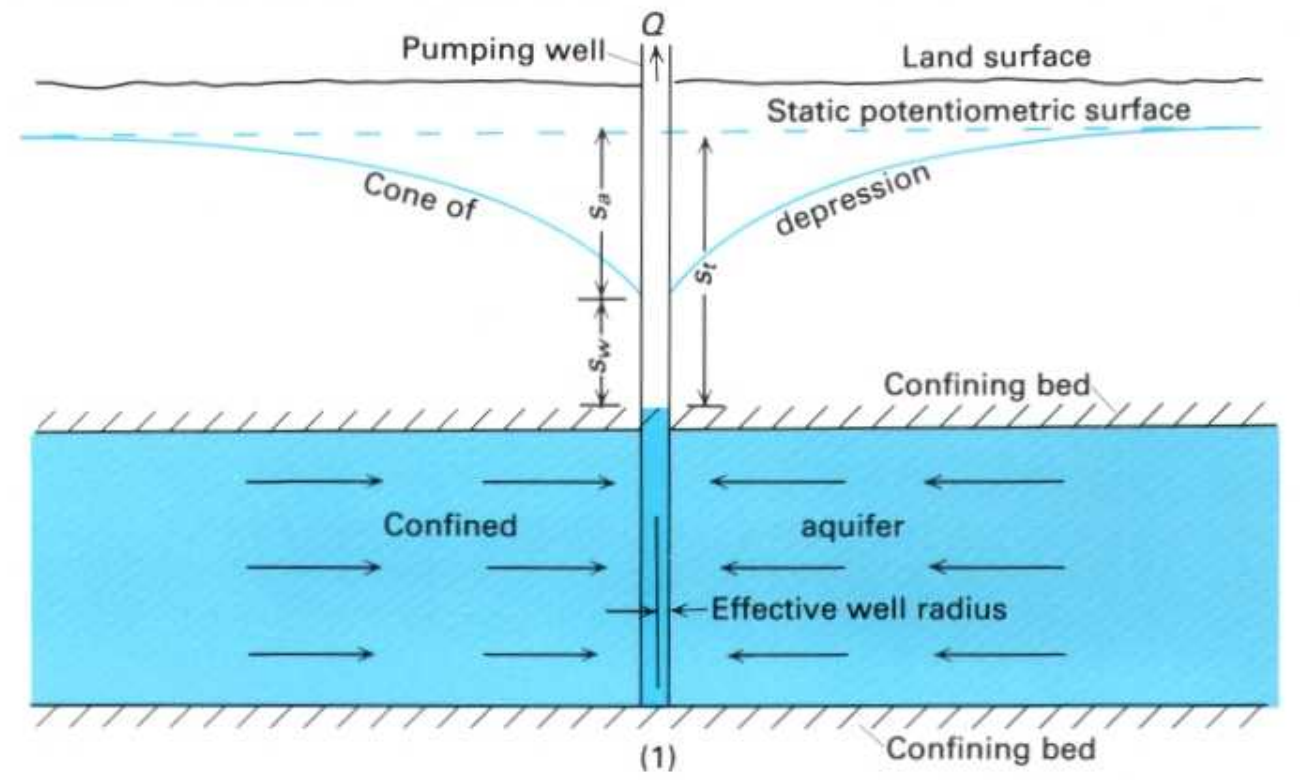

The most useful aquifer tests are those that include waterlevel measurements in observation wells. Such tests are commonly referred to as multiple-well tests. It is also possible to obtain useful data from production wells, even where observation wells are not available. Such tests are referred to as single-well tests and may consist of pumping a well at a single constant rate, or at two or more different but constant rates (see "Well-Acceptance Tests and Well Efficiency") or, if the well is not equipped with a pump, by "instantaneously" introducing a known volume of water into the well. This discussion will be limited to tests involving a single constant rate.

In order to analyze the data, it is necessary to understand the nature of the drawdown in a pumping well. The total drawdown $\left(s_{t}\right)$ in most, if not all, pumping wells consists of two components (1). One is the drawdown $\left(s_{a}\right)$ in the aquifer, and the other is the drawdown $\left(s_{w}\right)$ that occurs as water moves from the aquifer into the well and up the well bore to the pump intake. Thus, the drawdown in most pumping wells is greater than the drawdown in the aquifer at the radius of the pumping well.

The total drawdown $\left(s_{t}\right)$ in a pumping well can be expressed in the form of the following equations:

$$
\begin{gathered}
s_{t}=s_{a}+s_{w} \\
s_{t}=B Q+C Q^{2}
\end{gathered}
$$

where $s_{a}$ is the drawdown in the aquifer at the effective radius of the pumping well, $s_{w}$ is well loss, $Q$ is the pumping rate, $B$ is a factor related to the hydraulic characteristics of the aquifer and the length of the pumping period, and $C$ is a factor related to the characteristics of the well.

The factor $C$ in equation 1 is normally considered to be constant, so that, in a constant rate test, $C Q^{2}$ is also constant. As a result, the well loss $\left(s_{w}\right)$ increases the total drawdown in the pumping well but does not affect the rate of change in the drawdown with time. It is, therefore, possible to analyze drawdowns in the pumping well with the Jacob time-drawdown method using semilogarithmic graph paper. (See "TimeDrawdown Analysis.") Drawdowns are plotted on the arithmetic scale versus time on the logarithmic scale (2), and transmissivity is determined from the slope of the straight line through the use of the following equation:

$$
T=\frac{2.3 Q}{4 \pi \Delta s}
$$

Where well loss is present in the pumping well, the storage coefficient cannot be determined by extending the straight line to the line of zero drawdown. Even where well loss is not present, the determination of the storage coefficient from drawdowns in a pumping well likely will be subject to large error because the effective radius of the well may differ significantly from the "nominal" radius. 


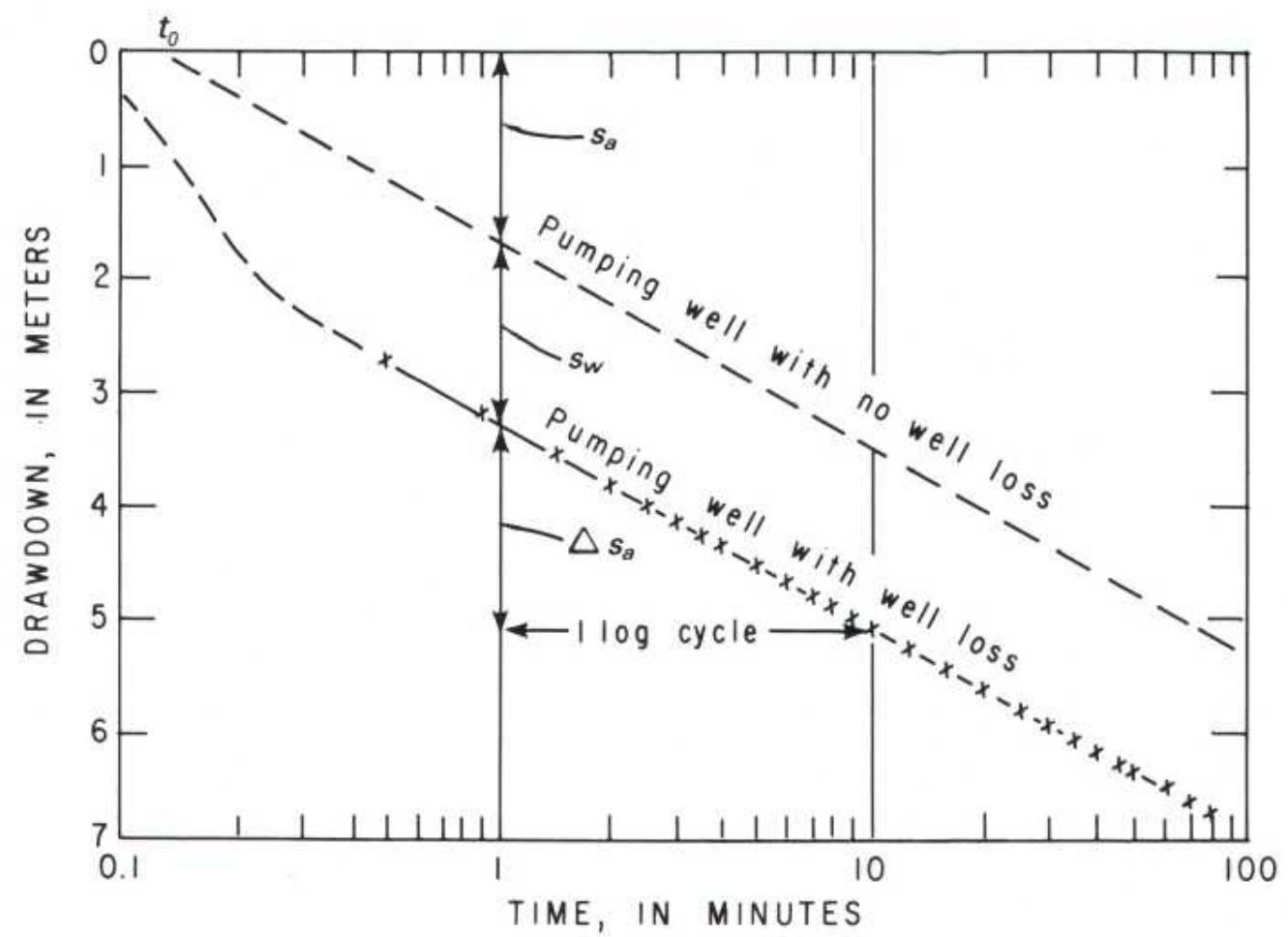

(2)

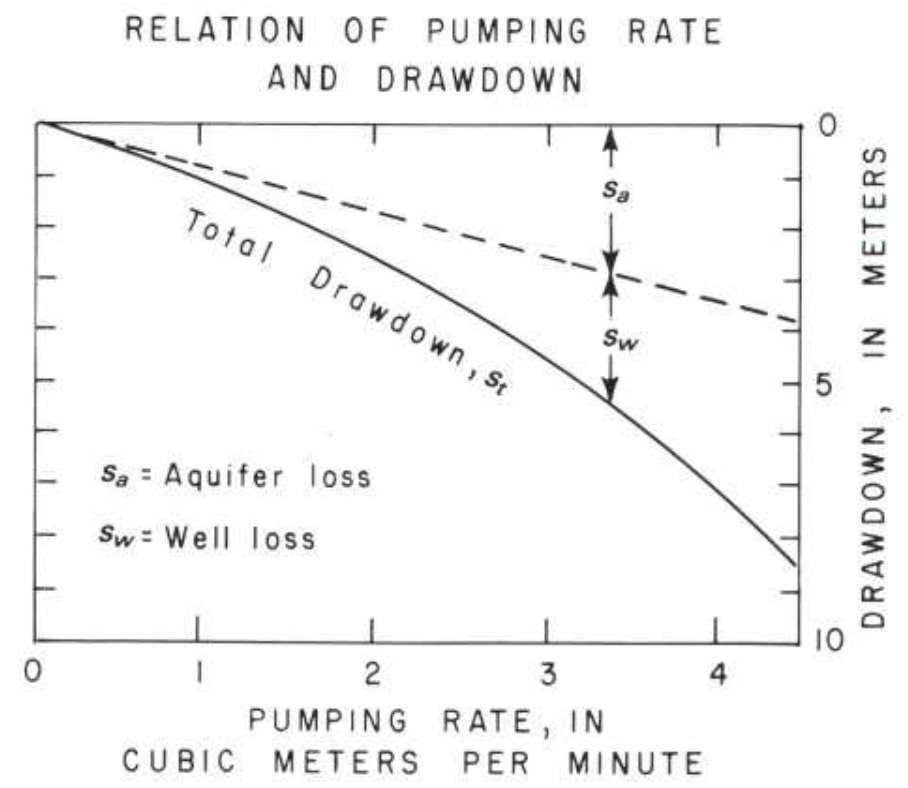

(3)

In equation 1, drawdown in the pumping well is proportional to the pumping rate. The factor $B$ in the aquifer-loss term $(B Q)$ increases with time of pumping as long as water is being derived from storage in the aquifer. The factor $C$ in the well-loss term $\left(\mathrm{CQ}^{2}\right)$ is a constant if the characteristics of the well remain unchanged, but, because the pumping rate in the well-loss term is squared, drawdown due to well loss increases rapidly as the pumping rate is increased. The relation between pumping rates and drawdown in a pumping well, if the well was pumped for the same length of time at each rate, is shown in sketch 3. The effect of well loss on drawdown in the pumping well is important both in the analysis of data from pumping wells and in the design of supply wells. 


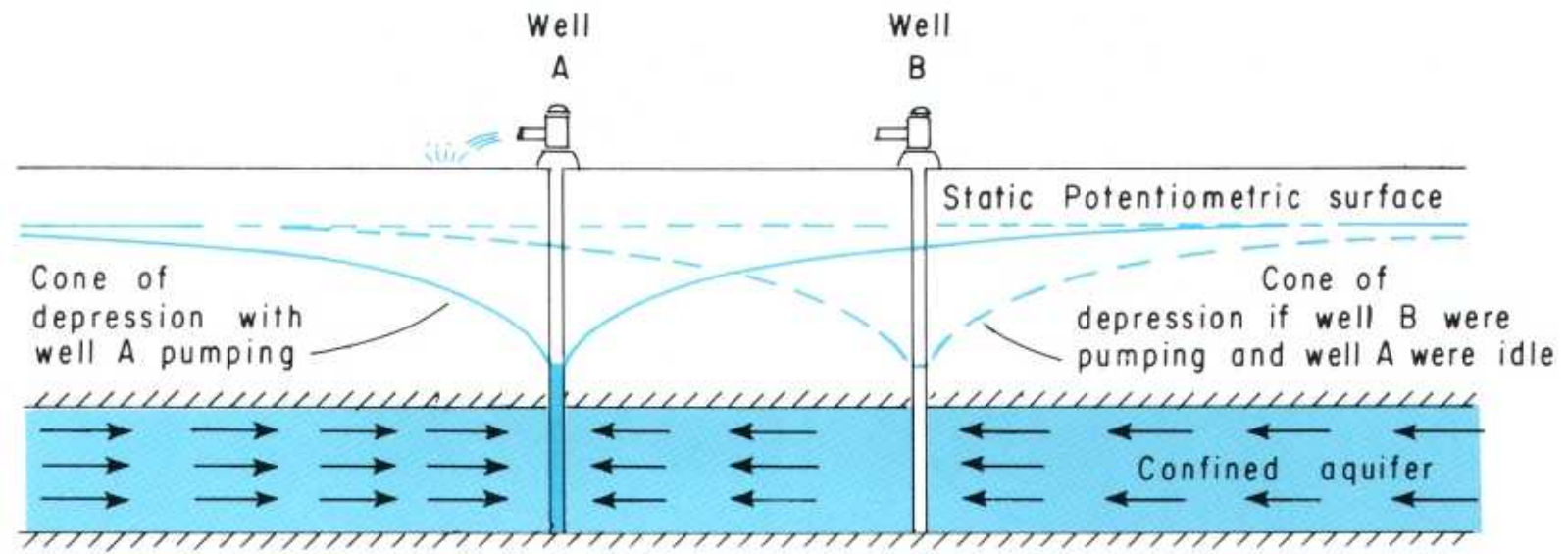

(1)

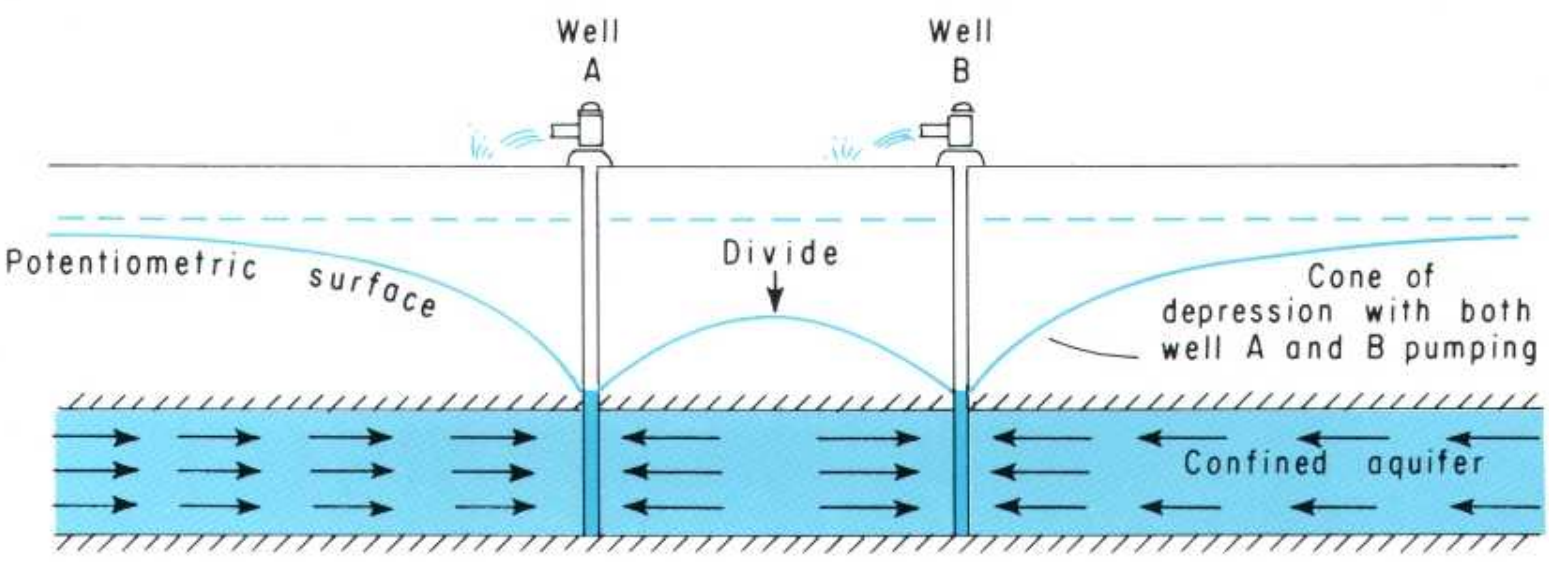

(2)

Pumping a well causes a drawdown in the ground-water level in the surrounding area. The drawdown in water level forms a conical-shaped depression in the water table or potentiometric surface, which is referred to as a cone of depression. (See "Cone of Depression.") Similarly, a well through which water is injected into an aquifer (that is, a recharge or injection well) causes a buildup in ground-water level in the form of a conical-shaped mound.

The drawdown (s) in an aquifer caused by pumping at any point in the aquifer is directly proportional to the pumping rate $(Q)$ and the length of time $(t)$ that pumping has been in progress and is inversely proportional to the transmissivity $(T)$, the storage coefficient $(S)$, and the square of the distance $\left(r^{2}\right)$ between the pumping well and the point. In other words,

$$
s \approx \frac{Q, t}{T, S, r^{2}}
$$

Where pumping wells are spaced relatively close together, pumping of one will cause a drawdown in the others. Drawdowns are additive, so that the total drawdown in a pumping well is equal to its own drawdown plus the drawdowns caused at its location by other pumping wells (1) (2). The drawdowns in pumping wells caused by withdrawals from other pumping wells are referred to as well interference. As sketch 2 shows, a divide forms in the potentiometric surface (or the water table, in the case of an unconfined aquifer) between pumping wells.

At any point in an aquifer affected by both a discharging well and a recharging well, the change in water level is equal to the difference between the drawdown and the buildup. If the rates of discharge and recharge are the same and if the wells are operated on the same schedule, the drawdown and the buildup will cancel midway between the wells, and the water level at that point will remain unchanged from the static level (3). (See "Aquifer Boundaries."') 


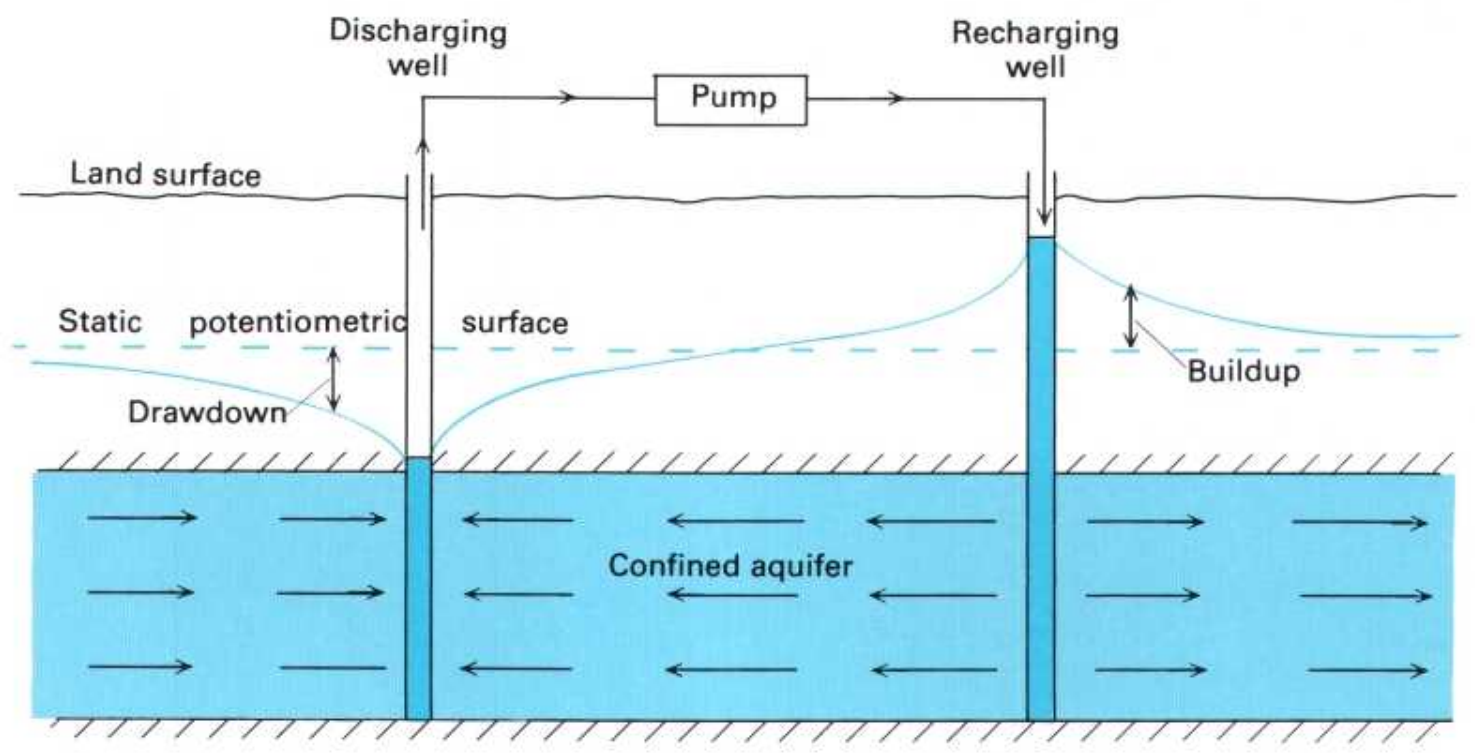

(3)

We see from the above functional equation that, in the absence of well interference, drawdown in an aquifer at the effective radius of a pumping well is directly proportional to the pumping rate. Conversely, the maximum pumping rate is directly proportional to the available drawdown. For confined aquifers, available drawdown is normally considered to be the distance between the prepumping water level and the top of the aquifer. For unconfined aquifers, available drawdown is normally considered to be about 60 percent of the saturated aquifer thickness.

Where the pumping rate of a well is such that only a part of the available drawdown is utilized, the only effect of well interference is to lower the pumping level and, thereby, increase pumping costs. In the design of a well field, the increase in pumping cost must be evaluated along with the cost of the additional waterlines and powerlines that must be installed if the spacing of wells is increased to reduce well interference. (See "Well-Field Design.")

Because well interference reduces the available drawdown, it also reduces the maximum yield of a well. Well interference is, therefore, an important matter in the design of well fields where it is desirable for each well to be pumped at the largest possible rate. We can see from equation 1 that, for a group of wells pumped at the same rate and on the same schedule, the well interference caused by any well on another well in the group is inversely proportional to the square of the distance between the two wells $\left(r^{2}\right)$. Therefore, excessive well interference is avoided by increasing the spacing between wells and by locating the wells along a line rather than in a circle or in a grid pattern. 
One of the assumptions inherent in the Theis equation (and in most other fundamental ground-water flow equations) is that the aquifer to which it is being applied is infinite in extent. Obviously, no such aquifer exists on Earth. However, many aquifers are areally extensive, and, because pumping will not affect recharge or discharge significantly for many years, most water pumped is from ground-water storage; as a consequence, water levels must decline for many years. An excellent example of such an aquifer is that underlying the High Plains from Texas to South Dakota.

All aquifers are bounded in both the vertical direction and the horizontal direction. For example, vertical boundaries may include the water table, the plane of contact between each aquifer and each confining bed, and the plane murking the lower limit of the zone of interconnected openings-in other words, the base of the ground-water system.

Hydraulically, aquifer boundaries are of two types: recharge boundaries and impermeable boundaries. A recharge boundary is a boundary along which flow lines originate. In other words, such a boundary will, under certain hydraulic

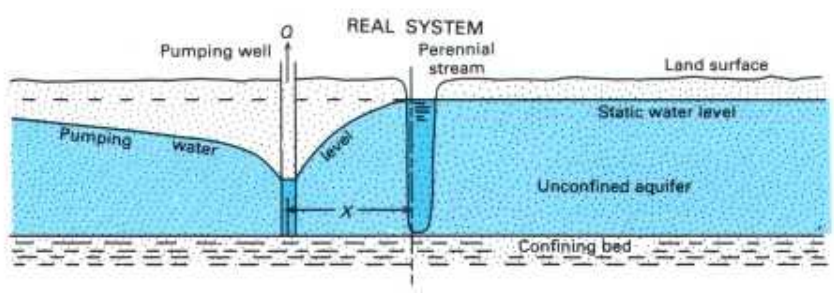

HYDRAULIC COUNTERPART OF REAL SYSTEM

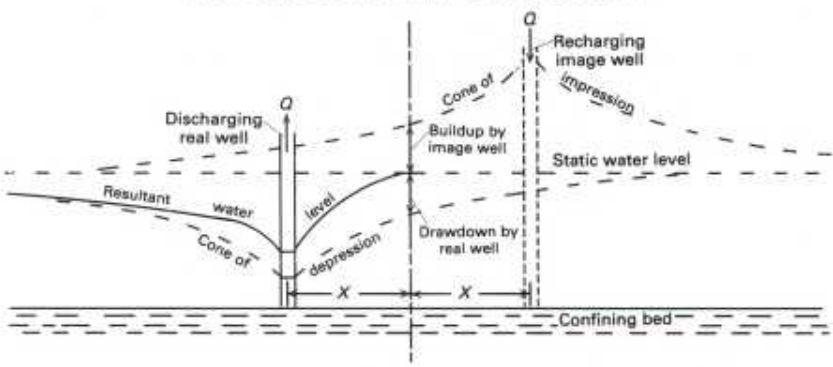

PLAN VIEW OF THE HYDRAULIC COUNTERPART

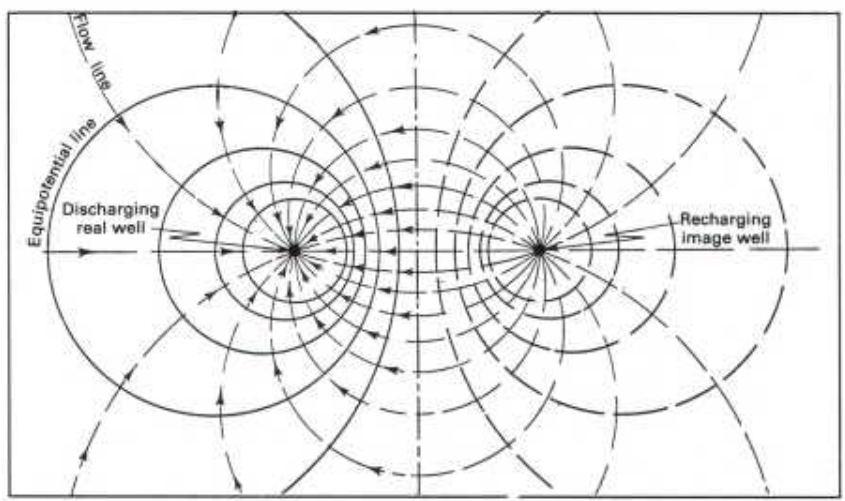

(1) conditions, serve as a source of recharge to the aquifer. Examples of recharge boundaries include the zones of contact between an aquifer and a perennial stream that completely penetrates the aquifer or the ocean.

An impermeable boundary is a boundary that flow lines do not cross. Such boundaries exist where aquifers terminate against "impermeable" material. Examples include the contact between an aquifer composed of sand and a laterally adjacent bed composed of clay.

The position and nature of aquifer boundaries are of critical importance in many ground-water problems, including the movement and fate of pollutants and the response of aquifers to withdrawals. Depending on the direction of the hydraulic gradient, a stream, for example, may be either the source or the destination of a pollutant.

Lateral boundaries within the cone of depression have a profound effect on the response of an aquifer to withdrawals. To analyze, or to predict, the effect of a lateral boundary, it is necessary to "make" the aquifer appear to be of infinite extent. This feat is accomplished through the use of imaginary

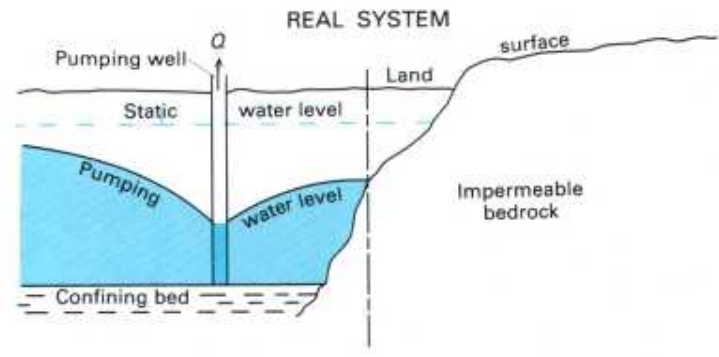

HYDRAULIC COUNTERPART OF REAL SYSTEM

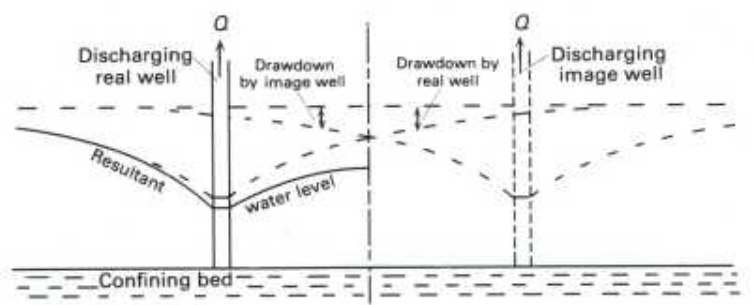

PLAN VIEW OF THE HYDRAULIC COUNTERPART

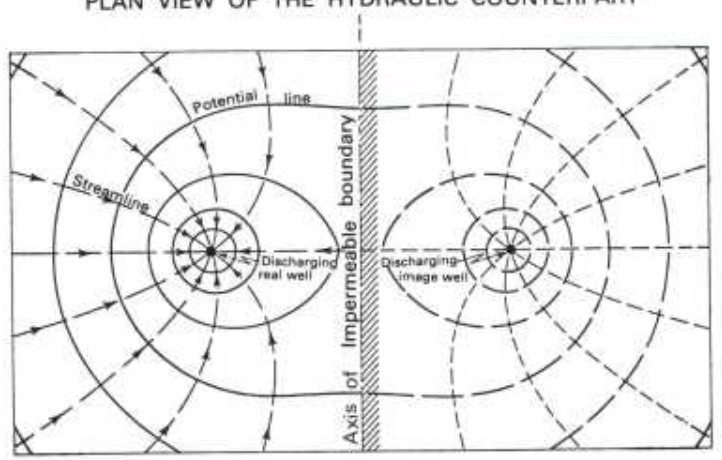

(2) 
wells and the theory of images. Sketches 1 and 2 show, in both plan view and profile, how image wells are used to compensate, hydraulically, for the effects of both recharging and impermeable boundaries. (See "Well Interference.")

The key feature of a recharge boundary is that withdrawals from the aquifer do not produce drawdowns across the boundary. A perennial stream in intimate contact with an aquifer represents a recharge boundary because pumping from the aquifer will induce recharge from the stream. The hydraulic effect of a recharge boundary can be duplicated by assuming that a recharging image well is present on the side of the boundary opposite the real discharging well. Water is injected into the image well at the same rate and on the same schedule that water is withdrawn from the real well. In the plan view in sketch 1, flow lines originate at the boundary, and equipotential lines parallel the boundary at the closest point to the pumping (real) well.

The key feature of an impermeable boundary is that no water can cross it. Such a boundary, sometimes termed a "noflow boundary," resembles a divide in the water table or the potentiometric surface of a confined aquifer. The effect of an impermeable boundary can be duplicated by assuming that a discharging image well is present on the side of the boundary opposite the real discharging well. The image well withdraws water at the same rate and on the same schedule as the real well. Flow lines tend to be parallel to an impermeable boundary, and equipotential lines intersect it at a right angle.

The image-well theory is an essential tool in the design of well fields near aquifer boundaries. Thus, on the basis of minimizing the lowering of water levels, the following conditions apply:

1. Pumping wells should be located parallel to and as close as possible to recharging boundaries.

2. Pumping wells should be located perpendicular to and as far as possible from impermeable boundaries.

Sketches 1 and 2 illustrate the effect of single boundaries and show how their hydraulic effect is compensated for through the use of single image wells. It is assumed in these sketches that other boundaries are so remote that they have a negligible effect on the areas depicted. At many places, however, pumping wells are affected by two or more boundaries. One example is an alluvial aquifer composed of sand

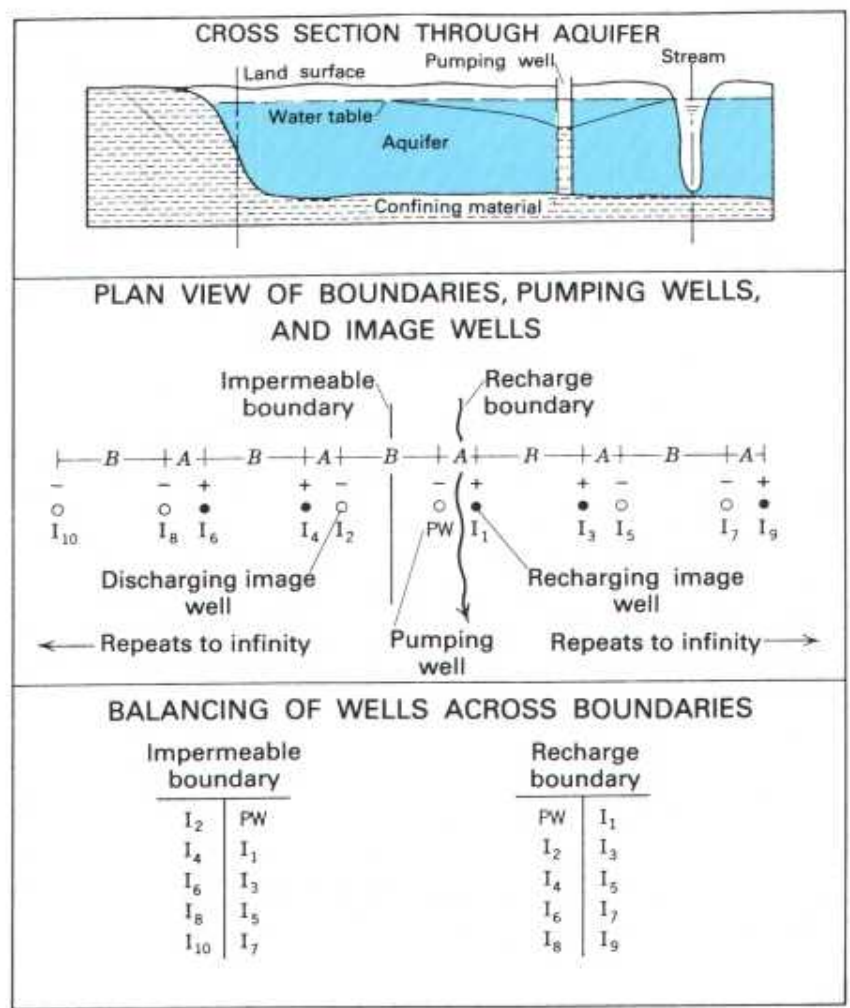

(3)

and gravel bordered on one side by a perennial stream (a recharge boundary) and on the other by impermeable bedrock (an impermeable boundary).

Contrary to first impression, these boundary conditions cannot be satisfied with only a recharging image well and a discharging image well. Additional image wells are required, as sketch 3 shows, to compensate for the effect of the image wells on the opposite boundaries. Because each new image well added to the array affects the opposite boundary, it is necessary to continue adding image wells until their distances from the boundaries are so great that their effect becomes negligible. 


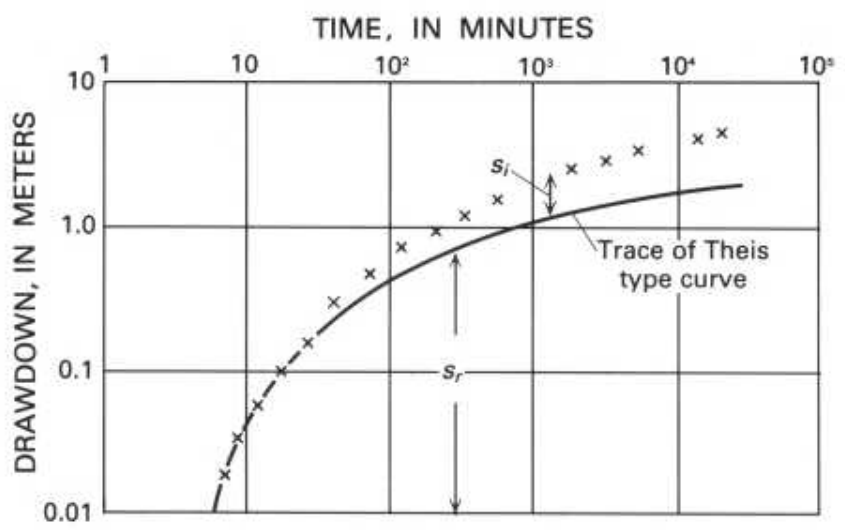

(1)

TIME, IN MINUTES

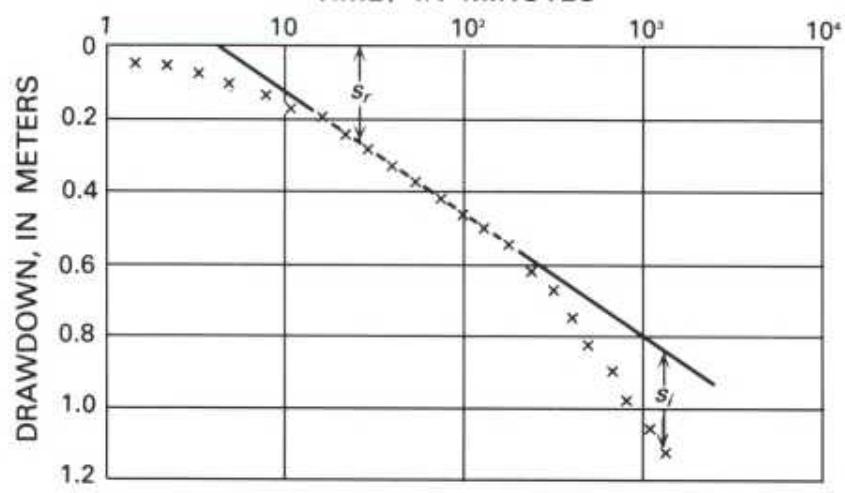

(2)

When an aquifer test is conducted near one of the lateral boundaries of an aquifer, the drawdown data depart from the Theis type curve and from the initial straight line produced by the Jacob method. The hydraulic effect of lateral boundaries is assumed, for analytical convenience, to be due to the presence of other wells. (See "Aquifer Boundaries.") Thus, a recharge boundary has the same effect on drawdowns as a recharging image well located across the boundary and at the same distance from the boundary as the real well. The image well is assumed to operate on the same schedule and at the same rate as the real well. Similarly, an impermeable boundary has the same effect on drawdowns as a discharging image well.

To analyze aquifer-test data affected by either a recharge boundary or an impermeable boundary, the early drawdown data in the observation wells nearest the pumping well must not be affected by the boundary. These data, then, show only the effect of the real well and can be used to determine the transmissivity $(T)$ and the storage coefficient $(S)$ of the aquifer. (See "Analysis of Aquifer-Test Data" and "Time-Drawdown Analysis.") In the Theis method, the type curve is matched to the early data, and a "match point" is selected for use in calculating values of $T$ and $S$. The position of the type curve, in the region where the drawdowns depart from the type curve, is traced onto the data plot (1) (3). The trace of the type curve shows where the drawdowns would have plotted if there had been no boundary effect. The differences in drawdown between the data plot and the trace of the type curve show the effect of an aquifer boundary. The direction in which the drawdowns depart from the type curve-that is, in the direction of either greater drawdowns or lesser drawdowns-shows the type of boundary.

Drawdowns greater than those defined by the trace of the type curve indicate the presence of an impermeable boundary because, as noted above, the effect of such boundaries can be duplicated with an imaginary discharging well (1). Conversely, a recharge boundary causes drawdowns to be less than those defined by the trace of the type curve (3).

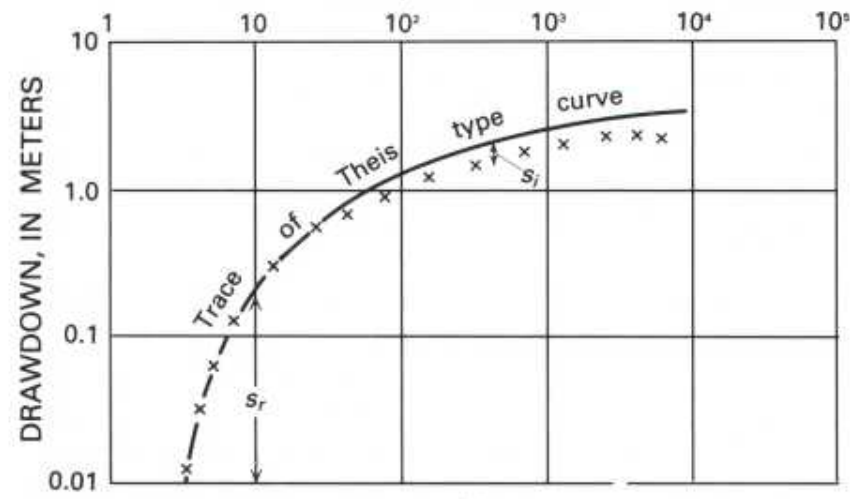

(3)

TIME, IN MINUTES

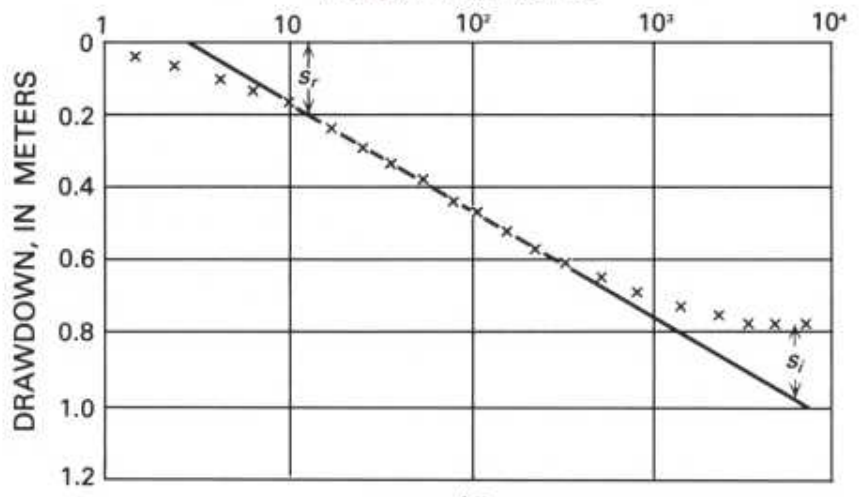

(4)

In the Jacob method, drawdowns begin to plot along a straight line after the test has been underway for some time (2) (4). The time at which the straight-line plot begins depends on the values of $T$ and $S$ of the aquifer and on the square of the 
distance between the observation well and the pumping well. (See "Time-Drawdown Analysis.") Values of $T$ and $S$ are determined from the first straight-line segment defined by the drawdowns after the start of the aquifer test. The slope of this straight line depends on the transmissivity $(T)$ and on the pumping rate $(Q)$. If a boundary is present, the drawdowns will depart from the first straight-line segment and begin to fall along another straight line (2) (4).

According to image-well theory, the effect of a recharge boundary can be duplicated by assuming that water is injected into the aquifer through a recharging image well at the same rate that water is being withdrawn from the real well. It follows, therefore, that, when the full effect of a recharge boundary is felt at an observation well, there will be no further increase in drawdown, and the water level in the well will stabilize. At this point in both the Theis and the Jacob methods, drawdowns plot along a straight line having a constant drawdown (3) (4). Conversely, an impermeable boundary causes the rate of drawdown to increase. In the Jacob method, as a result, the drawdowns plot along a new straight line having twice the slope as the line drawn through the drawdowns that occurred before the effect of the boundary was felt (2).

A word of caution should be injected here regarding use of the Jacob method when it is suspected that an aquifer test may be affected by boundary conditions. In many cases, the boundary begins to affect drawdowns before the method is applicable, the result being that $T$ and $S$ values determined from the data are erroneous, and the effect of the boundary is not identified. When it is suspected that an aquifer test may be affected by boundary conditions, the data should, at least initially, be analyzed with the Theis method.

The position and the nature of many boundaries are obvious. For example, the most common recharge boundaries are streams and lakes; possibly, the most common impermeable boundaries are the bedrock walls of alluvial valleys. The hydraulic distance to these boundaries, however, may not be obvious. A stream or lake may penetrate only a short distance into an aquifer, and their bottoms may be underlain by fine-grained material that hampers movement of water into the aquifer. Hydraulically, the boundaries formed by these surface-water bodies will appear to be farther from the pumping well than the near shore. Similarly, if a small amount of water moves across the bedrock wall of a valley, the hydraulic distance to the impermeable boundary will be greater than the distance to the valley wall.

Fortunately, the hydraulic distance to boundaries can be determined from the analysis of aquifer-test data. According to the Theis equation, if we deal with equal drawdowns caused by the real well and the image well (in other words, if $\left.s_{r}=s_{i}\right)$, then

$$
\frac{r_{r}{ }^{2}}{t_{r}}=\frac{r_{i}{ }^{2}}{t_{i}}
$$

where $r_{r}$ is the distance from the observation well to the real well, $r_{i}$ is the distance from the observation well to the image well, $t_{r}$ is the time at which a drawdown of $s_{r}$ is caused by the real well at the observation well, and $t_{i}$ is the time at which a drawdown of $s_{j}$ is caused by the image well at the observation well.

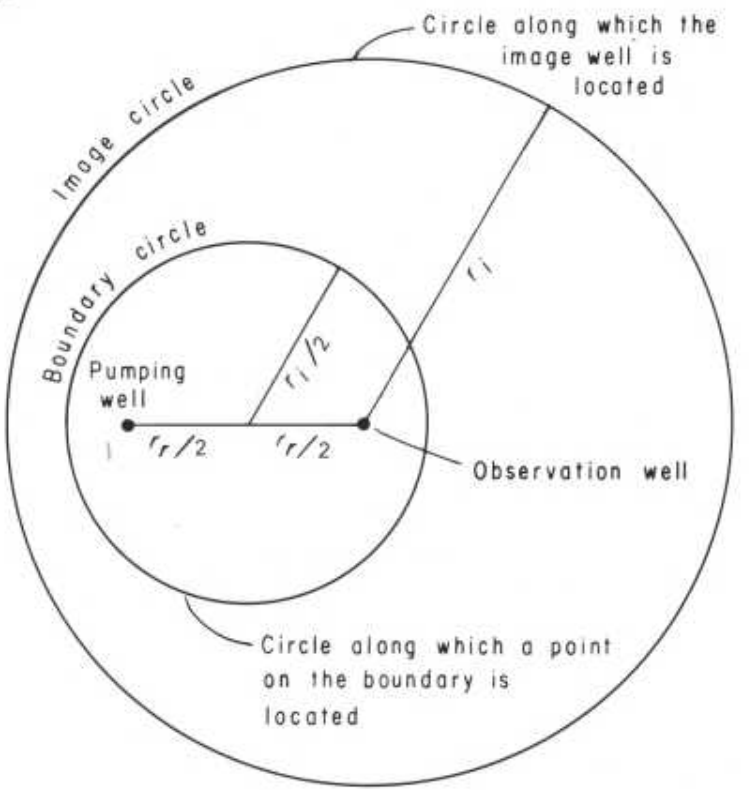

(5)

Solving equation 1 for the distance to the image well from the observation well, we obtain

$$
r_{i}=r_{r} \sqrt{\frac{t_{i}}{t_{r}}}
$$

The image well is located at some point on a circle having a radius of $r_{i}$ centered on the observation well (5). Because the image well is the same distance from the boundary as the real well, we know the boundary is halfway between the image well and the pumping well (5).

If the boundary is a stream or valley wall or some other feature whose physical position is obvious, its "hydraulic position" may be determined by using data from a single observation well. If, on the other hand, the boundary is the wall of a buried valley or some other feature not obvious from the land surface, distances to the image well from three observation wells may be needed to identify the position of the boundary. 


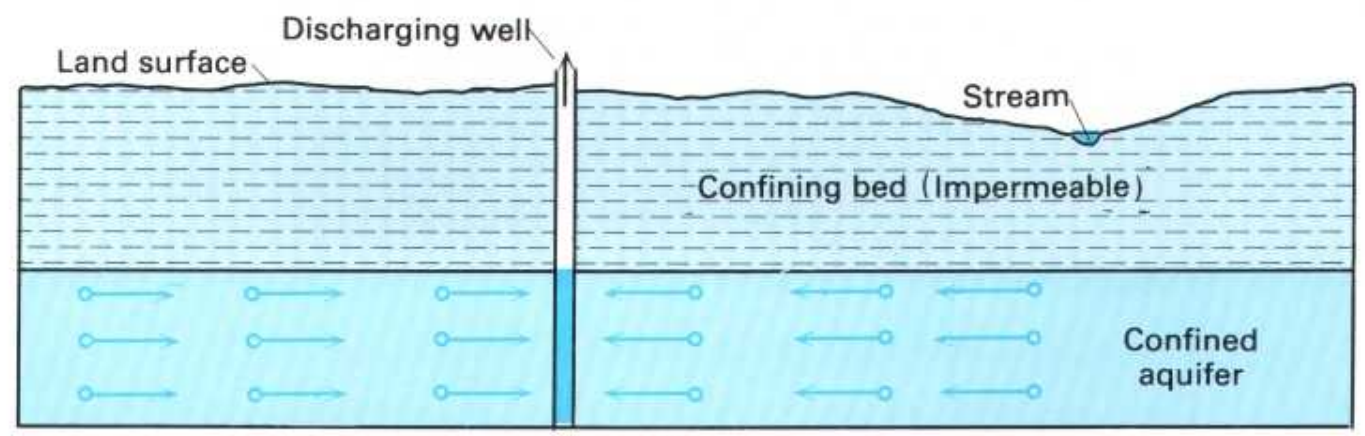

(1)

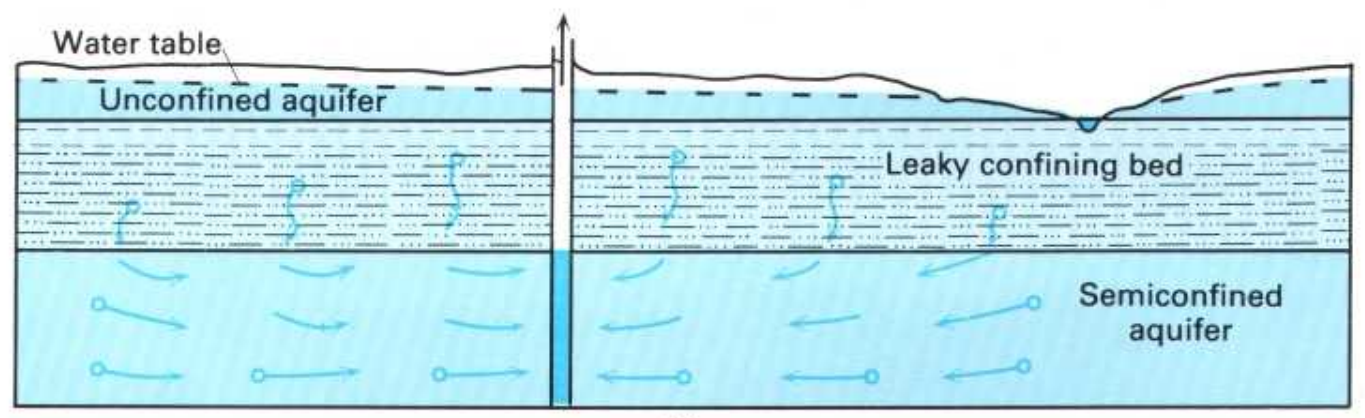

(2)

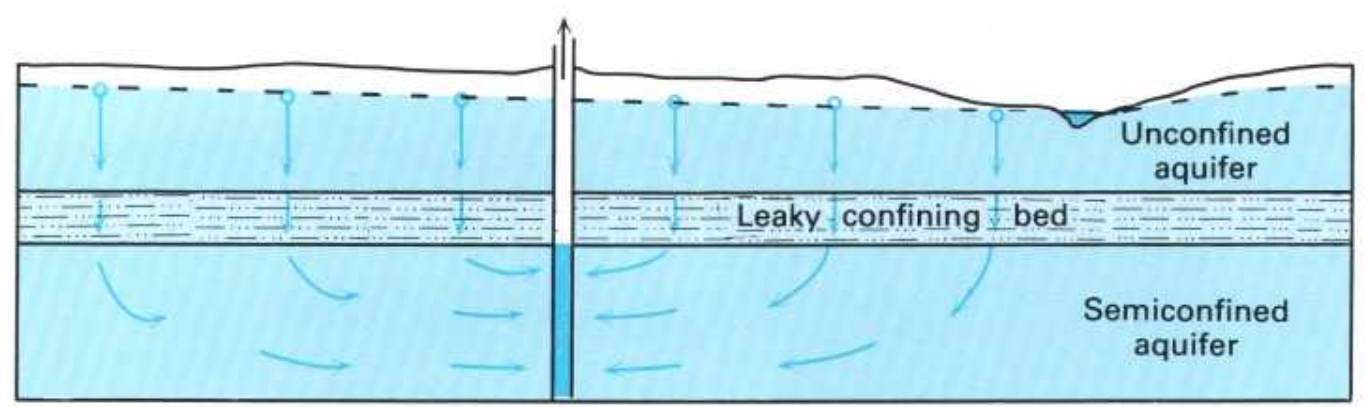

(3)

In the development of the Theis equation for the analysis of aquifer-test data, it was assumed that all water discharged from the pumping well was derived instantaneously from storage in the aquifer. (See "Analysis of Aquifer-Test Data.") Therefore, in the case of a confined aquifer, at least during the period of the test, the movement of water into the aquifer across its overlying and underlying confining beds is negligible. This assumption is satisfied by many confined aquifers. Many other aquifers, however, are bounded by leaky confining beds that transmit water into the aquifer in response to the withdrawals and cause drawdowns to differ from those that would be predicted by the Theis equation. The analysis of aquifer tests conducted on these aquifers requires the use of the methods that have been developed for semiconfined aquifers (also referred to in ground-water literature as "leaky aquifers"').

Sketches 1 through 3 illustrate three different conditions commonly encountered in the field. Sketch 1 shows a confined aquifer bounded by thick, impermeable confining beds. Water initially pumped from such an aquifer is from storage, and aquifer-test data can be analyzed by using the Theis equation. Sketch 2 shows an aquifer overlain by a thick, leaky confining bed that, during an aquifer test, yields significant water from storage. The aquifer in this case may properly be referred to as a semiconfined aquifer, and the release of water from storage in the confining bed affects the analysis of aquifer-test data. Sketch 3 shows an aquifer overlain by a thin confining bed that does not yield significant water from storage but that 


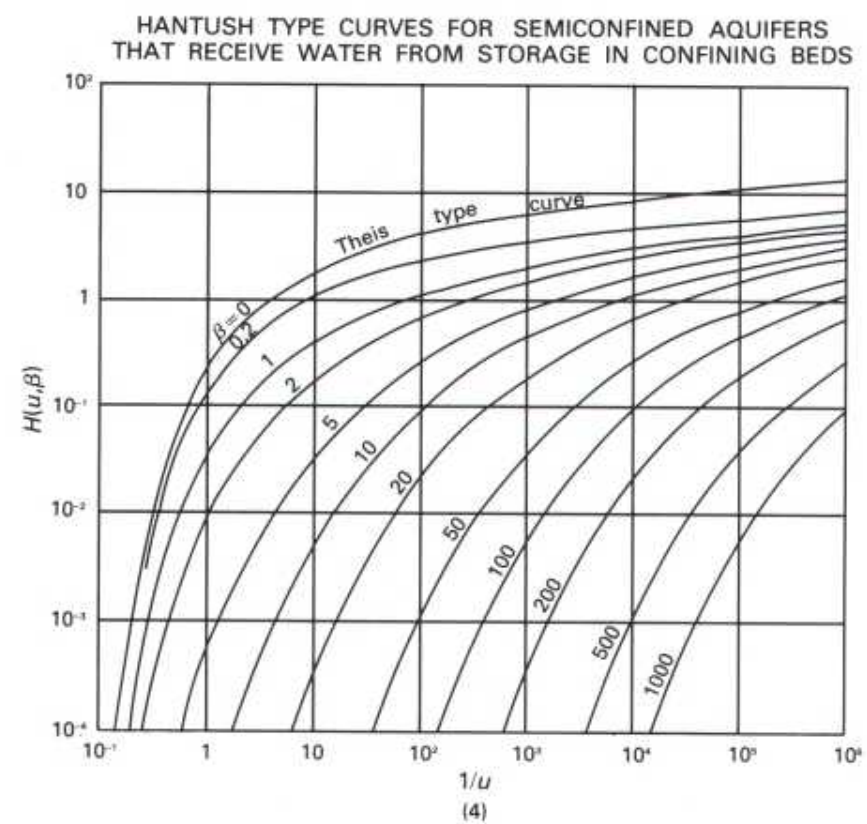

is sufficiently permeable to transmit water from the overlying unconfined aquifer into the semiconfined aquifer. Methods have been devised, largely by Madhi Hantush and C. E. Jacob, for use in analyzing the leaky conditions illustrated in sketches 2 and 3 .

The use of these methods involves matching data plots with type curves, as the Theis method does. The major difference is that, whereas the Theis method involves use of a single type curve, the methods applicable to semiconfined aquifers involve "families" of type curves, each curve of which reflects different combinations of the hydraulic characteristics of the aquifer and the confining beds. Data plots of $s$ versus $t$ on logarithmic graph paper for aquifer tests affected by release of water from storage in the confining beds are matched to the family of type curves illustrated in sketch 4. For convenience, these curves are referred to as Hantush type. Four match-point coordinates are selected and substituted into the following equations to determine values of $T$ and $S$ :

$$
\begin{gathered}
T=\frac{Q H(u, \beta)}{4 \pi s} \\
S=\frac{4 T t u}{r^{2}}
\end{gathered}
$$

Data plots of $s$ versus $t$ on logarithmic graph paper for aquifer tests affected by leakage of water across confining beds are matched to the family of type curves shown in sketch 5. These type curves are based on equations developed by Hantush and Jacob and, for convenience, will be referred to as the Hantush-Jacob curves. The four coordinates of the match point are substituted into the following equations to determine $T$ and $S$ :

$$
\begin{gathered}
T=\frac{Q W(u, r / B)}{4 \pi s} \\
S=\frac{4 T t u}{r^{2}}
\end{gathered}
$$

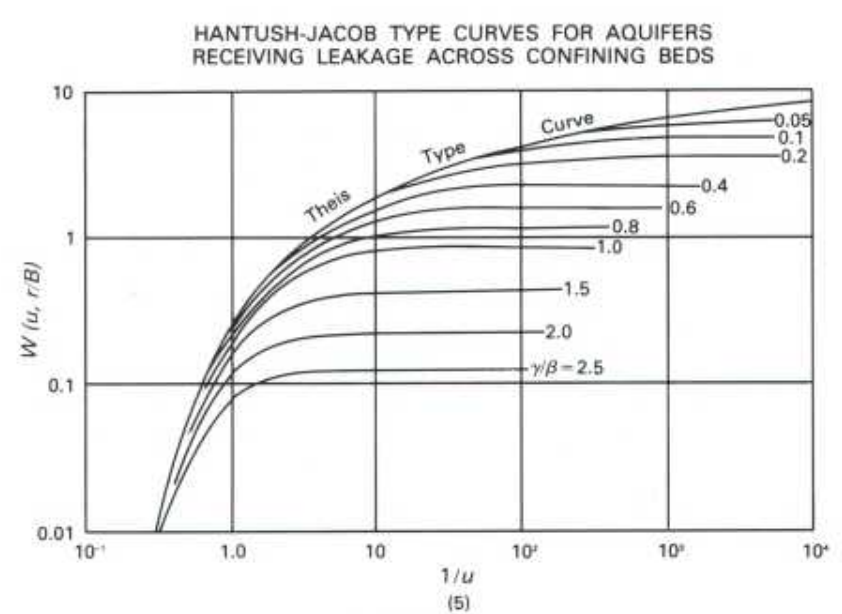

In planning and conducting aquifer tests, hydrologists must give careful consideration to the hydraulic characteristics of the aquifer and to the type of boundary conditions (either recharge or impermeable) that are likely to exist in the vicinity of the test site. Following completion of the test, the next problem is to select the method of analysis that most closely represents the geologic and hydrologic conditions in the area affected by the test. When these conditions are not well known, the common practice is to prepare a data plot of $s$ versus $t$ on logarithmic paper and match it with the Theis type curve. If the data closely match the type curve, the values of $T$ and $S$ determined by using the Theis equation should be reliable. Significant departures of the data from the type curve generally reflect the presence of lateral boundaries or leaky confining beds. Both the geology of the area and the shape of the data plot may provide clues as to which of these conditions most likely exist. It is important to note, however, that some data plots for tests affected by impermeable boundaries are similar in shape to the Hantush curves. 


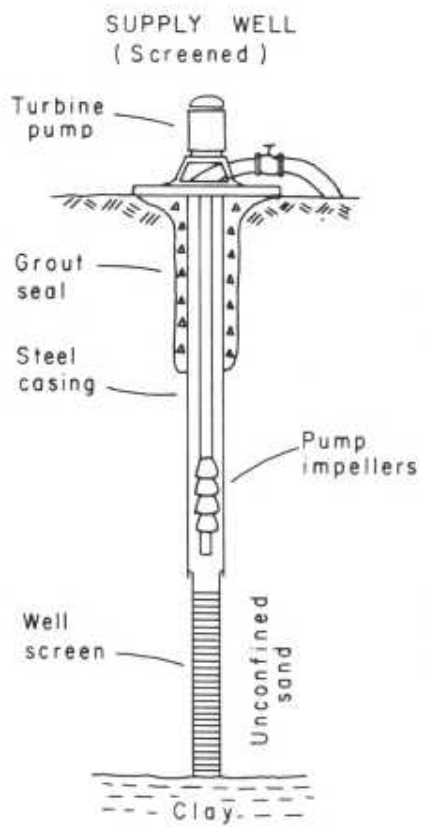

(1)

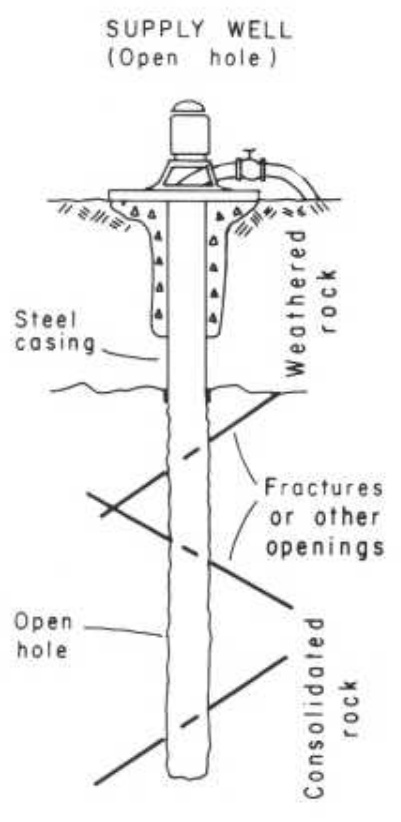

(2)
The seven different methods of well construction in fairly common use are listed in the table. The first four methods are limited to relatively shallow depths and are most commonly employed in the construction of domestic wells. One of the last three methods is usually employed in the construction of municipal and industrial wells and domestic wells in consolidated rock.

The objectives of well construction are to excavate a hole, usually of small diameter in comparison with the depth, to an aquifer and to provide a means for water to enter the hole while rock material is excluded. The means of excavating the hole is different for different methods.
Dug wells constructed with a pickax and shovel were relatively common in rural areas of the eastern and central parts of the country before the 1940's. Such wells are reasonably effective in fine-grained materials, such as glacial till, and thinly bedded sand and clay. The large irrigation ponds that extend below the water table, now being dug by bulldozer or dragline in the Atlantic Coastal Plain, are the modern version of the dug well.

Bored wells are constructed with earth augers turned either by hand or by power equipment and are the modern equivalent of the "hand-dug" well. Bored wells are relatively effective in material of low hydraulic conductivity and in areas underlain by thin surficial layers of silty and clayey sand.

Driven wells are constructed by driving a casing equipped with a screened drive point. Because of their relatively small diameter, these wells are suitable only for relatively permeable surficial aquifers. They are widely used as sources of domestic- and farm-water supplies in those parts of the Atlantic and Gulf Coastal Plains underlain by permeable sand.

Jetted wells are constructed by excavating a hole with a high-pressure jet of water. In dense clays, shell beds, and partially cemented layers, it may be necessary to attach a chisel bit to the jet pipe and alternately raise and drop the pipe to cut a hole.

The percussion drilling method (commonly referred to as the cable-tool method) consists of alternately raising and dropping a heavy weight equipped with a chisel bit. The rock at the bottom of the hole is thus shattered and, together with water, forms a slurry that is removed with a bailer. In unconsolidated material, the casing is driven a few feet at a time ahead of the drilling. After drilling to the maximum depth to be reached by the well, a screen is "telescoped" inside the casing and held in place while the casing is pulled back to expose the screen (1). The top of the screen is sealed against the casing by expanding a lead packer. In wells in consolidated

SUITABILITY OF DIFFERENT WELL-CONSTRUCTION METHODS TO GEOLOGIC CONDITIONS

[Modified from U.S. Environmental Protection Agency (1974), table 3]

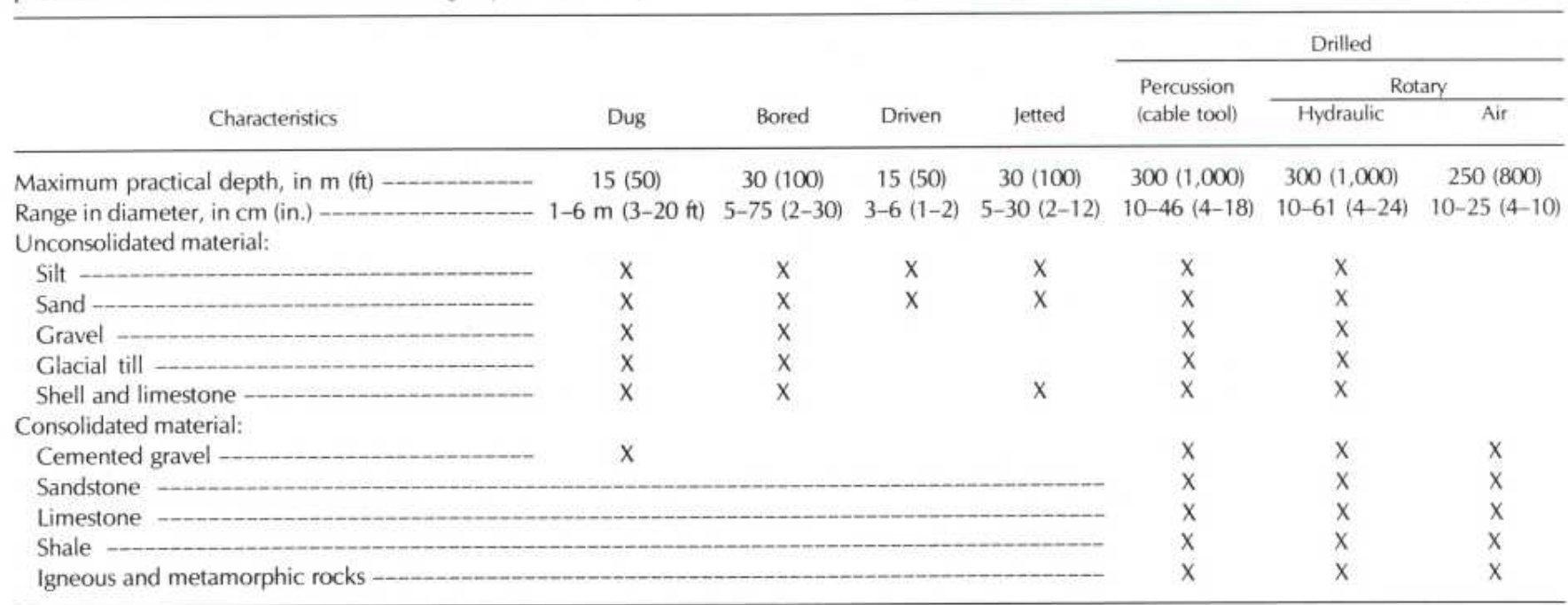


rock, the normal practice is to "seat" the casing firmly in the top of the rock and drill an open hole to the depth required to obtain the needed yield (2).

The hydraulic rotary method excavates a hole by rotating a drill pipe to which one of several types of drag or roller bits is attached. Water containing clay is circulated down the drill pipe in the "normal rotary" method and up the annular space, both to cool the bit and to remove the rock cuttings. In the "reverse rotary" method, the drilling fluid is circulated down the annular space and up the drill pipe. Clay in the drilling fluid adheres to the side of the hole and, together with the pressure exerted in the hole by the drilling fluid, prevents caving of the formation material. Thus, in the hydraulic rotary method, it is not necessary to install permanent-well casing during the drilling process. When the hole reaches the desired depth, a line of casing containing sections of screen at the desired intervals is lowered into the well. Hydraulic rotary is the method most commonly employed in drilling large-yield wells in areas underlain by thick sequences of unconsolidated deposits, such as the Atlantic and Gulf Coastal Plains. Where aquifers consist of alternating thin beds of sand and clay, the common practice is to install a gravel envelope around the screens. Such wells are referred to as gravel packed (3).

The air rotary method is similar to the hydraulic rotary method, except that the drilling fluid is air rather than mud. The air rotary method is suitable only for drilling in consolidated rocks. Most air rotary rigs are also equipped with mud pumps, which permit them to be used in the hydraulic rotary mode for drilling through saturated unconsolidated rock. This method is widely used in the construction of wells in fractured bedrock.

When the construction phase has been completed, it is necessary to begin the phase referred to as well development. The objective of this phase is to remove clay, silt, and fine-grained sand from the area adjacent to the screen or open hole so that the well will produce sediment-free water. The simplest method of development is to pump water from the well at a gradually increasing rate, the final rate being larger than the planned production rate. However, this method is not normally successful in screened and gravel-packed wells drilled by the hydraulic rotary method. For these wells, it is necessary to use a surge block or some other means to alternately force water into the formation and pull it back into the well. One of the most effective methods is to pump water under high pres-

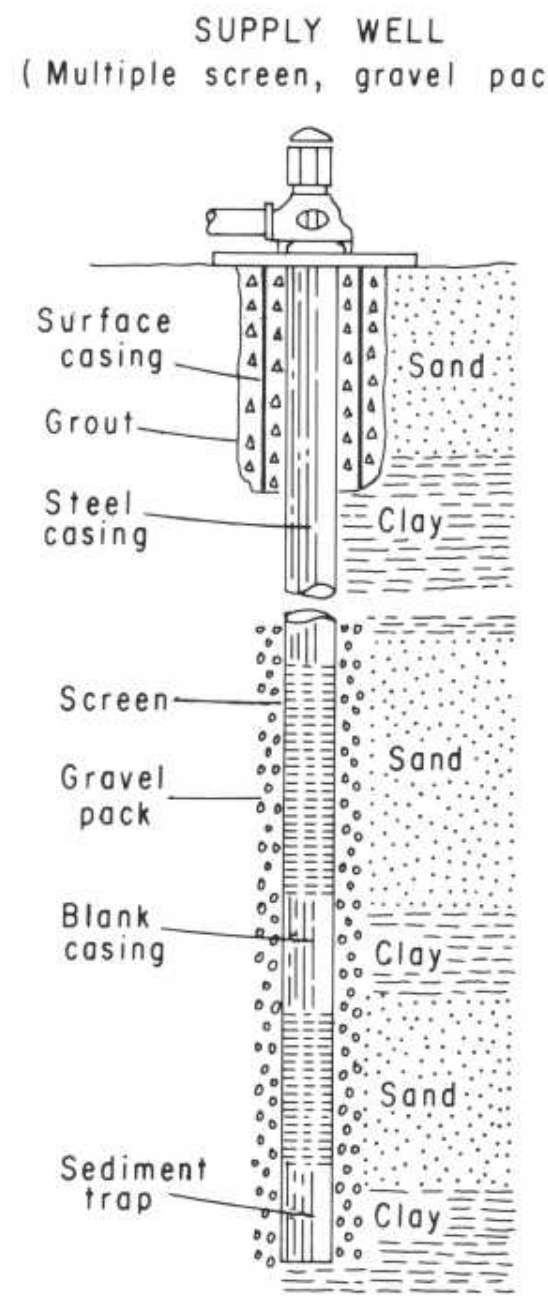

(3)

sure through orifices directed at the inside of the screen. The coarser grained particles pulled into the well during development tend to settle to the bottom of the well and must be removed with a bailer or pump. Chemicals that disperse clays and other fine-grained particles are also used as an aid in well development. 


\begin{tabular}{|c|c|c|c|c|}
\hline \multirow{3}{*}{$\begin{array}{l}\text { Depth below } \\
\text { land surface } \\
\text { (meters) }\end{array}$} & \multirow[b]{3}{*}{ Driller's log } & \multicolumn{3}{|c|}{ Geophysical logs } \\
\hline & & \multicolumn{2}{|c|}{ Electric log } & \multirow{2}{*}{$\begin{array}{l}\text { Gamma- } \\
\text { ray } \\
\text { log }\end{array}$} \\
\hline & & $\begin{array}{r}S P \\
-\quad \\
\end{array}$ & $\begin{array}{c}\text { Apparent } \\
\text { resistivity }\end{array}$ & \\
\hline \multirow{3}{*}{$\begin{array}{l}15.2- \\
19.0-\end{array}$} & $\begin{array}{l}\text { Sand, coarse with pebbles } \\
\text { (Cased to } 4 \mathrm{~m} \text { ) } \\
\text { (Water table at } 9 \mathrm{~m} \text { ) } \\
\text { (Freshwater) }\end{array}$ & & & \\
\hline & Clay, red and green & & & \\
\hline & $\begin{array}{l}\text { Sand, coarse } \\
\quad \text { (Freshwater) }\end{array}$ & & & \\
\hline \multirow{2}{*}{$\begin{array}{l}26.6- \\
29.7-\end{array}$} & Clay, brown & & & \\
\hline & $\begin{array}{l}\text { Clayey sand } \\
\quad \text { (Freshwater) }\end{array}$ & & & \\
\hline $38.8-$ & Clay, reddish brown & & & \\
\hline $43.3-$ & $\begin{array}{l}\text { Sand } \\
\text { (Brackish water) }\end{array}$ & & & \\
\hline \multirow{2}{*}{$\begin{array}{l}50.3- \\
53.9-\end{array}$} & Clay, red & & & \\
\hline & $\begin{array}{l}\text { Sand, coarse } \\
\text { (Saltwater) }\end{array}$ & & & \\
\hline 65.0 & Clay, brown & & & \\
\hline
\end{tabular}

An important part of well construction is determining the character and the thickness of the different layers of material penetrated by the well and the quality of the water in the permeable zones. This information is essential for the installation of casing and for the proper placement of screens. Information on materials penetrated is recorded in the form of "logs." The logs most commonly prepared for supply wells are drillers' logs and geophysical (electric) logs. Copies of logs should be carefully preserved by the well owner as a part of the file on each well.

Drillers' logs consist of written descriptions of the material penetrated by wells. These descriptions are based both on samples of rock cuttings brought to the surface during drilling operations and on changes in the rate of penetration of the drill and in the vibration of the rig. The well driller may also collect samples of the rock cuttings for study by geologists on his staff or those on the staff of State geological surveys or Federal and State water-resources agencies. Descriptions of these samples made by utilizing a microscope and other aids are commonly referred to as a geologic log to differentiate them from the driller's log. If the well is to be finished with a screen, the well driller will retain samples of material from the principal water-bearing zones for use in selecting the slot size of screens.
Geophysical logs provide indirect information on the character of rock layers. The most common type of geophysical $\log$, the type normally referred to as an electric $\log$, consists of a record of the spontaneous electrical potentials generated in the borehole and the apparent electrical resistivity of the rock units. Several types of electric loggers are available, but nearly all provide continuous graphs of spontaneous potential and resistivity as a sensing device is lowered into and removed from the borehole. Electric logs can be made only in the uncased portion of drill holes. The part of the hole to be logged must also contain drilling mud or water.

The spontaneous potential log (which is usually referred to as the SP log) is a record of the differences in the voltages of an electrode at the land surface and an electrode in the borehole. Variations in voltage occur as a result of electrochemical and other spontaneous electrical effects. The SP graph is relatively featureless in shallow water wells that penetrate only the freshwater zone. The right-hand boundary of an SP log generally indicates impermeable beds such as clay, shale, and bedrock. The left-hand boundary generally indicates sand, cavernous limestone, and other permeable layers. 
The resistivity log is a record of the resistance to the flow of an alternating electric current offered by the rock layers and their contained fluids and the fluid in the borehole. Several different electrode arrangements are used to measure the resistivity of different volumes of material, but the arrangement most commonly used by the water-well industry is referred to as the single-point electrode. The resistivity of waterbearing material depends primarily on the salt content of the water and the porosity of the material. Clay layers normally have a low resistivity because of their large porosity, and the water that they contain tends to be relatively highly mineralized. In contrast, sand layers saturated with freshwater tend to have a high resistivity. Sand layers containing salty water, on the other hand, tend to have a low resistivity resembling that of clay layers. Such layers tend to have a strongly negative spontaneous potential that, viewed together with the resistivity, aids in identification of the layers.
Several other types of geophysical logs are available, including gamma-ray logs that record the rate of emission of gamma rays by different rock layers. In fact, geophysical logging is a complex topic that has been developed, largely by the oil industry, into an advanced technical field. It is being utilized to an increasing extent by the water-well industry, especially in conjunction with the construction of large-yield wells by the hydraulic rotary method.

It is also important, either during well construction or following geophysical logging, to collect, for chemical analyses, water samples from the permeable zones that may supply water to the completed well. The chemical analyses made on these samples should include the concentration of any constituents that are known to be a problem in other supply wells drawing from the aquifer. These constituents might include iron, manganese, chloride, sulfate, nitrate, total dissolved solids, and others. (See "Quality of Ground Water.") 


\section{WATER-WELL DESIGNS INCLUDE SPECIFICATIONS ON}

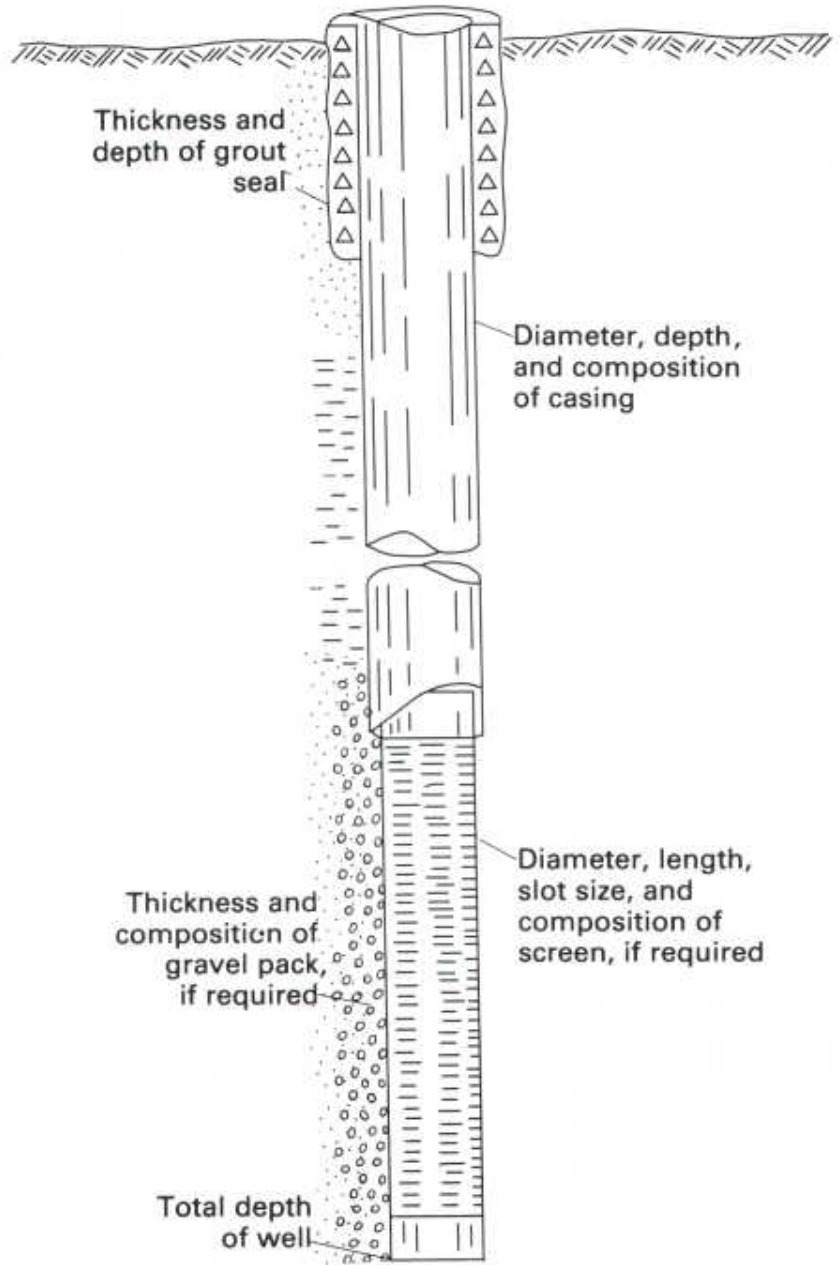

(1)
Water-well design is the first step in the construction of large-yield wells, such as those required by municipalities and industries. Before the initial design is started, it is necessary to know the yield expected from the well, the depth to aquifers underlying the area, the composition and hydraulic characteristics of those aquifers, and the quality of water in the aquifers. If information on an aquifer is not already available from other wells in the area, it will be necessary to construct a test well before completing the design. The completed design should specify the diameter, the total depth of the well and the position of the screen or open-hole sections, the method of construction, the materials to be used in the construction, and, if a gravel pack is required, its thickness and composition (1).

The well diameter is determined primarily by two factorsthe desired yield and the depth to the source aquifer. The diameter has a relatively insignificant effect on the yield (2). For example, doubling the diameter from 15 to 30 centimeters results in only about a 10 percent increase in yield.

WELL DIAMETER VERSUS YIELD
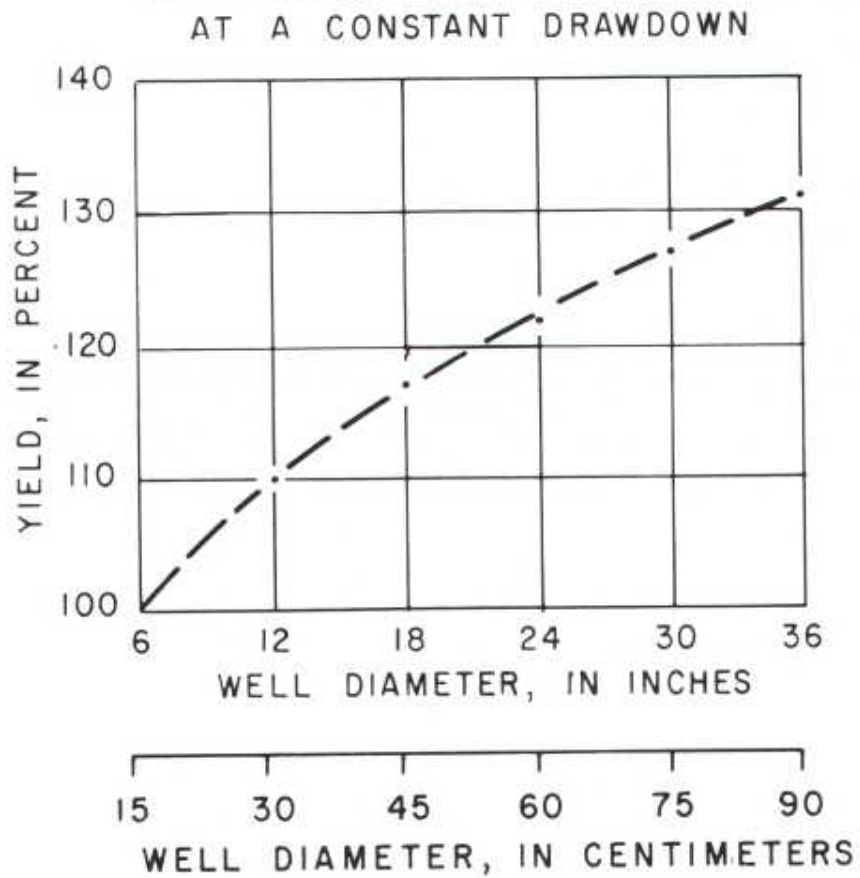

(2)

The primary effect of well diameter on yield is related to the size of the pump that can be installed, which, in turn, determines the pumping rate. Data on pumping rate, pump size, and well diameter are given in table 1 . In some designs, the upper part of the well is made larger than the remainder of the well in order to accommodate the pump. 
Table 1. Data on yield, pump size, and well diameter [ID, inside diameter, OD, outside diameter]

\begin{tabular}{|c|c|c|c|c|}
\hline \multicolumn{3}{|c|}{ Anticipated well yield } & \multirow{2}{*}{$\begin{array}{l}\text { Nominal size } \\
\text { of pump bowls } \\
\text { (in.) }\end{array}$} & \multirow{2}{*}{$\begin{array}{l}\text { Optimum wel } \\
\text { diameter } \\
\text { (in.) }\end{array}$} \\
\hline In gal min ${ }^{-1}$ & In $\mathrm{ft}^{3} \min ^{-1}$ & In $m^{3} \min ^{-1}$ & & \\
\hline Less than 100 & Less than 13 & Less than 0.38 & 4 & $6 \mathrm{ID}$ \\
\hline $75-175$ & $10-23$ & $.28-.66$ & 5 & 8 ID \\
\hline $150-400$ & $20-53$ & $.57-1.52$ & 6 & $10 \mathrm{ID}$ \\
\hline $350-650$ & $47-87$ & $1.33-2.46$ & 8 & $12 \mathrm{ID}$ \\
\hline $600-900$ & $80-120$ & $2.27-3.41$ & 10 & $14 \mathrm{OD}$ \\
\hline $850-1,300$ & $113-173$ & $3.22-4.93$ & 12 & $16 \mathrm{OD}$ \\
\hline $1,200-1,800$ & $160-240$ & $4.55-6.82$ & 14 & $20 \mathrm{OD}$ \\
\hline $1,600-3,000$ & $213-400$ & $6.06-11.37$ & 16 & $24 O 0$ \\
\hline
\end{tabular}

The screen diameter and length, the slot size, and the pumping rate determine the velocity at which water passes through the screen (that is, the so-called "entrance velocity"). The entrance velocity should not normally exceed about $6 \mathrm{ft}$ $\min ^{-1}\left(1.8 \mathrm{~m} \mathrm{~min}^{-1}\right)$. If the anticipated yield in cubic feet per minute shown in table 1 is divided by $6 \mathrm{ft} \mathrm{min}^{-1}$, the result is the minimum open area of screen needed in square feet." Because screen openings are partially blocked by aquifer or gravel-packed material, some well drillers increase the open area needed by 50 to 100 percent to assure that entrance velocities will not be excessive.

The amount of open area per unit length of well screen depends on the diameter, the slot size, and the type of screen. Table 2 shows, for example, the open area of screens manufactured by the Edward E. Johnson $\mathrm{Co}^{2}$ If the open area needed in square feet is divided by the open area per linear foot, the result is the length of screen, in feet, required to provide the yield without exceeding the recommended entrance velocity.

\footnotetext{
'Because dimensions of screens manufactured in the United States are still expressed in inches or feet, these units will be used in this discussion. SI units will be added only where it is useful to do so.

The use of a company name is for identification purposes only and does not imply endorsement by the U.S. Geological Survey.
}

The depth to the source aquifer also affects the well diameter to the extent that wells expected to reach aquifers more than a few hundred feet below land surface must be large enough to accept the larger diameter cable tool or drill rods required to reach these depths.

The total depth of a well depends on the depth below land surface to the lowest water-bearing zone to be tapped.

Table 2. Open areas of Johnson well screens

In denotes width of screen opening in thousandths $(1 / 1,000)$ of an inch. For example, slot no. 10 indicates an opening 10/1,000 or 0.01 inch]

\begin{tabular}{|c|c|c|c|c|c|c|c|}
\hline \multirow{2}{*}{$\begin{array}{l}\text { Nominal } \\
\text { screen } \\
\text { diameter } \\
\text { (in.) }\end{array}$} & \multicolumn{7}{|c|}{$\begin{array}{l}\text { Open areas per linear foot } \\
\text { of screen for slot no. } n\left(\mathrm{t}^{2}\right)\end{array}$} \\
\hline & 10 & 20 & 40 & 60 & 80 & 100 & 150 \\
\hline $4 \ldots$ & 0.17 & 0.30 & 0.47 & 0.60 & 0.68 & 0.64 & 0.76 \\
\hline $6 \ldots$ & .17 & .32 & .53 & .69 & .81 & .92 & .97 \\
\hline $8 \ldots$ & .22 & .41 & .69 & .90 & 1.05 & 1.19 & 1.28 \\
\hline 10 - & .28 & .51 & .87 & .96 & 1.15 & 1.30 & 1.60 \\
\hline $12-\ldots$ & .26 & .50 & .87 & 1.13 & 1.37 & 1.55 & 1.89 \\
\hline $14-\cdots$ & .30 & .56 & .96 & 1.26 & 1.53 & 1.74 & 2.11 \\
\hline $16 \ldots$ & .34 & .64 & 1.11 & 1.45 & 1.75 & 1.98 & 2.42 \\
\hline
\end{tabular}

The position of the screen depends on the thickness and composition of the source aquifer and whether the well is being designed to obtain the maximum possible yield. Because withdrawals from unconfined aquifers result in dewatering of the aquifers, wells in these aquifers are normally screened only in the lower part in order to obtain the maximum available drawdown. In confined aquifers, screens are set either in the most permeable part of the aquifer or, where vertical differences in hydraulic conductivity are not significant, in the middle part of the aquifer.

The length of the screen specified in the well design depends on the thickness of the aquifer, the desired yield, whether the aquifer is unconfined or confined, and economic considerations. When an attempt is being made to obtain the maximum available yield, screens are normally installed in the lower 30 to 40 percent of unconfined aquifers and in the middle 70 to 80 percent of confined aquifers. 


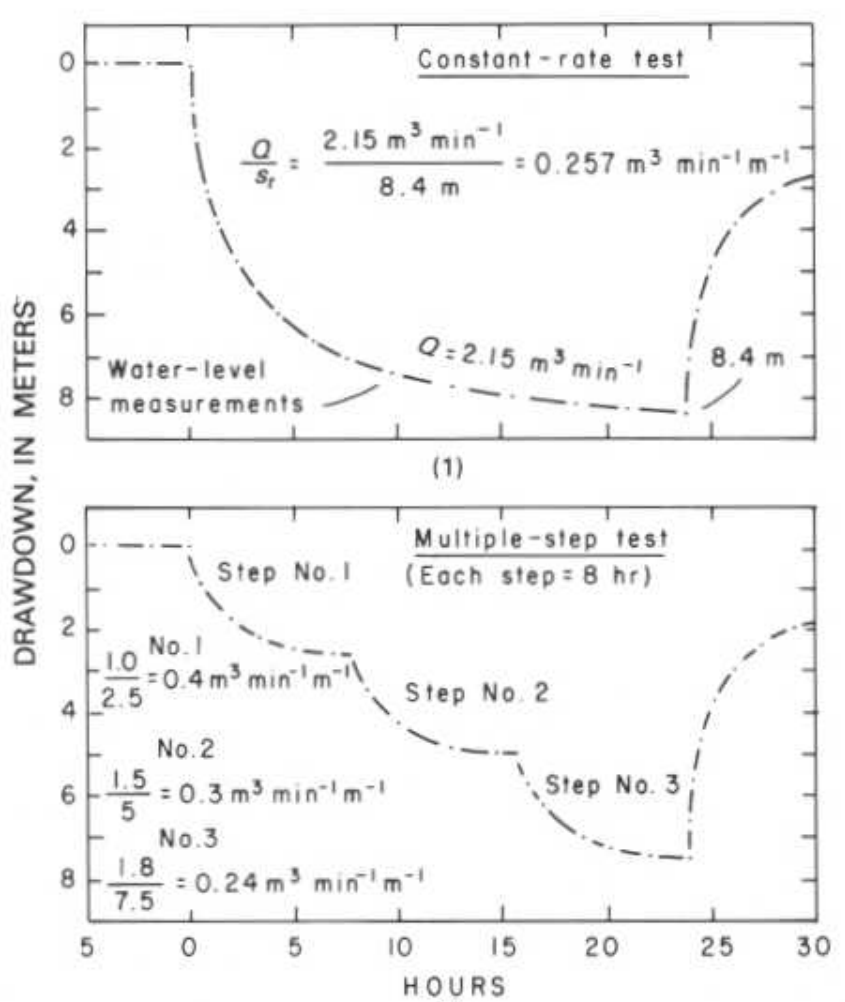

(2)

Many supply-well contracts require a "guaranteed" yield, and some stipulate that the well reach a certain level of "efficiency." Most contracts also specify the length of the "drawdown test" that must be conducted to demonstrate that the yield requirement is met. For example, many States require that tests of public-supply wells be at least 24 hours. Tests of most industrial and irrigation wells probably do not exceed about 8 hours.

Well-acceptance tests, if properly conducted, not only can confirm the yield of a well and the size of the production pump that is needed but can also provide information of great value in well operation and maintenance. Such tests should, therefore, be conducted with the same care as aquifer tests made to determine the hydraulic characteristics of aquifers. A properly conducted test will include:

1. Determination of well interference from nearby pumping wells, based on accurate water-level measurements made before the drawdown test.

2. A pumping rate that is either held constant during the entire test (1) or increased in steps of equal length (2). The pumping rate during each step should be held constant, and the length of each step should be at least 2 hours.
Of these requirements, the constant, carefully regulated pumping rate or rates and the accurate water-level measurements are the most important. When a constant-rate well-acceptance test has been completed, the drawdown data can be analyzed to determine the aquifer transmissivity. (See "Single-Well Tests.")

Many well-acceptance tests are made with temporary pump installations, usually powered with a gasoline or diesel engine. Instead of maintaining a constant rate for the duration of the test, the engine is frequently stopped to add fuel or to check the oil level or for numerous other reasons. The rate may also be increased and decreased on an irregular, unplanned schedule or, more commonly, gradually reduced during the test in an effort to maintain a pumping level above the pump intake. In such tests, the "yield" of the well is normally reported to be the final pumping rate.

Determining the long-term yield of a well from data collected during a short-period well-acceptance test is one of the most important, practical problems in ground-water hydrology. Two of the most important factors that must be considered are the extent to which the yield will decrease if the well is pumped continuously for periods longer than the test period and the effect on the yield of changes in the static (regional) water level from that existing at the time of the test.

When data are available only from the production well and when the pumping rate was not held constant during the acceptance test, the estimate of the long-term yield must usually be based on an analysis of specific-capacity data. Specific capacity is the yield per unit of drawdown and is determined by dividing the pumping rate at any time during the test by the drawdown at the same time. Thus,

$$
\text { specific capacity }=\frac{\text { pumping rate }}{\text { drawdown }}=\frac{Q}{s_{t}}
$$

Before the development of steady-state conditions, a part of the water pumped from an aquifer is derived from storage. The time required for steady-state conditions to develop depends largely on the distance to and characteristics of the recharge and discharge areas and the hydraulic characteristics of the aquifer. The time required to reach a steady state is independent of the pumping rate. At some places in some aquifers, a steady-state condition will be reached in several days, whereas, in others, six months to a year may be required; in some arid areas, a steady-state condition may never be achieved. Depending on the length of the well-acceptance test and the period required to reach a steady-state condition, it may be appropriate, in estimating the long-term yield of a well, to use a specific capacity smaller than that determined during the test. 
DECLINE IN SPECIFIC CAPACITY WITH TIME AT A CONTINUOUS PUMPING RATE

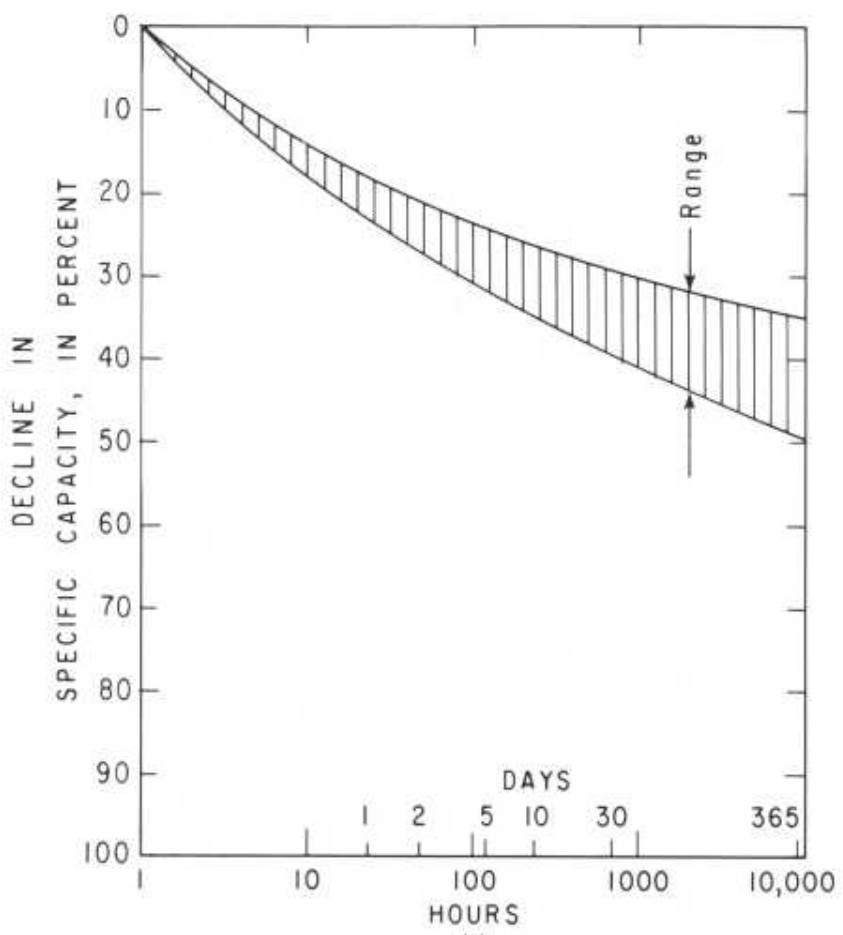

(3)

Sketch 3 shows the decline in specific capacity with time when a well is pumped continuously at a constant rate and all the water is derived from storage in an isotropic and homogeneous aquifer. For convenience in preparing the sketch, a value of 100 percent was assigned to the specific capacity 1 hour after the pump was started. The rate at which the specific capacity decreases depends on the decline of the water level due to depletion of storage and on the hydraulic characteristics of the aquifer. Differences in the rate for different aquifers are indicated by the width of the band on the sketch. When withdrawals are derived entirely from storage, the specific capacity will decrease about 40 percent during the first year.

In predicting the long-term yield of a well, it is also necessary to consider changes in the static water level resulting from seasonal and long-term variations in recharge and declines due to other withdrawals from the aquifer. The longterm yield is equal to the specific capacity, determined from the well-acceptance test, and reduced as necessary to compensate for the long-term decline discussed in the above paragraph, multiplied by the available drawdown.

The available drawdown at the time of a well-acceptance test is equal to the difference between the static water level at that time and the lowest pumping level that can be imposed on the well. The lowest pumping level in a screened well is normally considered to be a meter or two above the top of the screen. In an unscreened (open-hole) well, it may be at the level of either the highest or the lowest water-bearing opening penetrated by the well. The choice of the highest or the lowest opening depends on the chemical composition of the water and whether water cascading from openings above the pumping level results in precipitation of minerals on the side of the well and on the pump intake. If such precipitation is expected, the maximum pumping level should not be below the highest opening. The yield of a well is not increased by a pumping level below the lowest opening, and the maximum yield may, in fact, be attained at a much higher level.

To predict the maximum continuous long-term yield, it is necessary to estimate how much the static water level, and thus the available drawdown, may decline from the position that it occupied during the acceptance test. Records of waterlevel fluctuations in long-term observation wells in the area will be useful in this effort.

Well efficiency is an important consideration both in well design and in well construction and development. The objective, of course, is to avoid excessive energy costs by designing and constructing wells that will yield the required water with the least drawdown.

Well efficiency can be defined as the ratio of the drawdown $\left(s_{a}\right)$ in the aquifer at the radius of the pumping well to the drawdown $\left(s_{t}\right)$ inside the well. (See "Single-Well Tests.") Thus, the equation

$$
E=\frac{s_{a}}{s_{t}} \times 100
$$

expresses well efficiency as a percentage.

Drawdowns in pumping wells are measured during wellacceptance tests. Determining the drawdown in the aquifer is a much more difficult problem. It can be calculated if the hydraulic characteristics of the aquifer, including the effect of boundary conditions, are known.

The difference between $s_{t}$ and $s_{a}$ is attributed to head losses as water moves from an aquifer into a well and up the well bore. These well losses can be reduced by reducing the entrance velocity of the water, which can be done by installing the maximum amount of screen and pumping at the lowest acceptable rate. Tests have been devised to determine well losses, and the results can be used to determine well efficiency. However, these tests are difficult to conduct and are not widely used. Because of difficulties in determining $s_{a}$, well efficiency is generally specified in terms of an "optimum" specific capacity based on other producing wells in the vicinity.

Under the best conditions, an efficiency of about 80 percent is the maximum that is normally achievable in most screened wells. Under less than ideal conditions, an efficiency of 60 percent is probably more realistic. 


\section{FACTORS AFFECTING ESTIMATES OF TRANSMISSIVITY BASED ON SPECIFIC CAPACITY}

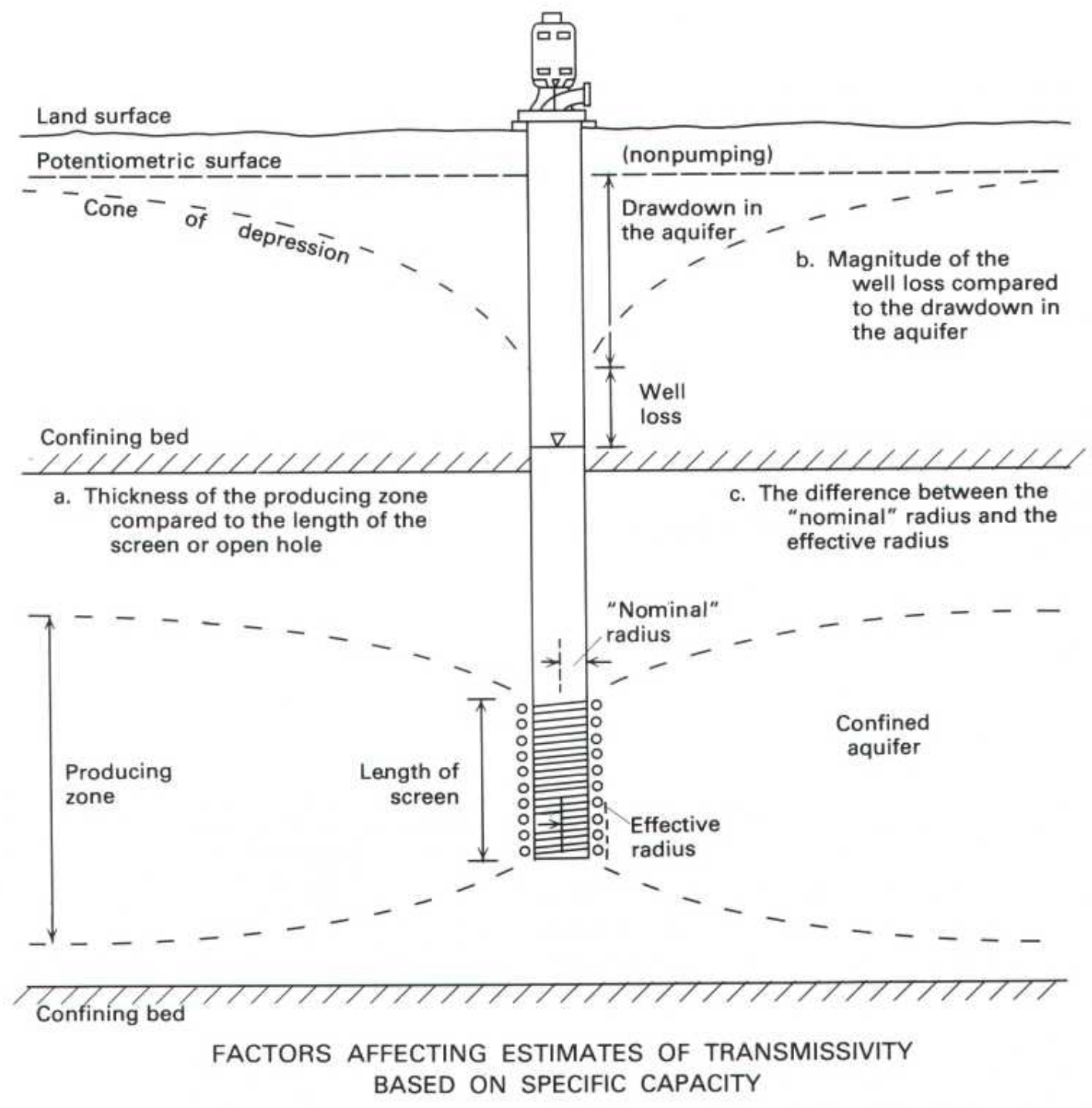

The specific capacity of a well depends both on the hydraulic characteristics of the aquifer and on the construction and other features of the well. Values of specific capacity, available for many supply wells for which aquifer-test data are not available, are widely used by hydrologists to estimate transmissivity. Such estimates are used to evaluate regional differences in transmissivity and to prepare transmissivity maps for use in models of ground-water systems.

The factors that affect specific capacity include:

1. The transmissivity of the zone supplying water to the well, which, depending on the length of the screen or open hole, may be considerably less than the transmissivity of the aquifer.
2. The storage coefticient of the aquifer.

3. The length of the pumping period.

4. The effective radius of the well, which may be significantly greater than the "nominal" radius.

5. The pumping rate.

The Theis equation can be used to evaluate the effect of the first four factors on specific capacity. The last factor, pumping rate, affects the well loss and can be determined only from a stepped-rate test or an aquifer test in which drawdowns are measured in both the pumping well and observation wells.

The Theis equation, modified for the determination of transmissivity from specific capacity, is 


$$
T=\frac{W(u)}{4 \pi} \times \frac{Q}{s}
$$

where $T$ is transmissivity, $Q / s$ is specific capacity, $Q$ is the pumping rate, $s$ is the drawdown, and $W(u)$ is the well function of $u$, where

$$
u=\frac{r^{2} S}{4 T t}
$$

where $r$ is the effective radius of the well, $S$ is the storage coefficient, and $t$ is the length of the pumping period preceding the determination of specific capacity.

For convenience in using equation 1, it is desirable to express $W(u) / 4 \pi$ as a constant. To do so, it is first necessary to determine values for $u$ and, using a table of values of $u$ (or $1 / u$ ) and $W(u)$, determine the corresponding values for $W(u)$.

Values of $u$ are determined by substituting in equation 2 values of $T, S, r$, and $t$ that are representative of conditions in the area. To illustrate, assume, in an area under investigation and for which a large number of values of specific capacity are available, that:

1. The principal aquifer is confined, and aquifer tests indicate that it has a storage coefficient of about $2 \times 10^{-4}$ and a transmissivity of about $11,000 \mathrm{ft}^{2} \mathrm{~d}^{-1}$.

2. Most supply wells are 8 in. $(20 \mathrm{~cm})$ in diameter (radius, $0.33 \mathrm{ft}$.

3. Most values of specific capacity are based on 12-hour wellacceptance tests ( $t=0.5 \mathrm{~d})$.

Substituting these values in equation 2, we obtain

$$
\begin{gathered}
u=\frac{r^{2} S}{4 T t}=\frac{\left(0.33 \mathrm{ft}^{2} \times\left(2 \times 10^{-4}\right)\right.}{4 \times\left(11,000 \mathrm{ft}^{2} \mathrm{~d}^{-1}\right) \times 0.5 \mathrm{~d}} \\
u=\frac{2.22 \times 10^{-5} \mathrm{ft}^{2}}{2.2 \times 10^{4} \mathrm{ft}^{2}}=1.01 \times 10^{-9}
\end{gathered}
$$

A table of values of $W(u)$ for values of $1 / u$ is contained in the section of this report entitled "Aquifer Tests." Therefore, the value of $u$ determined above must be converted to $1 / u$, which is $9.91 \times 10^{8}$, and this value is used to determine the value of $W(u)$. Values of $W(u)$ are given for values of $1 / u$ of $7.69 \times 10^{8}$ and $10 \times 10^{8}$ but not for $9.91 \times 10^{8}$. However, the value of 10 is close enough to 9.91 for the purpose of estimating transmissivity from specific capacity. From the table, we determine that, for a value of $1 / u$ of $10 \times 10^{B}$, the value of $W(u)$ is 20.15 . Substituting this value in equation 1 , we find the constant $W(u) / 4 \pi$ to be 1.60 .
Equation 1 is in consistent units. However, transmissivity is commonly expressed in the United States in units of square feet per day, pumping rates are reported in units of gallons per minute, and drawdowns are measured in feet. To obtain an equation that is convenient to use, it is desirable to convert equation 1 to these inconsistent units. Thus

$$
\begin{gathered}
T=1.60 \times \frac{1,440 \mathrm{~min}}{\mathrm{~d}} \times \frac{\mathrm{ft}^{3}}{7.48 \mathrm{gal}} \times \frac{\mathrm{Q}}{\mathrm{s}} \\
T=308 \frac{\mathrm{Q}}{\mathrm{s}} \text { or } 300 \frac{\mathrm{Q}}{\mathrm{s}} \text { (rounded) }
\end{gathered}
$$

Many readers will find it useful at this point to substitute different values of $T, S, r$, and $t$ in equation 2 to determine how different values affect the constant in equation 3 . In using equation 3, modified as necessary to fit the conditions in an area, it is important to recognize its limitations. Among the most important factors that affect its use are the accuracy with which the thickness of the zone supplying water to the well can be estimated, the magnitude of the well loss in comparison with drawdown in the aquifer, and the difference between the "nominal" radius of the well and its effective radius.

Relative to these factors, the common practice is to assume that the value of transmissivity estimated from specific capacity applies only to the screened zone or to the open hole. To apply this value to the entire aquifer, the transmissivity is divided by the length of the screen or open hole (to determine the hydraulic conductivity per unit of length), and the result is multiplied by the entire thickness of the aquifer. The value of transmissivity determined by this method is too large if the zone supplying water to the well is thicker than the length of the screen or the open hole. Similarly, if the effective radius of the well is larger than the "nominal" radius (assuming that the "nominal" radius is used in equation 2), the transmissivity based on specific capacity again will be too large.

On the other hand, if a significant part of the drawdown in the pumping well is due to well loss, the transmissivity based on specific capacity will be too small. Whether the effect of all three of these factors cancels depends on the characteristics of both the aquifer and the well. Where a sufficient number of aquifer tests have been conducted, it may be feasible to utilize the results to modify the constant in equation 3 to account for the effect of these factors. 


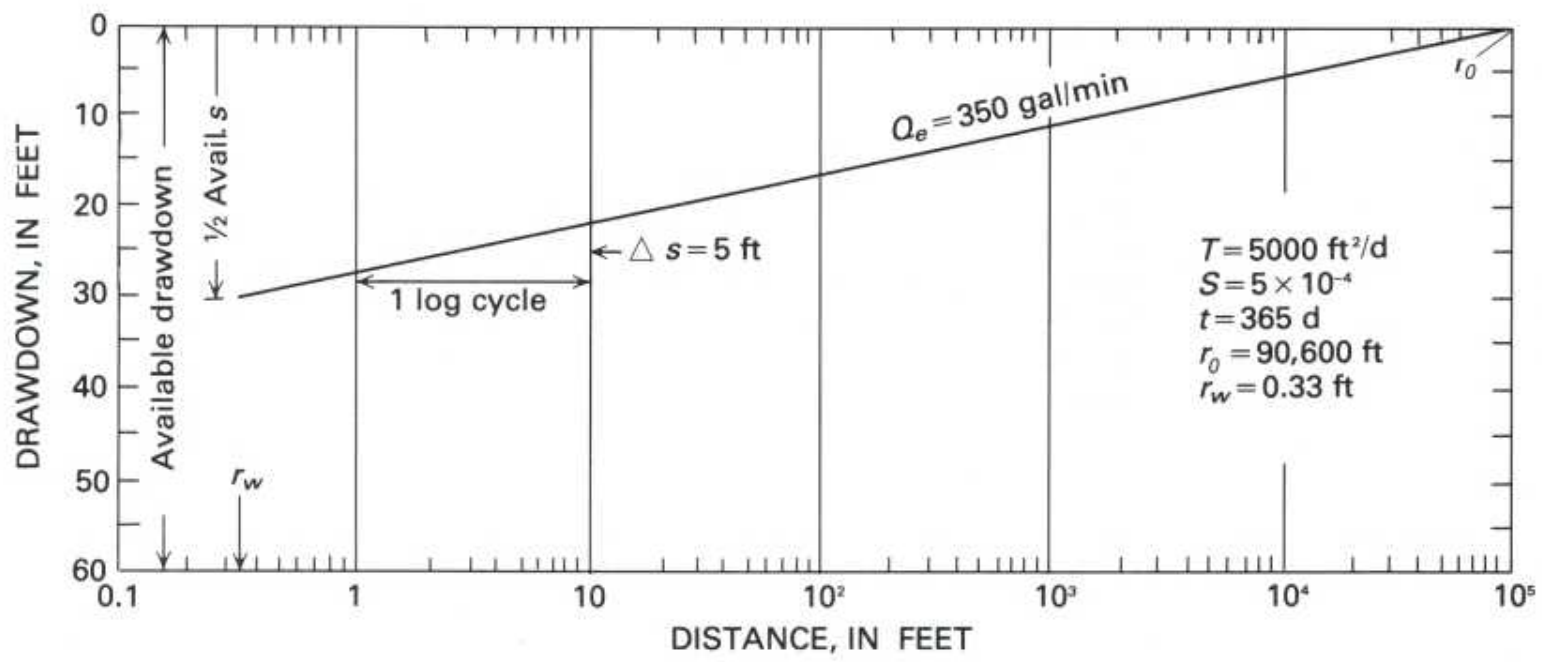

(1)

The development of moderate to large supplies of water from most aquifers requires more than one well; in other words, it requires what is commonly referred to as a well field. Consequently, the design of well fields is an important problem in ground-water development. The objective of well-field design is to obtain the required amount of water for the least cost, including the initial construction cost of wells and pipelines, the cost of operation and maintenance, and the cost of well replacement.

The final product of a design is a plan showing the arrangement and spacing of wells and specifications containing details on well construction and completion, including information on well diameter, depth, and position of screens or open hole, the type of casing and screens, and the type, size, and setting of pumps.

The key elements in well-field design are the total quantity of water to be obtained from the field, the rate at which each well can be pumped (which determines the number of wells that will be required), and the spacing of the wells.

The pumping rate for each well can be estimated with Jacob's modification of the Theis equation. (See "DistarceDrawdown Analysis.") It depends on the transmissivity and storge coefficient of the aquifer, the distance to and nature of lateral boundaries, the hydraulic characteristics of confining beds, the available drawdown, and the pumping period. For the purpose of this discussion, we will not consider the effect of boundaries or confining beds. (For a discussion of available drawdown, see "Well Interference" and "Well-Acceptance Tests and Well Efficiency.") The pumping period is normally taken as 1 year. To determine the pumping rate, Jacob's equations are solved as follows:

$$
\begin{aligned}
& r_{0}{ }^{2}=\frac{2.25 T t}{S} \\
& Q_{e}=2.7 T \Delta s
\end{aligned}
$$

where $r_{0}$ is the distance from the pumping well, in meters (or feet), to the point of zero drawdown on a semilogarithmic graph in which drawdown is on the arithmetic scale and distance is on the logarithmic scale, $T$ is aquifer transmissivity, in square meters per day (or square feet per day), $t$ is 365 days ( 1 year), $S$ is the aquifer storage coefficient (dimensionless), $\Delta s$ is the drawdown, in meters (or feet), across one log cycle along a line connecting point $r_{0}$ and a point at the proposed radius of the pumping well at which the drawdown equals about half the available drawdown, ${ }^{1}$ and $Q_{e}$ is the first estimate of the pumping rate in cubic meters per day (or cubic feet per day). To convert to gallons per minute, when $Q_{e}$ is in cubic meters per day, divide by 5.45 (when $Q_{e}$ is in cubic feet per day, divide by 192).

The estimated pumping rate $Q_{e}$ is divided into the total quantity of water needed from the well field in order to determine the number of wells that will be needed. The next step is to determine the optimum well spacing. This determination involves both hydrologic and economic considerations. The hydrologic considerations include the following:

1. The minimum distance between pumping wells should be at least twice the aquifer thickness if the wells are open to less than about half the aquifer thickness.

2. Wells near recharging boundaries should be located along a line parallel to the boundary and as close to the boundary as possible.

3. Wells near impermeable boundaries should be located along a line perpendicular to the boundary and as far from the boundary as possible.

\footnotetext{
${ }^{1}$ At this point, we use half the available drawdown in order to get a first estimate of well loss and well interierence, If we determine that, at a pumping rate of $Q_{e}$, the drawdown in the aquifer is less than the available drawdown and the drawdown in the well is above the top of the screen, we can assume a larger value of $s$ and recompute $Q_{e}$. It is important also to note that, in the initial determination of available drawdown, the seasonal fluctuation of static water level must be considered.
} 
The primary economic considerations involved in well spacing include the cost of wells and pumps, power costs, and the cost of interconnecting pipelines and powerlines. The closer wells are spaced, the smaller the yield of each well because of well interference. The smaller yield of closely spaced wells means that more wells and well pumps are required, and power costs are higher. The cost of the additional wells and the larger pumping costs must be evaluated in relation to the cost of shorter interconnecting pipelines and powerlines.

Sketch 1 shows a distance-drawdown graph for a pumping well at the end of a continuous pumping period of one year for an aquifer having a transmissivity $(T)$ of $5,000 \mathrm{ft}^{2} \mathrm{~d}^{-1}$ $\left(465 \mathrm{~m}^{3} \mathrm{~d}^{-1}\right)$, a storage coefficient $(S)$ of $5 \times 10^{-4}$, and an available drawdown of $60 \mathrm{ft}(18 \mathrm{~m})$. The assumed radius of the pumping well $\left(r_{w}\right)$ is $0.33 \mathrm{ft}$ (diameter, $8 \mathrm{in}$. or $20 \mathrm{~cm}$ ). When one-half the available drawdown is used, along with the other values as stated, equation 2 yields an estimated pumping rate $\left(Q_{e}\right)$ of $350 \mathrm{gal} \mathrm{min}^{-1}$ or $504,000 \mathrm{gal} \mathrm{d}^{-1}$. $^{2}$

To illustrate the use of sketch 1 in analyzing the wellspacing problem, we will assume that a yield of 1,500,000 gal $\mathrm{d}^{-1}\left(1,040 \mathrm{gal} \mathrm{min}^{-1}\right)$ is desired from the aquifer. This yield can be obtained from three wells producing $500,000 \mathrm{gal} \mathrm{d}^{-1}$ (350 $\mathrm{gal} \mathrm{min}^{-1}$ ) each. Assume that the wells are located on a straight line and are numbered 1,2, and 3 . Well 2, being in the middle, will obviously have the most well interference and, therefore, the largest drawdown. How close can it be to wells 1 and 3 without its drawdown exceeding the available drawdown of $60 \mathrm{ft}$ ?

When well 2 is pumped at a rate of $350 \mathrm{gal} \mathrm{min}^{-1}$, the drawdown in the aquifer at the radius of the well will be onehalf the available drawdown, or $30 \mathrm{ft}$. The remaining $30 \mathrm{ft}$ of the available drawdown must be apportioned between well loss in well 2 and interference from wells 1 and 3 . According to sketch 1 , if well 2 were 100 percent efficient, its specific capacity would be

$$
\frac{350 \mathrm{gal} \mathrm{min}^{-1}}{30 \mathrm{ft}}=11.7 \mathrm{gal} \mathrm{min}^{-1} \mathrm{ft}^{-1}
$$

We will assume, however, that well 2 will be only 80 percent efficient. If so, its specific capacity will be

$$
\frac{11.7 \mathrm{gal} \mathrm{min}^{-1} \mathrm{ft}^{-1}}{100 \text { percent }}=\frac{X}{80 \text { percent }}=9.4 \mathrm{gal} \mathrm{min}^{-1} \mathrm{ft}^{-1}
$$

and a yield of $350 \mathrm{gal} \mathrm{min}^{-1}$ will produce a drawdown in well 2 of about $37 \mathrm{ft}(350 / 9.4)$. Subtracting $37 \mathrm{ft}$ from $60 \mathrm{ft}$ leaves a difference of $23 \mathrm{ft}$, which can be assigned to well interference from wells 1 and 3 . If fractional feet are ignored, the amount of interference by each well is about $11 \mathrm{ft}$.

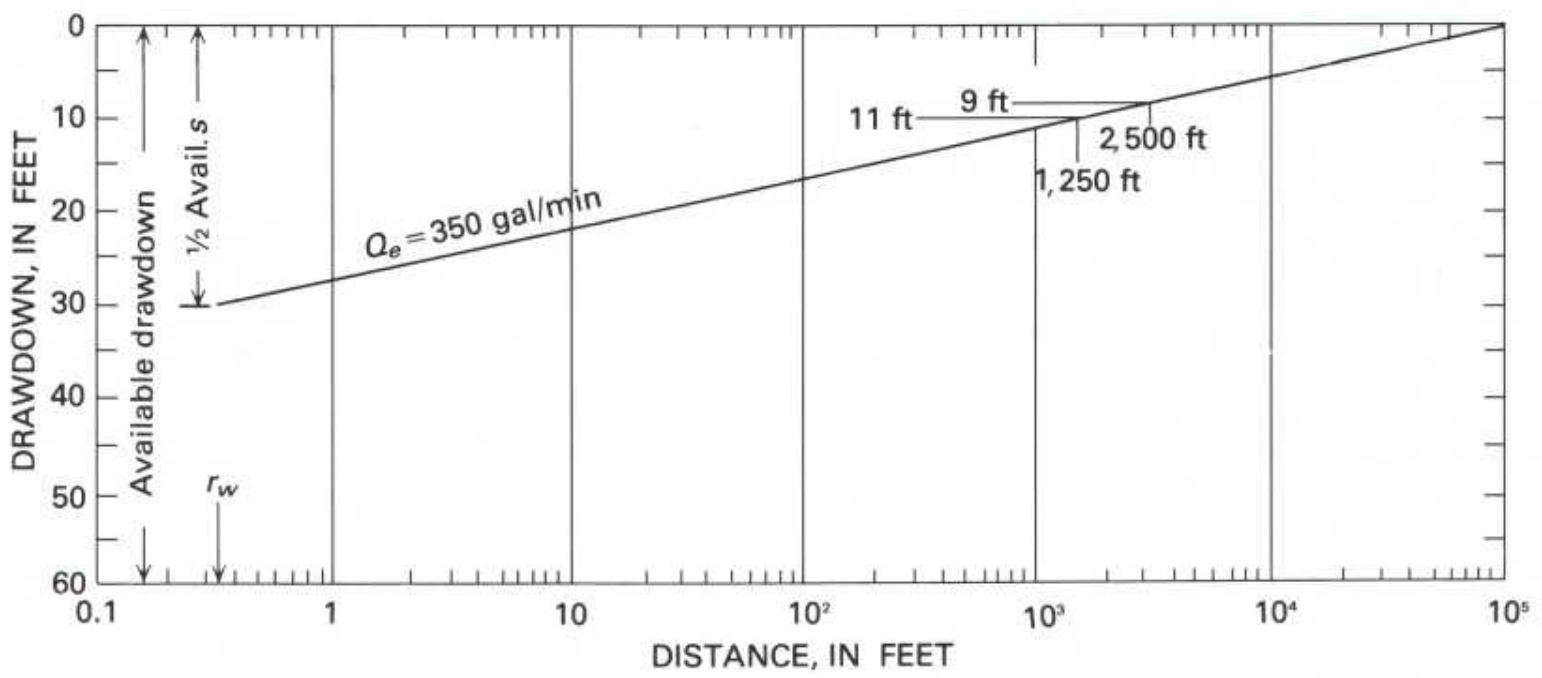

(2)

Sketch 2 shows that a well pumping $350 \mathrm{gal} \mathrm{min}^{-1}$ from the aquifer will produce a drawdown of $11 \mathrm{ft}$ at a distance of about 1,250 ft. Therefore, the spacing between wells 1 and 2

\footnotetext{
${ }^{2}$ Inch-pound units are used in this example for the convenience of those eaders who are not yet accustomed to using metric units.
}

and between wells 2 and 3 would have to be 1,250 ft in order not to exceed the available drawdown at well 2 . With this spacing, wells 1 and 3 would be 2,500 ft apart. Sketch 2 shows the drawdown at $2,500 \mathrm{ft}$ to be about $9 \mathrm{ft}$. Consequently, the drawdowns in both wells 1 and 3 would be $58 \mathrm{ft}$, or about $2 \mathrm{ft}$ less than the drawdown in well 2. 


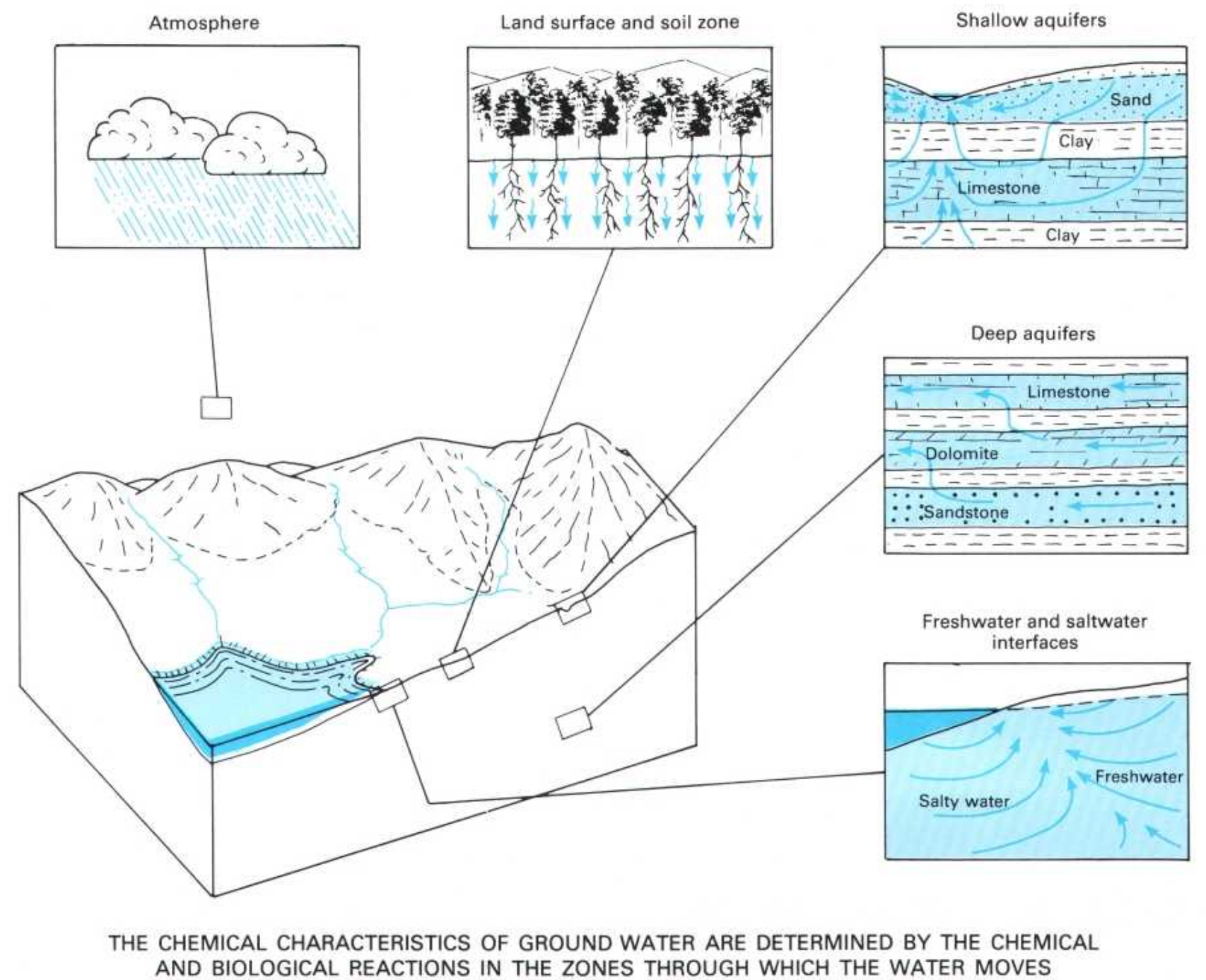

Water consists of two atoms of hydrogen and one of oxygen, which give it a chemical formula of $\mathrm{H}_{2} \mathrm{O}$. Water frequently is referred to as the universal solvent because it has the ability to dissolve at least small amounts of almost all substances that it contacts. Of the domestic water used by man, ground water usually contains the largest amounts of dissolved solids. The composition and concentration of substances dissolved in unpolluted ground water depend on the chemical composition of precipitation, on the biologic and chemical reactions occurring on the land surface and in the soil zone, and on the mineral composition of the aquifers and confining beds through which the water moves.

The concentrations of substances dissolved in water are commonly reported in units of weight per volume. In the International System (SI), the most commonly used units are milligrams per liter. A milligram equals $1 / 1,000(0.001)$ of a gram, and a liter equals $1 / 1,000$ of a cubic meter, so that $1 \mathrm{mg} / \mathrm{L}$ equals 1 gram $\mathrm{m}^{-3} \cdot{ }^{1}$ Concentrations of substances in water were reported for many years in the United States in units of weight per weight. Because the concentration of most substances dissolved in water is relatively small, the weight per weight unit commonly used was parts per million (ppm). In inch-pound units, $1 \mathrm{ppm}$ is equal to $1 \mathrm{lb}$ of a substance dissolved in $999,999 \mathrm{lb}$ of water, the weight of the solution thus being 1 million pounds.

The quality of ground water depends both on the substances dissolved in the water and on certain properties and characteristics that these substances impart to the water. Table 1 contains information on dissolved inorganic substances that normally occur in the largest concentrations and are most likely to affect water use. Table 2 lists other characteristics of water that are commonly reported in water analyses and that may affect water use. Dissolved constituents for which concentration limits have been established for drinking water are discussed in "Pollution of Ground Water."

\footnotetext{
${ }^{1}$ To put these units in possibly more understandable terms, $1 \mathrm{mg} / \mathrm{L}$ equals $1 \mathrm{oz}$ of a substance dissolved in 7,500 gal of water.
} 
Table 1. Natural inorganic constituents commonly dissolved in water that are most likely to affect use of the water

\begin{tabular}{|c|c|c|c|}
\hline Substance & Major natural sources & Effect on water use & $\begin{array}{l}\text { Concentrations of } \\
\text { significance }(\mathrm{mg} / \mathrm{L})^{1}\end{array}$ \\
\hline Bicarbonate $\left(\mathrm{HCO}_{3}\right)$ and carbonate $\left(\mathrm{CO}_{3}\right) \ldots$ & $\begin{array}{l}\text { Products of the solution of carbonate rocks, } \\
\text { mainly limestone }\left(\mathrm{CaCO}_{3}\right) \text { and dolomite } \\
\left(\mathrm{CaMgCO} \mathrm{CO}_{3}\right) \text {, by water containing } \\
\text { carbon dioxide. }\end{array}$ & $\begin{array}{l}\text { Control the capacity of water to neu- } \\
\text { tralize strong acids. Bicarbonates of } \\
\text { calcium and magnesium decompose in } \\
\text { steam boilers and water heaters to } \\
\text { form scale and release corrosive carbon } \\
\text { dioxide gas. In combination with } \\
\text { calcium and magnesium, cause car- } \\
\text { bonate hardness. }\end{array}$ & $150-200$ \\
\hline Calcium ( $\mathrm{Ca}$ ) and magnesium $(\mathrm{Mg}) \ldots$ & $\begin{array}{l}\text { Soils and rocks containing limestone, } \\
\text { dolomite, and gypsum }\left(\mathrm{CaSO}_{4}\right) \text {. } \\
\text { Small amounts from igneous } \\
\text { and metamorphic rocks. }\end{array}$ & $\begin{array}{l}\text { Principal cause of hardness and ofr } \\
\text { boiler scale and deposits in hot- } \\
\text { water heaters. }\end{array}$ & $25-50$ \\
\hline 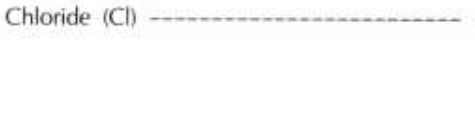 & $\begin{array}{l}\text { In inland areas, primarily from seawater } \\
\text { trapped in sediments at time of deposition; } \\
\text { sition; in coastal areas, from seawater in contact } \\
\text { with freshwater in productive aquifers. }\end{array}$ & $\begin{array}{l}\text { In large amounts, increases corrosiveness } \\
\text { of water and, in combination with } \\
\text { sodium, gives water a salty taste. }\end{array}$ & 250 \\
\hline Fluoride $(\mathrm{F}) \ldots$ & $\begin{array}{l}\text { Both sedimentary and igneous rocks. } \\
\text { Not widespread in occurrence. }\end{array}$ & $\begin{array}{l}\text { In certain concentrations, reduces tooth } \\
\text { decay; at higher concentrations, causes } \\
\text { mottling of tooth enamel. }\end{array}$ & $0.7-1.2^{2}$ \\
\hline Iron (Fe) and manganese $(\mathrm{Mn}) \ldots$ & $\begin{array}{l}\text { Iron present in most soils and rocks; } \\
\text { manganese less widely distributed. }\end{array}$ & $\begin{array}{l}\text { Stain laundry and are objectionable in } \\
\text { food processing, dyeing, bleaching, ice } \\
\text { manufacturing, brewing, and certain } \\
\text { other industrial processes. }\end{array}$ & $\mathrm{Fe}>0.3, \mathrm{Mn}>0.05$ \\
\hline Sodium (Na) _............................ & $\begin{array}{l}\text { Same as for chloride. In some sedimentary } \\
\text { rocks, a few hundred milligrams per } \\
\text { liter may occur in freshwater as a } \\
\text { result of exchange of dissolved calcium } \\
\text { and magnesium for sodium in the } \\
\text { aquifer materials. }\end{array}$ & $\begin{array}{l}\text { See chloride. In large concentrations, may } \\
\text { affect persons with cardiac difficulties, } \\
\text { hypertension, and certain other medical } \\
\text { conditions. Depending on the concen- } \\
\text { trations of calcium and magnesium also } \\
\text { present in the water, sodium may be } \\
\text { detrimental to certain irrigated crops. }\end{array}$ & $\begin{array}{l}69 \text { (irrigation), } \\
20-170 \text { (health) }\end{array}$ \\
\hline Sulfate $\left(\mathrm{SO}_{4}\right) \ldots$ & $\begin{array}{l}\text { Gypsum, pyrite (FeS), and other rocks } \\
\text { containing sulfur }(S) \text { compounds. }\end{array}$ & $\begin{array}{l}\text { In certain concentrations, gives water a } \\
\text { bitter taste and, at higher concentra- } \\
\text { tions, has a laxative effect. In } \\
\text { combination with calcium, forms a hard } \\
\text { calcium carbonate scale in steam boilers. }\end{array}$ & $\begin{array}{l}300-400 \text { (taste), } \\
600-1,000 \text { (laxative) }\end{array}$ \\
\hline
\end{tabular}

Table 2. Characteristics of water that affect water quality

\begin{tabular}{|c|c|c|c|}
\hline Characteristic & Principal cause & Significance & Remarks \\
\hline Hardness -........................ & $\begin{array}{l}\text { Calcium and magnesium } \\
\text { dissolved in the water. }\end{array}$ & $\begin{array}{l}\text { Calcium and magnesium combine with soap to form an } \\
\text { insoluble precipitate (curd) and thus hamper the } \\
\text { formation of a lather. Hardness also affects the suitability } \\
\text { of water for use in the textile and paper industries and } \\
\text { certain others and in steam boilers and water heaters. }\end{array}$ & $\begin{array}{l}\text { USGS classification of hardness } \\
\left(\mathrm{mg} / \mathrm{L} \text { as } \mathrm{CaCO}_{3}\right) \text { : } \\
0-60 \text { : Soft } \\
\text { 61-120: Moderately hard } \\
\text { 121-180: Hard } \\
\text { More than 180: Very hard }\end{array}$ \\
\hline $\mathrm{pH}$ (or hydrogen-ion activity) -.... & $\begin{array}{l}\text { Dissociation of water } \\
\text { molecules and of acids } \\
\text { and bases dissolved in } \\
\text { water. }\end{array}$ & $\begin{array}{l}\text { The } \mathrm{pH} \text { of water is a measure of its reactive characteristics. } \\
\text { Low values of } \mathrm{pH} \text {, particularly below } \mathrm{pH} 4 \text {, indicate a } \\
\text { corrosive water that will tend to dissolve metals and } \\
\text { other substances that it contacts. High values of } \mathrm{pH} \text {, } \\
\text { particularly above } \mathrm{pH} 8.5 \text {, indicate an alkaline water } \\
\text { that, on heating, will tend to form scale. The } \mathrm{pH} \\
\text { significantly affects the treatment and use of water. }\end{array}$ & $\begin{array}{l}\mathrm{pH} \text { values: less than } 7 \text {, water is acidic; } \\
\text { value of } 7 \text {, water is neutral; } \\
\text { more than } 7 \text {, water is basic. }\end{array}$ \\
\hline Specific electrical conductance --- S & $\begin{array}{l}\text { Substances that form ions } \\
\text { when dissolved in } \\
\text { water. }\end{array}$ & $\begin{array}{l}\text { Most substances dissolved in water dissociate into ions that } \\
\text { can conduct an electrical current. Consequently, specific } \\
\text { electrical conductance is a valuable indicator of the } \\
\text { amount of material dissolved in water. The langer the } \\
\text { conductance, the more mineralized the water. }\end{array}$ & $\begin{array}{l}\text { Conductance values indicate the elec- } \\
\text { trical conductivity, in micromhos, } \\
\text { of } 1 \mathrm{~cm}^{3} \text { of water at a temper- } \\
\text { ature of } 25^{\circ} \mathrm{C} \text {. }\end{array}$ \\
\hline Total dissolved solids ............ & $\begin{array}{l}\text { Mineral substances } \\
\text { dissolved in water. }\end{array}$ & $\begin{array}{l}\text { Total dissolved solids is a measure of the total amount } \\
\text { of minerals dissolved in water and is, therefore, } \\
\text { a very useful parameter in the evaluation } \\
\text { of water quality. Water containing less than } \\
500 \text { mg/L is preferred for domestic use and } \\
\text { for many industrial processes. }\end{array}$ & $\begin{array}{l}\text { USGS classification of water based } \\
\text { on dissolved solids (mg/L): } \\
\text { Less than 1,000: Fresh } \\
\text { 1,000-3,000: Slightly saline } \\
\text { 3,000-10,000: Moderately saline } \\
\text { 10,000-35,000: Very saline } \\
\text { More than 35,000: Briny }\end{array}$ \\
\hline
\end{tabular}


Pollution of ground water is receiving increased attention from both Federal and State regulatory agencies and from water users. As a result, pollution has been found to be much more widespread than we had believed only a few years ago. This attention has also resulted in widespread recognition of the facts that polluted ground water may pose a serious threat to health that is often not apparent to those affected and that purification of polluted ground-water systems may require centuries or the expenditure of huge sums of money. These facts alone make it imperative that the pollution of ground water by harmful substances absolutely be avoided to the maximum possible extent.

Pollution of ground water, as it is used in this discussion, refers to any deterioration in the quality of the water resulting from the activities of man. This definition includes saltwater encroachment into freshwater-bearing aquifers resulting from the artificial lowering of ground-water heads. That topic, however, is covered in a separate discussion. (See "Saltwater Encroachment." )

Most pollution of ground water results from the disposal of wastes on the land surface, in shallow excavations including septic tanks, or through deep wells and mines; the use of fertilizers and other agricultural chemicals; leaks in sewers, storage tanks, and pipelines; and animal feedlots. The magnitude of any pollution problem depends on the size of the area affected and the amount of the pollutant involved, the solubility, toxicity, and density of the pollutant, the mineral composition and hydraulic characteristics of the soils and rocks through which the pollutant moves, and the effect or potential effect on ground-water use.

Affected areas range in size from point sources, such as septic tanks, to large urban areas having leaky sewer systems and numerous municipal and industrial waste-disposal sites. Nearly all substances are soluble to some extent in water, and many chemical wastes are highly toxic even in minute concentrations. For example, table 1 lists the maximum concentrations of inorganic substances permitted in drinking-water supplies. Limits have also been established by the Environmental Protection Agency for radioactive and certain organic substances.

The density of a liquid substance-that is, the weight per unit volume of the substance relative to that of wateraffects its underground movement. Densities range from those of petroleum products that are less dense than water to brines and other substances that are denser than water. Substances less dense than water tend to accumulate at the top of
URBAN AREAS

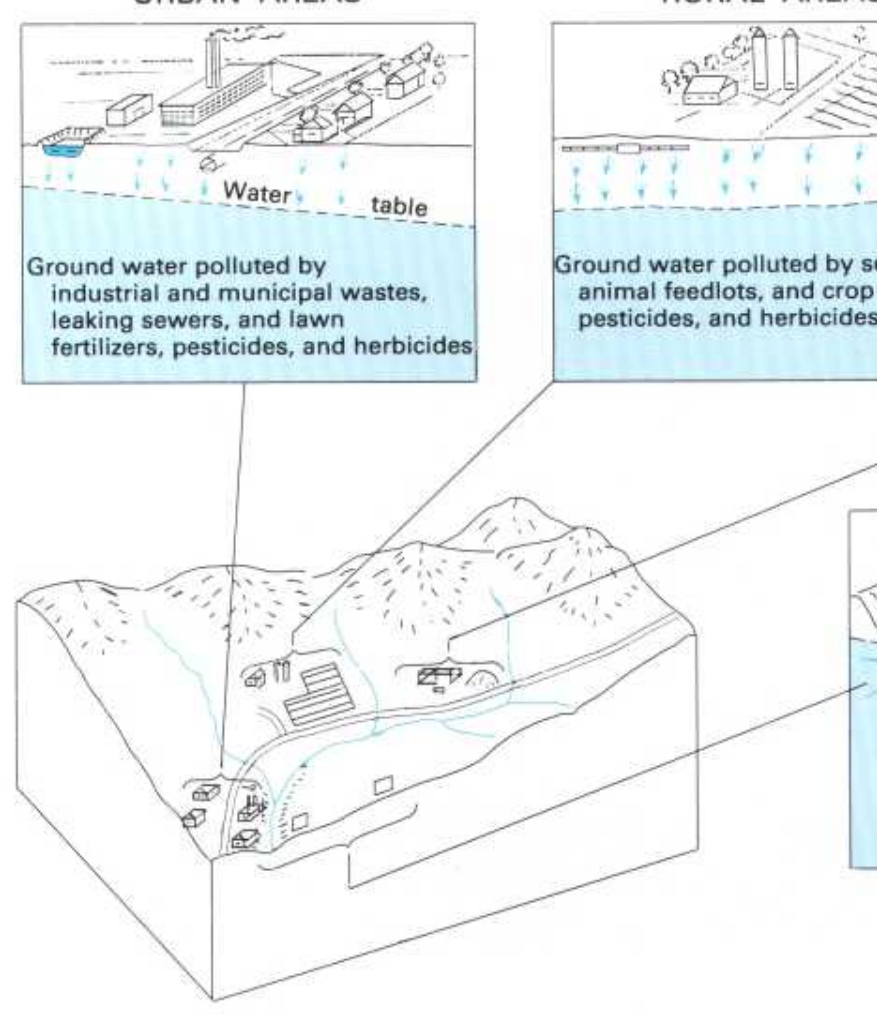

DENSITY EFFECTS

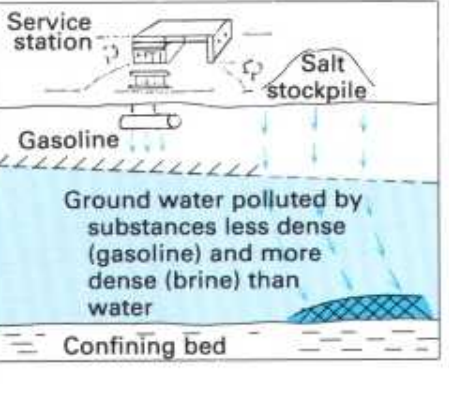

\section{DISTANCE EFFECTS}

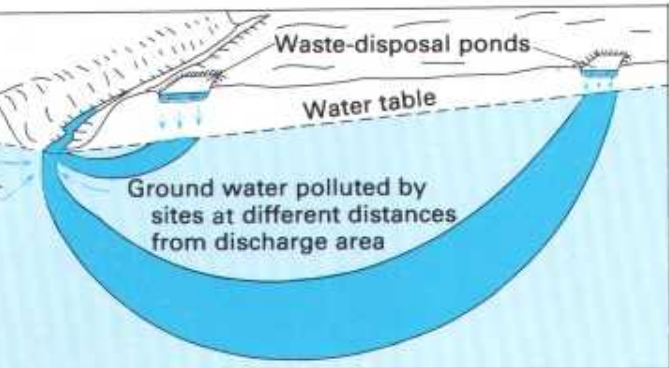

GROUND-WATER POLLUTION OCCURS IN BOTH URBAN AND RURAL AREAS AND IS AFFECTED BY DIFFERENCES IN CHEMICAL COMPOSITION, BIOLOGICAL AND CHEMICAL REACTIONS, DENSITY, AND DISTANCE FROM DISCHARGE AREAS 
the saturated zone; if, like petroleum, they are immiscible, they will tend to spread in all directions as a thin film. Substances denser than water tend to move downward through the saturated zone to the first extensive confining bed.

The mineral composition and physical characteristics of soils and rocks through which pollutants move may affect the pollutants in several ways. If a pollutant enters the ground at a "point," it will be dispersed longitudinally and laterally in granular materials so that its concentration will be reduced in the direction of movement. (See "Saturated Flow and Dispersion.") Organic substances and other biodegradable materials tend to be broken down both by oxidation and by bacterial action in the unsaturated zone. Certain earth materials, especially clays and organic matter, may also absorb trace metals and certain complex organic pollutants and thereby reduce their concentration as they move through the underground environment.

The hydraulic characteristics of the soils and rocks determine the path taken by and the rate of movement of pollutants. Substances dissolved in water move with the water except to the extent that they are tied up or delayed by adsorption. Thus, the movement of pollutants tends to be through the most permeable zones; the farther their point of origin from a ground-water discharge area, the deeper they penetrate into the ground-water system and the larger the area ultimately affected.

The factors related to the movement of pollutants discussed in the preceding paragraphs must be carefully considered in the selection of waste-disposal sites, animal feedlots, and sites for other operations that may cause ground-water pollution. With these factors in mind, it is obvious that significant ground-water pollution can be avoided only if wastedisposal sites are selected in such a way that:

1. Significant thicknesses of unsaturated material containing clay and (or) organic material are present.

2. Areas are as close as possible to places of natural groundwater discharge.

3. Overland runoff is excluded, and surface infiltration is held to the minimum possible amount.

Table 1. Maximum concentrations of inorganic constituents allowed in drinking water

[Data from U.S. Environmental Protection Agency (1977)]

\begin{tabular}{lc}
\hline Constituents & $\begin{array}{c}\text { Concentration } \\
(\mathrm{mg} / \mathrm{L})\end{array}$ \\
\hline Arsenic & 0.05 \\
Barium - & 1. \\
Cadmium & .010 \\
Chromium & .05 \\
Lead - & .05 \\
Mercury & .002 \\
Nitrate (as N) & 10. \\
Selenium - & .01 \\
Silver & .05 \\
\hline
\end{tabular}

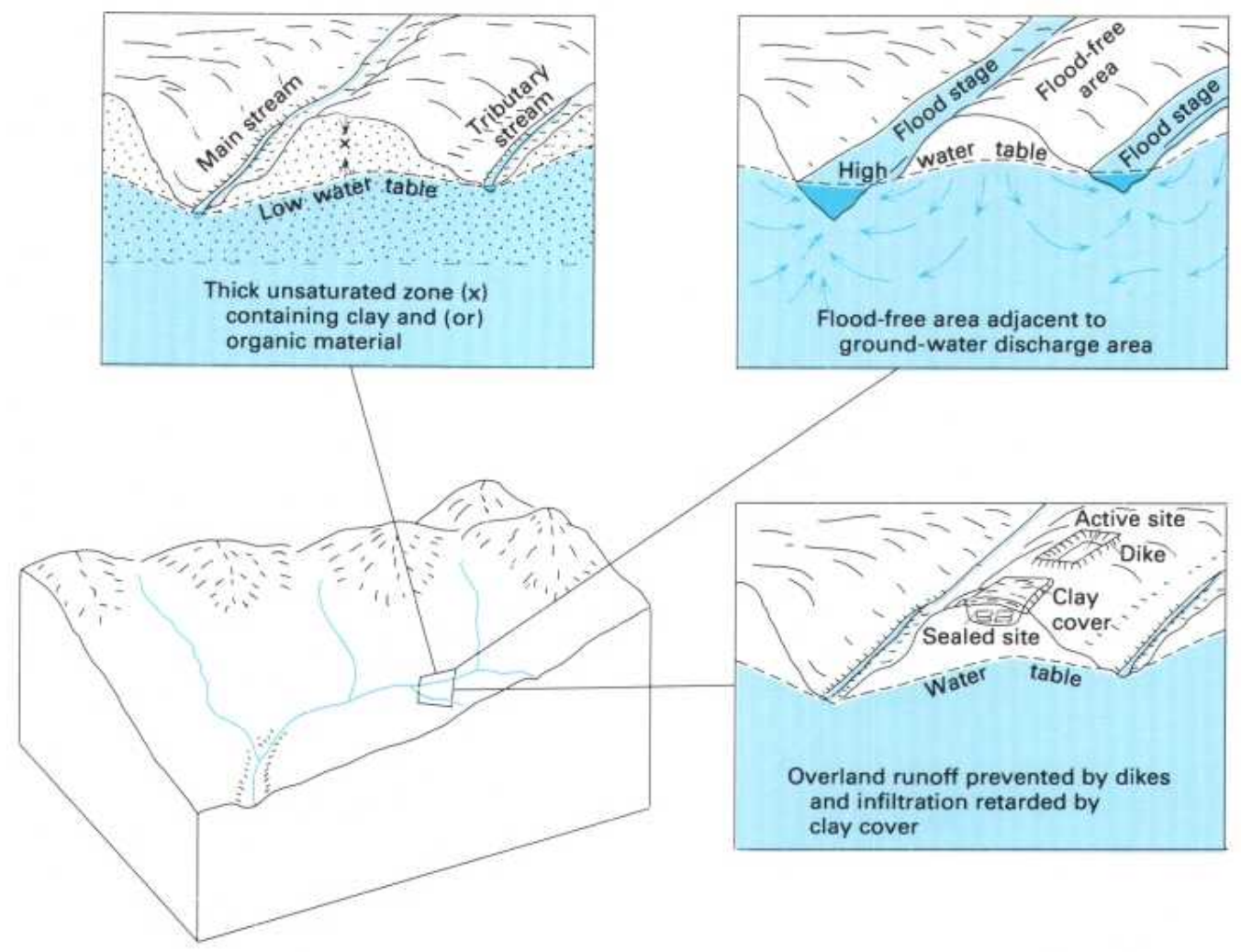

SELECTION OF WASTE-DISPOSAL SITES INVOLVES CONSIDERATION OF THE UNSATURATED ZONE, FLOOD DANGER, GROUND-WATER DISCHARGE, OVERLAND RUNOFF, AND INFILTRATION 
In coastal areas, fresh ground water derived from precipitation on the land comes in contact with and discharges into the sea or into estuaries containing brackish water. The relation between the freshwater and the seawater, or brackish water, is controlled primarily by the differences in their densities.

The density of a substance is its mass per unit volume; thus, the density of water is affected by the amount of minerals, such as common salt $(\mathrm{NaCl})$, that the water contains in solution. In metric units, the density of freshwater is about $1 \mathrm{gm}$ $\mathrm{cm}^{-3}$, and the density of seawater is about $1.025 \mathrm{gm} \mathrm{cm}^{-3}$. Thus, freshwater, being less dense than seawater, tends to override or float on seawater.

On islands, such as the Outer Banks of North Carolina, precipitation forms a freshwater lens that "floats" on the underlying saltwater (1). The higher the water table stands above sea level, the thicker the freshwater lens. This relation-between the height of the water table and the thickness of the freshwater lens was discovered, independently, by a Dutchman, Badon Ghyben, and a German, B. Herzberg, and is referred to as the Chyben-Herzberg relationship. This relation, expressed as an equation, is

$$
h_{s}=\frac{\rho_{f}}{\rho_{s}-\rho_{f}}\left(h_{f}\right)
$$

where $h_{s}$ is the depth of freshwater below sea level, $\rho_{f}$ is the density of freshwater, $\rho_{s}$ is the density of seawater, and $h_{f}$ is the height of the water table above sea level.
On the basis of equation 1 and the differences between the densities of freshwater and seawater, the freshwater zone should extend to a depth below sea level $\left(h_{s}\right)$ equal to 40 times the height of the water table above sea level $\left(h_{f}\right)$. The GhybenHerzberg relation applies strictly, however, only to a homogenous and isotropic aquifer in which the freshwater is static and is in contact with a tideless sea or body of brackish water.

Tides cause saltwater to alternately invade and retreat from the freshwater zone, the result being a zone of diffusion across which the salinity changes from that of freshwater to that of seawater (1). A part of the seawater that invades the freshwater zone is entrained in the freshwater and is flushed back to the sea by the freshwater as it moves to the sea to discharge.

Because both the seawater and the freshwater are in motion (not static), the thickness of the freshwater zone in a homogenous and isotropic aquifer is greater than that predicted by the Ghyben-Herzberg equation. On the other hand, in a stratified aquifer (and nearly all aquifers are stratified), the thickness of the freshwater lens is less than that predicted because of the head loss incurred as the freshwater moves across the least permeable beds.

When freshwater heads are lowered by withdrawals through wells, the freshwater-saltwater contact migrates toward the point of withdrawals until a new balance is established (2). The movement of saltwater into zones previously occupied by freshwater is referred to as saltwater encroachment.

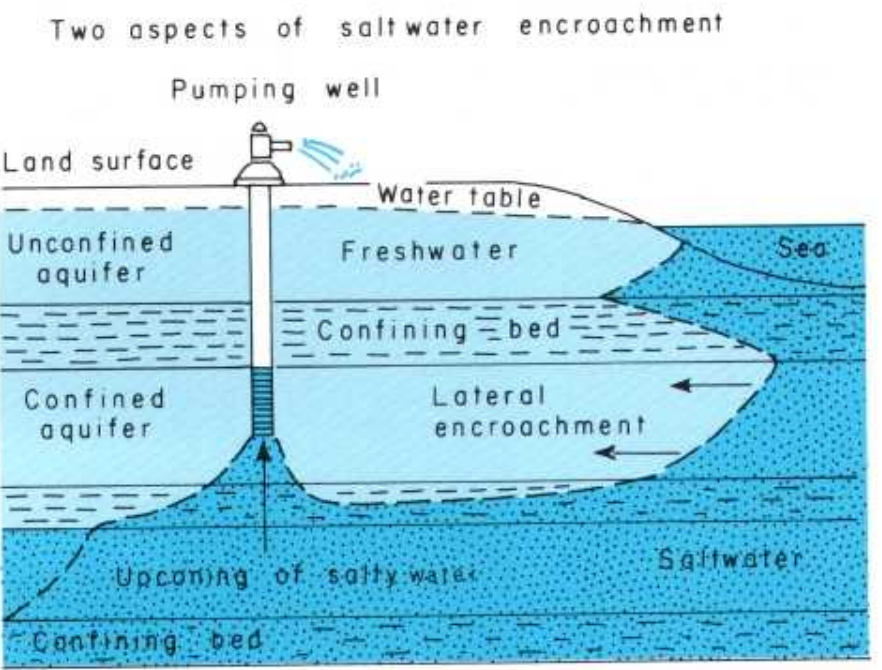

(2) 


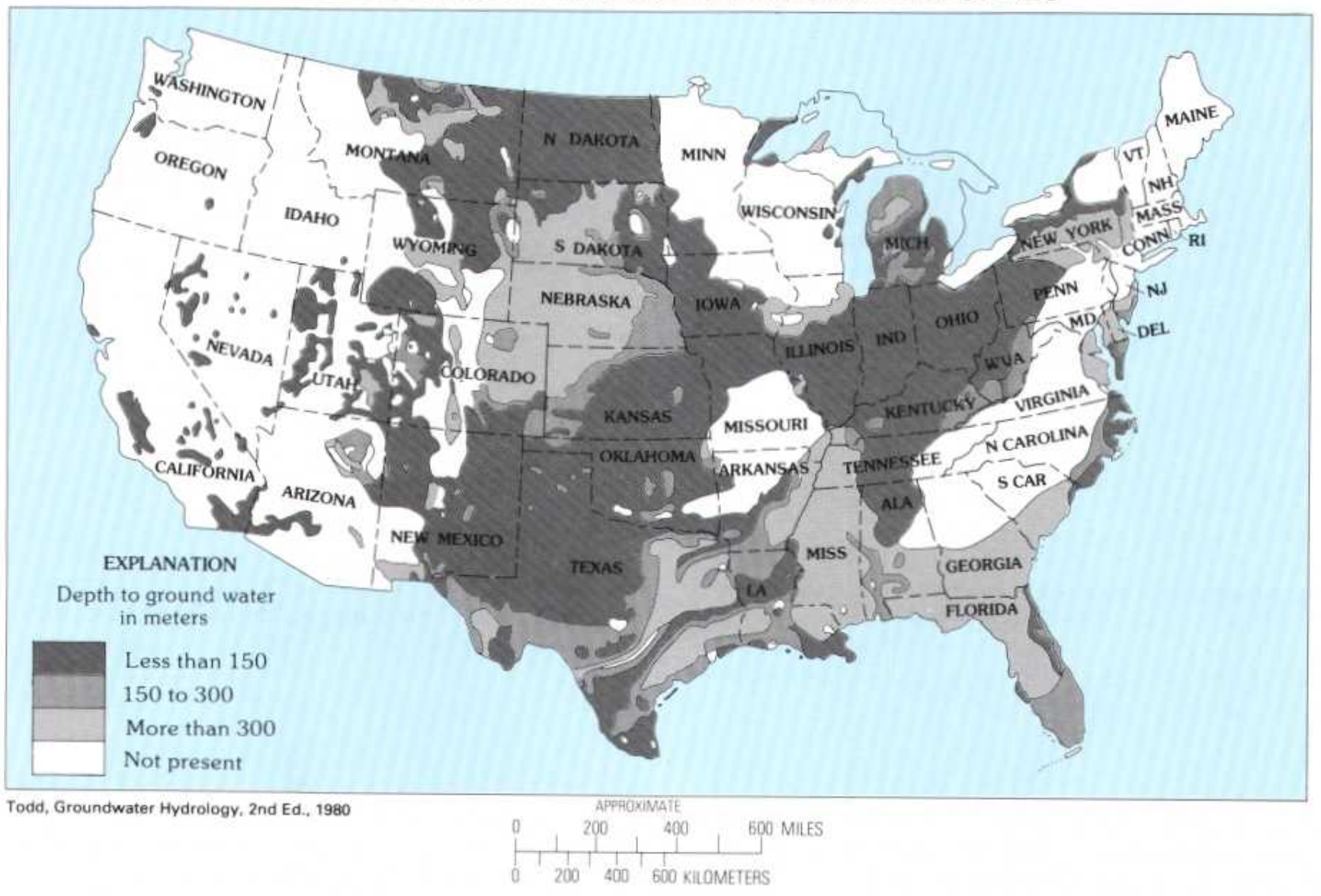

(3)

Saltwater encroachment is a serious problem in some coastal areas. Upconing of salty water beneath pumping wells is a more imminent problem than lateral encroachment in most areas. One reason is that lateral encroachment must displace a volume of freshwater much larger than that displaced by upconing. Another reason is that approximately two-thirds of the United States is underlain by aquifers that yield water containing more than $1,000 \mathrm{mg} / \mathrm{L}$ of total dissolved solids (3). (See table 2 in "Quality of Ground Water.") In most places, these aquifers are overlain by other aquifers that con- tain freshwater and that serve as sources of water supply. However, where supply wells are drilled too deeply or are pumped at too large a rate, upconing of the mineralized (salty) water may occur.

In the design of supply wells in areas underlain by or adjacent to salty water, consideration must be given to the possibility of saltwater encroachment. This consideration may involve selection of shallow aquifers or small pumping rates to avoid upconing or involve moving wells to more inland locations to avoid lateral encroachment. 


\section{TEMPERATURE OF GROUND WATER}

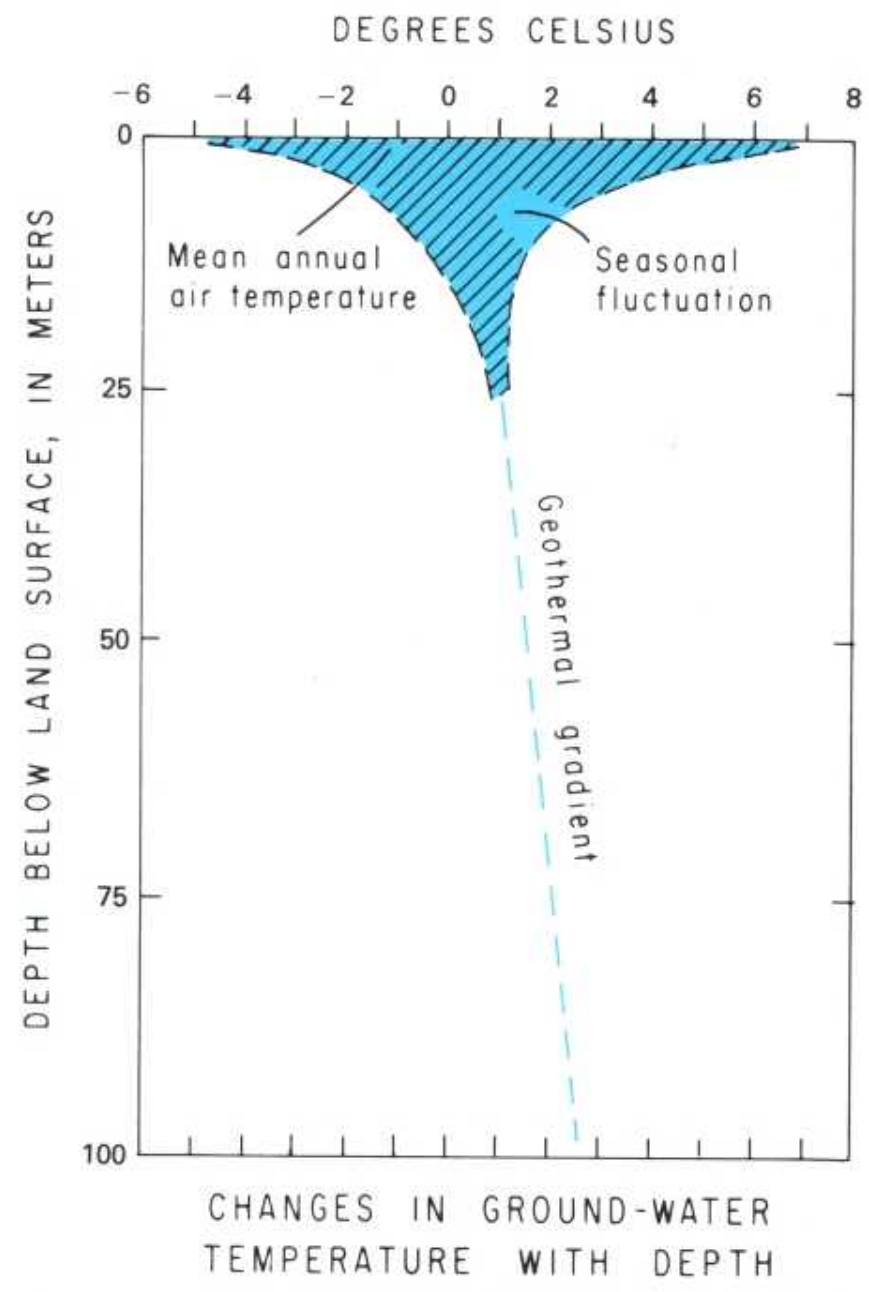

(1)
The temperature of ground water is one of its most useful characteristics. Ground water has been used for many years on Long Island, N.Y., and at other places as a heat-exchange medium for air-conditioning systems. As a result of recent increases in energy costs, ground water is also now becoming increasingly important as a source of heat for "heat pumps."

The temperature of ground water responds to seasonal variations in the heat received at the Earth's surface from the Sun and by movement of heat from the Earth's interior. The seasonal movement of heat into and out of the upper layers of the Earth's crust causes a seasonal fluctuation in ground-water temperatures to a depth of 10 to $25 \mathrm{~m}$ (1). The fluctuation is greatest near the surface, amounting to $5^{\circ}$ to $10^{\circ} \mathrm{C}$ at depths of a few to several meters. In the zone affected by seasonal fluctuations, the mean annual ground-water temperature is $1^{\circ}$ to $2^{\circ} \mathrm{C}$ higher than the mean annual air temperature (1). Consequently, a map showing the mean annual temperature of shallow ground water can be prepared on the basis of mean annual air temperature (sketch 2, based on a map showing mean annual air temperature prepared by the National Weather Service).

Movement of heat from the Earth's interior causes groundwater temperatures to increase with depth (1). This increase is referred to as the geothermal gradient and ranges from about $1.8^{\circ} \mathrm{C}$ per $100 \mathrm{~m}$ in areas underlain by thick sections of sedimentary rocks to about $3.6^{\circ} \mathrm{C}$ per $100 \mathrm{~m}$ in areas of recent volcanic activity. The effect of the geothermal gradient is not readily apparent in the zone affected by seasonal temperature fluctuations.

Movement of ground water causes a distortion in isotherms (lines depicting equal temperatures). This effect is most noticeable where ground-water withdrawal induces a movement of water from a stream into an aquifer. The distortion in ground-water temperature is most pronounced in the more permeable zones of the aquifer. 
APPROXIMATE TEMPERATURE OF GROUND WATER, IN DEGREES CELSIUS, IN THE CONTERMINOUS UNITED STATES AT DEPTHS OF 10 TO $25 \mathrm{M}$

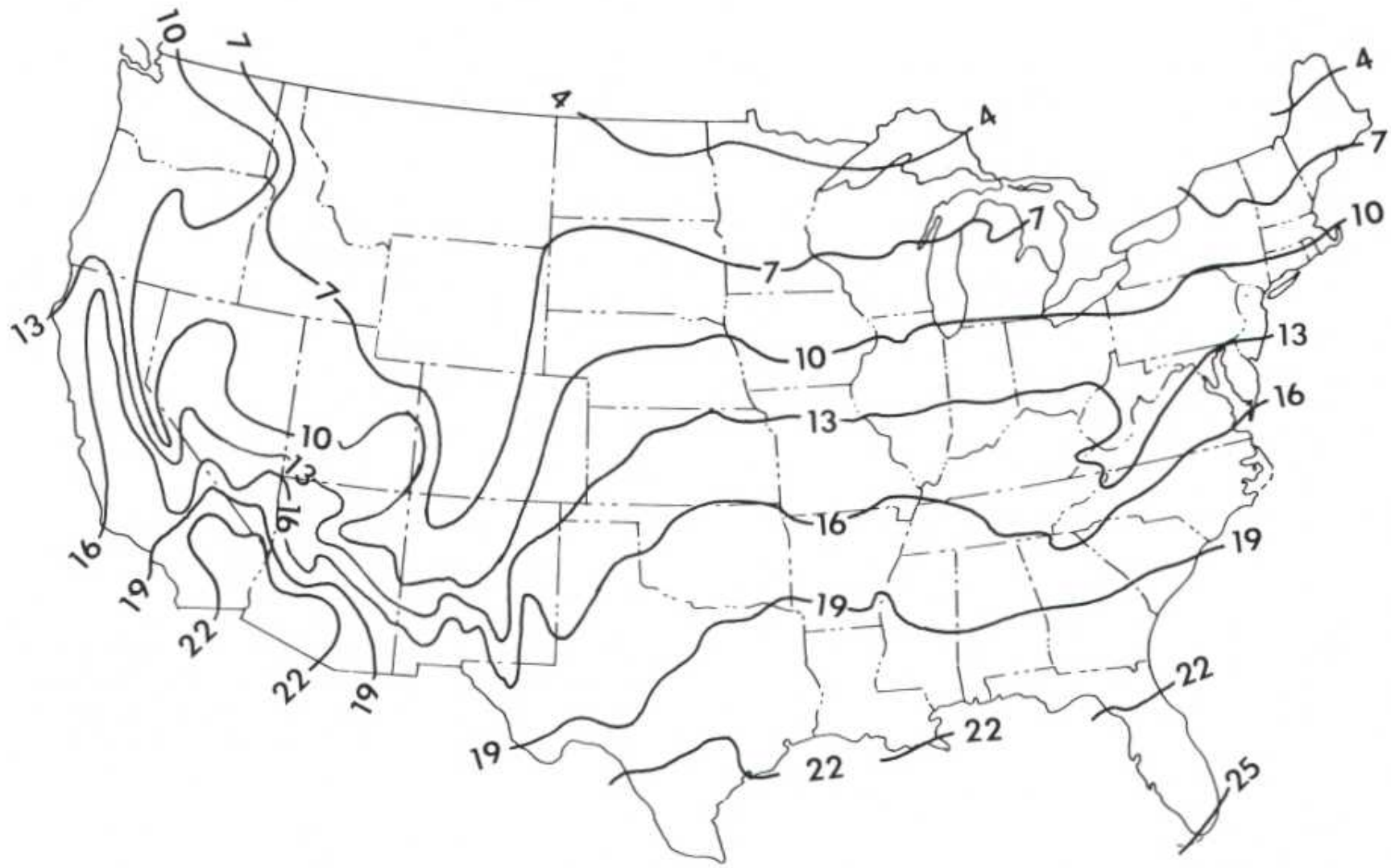

(2) 


\section{MEASUREMENTS OF WATER LEVELS AND PUMPING RATES}

METHODS FOR MEASURING THE DEPTH TO WATER LEVEL IN WELLS

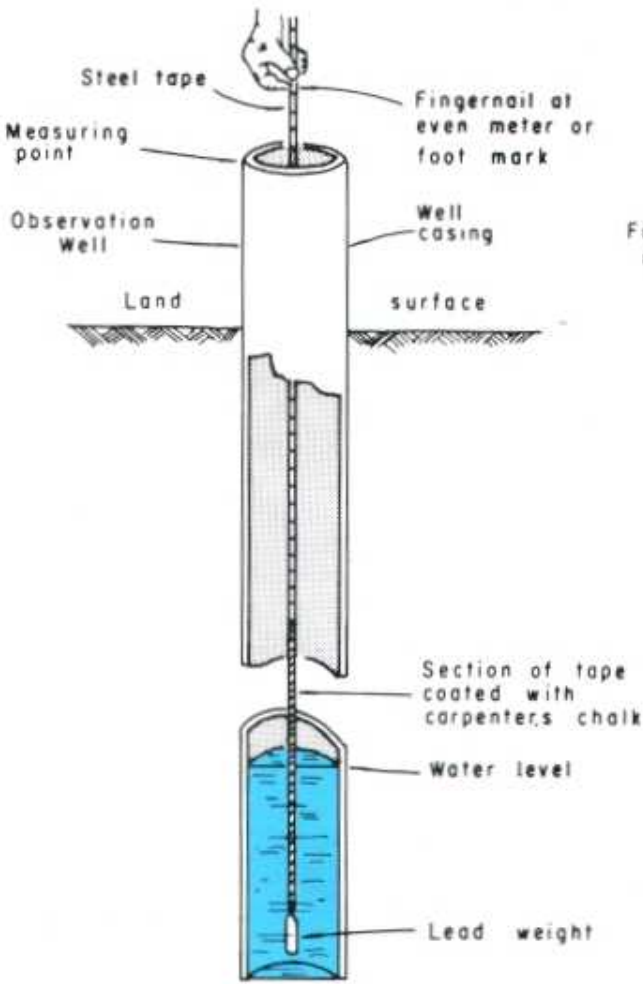

(1)
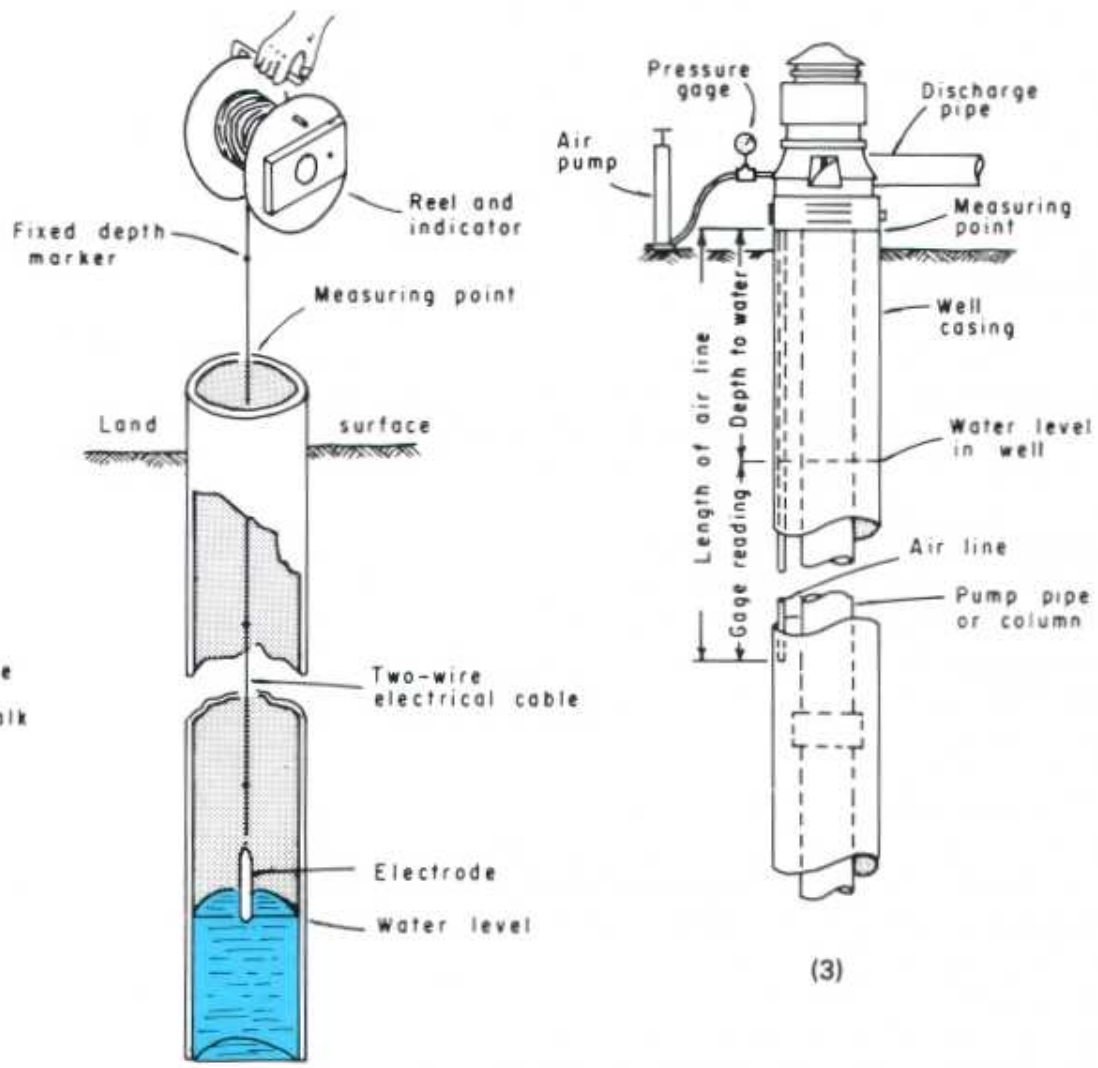

(3)
Each supply well, regardless of whether it is used for domestic, irrigation, industrial, or public-supply needs, should be provided with a means for measuring the position of the water level in the well. Public-supply and industrial wells should also be provided with a means for measuring the pumping rate. The use of water-level and pumping-rate measurements is discussed in "Supply-Well Problems-Decline in Yield."

The first step in measuring the position of the water level is to identify (and describe) a fixed point-that is, a measuring point-to which all measurements will be referred. This point is usually the top of the casing, well cap, or access port. The three most common methods used in measuring the depth to water in wells are wetted tape, electric tape, and air line.

The wetted-tape method is probably the most common and most accurate of the three methods (1). This method utilizes a graduated steel tape with a weight attached to its end. The graduations on the lower meter ( 3 to $4 \mathrm{ft}$ ) of the tape are coated with blue carpenter's chalk, and the tape is lowered into the well until the lower part of the tape is submerged and an even meter (or foot) mark is at the measuring point. The tape is then quickly withdrawn, and the value held at the measuring point and the amount of tape that was submerged are entered on a record form. The amount of tape that was submerged is obvious from the change in color of the chalk coating. The depth to the water level below the measuring point is determined by subtracting the length of wet tape from the total length of tape that was lowered into the well.

The electric-tape method involves an ammeter connected across a pair of insulated wires whose exposed ends are separated by an air gap in an electrode and containing, in the circuit, a source of power such as flashlight batteries (2). When the electrode contacts the water surface, a current flows through the system circuit and is indicated by a deflection of 
the ammeter needle. The insulated wires are marked at 1-m (or $5 \mathrm{ft}$ ) intervals. The nail of the index finger is placed on the insulated wires at the measuring point when the ammeter indicates that the circuit is closed. A steel tape or carpenter's rule is used to measure the distance from the point indicated by the fingernail to the next highest meter (or $5 \mathrm{ft}$ ) mark. This distance is subtracted from the value of the mark to determine the depth to water. One difference between the wettedtape method and the electric-tape method is that, in the wetted-tape method, the subtraction involves the length of the submerged tape, whereas, in the electric-tape method, the subtraction involves the distance between the measuring point and the next highest mark.

The air-line method is generally used only in wells on which pumps are installed. This method involves the installation of a small-diameter pipe or tube (the air line) from the top of the well to a point about $3 \mathrm{~m}$ (10 ft) below the lowest anticipated position of the water level during extended pumping periods (3). The water level in this pipe is the same as that in the well. To determine the depth to water, an air pump and a pressure gage are attached to the top of the air line. Air is pumped into the line to force the water out of the lower end. As the water level in the air line is depressed, the pressure indicated by the gage increases. When all the water has been forced out of the line, the pressure-gage reading stabilizes and indicates the length of the water column originally in the air line. If the pressure-gage reading is subtracted from the length of the air line below the measuring point, which was carefully determined when the air line was installed, the remainder is the depth to water below the measuring point.

The preceding discussion has covered the measurement of water levels in nonflowing wells-that is, in wells in which the water level is below the measuring point. In many coastal areas and valleys underlain by confined aquifers, water levels in wells will stand at some height above the land surface. These areas are referred to as areas of artesian flow, and the measurement of water levels in wells, where casings have not been extended above the static level, may pose problems. If the well is equipped with a valve and a threaded fitting, the height of the water level can be determined by attaching the appropriate pipe connection and a pressure gage or transparent plastic tube.

Measuring the water level of flowing wells not equipped with a valve or a threaded fitting requires the use of soil-test plugs or some other device to control the flow. The position of the static water level above the measuring point is determined either with a pressure gage or with a plastic tube (4).

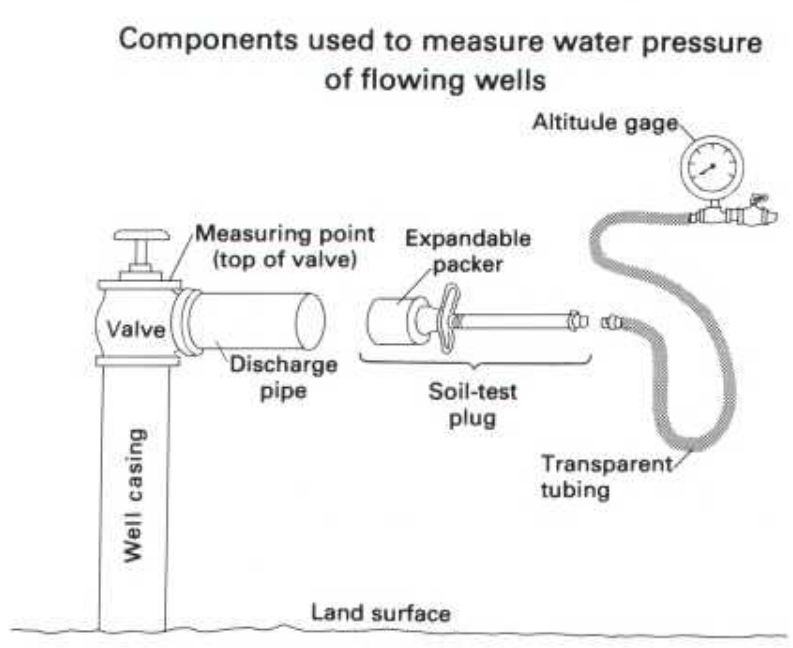

Components installed for a pressure measurement

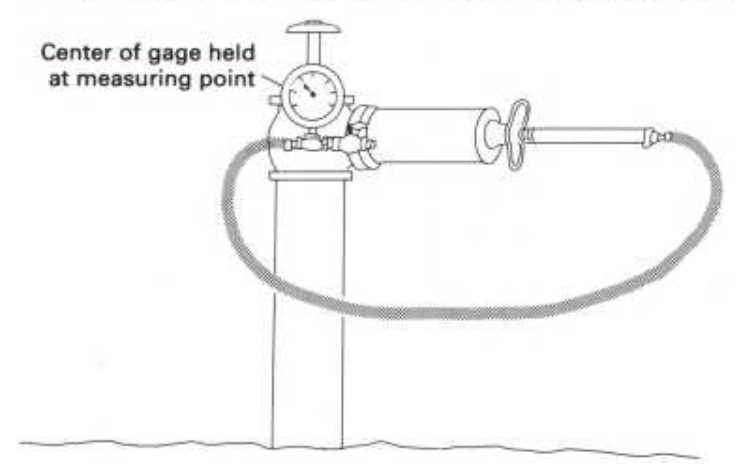

(4)

The measurement of the pumping rates of supply wells requires the installation of a flowmeter in the pump-discharge line. Either of two types of meters may be used, depending on the pumping rate. Up to a rate of about $1 \mathrm{~m}^{3} \mathrm{~min}^{-1}$ ( $\left.250 \mathrm{gal} \mathrm{min}^{-1}\right)$, an "active-element" -type meter may be used. These meters utilize either a propeller or a disk that is turned by the moving water. For larger pumping rates, meters that utilize a constriction in the discharge pipe are commonly used. These include venturi meters, flow nozzles, and orifices.

Flowmeters have dials that show either the total amount of water that has passed the meter or the rate at which the water is passing. With the first (the totalizing dial), the rate of discharge is determined by using a stopwatch to time the period for a certain volume of water to be pumped. 


\title{
PROTECTION OF SUPPLY WELLS
}

\author{
TYPICAL REQUIREMENTS FOR SUPPLY WELLS
}

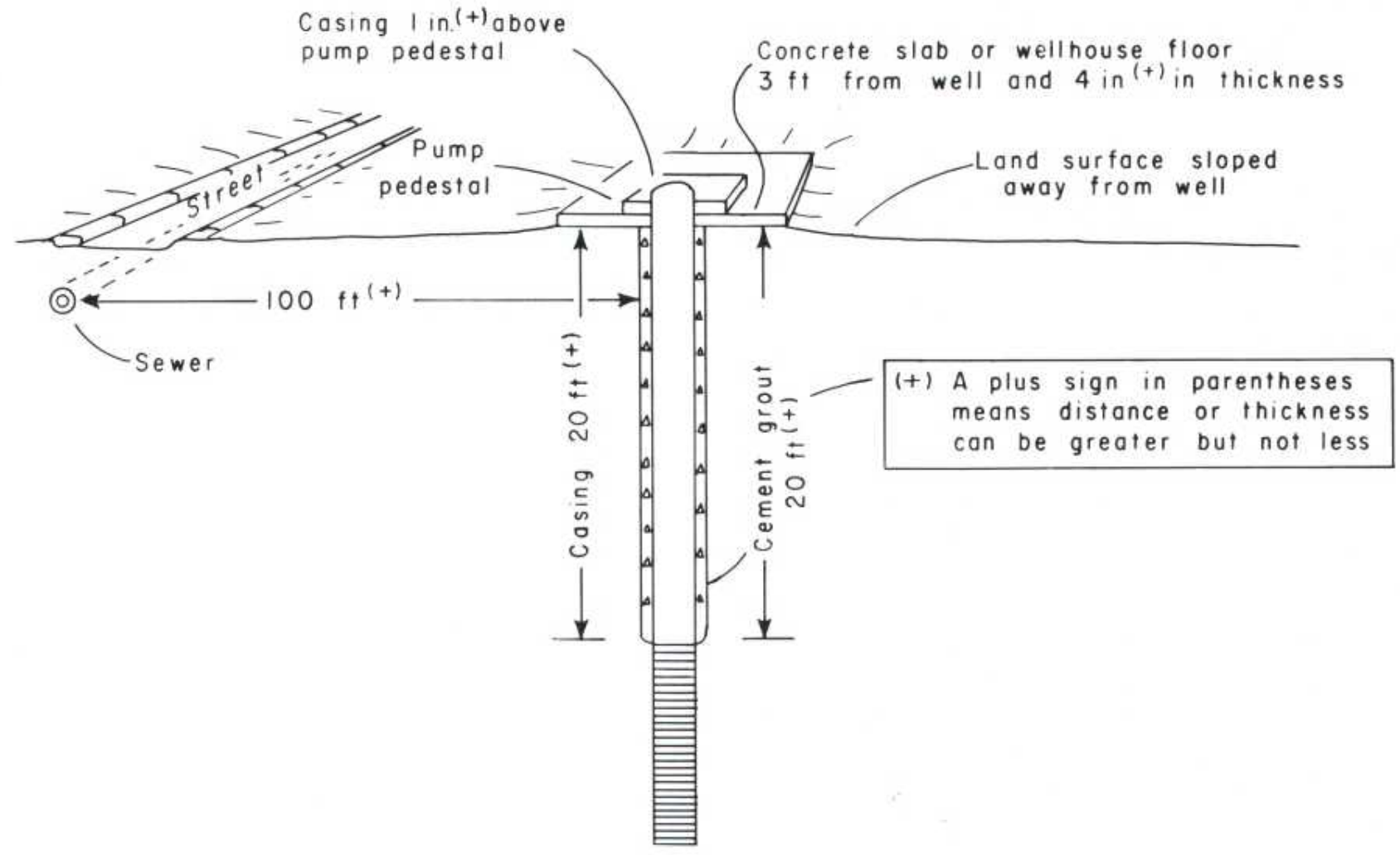

Most, if not all, States have laws related to the location and construction of public-supply wells. These laws and the rules and regulations developed for their administration and enforcement are concerned, among other things, with protecting supply wells from pollution. Pollution of the environment results from man's activities, and, consequently, except where deep wells or mines are used for waste disposal, it primarily affects the land surface, the soil zone, and the upper part of the saturated (ground water) zone. Therefore, the protection of supply wells includes avoiding areas that are presently polluted and sealing the wells in such a way as to prevent pollution in the future.

Fortunately, most ground-water pollution at the present time affects only relatively small areas that can be readily avoided in the selection of well sites. Among the areas in which at least shallow ground-water pollution should be expected are:

1. Industrial districts that include chemical, metalworking, petroleum-refining, and other industries that involve fluids other than cooling water.

2. Residential areas in which domestic wastes are disposed of through septic tanks and cesspools.
3. Animal feedlots and other areas in which large numbers of animals are kept in close confinement.

4. Liquid and solid waste disposal sites, including sanitary landfills, "evaporation ponds," sewage lagoons, and sites used for the disposal of sewage-plant effluent and solid wastes.

5. Chemical stockpiles, including those for salt used to deice streets and highways and for other chemical substances soluble in water.

In the selection of a well site, areas that should be avoided include not only those listed but also the zones surrounding them that may be polluted by movement of wastes in response to both the natural hydraulic gradient and the artificial gradient that will be developed by the supply well.

Rules and regulations intended to prevent future pollution include provision of "exclusion" zones around supply wells, requirements for casing and for sealing of the annular space, and sealing of the upper end of the wells.

Many State regulations require that supply wells be located at least $100 \mathrm{ft}(30 \mathrm{~m})$ from any sources or potential sources of pollution. In the case of public-supply wells, the well owner must either own or control the land within $100 \mathrm{ft}(30 \mathrm{~m})$ of the 
well. In some States, a public-supply well may be located as close as $50 \mathrm{ft}(15 \mathrm{~m})$ to a sewer if the joints in the sewerline meet water-main standards.

Some State regulations require that all supply wells be cased to a depth of at least $20 \mathrm{ft}(6 \mathrm{~m})$ and that the annular space between the land surface and a depth of $20 \mathrm{ft}(6 \mathrm{~m})$ be completely filled with cement grout. The casing of supply wells drawing water from fractured bedrock must be seated and sealed into the top of the rock.

Most regulations require that the casing of all supply wells terminate above land surface and that the land surface at the site be graded or sloped so that surface water is diverted away from the well. Many States also require that public-supply wells have a continuous-bond concrete slab or concrete wellhouse floor at least $4 \mathrm{in}$. $(10 \mathrm{~cm})$ thick and extending at least $3 \mathrm{ft}(1 \mathrm{~m})$ horizontally around the outside of the well casing. The top of the well casing must project not less than 6 in. $(15 \mathrm{~cm})$ above the concrete slab or wellhouse floor. The top of the well casing must also project at least 1 in. $(2.5 \mathrm{~cm})$ above the pump pedestal. The top of the well casing must be sealed watertight except for a vent pipe or vent tube having a downward-diverted screened opening.
The regulations cited above provide, at best, only minimal protection for supply wells. There are numerous situations in which both the size of the exclusion zone and the depth of casing are inadequate. Relative to the radius of the exclusion zone, there are no arbitrary limits, except the physical boundaries of an aquifer, past which ground water cannot move. Relative to the minimum required casing, there are no vertical limits, except for the impermeable base of the ground-water system, past which polluted water cannot move.

On the other hand, there are geologic and hydrologic situations in which these regulations may be unnecessarily restrictive. An example is pollution in an unconfined aquifer down the hydraulic gradient from a supply well drawing from a deep confined aquifer overlain by a nonleaky confining bed.

Because of these factors, it is essential that officials involved in regulating the location and construction of supply wells be adequately trained in the fields of ground-water geology and hydrology so that they can protect the public health on the basis of scientific knowledge and technical judgment rather than that of blind application of arbitrary regulations. 


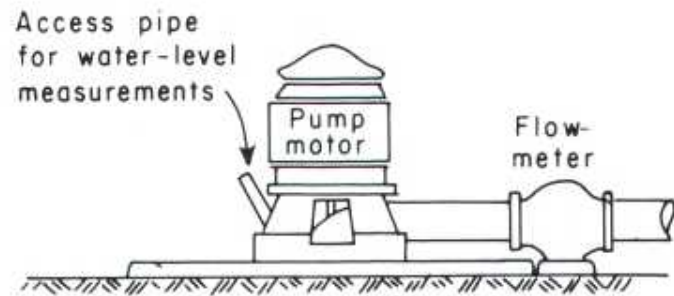

(1)

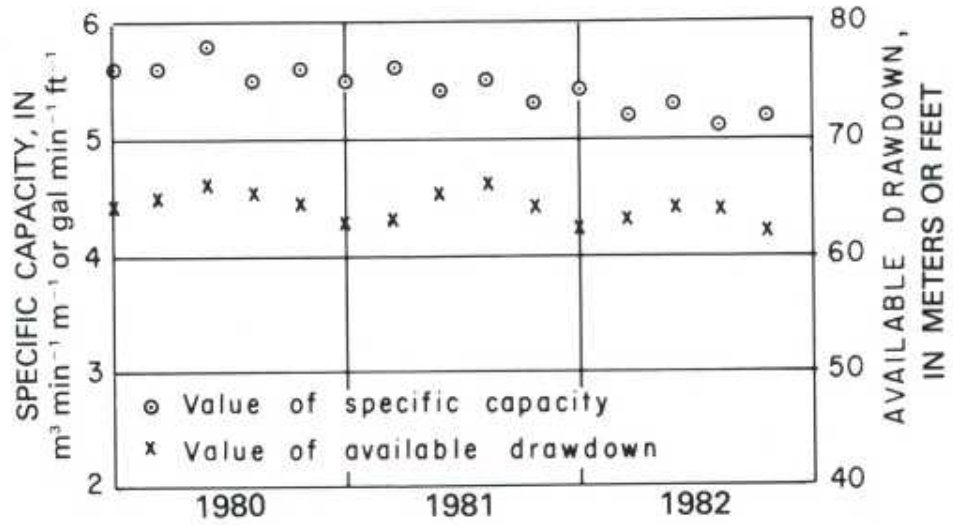

(2)
The yield of any water-supply well depends on three elements: the aquifer, the well, and the pump. A decline in yield is due to a change in one of these elements, and correction of the problem depends on identification of the element that is involved. This identification in many cases can be made only if data are available on the depth to the water level in the well and the pumping rate. Inability to identify reasons for a decline in yield frequently results in discontinuing the use of ground water and developing more expensive supplies from surface-water sources.

The depth to the water level in a well equipped with a pump may be determined by using a steel tape, an electric tape, or an air line and pressure gage. The pumping rate of a supply well can be determined by any one of several different types of metering devices (1). (See "Measurements of Water Levels and Pumping Rates.")

The yield of a well depends on the drawdown and on the specific capacity. The specific capacity is the yield per unit of drawdown, and, in nearly all pumping wells, it varies with the pumping rate. Therefore, a discussion of decline in yield is meaningful only in terms of the maximum yield. The maximum yield of a well is controlled by the available drawdown and the specific capacity when the drawdown in the well equals the available drawdown. (See "Well-Acceptance Tests and Well Efficiency.")

The available drawdown is determined at the time of construction of a supply well and consists of the difference between the static (nonpumping) water level and the lowest practical pumping level. The lowest practical pumping level depends on the type of well. In screened wells, it is at the top of the uppermost screen. In open-hole fractured-rock wells, it is at the position of the lowest water-bearing fracture or at the lowest level at which the pump intake can be placed.
The specific capacity and the "yield" of supply wells are determined at the time of well construction. If the pumping level during the well-acceptance test is relatively close (within a few meters) to the lowest practical level, the specific capacity determined during the test can be used to accurately estimate the maximum yield. However, it is important to note that apparent declines in yield after wells are placed in production reflect, in many cases, overestimation of the yields at the time of construction. Actual declines in yield after wells are placed in operation result from deterioration of pumps, declines in the static water level or the specific capacity, or combinations of all three.

The yield of a well field is the sum of the yields of the individual wells. Successful operation, therefore, requires periodic measurements of both the specific capacity and the available drawdown for each well. Changes in these values are used to predict the yield of the field at different times in the future and, when they are used in conjunction with predictions of needs, to plan the rehabilitation of existing wells or the construction of new wells.

Measurements of specific capacity and available drawdown are neither difficult nor time consuming. The determination of both requires only the three measurements listed below:

1. Static (nonpumping) water level (w. I.), measured weekly near the end of the longest nonpumping period, which, in most systems with large industrial uses, is near the end of the weekend.

2. Maximum pumping water level, measuied weekly near the end of the longest period of continuous use, which, in most water systems, is near the end of the workweek.

3. Pumping rate, measured at the same time as the maximum pumping water level. 
These three items of data are analyzed as follows to determine the maximum yield of the well.

specific capacity

$$
\begin{aligned}
& =\frac{\text { pumping rate }\left(\mathrm{m}^{3} \mathrm{~min}^{-1} \text { or gal } \mathrm{min}^{-1}\right)}{\text { static } \mathrm{w} . \mathrm{I} \cdot(\mathrm{m} \text { or } \mathrm{ft})-\text { pumping } \mathrm{w} . \mathrm{I} \cdot(\mathrm{m} \text { or } \mathrm{ft})} \\
& =\frac{\mathrm{m}^{3}}{\min \mathrm{m}} \text { or } \frac{\text { gal }}{\min \mathrm{ft}}
\end{aligned}
$$

available drawdown ( $\mathrm{m}$ or $\mathrm{ft}$ )

$=($ static water level, in $\mathrm{m}$ or $\mathrm{ft})-($ lowest

practical water level, in $\mathrm{m}$ or $\mathrm{ft}$ )
Determinations of specific capacity and available drawdown should be carefully preserved as a part of the permanent file on each well. (See "Well Records and Files.") They should be analyzed at least quarterly to determine if changes in either are occurring. This analysis can be done most conveniently if the values are plotted on graph paper versus the time of the determination (2). Changes in available drawdown and (or) specific capacity and suggested causes and corrective action are listed in the accompanying table.

maximum yield $=($ specific capacity $) \times($ available drawdown $)$

\begin{tabular}{|c|c|c|}
\hline Identifying criteria & Cause & Corrective action \\
\hline $\begin{array}{l}\text { Decline in available drawdown, } \\
\text { no change in specific capacity. }\end{array}$ & $\begin{array}{l}\text { The aquifer, due to a decline in } \\
\text { ground-water level resulting } \\
\text { from depletion of storage caused } \\
\text { by decline in recharge or excessive } \\
\text { withdrawals. }\end{array}$ & $\begin{array}{l}\text { Increase spacing of new supply wells. } \\
\text { Institute measures for artificial recharge. }\end{array}$ \\
\hline $\begin{array}{l}\text { No change in available drawdown, ....... } \\
\text { decline in specific capacity. }\end{array}$ & $\begin{array}{l}\text { The well, due to increase in well } \\
\text { loss resulting from blockage of } \\
\text { screen by rock particles or by } \\
\text { deposition of carbonate or iron } \\
\text { compounds; or reduction in length } \\
\text { of the open hole by movement of } \\
\text { sediment into the well. }\end{array}$ & $\begin{array}{l}\text { Redevelop the well through the use of a } \\
\text { surge block or other means. Use acid to } \\
\text { dissolve encrustations. }\end{array}$ \\
\hline $\begin{array}{l}\text { No change in available drawdown, } \\
\text { no change in specific capacity. }\end{array}$ & $\begin{array}{l}\text { The pump, due to wear of impellers } \\
\text { and other moving parts or loss of } \\
\text { power from the motor. }\end{array}$ & $\begin{array}{l}\text { Recondition or replace motor, or pull pump } \\
\text { and replace worn or damaged parts. }\end{array}$ \\
\hline
\end{tabular}

ANALYSIS OF DECLINES IN WELL YIELD 


\section{SUPPLY-WELL PROBLEMS—CHANGES IN WATER QUALITY}

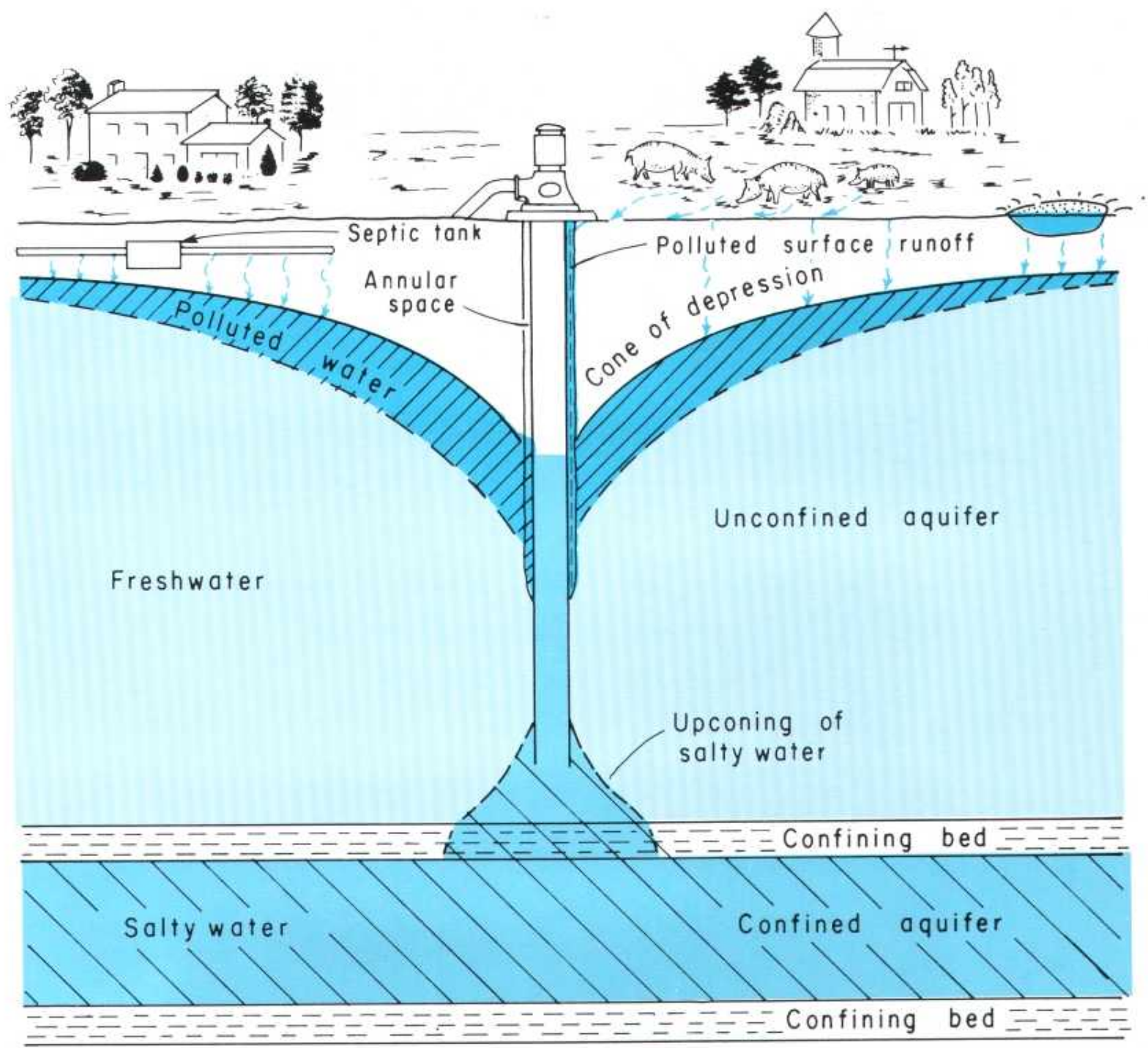

The problems most frequently encountered in the operation of supply wells relate either to declines in yield or to deterioration in the quality of the water. Declines in yield are discussed in "Supply-Well Problems-Decline in Yield."

Deterioration in water quality may result either from changes in the quality of water in the aquifer or changes in the well. These changes may affect the biological quality, the chemical quality, or the physical quality. Deterioration in biological and chemical quality generally results from conditions in the aquifer, whereas changes in physical quality result from changes in the well.

Both the biological and the chemical quality of water from new public-supply wells must be analyzed before the wells are placed in use to determine if the water meets water-supply standards and, if it does not, what treatment is required. Drinking-water regulations of the U.S. Environmental Protection Agency also require that analyses of biological quality be made monthly and that analyses of inorganic quality be made at least every 3 years for all community systems supplied entirely by ground water. It is good practice to periodically determine the biological and chemical quality of water from all wells, especially those that supply domestic needs, in order to determine if changes in quality are occurring.

Deterioration in biological quality refers to the appearance in the water of bacteria and (or) viruses associated with human or animal wastes. Such deterioration is referred to under the general term pollution and indicates, in nearly all cases, a connection between the land surface or a near-surface zone and the open section of the well. The connection most frequently exists in the annular space between the casing and the aquifer. To avoid pollution of wells, many well-construction regulations require that the annular space be completely filled with cement grout from the land surface to a depth of at least $20 \mathrm{ft}$ $(6 \mathrm{~m})$. 
Deterioration in chemical quality refers to the arrival at a supply well of water containing dissolved chemicals in an undesirably large concentration. Withdrawals of water from a well cause water to converge on the well from different directions. If this convergence involves water containing a large concentration of any substance, the concentration of that substance will, after some period of time, begin to increase. The most commonly observed increases in concentration involve $\mathrm{NaCl}$ (sodium chloride or common salt) and $\mathrm{NO}_{3}$ (nitrate), but, if the well is near a sanitary landfill or other waste-disposal site, the increase may involve almost any substance commonly used by man.

- Nitrate is an important constituent in fertilizers and is present in relatively large concentrations in human and animal wastes. Therefore, nitrate concentrations in excess of a few milligrams per liter almost invariably indicate that water is arriving at the well from shallow aquifers that are polluted by septic tanks or animal feedlots or that are contaminated by excess nitrates used in farming operations.

Sodium chloride is the principal constituent of seawater and is also present in significant concentrations in human and animal wastes and in some industrial wastes. An increase in the chloride content in well water most commonly indicates upward movement of water from an underlying zone of salty water. Other increases are due to pollution by sources at or near the land surface, such as deicing operations on streets and highways in the northern part of the country.

Although increases in chloride and nitrate content are probably the most common changes in chemical quality that occur in ground water, changes may involve almost any sub- stance soluble in water. Thus, it is important to be aware of the accidental or intentional release of potential pollutants within the area of influence of all supply wells. Substances that are of particular concern in this regard include herbicides, pesticides and other complex organics, petroleum products, and those substances that contain trace concentrations of metals. In planning a sampling program, for these substances or any others, it is important to consider the slow rate at which most ground water moves.

Deterioration in physical quality involves changes in appearance, taste, and temperature. Most commonly, a change in appearance or color involves either the gradual or the sudden appearance of rock particles in the water. These particles can range in size from clay, which gives the water a turbid or "bluish" appearance, to sand. The size of the particles is indicated by the rate at which the particles settle. If the particles settle exceedingly slowly, or not at all, they are clay size. If they settle immediately, they are sand size.

The gradual appearance of particles generally indicates that the finer grained material was not adequately removed from the zone adjacent to the well during well development. (See "Well-Construction Methods.") During use of the well, these particles slowly migrate to and into the well. The sudden appearance of particles-that is, when the concentration of particles is large (very obvious) from the beginning-generally indicates the failure (collapse) of the screen or a rupture of the well casing.

Changes in the quality of water produced by a well, likely causes of the change, and suggested corrective action are listed in the accompanying table.

ANALYSIS OF CHANGES IN WATER QUALITY

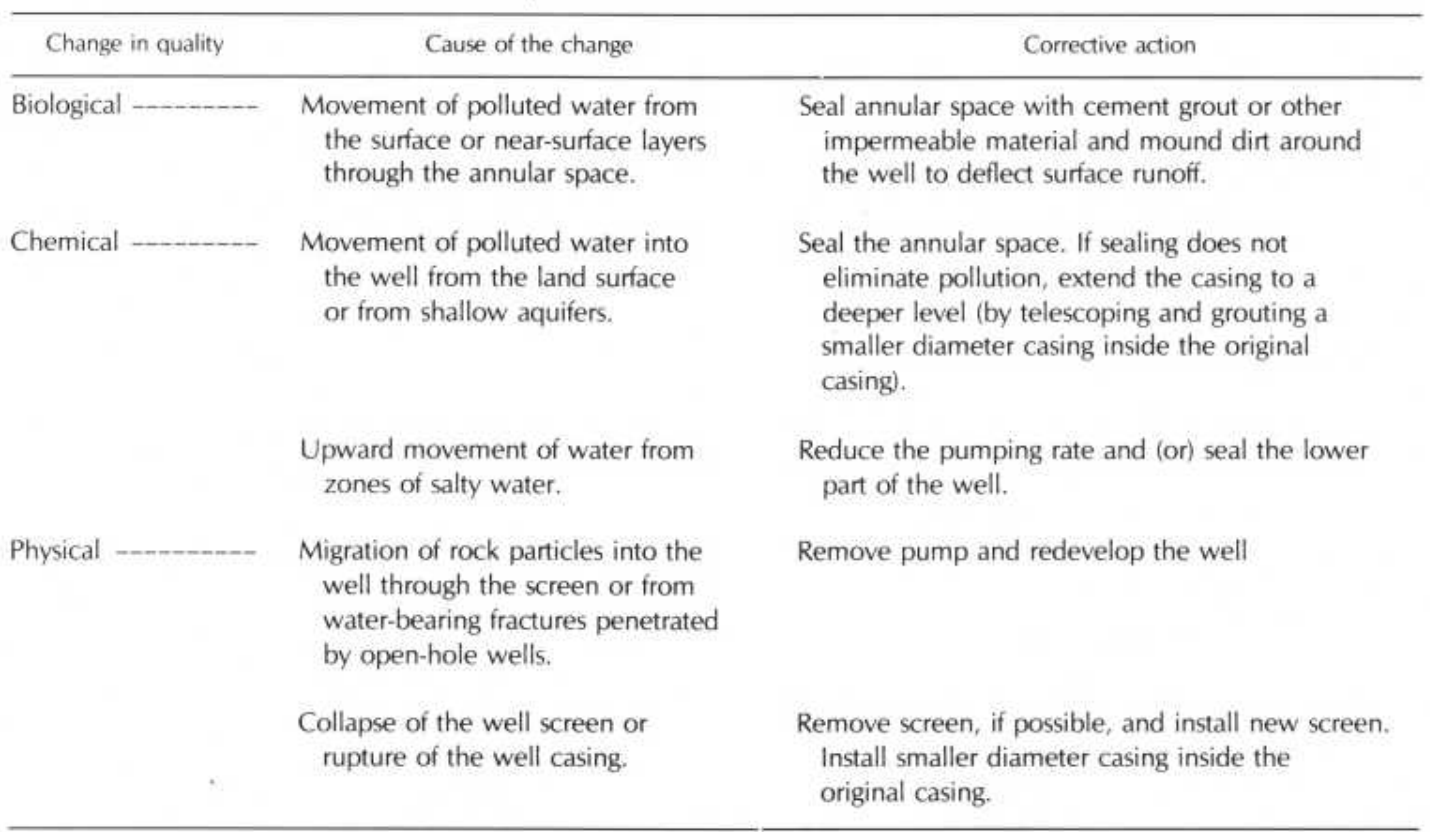




\section{WELL RECORDS AND FILES}

The collection and preservation of records on the construction, operation, maintenance, and abandonment of supply wells are an essential but largely neglected activity. This responsibility rests largely on the well owner or operator. The consequence of this neglect is that it is not possible to identify and to economically correct problems of declining yield or deterioration in water quality, and the design of new wells cannot incorporate past operational experience.

A file should be established on each supply well at the time when plans for its construction are initiated. From the initial planning to the final abandonment of the well, the following records should be generated and carefully preserved in this file:

1. Initial design, including drawings or written specifications on diameter, proposed total depth, position of screens or open hole, method of construction, and materials to be used in construction. (See "Water-Well Design." )

2. Construction record, including the method of construction and the driller's log and a geophysical log of the materials penetrated during construction, the diameter of casings and screens, the slot size and metallic composition of screens, the depths of casing and screens, the total depth of the well, and the weight of the casing. (See "Well-Construction Methods" and "Well Logs.") Records and logs should also be retained for all test wells, including those that were not successful because of small yields.

3. Well-acceptance test, including a copy of the water-level measurements made before, during, and after the drawdown (pumping) test, a record of the pumping rate or rates, copies of any graphs of the data, and a copy of the hydrologist's report on the interpretation of the test results. (See "Well-Acceptance Tests and Well Efficiency.")

4. Pump and installation data, including the type of pump, the horsepower of the motor, the depth to the pump intake, a copy of the pump manufacturer's performance and efficiency data, and data on the length of the air line or a description of facilities provided for water-level measurements, including a description of the measuring point. (See "Measurements of Water Levels and Pumping Rates." )

5. Operating record, including data on the type of meter used to measure the flow rate, weekly readings of the flowmeter dial, weekly measurements of the static and pumping water levels, and periodic analyses of water quality. (See "Supply-Well Problems-Decline in Yield."')

6. Record of well maintenance, including the dates and the activities instituted to increase the yield or to improve the water quality and data showing the results achieved. (See "Supply-Well Problems-Decline in Yield" and "Supply-Well Problems-Changes in Water Quality."

7. Record of well abandonment, including the date that use of the well was discontinued and a description of the methods and materials used to seal or plug the well.

The type of forms used for the records described above is not of critical importance. It is more important that the records be collected, regardless of the type of form that is used. It is important, however, that the date and the watch time be noted with each measurement of pumping rate and depth to water and on each water sample collected for waterquality analyses. 


\section{REFERENCES}

A large number of publications on ground-water hydrology were consulted in the preparation of this report. A citation is shown in the text only where a publication was used as a specific source of tabular data.

The following list of principal references consulted is included to identify sources of specific information and for the benefit of those who wish to obtain additional information.

\section{General References}

Bouwer, Herman, 1978, Groundwater hydrology: New York, McGrawHill, $480 \mathrm{p}$.

Fetter, C. W., Jr., 1980, Applied hydrogeology: Columbus, Charles E. Merrill, $488 \mathrm{p}$.

Freeze, R. A., and Cherry, J. A., 1979, Groundwater: Englewood Cliffs, N.J., Prentice Hall, 604 p.

Heath, R. C., and Trainer, F. W., 1981, Introduction to ground-water hydrology: Worthington, Ohio, Water-Well Journal Publishing Co., $285 \mathrm{p}$.

Todd, D. K., 1980, Groundwater hydrology, 2d ed.: New York, John Wiley, $535 \mathrm{p}$.

Walton, W. C., 1970, Groundwater resource evaluation: New York, McGraw-Hill, 664 p.

\section{Section References}

A few publications were consulted in the preparation of two or more sections. To save space, the complete citation to a publication is shown only the first time that it is mentioned.

\section{Ground-water hydrology}

L'vovich, M. I., 1979, World water resources and their future (English translation, edited by R. L. Nace): Washington, D.C., American Geophysical Union, $415 \mathrm{p}$.

\section{Underground water}

Meinzer, O. E., 1923, The occurrence of ground water in the United States, with a discussion of principles: U.S. Geological Survey Water-Supply Paper 489, $321 \mathrm{p}$.

\section{Hydrologic cycle}

L'vovich (1979)

\section{Porosity}

Meinzer (1923)

\section{Specific yield and specific retention}

Meinzer (1923)

\section{Hydraulic conductivity}

Lohman, S. W., and others, 1972, Definitions of selected groundwater terms-Revisions and conceptual refinements: U.S. Geological Survey Water-Supply Paper 1988, 21 p.

\section{Stratification and unsaturated flow}

Palmquist, W. N., Jr., and Johnson, A. -., 1962, Vadose flow in layered and nonlayered materials, in Short papers in geology and hydrology: U.S. Geological Survey Professional Paper 450-C, 146 p.

\section{Saturated flow and dispersion}

Danel, Pierre, 1953, The measurement of ground-water flow, in Ankara Symposium on Arid Zone Hydrology, Paris 1953, Proceedings: UNESCO, p. 99-107.

\section{Source of water derived from wells}

Theis, C. V., 1940, The source of water derived from wells essential factors controlling the response of an aquifer to development: Civil Engineering, v. 10, no. 5, p. 277-280.

\section{Aquifer tests}

Stallman, R. W., 1971, Aquifer-test design, observations, and data analysis: U.S. Geological Survey Techniques of Water-Resources Investigations, Book 3, Chapter B1, 26 p.

\section{Analysis of aquifer-test data}

Jacob, C. E., 1963, Determining the permeability of water-table aquifers: U.S. Geological Survey Water-Supply Paper 1536-I, p. $1245-\mid 271$.

Lohman, S. W., 1972, Ground-water hydraulics: U.S. Geological Survey Professional Paper 708, $70 \mathrm{p}$.

Theis, C. V., 1935, The relation between the lowering of the piezometric surface and the rate and duration of discharge of a well using ground-water storage: Transactions of the American Geophysical Union, v. 16, p. 519-524.

\section{Time-drawdown analysis}

Jacob, C. E., 1950, Flow of ground water, in Rouse, Hunter, Engineering hydraulics: New York, John Wiley, chapter 5, p. 321-386.

\section{Distance-drawdown analysis}

Jacob (1950)

\section{Aquifer boundaries}

Ferris, J. G., Knowles, D. B., Brown, R. H., and Stallman, R. W., 1962, Theory of aquifer tests: U.S. Geological Survey Water-Supply Paper 1536-E, p. E69-E174. 


\section{Tests affected by lateral boundaries}

Moulder, E. A., 1963, Locus circles as an aid in the location of a hydrogeologic boundary, in Bentall, Ray, comp., Shortcuts and special problems in aquifer tests: U.S. Geological Survey WaterSupply Paper 1545-C, p. C110-C115.

\section{Tests affected by leaky confining beds}

Hantush, M. S., 1960, Modification of the theory of leaky aquifers: Journal of Geophysical Research, v. 65, no. 11, p. 3713-3725.

Hantush, M. S., and Jacob, C. E., 1955, Non-steady radial flow in an infinite leaky aquifer: Transactions of the American Geophysical Union, v. 36, no. 1, p. 95-100.

Jacob, C. E., 1946, Radial flow in a leaky artesian aquifer: Transactions of the American Geophysical Union, v. 27, no. 2, p. 198-205.

\section{Well-construction methods}

Campbell, M. C., and Lehr, J. H., 1973, Water well technology: New York, McGraw-Hill, 681 p.

U.S. Environmental Protection Agency, 1974, Manual of individual water-supply systems: EPA-430/9-74-007, $155 \mathrm{p}$.

\section{Well logs}

Edward E. Johnson, Inc., 1966, Ground water and wells, 1st ed: Saint Paul, Minn., 440 p.

\section{Water-well design}

U.S. Bureau of Reclamation, 1977, Ground-water manual: Washington, D.C., U.S. Government Printing Office, 480 p.

\section{Specific capacity and transmissivity}

McClymonds, N. E., and Franke, O. L., 1972, Water-transmitting properties of aquifers on Long Island, New York: U.S. Geological Survey Professional Paper 627-E, 24 p.

\section{Quality of ground water}

Hem, J. D., 1970, Study and interpretation of the chemical characteristics of natural water: U.S. Geological Survey Water-Supply Paper 1473, $363 \mathrm{p}$.

U.S. Environmental Protection Agency, 1977, National interim primary drinking water regulations: EPA-570/9-76-003, $159 \mathrm{p}$.

\section{Pollution of ground water}

U.S. Environmental Protection Agency (1977)

\section{Saltwater encroachment}

Feth, J. H., and others, 1965, Preliminary map of the conterminous United States showing depth to and quality of shallowest ground water containing more than 1,000 parts per million dissolved solids: U.S. Geological Survey Hydrologic Investigations Atlas 199, scale 1:3,168,000, two sheets, accompanied by 31-p. text. 
The preceding discussions of basic ground-water hydrology involve the use of equations and physical units with which some readers may not be familiar. This discussion of numbers, equations, and conversion of units from one system of measurement to another is included for the benefit of those readers and for others who need to refresh their memories.

\section{Expressing Large Numbers}

$1,000=10 \times 10 \times 10=1 \times 10^{3}$

$1,000,000=10 \times 10 \times 10 \times 10 \times 10 \times 10=1 \times 10^{6}$

The numbers 3 and 6 are called exponents and indicate the number of times that 10 must be multiplied by itself to obtain the initial number.

\section{Expressing Small Numbers}

$$
\begin{aligned}
& 0.001=\frac{1}{1,000}=\frac{1}{1 \times 10^{3}}=1 \times 10^{-3} \\
& 0.000001=\frac{1}{1,000,000}=\frac{1}{1 \times 10^{6}}=1 \times 10^{-6}
\end{aligned}
$$

Exponents in the denominator acquire a negative sign when they are moved to the numerator.

\section{Simplifying Equations}

Symbols in equations have numerical values and, in most cases, units of measurement, such as meters and feet, in which the values are expressed. For example, Darcy's law, one of the equations used in basic ground-water hydrology, is

$$
Q=K A\left(\frac{d h}{d l}\right)
$$

In metric units, hydraulic conductivity $(K)$ is in meters per day, area $(A)$ is in square meters, and hydraulic gradient $(d h / d l)$ is in meters per meter. Substituting these units in Darcy's law, we obtain

$$
Q=\frac{\text { meters }}{\text { day }} \times \text { meters }^{2} \times \frac{\text { meters }}{\text { meters }}=\frac{\text { meters }^{4}}{\text { meters day }}=\mathrm{m}^{4-1} \mathrm{~d}^{-1}=\mathrm{m}^{3} \mathrm{~d}^{-1}
$$

Similarly, in inch-pound units, $K$ is in feet per day, $A$ is in square feet, and $d h / d l$ is in feet per feet. Substituting these units in Darcy's law, we obtain

$$
Q=\frac{\text { feet }}{\text { day }} \times \text { feet }^{2} \times \frac{\text { feet }}{\text { feet }}=\frac{\text { feet }}{\text { feet day }}=\mathrm{ft}^{4-1} \mathrm{~d}^{-1}=\mathrm{ft}^{3} \mathrm{~d}^{-1}
$$

The characteristics of exponents are the same, whether they are used with numbers or with units of measurement. Exponents assigned to units of measurement are understood to apply, of course, to the value that the unit of measurement has in a specific problem. 


\section{Conversion of Units}

Units of measurements used in ground-water literature are gradually changing from the inch-pound units of gallons, feet, and pounds to the International System of units of meters and kilograms (metric units). It is, therefore, increasingly important that those who use this literature become proficient in converting units of measurement from one system to another. Most conversions involve the fundamental principle that the numerator and denominator of a fraction can be multiplied by the same number (in essence, multiplying the fraction by 1) without changing the value of the fraction. For example, if both the numerator and the denominator of the fraction $1 / 4$ are multiplied by 2 , the value of the fraction is not changed. Thus,

$$
\frac{1}{4} \times \frac{2}{2}=\frac{2}{8}=\frac{1}{4} \text { or } \frac{1}{4} \times \frac{2}{2}=\frac{1}{4} \times 1=\frac{1}{4}
$$

Similarly, to convert gallons per minute to other units of measurement, such as cubic feet per day, we must first identify fractions that contain both the units of time (minutes and days) and the units of volume (gallons and cubic feet) and that, when they are used as multipliers, do not change the numerical value. Relative to time, there are 1,440 minutes in a day. Therefore, if any number is multiplied by $1,440 \mathrm{~min} / \mathrm{d}$, the result will be in different units, but its numerical value will be unchanged. Relative to volume, there are 7.48 gallons in a cubic foot. Therefore, to convert gallons per minute to cubic feet per day, we multiply by these "unit" fractions, cancel the units of measurement that appear in both the numerator and the denominator, and gather together the units that remain. In other words, to convert gallons per minute to cubic feet per day, we have

$$
\frac{\text { gallons }}{\text { minute }}=\frac{\text { gallons }}{\text { minute }} \times \frac{1,440 \mathrm{~min}}{\mathrm{~d}} \times \frac{\text { cubic feet }}{7.48 \text { gal }}
$$

and, canceling gallons and minutes in the numerators and denominators, we obtain

$$
\frac{\text { gallons }}{\text { minute }}=\frac{1,440 \mathrm{ft}^{3}}{7.48 \mathrm{~d}}=192.5 \mathrm{ft}^{3} \mathrm{~d}^{-1}
$$

which tells us that $1 \mathrm{gal}$ min $^{-1}$ equals $192.5 \mathrm{ft}^{3} \mathrm{~d}^{-1}$.

We follow the same procedure in converting from inch-pound units to metric units. For example, to convert square feet per day to square meters per day, we proceed as follows:

$$
\frac{\mathrm{ft}^{2}}{\mathrm{~d}}=\frac{\mathrm{ft}^{2}}{\mathrm{~d}} \times \frac{\mathrm{m}^{2}}{10.76 \mathrm{ft}^{2}}=\frac{\mathrm{m}^{2}}{10.76 \mathrm{~d}}=0.0929 \mathrm{~m}^{2} \mathrm{~d}^{-1}=9.29 \times 10^{-2} \mathrm{~m}^{2} \mathrm{~d}^{-1}
$$




\section{DEFINITIONS OF TERMS}

[Number in parentheses is the page on which the term is first mentioned]

AQUIFER ( 6 ): A water-bearing layer of rock that will yield water in a usable quantity to a well or spring.

BEDROCK ( 2 ): A general term for the consolidated (solid) rock that underlies soils or other unconsolidated surficial material.

CAPILLARY FRINGE ( 4 ): The zone above the water table in which water is held by surface tension. Water in the capillary fringe is under a pressure less than atmospheric.

CONE OF DEPRESSION ( 30 ): The depression of heads around a pumping well caused by the withdrawal of water.

CONFINING BED ( 6 ): A layer of rock having very low hydraulic conductivity that hampers the movement of wa+er into and out of an aquifer.

DATUM PLANE ( 10 ): An arbitrary surface (or plane) used in the measurement of ground-water heads. The datum most commonly used is the National Geodetic Vertical Datum of 1929, which closely approximates sea level.

DISPERSION ( 19 ): The extent to which a liquid substance introduced into a ground-water system spreads as it moves through the system.

DRAWDOWN ( 34 ): The reduction in head at a point caused by the withdrawal of water from an aquifer.

EQUIPOTENTIAL LINE ( 21 ): A line on a map or cross section along which total heads are the same.

FLOW LINE ( 21 ): The idealized path followed by particles of water.

FLOW NET ( 21 ): The grid pattern formed by a network of flow lines and equipotential lines.

GROUND WATER ( 4 ): Water in the saturated zone that is under a pressure equal to or greater than atmospheric pressure.

HEAD SEe TOTAL HEAD.

HYDRAULIC CONDUCTIVITY ( 12 ): The capacity of a rock to transmit water. It is expressed as the volume of water at the existing kinematic viscosity that will move in unit time under a unit hydraulic gradient through a unit area measured at right angles to the direction of flow.

HYDRAULIC GRADIENT ( 10 ): Change in head per unit of distance measured in the direction of the steepest chang?.

POROSITY ( 7 ): The voids or openings in a rock. Porosity may be expressed quantitatively as the ratio of the vol ume of openings in a rock to the total volume of the rock.

POTENTIOMETRIC SURFACE ( 6 ): A surface that represents the total head in an aquifer; that is, it represents the height above a datum plane at which the water level stands in tightly cased wells that penetrate the aquifer.

ROCK ( 2 ): Any naturally formed, consolidated or unconsolidated material (but not soil) consisting of two or more minerals.

SATURATED ZONE ( 4 ): The subsurface zone in which all openings are full of water.

SOIL ( 4 ): The layer of material at the land surface that supports plant growth.

SPECIFIC CAPACITY ( 58 ): The yield of a well per unit of drawdown.

SPECIFIC RETENTION ( 8 ): The ratio of the volume of water retained in a rock after gravity drainage to the volume of the rock.

SPECIFIC YIELD ( 8 ): The ratio of the volume of water that will drain under the influence of gravity to the volume of saturated rock.

STORAGE COEFFICIENT ( 28 ): The volume of water released from storage in a unit prism of an aquifer when the head is lowered a unit distance.

STRATIFICATION ( 18 ): The layered structure of sedimentary rocks.

TOTAL HEAD ( 10 ): The height above a datum plane of a column of water. In a ground-water system, it is composed of elevation head and pressure head.

TRANSMISSIVITY ( 26 ): The rate at which water of the prevailing kinematic viscosity is transmitted through a unit width of an aquifer under a unit hydraulic gradient. It equals the hydraulic conductivity multiplied by the aquifer thickness.

UNSATURATED ZONE ( 4 ): The subsurface zone, usually starting at the land surface, that contains both water and air.

WATER TABLE ( 4 ): The level in the saturated zone at which the pressure is equal to the atmospheric pressure. 
RELATION OF UNITS OF HYDRAULIC CONDUCTIVITY, TRANSMISSIVITY, RECHARGE RATES, AND FLOW RATES

Hydraulic conductivity $(K)$

\begin{tabular}{llll}
\hline $\begin{array}{c}\text { Meters per day } \\
\left(\mathrm{m} \mathrm{d}^{-1}\right)\end{array}$ & $\begin{array}{c}\text { Centimeters per } \\
\text { second } \\
\left(\mathrm{cm} \mathrm{s}^{-1}\right)\end{array}$ & $\begin{array}{c}\text { Feet per day } \\
\left(\mathrm{ft} \mathrm{d}^{-1}\right)\end{array}$ & $\begin{array}{c}\text { Gallons per day } \\
\text { per square foot } \\
\left(\mathrm{gal} \mathrm{d}^{-1} \mathrm{ft}^{-2}\right)\end{array}$ \\
\hline 1 & $1.16 \times 10^{-3}$ & 3.28 & $2.45 \times 10^{1}$ \\
& 1 & $2.83 \times 10^{3}$ & $2.12 \times 10^{4}$ \\
\\
$3.64 \times 10^{2}$ & $3.53 \times 10^{-4}$ & 1 & 1.48 \\
\hline
\end{tabular}

Transmissivity $(n$

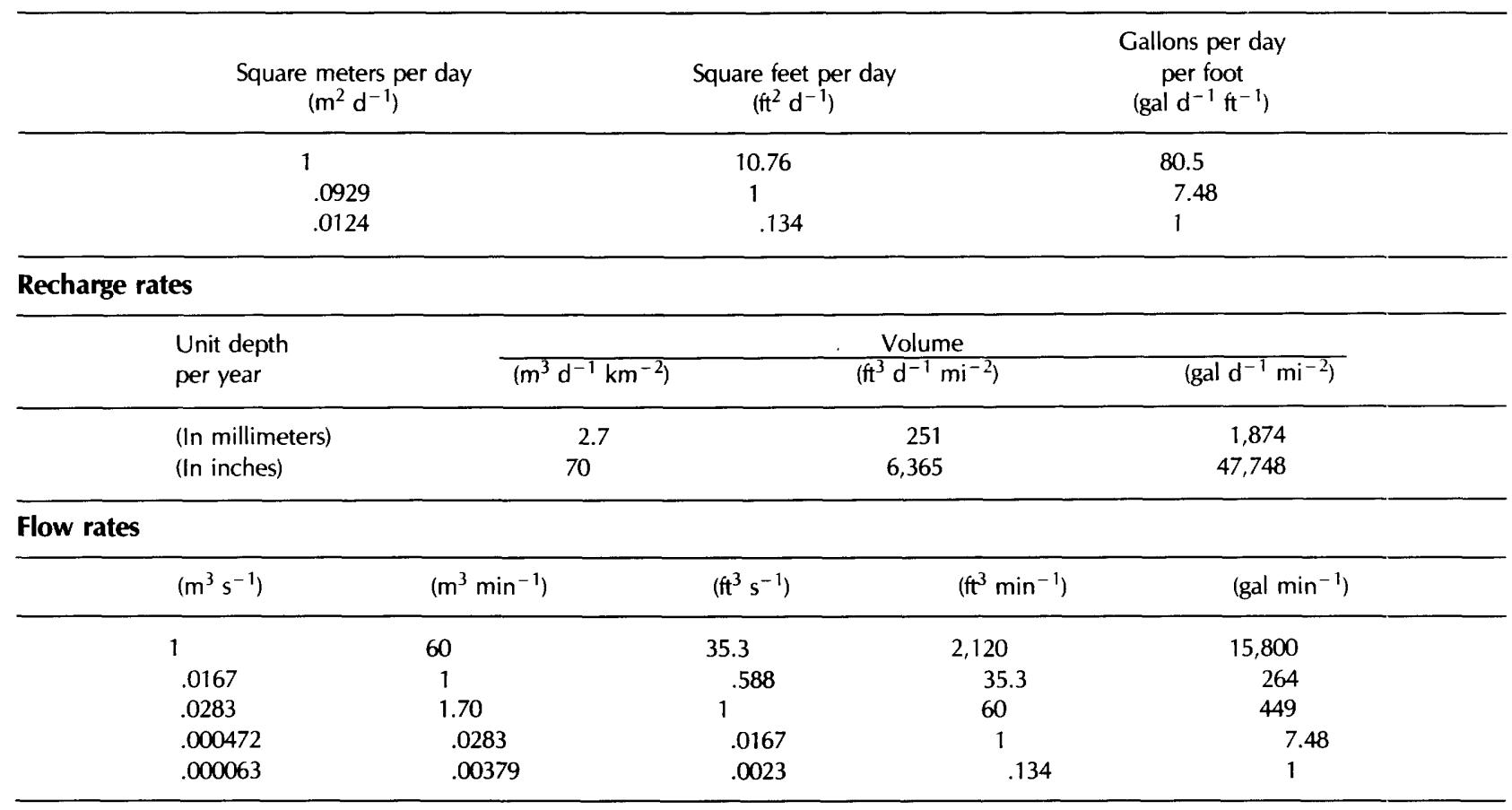

\section{UNITS AND CONVERSIONS}

Metric to inch-pound units

\section{LENGTH}

1 millimeter $(\mathrm{mm})=0.001 \mathrm{~m}=0.03937 \mathrm{in}$.

1 centimeter $(\mathrm{cm})=0.01 \mathrm{~m}=0.3937$ in. $=0.0328 \mathrm{ft}$

1 meter $(\mathrm{m})=39.37 \mathrm{in} .=3.28 \mathrm{ft}=1.09 \mathrm{yd}$

1 kilometer $(\mathrm{km})=1,000 \mathrm{~m}=0.62 \mathrm{mi}$

AREA

$1 \mathrm{~cm}^{2}=0.155$ in..$^{2}$

$1 \mathrm{~m}^{2}=10.758 \mathrm{ft}^{2}=1.196 \mathrm{yd}^{2}$

$1 \mathrm{~km}^{2}=247$ acres $=0.386 \mathrm{mi}^{2}$

\section{VOLUME}

$1 \mathrm{~cm}^{3}=0.061$ in. $^{3}$

$1 \mathrm{~m}^{3}=1,000 \mathrm{l}=264$ U.S. gal $=35.314 \mathrm{ft}^{3}$

1 liter $(l)=1,000 \mathrm{~cm}^{3}=0.264$ U.S. gal

MASS

1 microgram $(\mu \mathrm{g})=0.000001 \mathrm{~g}$

1 milligram $(\mathrm{mg})=0.001 \mathrm{~g}$

1 gram $(\mathrm{g})=0.03527 \mathrm{oz}=0.002205 \mathrm{lb}$

1 kilogram $(\mathrm{kg})=1,000 \mathrm{~g}=2.205 \mathrm{lb}$
Inch-pound to metric units

\section{LENGTH}

1 inch (in.) $=25.4 \mathrm{~mm}=2.54 \mathrm{~cm}=0.0254 \mathrm{~m}$

1 foot $(\mathrm{ft})=12$ in. $=30.48 \mathrm{~cm}=0.3048 \mathrm{~m}$

1 yard $(y d)=3 \mathrm{ft}=0.9144 \mathrm{~m}=0.0009144 \mathrm{~km}$

1 mile $(\mathrm{mi})=5,280 \mathrm{ft}=1,609 \mathrm{~m}=1.603 \mathrm{~km}$

AREA

1 in. ${ }^{2}=6.4516 \mathrm{~cm}^{2}$

$1 \mathrm{ft}^{2}=929 \mathrm{~cm}^{2}=0.0929 \mathrm{~m}^{2}$

$1 \mathrm{mi}^{2}=2.59 \mathrm{~km}^{2}$

VOLUME

1 in. $^{3}=0.00058 \mathrm{ft}^{3}=16.39 \mathrm{~cm}^{3}$

$1 \mathrm{ft}^{3}=1728$ in. $^{3}=0.02832 \mathrm{~m}^{3}$

1 gallon $($ gal $)=231$ in. $^{3}=0.13368 \mathrm{ft}^{3}=0.00379 \mathrm{~m}^{3}$

MASS

1 ounce (oz) $=0.0625 \mathrm{lb}=28.35 \mathrm{~g}$

1 pound $(\mathrm{lb})=16 \mathrm{oz}=0.4536 \mathrm{~kg}$ 